\title{
The Analytical Repository Source-Term (AREST) Model: Description and Documentation
}
A. M. Liebetrau
C. R. Reid
M. J. Apted
C. F. Windisch
D. W. Engel
R. L. Erikson
M. K. Altenhofen
K. I. Johnson
D. M. Strachan

October 1987

Prepared for the U.S. Department of Energy under Contract DE-AC06-76RLO 1830

Pacific Northwest Laboratory

Operated for the U.S. Department of Energy

by Battelle Memorial Institute 


\section{DISCLAIMER}

This report was prepared as an account of work sponsored by an agency of the United States Government. Neither the United States Government nor any agency thereof, nor Battelle Memorial Institute, nor any of their employees, makes any warranty, expressed or implied, or assumes any legal liability or responsibility for the accuracy, completeness, or usefulness of any information, apparatus, product, or process disclosed, or represents that its use would not infringe privately owned rights. Reference herein to any specific commercial product, process, or service by trade name, trademark, manufacturer, or otherwise, does not necessarily constitute or imply its endorsement, recommendation, or favoring by the United States Government of any agency thereof, or Battelle Memorial institute. The views and opinions of authors expressed herein do not necessarly state or reflect those of the United States Government or any agency thereof, or Battelle Memorial Institute.

\section{PACIFIC NORTHWEST LABORATORY operated by BATTELLE MEMORIAL INSTITUTE for the \\ UNITED STATES DEPARTMENT OF ENERGY under Contract DE-AC06-76RLO 1830}

\begin{tabular}{|c|c|}
\hline \multicolumn{2}{|c|}{ Printed in the United States of America } \\
\hline \multicolumn{2}{|c|}{ Available from } \\
\hline \multirow{2}{*}{\multicolumn{2}{|c|}{$\begin{array}{l}\text { National Technical Information Service } \\
\text { United States Department of Commerce }\end{array}$}} \\
\hline & \\
\hline \multicolumn{2}{|c|}{5285 Port Royal Road } \\
\hline \multirow{2}{*}{\multicolumn{2}{|c|}{$\begin{array}{l}\text { NTIS Price Codes } \\
\text { Microfiche A01 }\end{array}$}} \\
\hline & \\
\hline \multicolumn{2}{|c|}{ Printed Copy } \\
\hline & Price \\
\hline Pages & Codes \\
\hline $001-025$ & A02 \\
\hline $026-050$ & $\mathrm{~A} 03$ \\
\hline $051-075$ & A04 \\
\hline $076-100$ & A05 \\
\hline $101 \cdot 125$ & $\mathrm{~A} 06$ \\
\hline $126-150$ & $\mathrm{~A} 07$ \\
\hline $151-175$ & $\mathrm{~A} 0 \mathrm{~B}$ \\
\hline $176-200$ & $\mathrm{~A} 09$ \\
\hline $201-225$ & A010 \\
\hline $226-250$ & A011 \\
\hline $251-275$ & A012 \\
\hline $276-300$ & A013 \\
\hline
\end{tabular}


THE ANALYTICAL REPOSITORY SOURCE-TERM (AREST) MODEL: DESCRIPTION AND DOCUMENTATION
A. M. Liebetrau
C. R. Reid
M. U. Apted
C. F. Windisch
D. W. Engel
R. L. Erikson
M. K. Altenhofen
D. M. Strachan
K. I. Johnson
October 1987

Prepared for

the U.S. Department of Energy

under Contract DE-AC06-76RLO 1830

Pacific Northwest Laboratory

Richland, Washington 99352 

The Office of Civilian Radioactive Waste Management (OCRWM) of the U.S. Department of Energy (DOE) has a mission to provide for the permanent disposal of radioactive wastes in deep geologic repositories. The OCRWM is currently developing a performance assessment strategy for demonstrating compliance with the safety and performance criteria developed by the U.S. Nuclear Regulatory Commission (NRC) and the U.S. Environmental Protection Agency (EPA). Because of the long time (more than 10,000 years) involved, the OCRWM performance assessment strategy necessarily relies upon computerized models of the geologic repository system and its components.

The geologic repository system consists of several components, one of which is the engineered barrier system. The engineered barrier system interfaces with natural barriers that constitute the setting of the repository. A model that simulates the releases from the engineered barrier system into the natural barriers of the geosphere, called a source-term model, is an important component of any model for assessing the overall performance of the geologic repository system. The Analytical Repository Source-Term (AREST) mode1 being developed by the Performance Assessment Scientific Support (PASS) Program is one such model. The purpose of this report is to describe the current state of development of the AREST model and the code in which the model is implemented.

The AREST model consists of three component models and five process models that describe the post-emplacement environment of a waste package. All of these components are combined within a probabilistic framework. The component mode is are

- a waste package containment (WPC) model that simulates the corrosion and degradation processes which eventually result in waste package containment failure

- a waste package release (WPR) model that calculates the rates of radionuclide release from the failed waste package 
- an engineered system release (ESR) model that controls the flow of information among all AREST components and process models and, in particular, combines release output from the WPR model with failure times from the WPC model to produce estimates of total release.

The WPC model incorporates models that simulate a variety of corrosion and degradation processes affecting the containment performance of the waste package. Included are models of uniform and pitting corrosion that may be applied to container materials and spent fuel cladding. The WPR model also contains a model of stress corrosion that is applicable to the waste package container. Emphasis has been placed upon the adaptation and use of published mechanistic models to describe relevant corrosion and degradation processes. To date, several uniform corrosion rate models have been coded for use in the: WPC model.

The WPR model includes two complementary mass transfer models for the calculation of release rates for individual waste packages, one for solubilitylimited release and one for inventory-limited release. The mass transfer models are used to calculate release rates from the waste form into the packing (backfill) material that may be part of an engineered barrier system, and from packing into the host rock.

The AREST model contains models of the thermal, geochemical, hydrological, mechanical, and radiation processes that determine the waste package environment. All mode1s of the waste package environment used in AREST are repository- or site-specific. The thermal model provides the basis for determining waste package temperatures at all times of interest. A key assumption is that at all times, the rise in waste package temperature above average repository temperature in the vicinity of the waste package is proportional to the initial heat loading of the waste package. The geochemical model specifies required information on the composition of groundwater in the repository as a function of temperature and chemical reactions with engineered barrier materials. The hydrological model provides the rationale for calculating the time of "resaturation," and the mechanical model provides stresses that affect the waste package container. Although the AREST model makes provision for one, a 
separate radiolysis-effects model has not be developed. The effects of radiolysis on groundwater, however, are incorporated into the geochemical mode 1.

The thermal and geochenical models require logistical information and outputs from the detailed modeling of physical and chemical processes that involve too much computing time for them to be included in the AREST code. Support codes external to the AREST code are used to generate the required inputs for the thermal and geochemical models. The thermal history (temperature expressed as a function of time) of a design-basis waste package, for example, is calculated by external support codes and supplied to the AREST code in tabular form. Likewise, tables of groundwater composition are provided by geochenical support codes. The use of external support codes preserves the computational efficiency of the AREST code and frees the AREST model from dependence on any particular support code. Moreover, this feature makes it possible to use a general-purpose executive code such as AREST to investigate a variety of specific host rock, groundwater, and waste package design configurations.

The AREST Inodel has been developed to support the OCRWM Office of Geologic Repositories (OGR) in providing quantitative assessments of the performance of the overall engineered barrier system and its individual components for a number of repository designs and geologic settings. To meet this need, the AREST code has been designed for computational efficiency, flexibility, and ease of modification. Insofar as possible, the code has been written in modular form to achieve these objectives. In particular, the AREST code has been designed so that new information and or improved process models can easily be incorporated as they become available.

The components of the AREST model, the corrosion models and models of the waste package environment it incorporates, the support codes it employs, and its overall probabilistic structure are described in detail in this report. Also described are the inputs to and the outputs from the AREST model. Finally, current limitations of both the AREST model and code are discussed, and specific areas for further development are identified. 


\section{ACKNOWLEDGMENTS}

The basic simulation approach for the AREST code was developed in collaboration with D. H. Alexander, A. E. Van Luik, and P. G. Doctor. Conversations with $K$. Stephens and $R$. Moler on probablistic waste package modeling were also quite helpful. Reviews of an earlier draft of this docunent by R. D. Peters, W. A. Ross, W. L. Kuhn and G. K. Jacobs are gratefully acknowledged. We thank C. Brim, S. Liebetrau, and C. Counts for their efficient and timely editorial assistance. Special appreciation is reserved for T. H. Pigford, P. L. Chambré and their students at the University of California at Berkeley; they have developed and shared essentially all of the mass transfer equations used in the AREST code. A particularly thorough review by this group of an earlier version of portions of this document was especially crucial to improvement of the AREST code. 



\section{CONTENTS}

EXECUTIVE SUMMARY

ACKNOWLEDGMENTS

vii

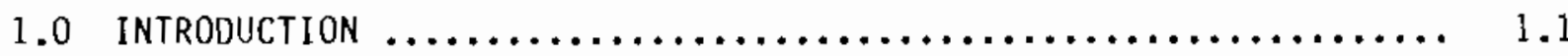

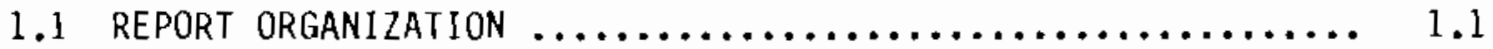

1.2 GENERAL DESCRIPTION OF THE AREST MODEL $\ldots \ldots \ldots \ldots \ldots \ldots \ldots \ldots . . .2$

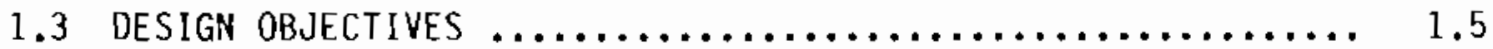

1.4 "MODEL" versus "EXPERIMENT" $\ldots \ldots \ldots \ldots \ldots \ldots \ldots \ldots \ldots \ldots \ldots \ldots . . \ldots \ldots$

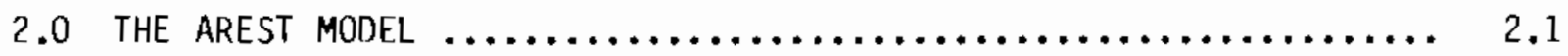

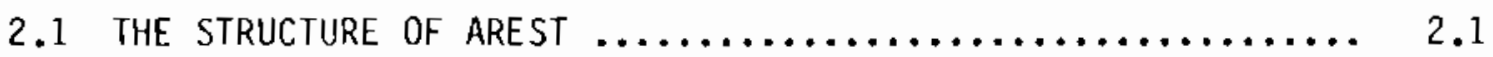

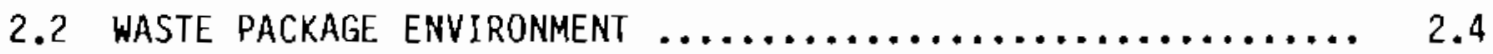

2.2 .1 Thermal Model $\ldots \ldots \ldots \ldots \ldots \ldots \ldots \ldots \ldots \ldots \ldots \ldots \ldots . . \ldots$

2.2 .2 Geochenical Model $\ldots \ldots \ldots \ldots \ldots \ldots \ldots \ldots \ldots \ldots \ldots \ldots \ldots . . . . \ldots$

2.2 .3 Hydrological Model ..................... 2.9

2.2 .4 Radiation Model $\ldots \ldots \ldots \ldots \ldots \ldots \ldots \ldots \ldots \ldots \ldots \ldots \ldots . . \ldots \ldots$

2.2 .5 Mechanical Model ........................ 2.14

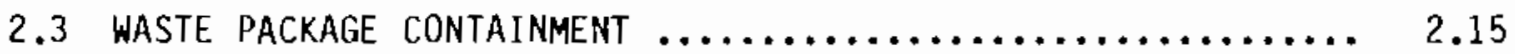

2.3 .1 Unjform Corrosion $\ldots \ldots \ldots \ldots \ldots \ldots \ldots \ldots \ldots \ldots \ldots \ldots \ldots$

2.3.2 Pitting Corrosion $\ldots \ldots \ldots \ldots \ldots \ldots \ldots \ldots \ldots \ldots \ldots \ldots .2 .18$

2.3 .3 Stress Corrosion $\ldots \ldots \ldots \ldots \ldots \ldots \ldots \ldots \ldots \ldots \ldots \ldots \ldots .2 .20$

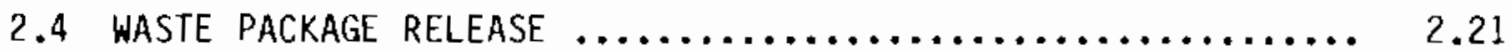

2.4.1 Mass-Transfer Analysis of Release Rate .......... 2.24

2.4.2 Solubility-Limited Release Model $\ldots . . . \ldots . . . \ldots .2 .27$

2.4 .3 Inventory - Limited Release $\ldots \ldots \ldots \ldots \ldots \ldots \ldots \ldots . \ldots . \ldots . \ldots$

2.4.4 WPR Modeling of Spent Fuel $\ldots \ldots \ldots \ldots \ldots \ldots \ldots \ldots \ldots . . \ldots \ldots$ 
2.4.5 Limitation of Mass Transfer Analysis ........... 2.36

2.5 CONTAINMENT-RELEASE PROGRAM LOGIC $\ldots \ldots \ldots \ldots \ldots \ldots \ldots \ldots \ldots . \ldots \ldots$

2.6 ENGINEERED SYSTEM RELEASE $\ldots \ldots \ldots \ldots \ldots \ldots \ldots \ldots \ldots \ldots \ldots \ldots \ldots \ldots \ldots$

2.6.1 Program Control ....................... 2.43

2.6 .2 Integrated Release $\ldots \ldots \ldots \ldots \ldots \ldots \ldots \ldots \ldots \ldots \ldots \ldots \ldots \ldots$

3.0 MODEL INPUTS AND DATA REQUIREMENTS $\ldots \ldots \ldots \ldots \ldots \ldots \ldots \ldots \ldots \ldots \ldots \ldots$

3.1 WASTE PACKAGE ENVIRONMENT $\ldots \ldots \ldots \ldots \ldots \ldots \ldots \ldots \ldots \ldots \ldots \ldots \ldots \ldots$

3.1 .1 Thermal Model $\ldots \ldots \ldots \ldots \ldots \ldots \ldots \ldots \ldots \ldots \ldots \ldots \ldots \ldots \ldots \ldots . \ldots \ldots$

3.1 .2 Geochemical Model $\ldots \ldots \ldots \ldots \ldots \ldots \ldots \ldots \ldots \ldots \ldots \ldots \ldots \ldots . . \ldots$

3.1 .3 Hydrological Model $\ldots \ldots \ldots \ldots \ldots \ldots \ldots \ldots \ldots \ldots \ldots \ldots \ldots . \ldots . \ldots \ldots$

3.1 .4 Mechanicat Model ............................. 3.5

3.1 .5 Radiation Model $\ldots \ldots \ldots \ldots \ldots \ldots \ldots \ldots \ldots \ldots \ldots \ldots \ldots \ldots . \ldots \ldots$

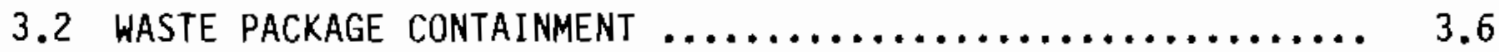

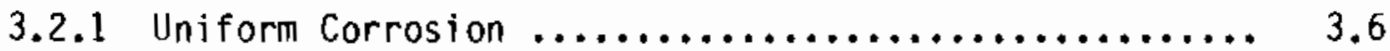

3.2 .2 Pitting Corrosion $\ldots \ldots \ldots \ldots \ldots \ldots \ldots \ldots \ldots \ldots \ldots \ldots . . \ldots \ldots$

3.2 .3 Stress Corrosion $\ldots \ldots \ldots \ldots \ldots \ldots \ldots \ldots \ldots \ldots \ldots \ldots \ldots . . . \ldots$

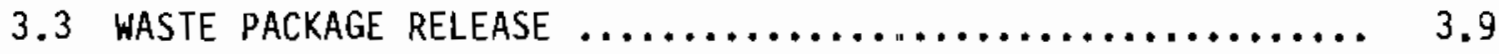

3.3.1 Solubility-Limited Release ................. 3.9

3.3 .2 Inventory-Limited Release $\ldots \ldots \ldots \ldots \ldots \ldots \ldots \ldots \ldots . . \ldots \ldots$

3.4 ENGINEERED SYSTEM RELEASE $\ldots \ldots \ldots \ldots \ldots \ldots \ldots \ldots \ldots \ldots \ldots \ldots \ldots . .18$

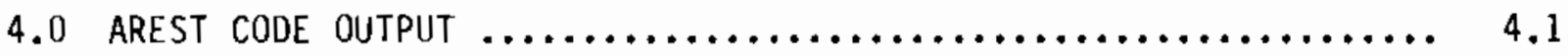

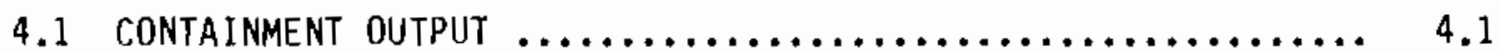

4.2 RELEASE DUTPUT $\ldots \ldots \ldots \ldots \ldots \ldots \ldots \ldots \ldots \ldots \ldots \ldots \ldots \ldots \ldots \ldots \ldots \ldots$

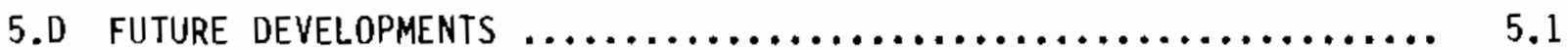

5.1 STOCHASTIC SUBMODELS $\ldots \ldots \ldots \ldots \ldots \ldots \ldots \ldots \ldots \ldots \ldots \ldots \ldots \ldots \ldots \ldots$ 
5.2 WASTE FORM RELEASE $\ldots \ldots \ldots \ldots \ldots \ldots \ldots \ldots \ldots \ldots \ldots \ldots \ldots, 5.2$

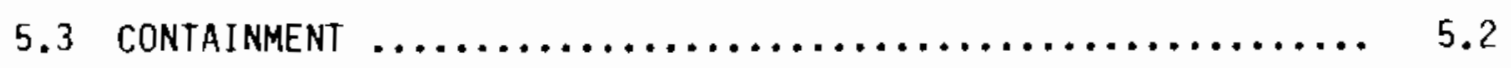

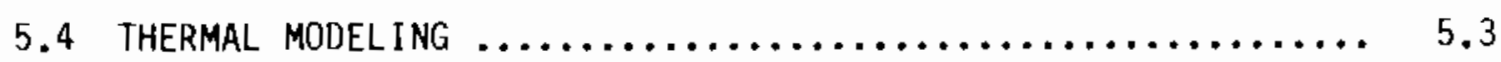

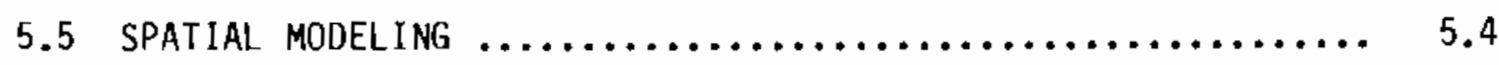

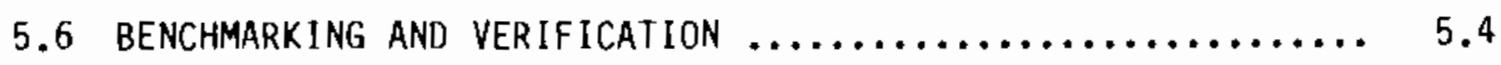

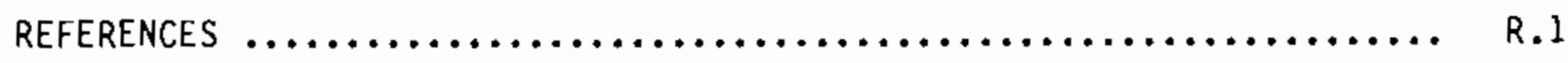

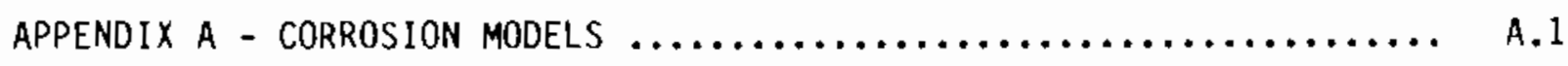

APPENDIX B - THERMAL MODELS FOR SPENT FUEL $\ldots \ldots \ldots \ldots \ldots \ldots \ldots \ldots \ldots \ldots \ldots \ldots \ldots \ldots \ldots \ldots$

APPENDIX $C$ - GROUNDWATER/GEOCHEMICAL VARIABLES $\ldots \ldots \ldots \ldots \ldots \ldots \ldots \ldots, c .1$

APPENDIX D - RADIONUCLIDE RELEASE FROM SPENT FUEL $\ldots \ldots \ldots \ldots \ldots \ldots \ldots$ D. 1

APPENDIX E - MASS TRANSFER RELEASE EquATIONS $\ldots \ldots \ldots \ldots \ldots \ldots \ldots \ldots \ldots \ldots \ldots \ldots \ldots \ldots \ldots \ldots$ 


\section{FIGURES}

1.1 Flow Diagram Showing the WPC, the WPR, and the ESR Models in the Context of the Overal1 Repository Performance Model ........... 1.3

2.1 Relationships Among AREST Submodels and Various Process Models,

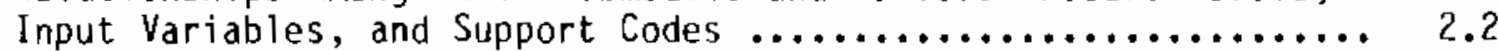

2.2 The AREST Thermal Model $\ldots \ldots \ldots \ldots \ldots \ldots \ldots \ldots \ldots \ldots \ldots \ldots \ldots \ldots \ldots \ldots$

2.3 Simulation of Haste Package Temperature Histories $\ldots \ldots \ldots \ldots . . .7$

2.4 The AREST Geochenical Model $\ldots \ldots \ldots \ldots \ldots \ldots \ldots \ldots \ldots \ldots \ldots \ldots \ldots \ldots . \ldots \ldots$

2.5 Relationship Between Resaturation Time and Rock Mass Permeability .................................... 2.13

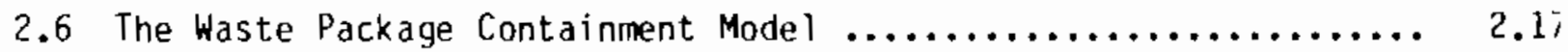

2.7 The Waste Package Release Model ....................... 2.2:

2.8 Waste Package Geometry for Solubility-Limited Release ........ 2.28

2.9 Radionuclide Concentration at the Waste Package Boundary ...... 2.31

2.10 Radionuclide -Specific Mass Transfer Rates from the Waste Form and the Waste Package ................................ 2.32

2.11 Waste Package Geometry for Inventory-Limited Release ......... 2.33

2.12 Example of Release Rate for Gap Model ................... 2.34

2.13 AREST Containment-Release Logic .................... 2.40

3.1 Waste Package Geometry for Solubility-Limited Release ......... 3.11

3.2 Stability Diagraln for U-H-O System at $25^{\circ} \mathrm{C} \ldots \ldots \ldots \ldots \ldots \ldots \ldots \ldots$

3.3 Waste Package Geometry for Inventory-Limited Release ......... 3.17

4.1 Distribution of Containment Failures by Uni ${ }^{5}$ orm and Pitting
Corrosion $\ldots \ldots \ldots \ldots \ldots \ldots \ldots \ldots \ldots \ldots \ldots \ldots \ldots \ldots \ldots \ldots \ldots \ldots \ldots \ldots \ldots \ldots \ldots \ldots \ldots \ldots$

4.2 Sample Plot of Fractional Release Rates Versus Time ......... 4.3

4.3 Sample Plot of Cumulative Releases Normalized by EPA Limits .... 4.4

4.4 Sample Plot of ${ }^{237} \mathrm{~Np}$ Release Rate 0istributions 5000 Years After Repository Closure ........................ 4.5 
A.1 Corrosion Rate for Carbon Steel in Brine Solution ............ A.7

A.2 Variation in Crack Tip Velocity with Changes in Stress

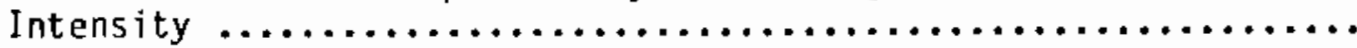

A.3 Predicted Crack Depth as a Function of Time for $3 \% \mathrm{Cr}-$ Mo

in a Caustic Envi ronment ............................. A.19

B.1 Waste Package Scale Finite Element Model Grid for BWIP

Reference Design - Horizontal Emplacement Concept ............ B.6

B.2 Waste Package Scale Finite Element Model Grid for the Nevada

Nuclear Waste Isolation Project and the Salt Repository

Project Reference Designs - Vertical Emplacement Concept ....... B.7

B.3 Repository Scale Finite Element Grid ................... B.9

B.4 Waste Package Thermal Model Verification Test Results:

Constant Heat Input ............................. B.10

B.5 Waste Package Thermal Model Verification Test Results:

Time Dependent Heat Input .......................... B. 10

B.6 Waste Package Container and Repository Average Temperatures

for the Reference BWIP Design ......................... B.11

B.7 Waste Package Container and Repository Average Temperatures

for the Reference SRP Design ......................... B.11

B.8 Waste Package Container and Repository Average Temperatures

for the Reference NNWSI Design ....................... B.12

B.9 PWR Spent Fuel Heat Generation Rate Data Used in Wastes Mode1

Evaluations ........................................ B.15

D.1 Schematic Cross-Section of Spent Nuclear Fuel $\ldots \ldots \ldots \ldots \ldots \ldots \ldots .6$

E.l Waste Package Geometry for Solubility-Limited Release Model ..... E.3

E.2 Variation of Inventory from Radioactive Decay $\ldots \ldots \ldots \ldots \ldots \ldots \ldots$... E.

E.3 Fractional Release Rate $\ldots \ldots \ldots \ldots \ldots \ldots \ldots \ldots \ldots \ldots \ldots \ldots \ldots \ldots$ E. 9

E.4 Waste Package Geometry for Inventory-Limited Release Model ..... E.15

E.5 Fractional Release Rate Versus Time for Gap Model ........... E.18 


\section{TABLES}

3.1 Inputs for the Uniform Corrosion Module $\ldots \ldots \ldots \ldots \ldots \ldots \ldots \ldots .6$

A.1 Values Used in Pitting Corrosion Model far Ferrous Materials .... A.14

A.2 Numerical Values for Model Parameters .................... A. 18

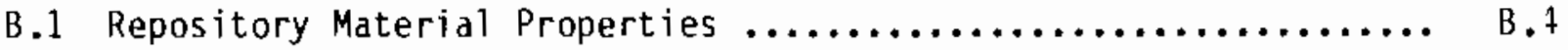

B.2 Repository Waste Package Design Parameters ................. B.t

B.3 Normalized Decay Heat Data for Consolidated Spent Fuel ........ B.!

B.4 Waste Acceptance Schedule--Authorized Plan System ........... B..4

B.5 Characteristics of Spent Fuel Received at First Repository ..... B.:7

B.6 Spent Fuel Thermal Receipt Characteristics at the First

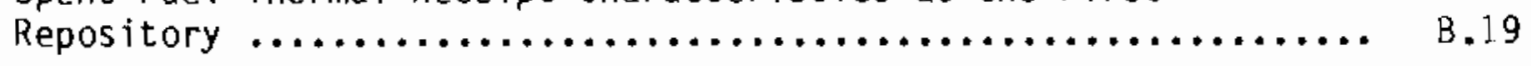

C.1 Compositions of Repository Groundwaters Used in the AREST Code .. C.2

C.2 Example Reference Table $\ldots \ldots \ldots \ldots \ldots \ldots \ldots \ldots \ldots \ldots \ldots \ldots \ldots \ldots \ldots$. 6

C.3 Values for $\log (K)$ of the Montmorillonites Used in this Study .... C.11 


\subsection{INTRODUCTION}

The Office of Civilian Radioactive Waste Management (OCRWM) of the U.S. Department of Energy (DOE) has a mission to investigate the permanent disposal of radioactive waste in deep geologic repositories. The OCRWM is currently developing a performance assessment strategy to demonstrate compliance with performance criteria developed by the Nuclear Regulatory Cormission (NRC) and the Environmental Protection Agency (EPA). The NRC has established performance criteria for the engineered barrier system of a nuclear waste repository that require an initial period of substantially complete containment followed by a period of acceptably low releases of radionuclides (10 CFR 60, 1983). Because of the long time (more than 10,000 years) involved, the OCRWM performance assessment strategy necessarily relies upon computerized models of the geologic repository system supported by relevant experimental studies.

The OCRWM performance assessment strategy will involve a model of the overall geologic repository system. An important component of an overall systen model is a source-term model for evaluating radionuclide release from an engineered barrier system. One such model is the Analytical Repository SourceTerm (AREST) model being developed for OCRWM by the Performance Assessment Scientific Support (PASS) program (Alexander et al. 1985; Apted et al. 1985). The purpose of this document is to describe the current status of the development of the AREST model and the code that implements it. (a)

\subsection{REPORT ORGANIZATION}

This report is organized into five sections. A general description of the AREST model is presented in the remainder of Section 1.0. A distinction is made between the AREST "model" and AREST "experiments," i.e., simulations conducted with the aid of the AREST code.

(a) In this document the word "code" (e.g., the AREST code) refers to a code that implements a conceptual model (e.g., the AREST model). The word AREST may be used by itself in discussions that pertain to both the model and the code, or when it is not important to distinguish the model from the code. 
Section 2.0 contains a detailed description of AREST. Section 2.1 gives an overview, and the waste package environment is discussed in Section 2.2. Sections 2.3 and 2.4 deal with containment and release, respectively, while Section 2.5 describes how the interface between containment and release is modeled in AREST. The integration of individual waste package releases is the topic of Section 2.6 .

Model inputs are discussed in Section 3.0. The discussion involves not only variables used to describe the design of the repository and the design and environment of the waste package, but also deals with the selection of process submodels and requisite data needs. Model output is discussed in Section 4.0.

Finally, possible directions for future development of AREST are given in Section 5.0. Included are suggestions for removing present limitations, for expanding present capabilities, and for adding options that increase both the flexibility and the range of applicability of the code.

\subsection{GENERAL DESCRIPTION OF THE AREST MOOEL}

The AREST model has been designed and implemented to support the DOE Office of Geologic Repositories (OGR) need for a model to assess the performance of the engineered barrier system (EBS) within the context of an overall geologic repository system model. In particular. AREST (the model and code) is intended to provide a quantitative probabilistic assessment of the performance of individual barrier materials and the overall EBS relative to federal regulatory requirements for the containment and isolation of nuclear wastes. In order to provide the repository-scale information required for this purpose, the waste package has been established as the basic unit of simulation.

The AREST model is composed of three major components or submodels, each of which contains models of certain physical and chemical processes that affect release. (a) The components of AREST, which have been described previously (Alexander et al. 1985; Apted et al. 1985; Liebetrau and Apted 1985), are

(a) The AREST model consists of several submodels, each of which is cornposed of additional component models. Unless the hierarchical relationships among them are pertinent to the discussion, all models, submodels, component models, etc. will be referred to simply as "models" when no ambiguity results. 
- a waste package containment (WPC) model

- a waste package release (WPR) model

- an engineered system (ESR) model.

Figure 1.1 shows the WPC, WPR, and ESR models in the context of an overall geologic repository performance model. The WPC model describes the containment performance of an individual waste packaye from the time it is emplaced until the time of containment failure. Specifically, the encoded WPC model simulates those corrosion processes and degradation mechanisms that ultimately result in

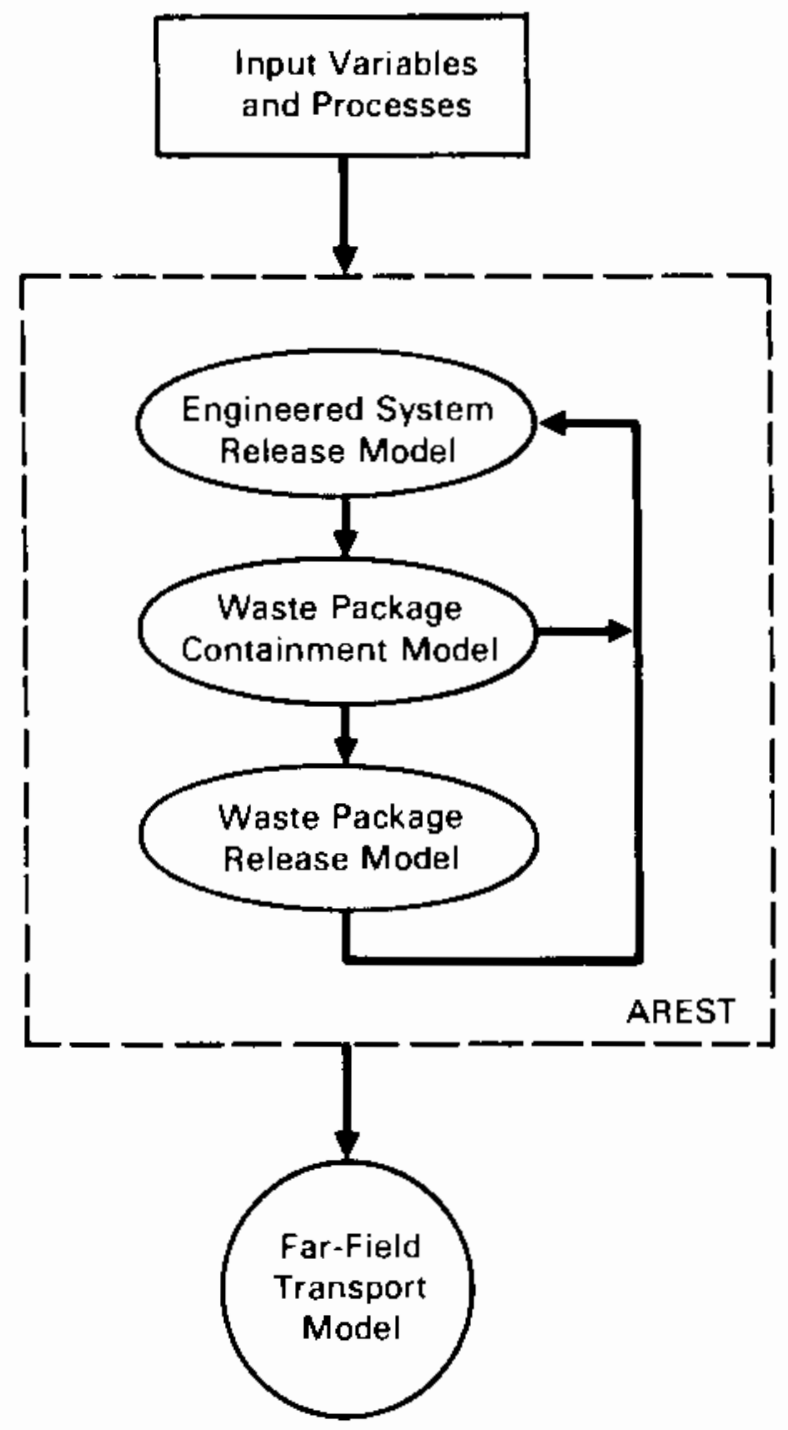

FIGURE 1.1. Flow Diagram Showing the WPC, the WPR, and the ESR Models in the Context of the Overall Repository Performance Model 
the failure of the waste package container to isolate the waste form it contains. Upon container failure, the WPR model describes the releases of radionuclides and their migration outward through waste package. The encoded WPR model employs deterministic submodels based upon the analytical mass transfer equations of Pigford, Chambré, and coworkers to calculate waste package releases (Pigford and Chambré 1986). Individual waste package release esti-mates are combined by the ESR model to produce estimates of total release. Operationally, the flow of information among the various components, models, and subinodels of AREST, including input and output operations, is also controlled by the ESR module. (a)

Using appropriate site- and material-specific corrosion modules together with information about the waste package environment, the WPC model simulates the performance of an individual waste package from the time it is emplaced in the repository until the time of container failure. The containment phase of the simulation ceases at the time when physical containment is lost and the possibility for the release of radionuclides from the waste package exists. The time of container failure is the basic output of the WPC model for each simulated waste package; an empirical waste package failure time distribution is generated by repeatedly simulating failure times for individual waste packages. Other outputs of the WPC model include the values of variables, at the time of failure, that are required for release calculations. Of the variables that change with time, and hence, whose values depend upon the time of failure, temperature and groundwater composition are considered to be the most significant.

Upon failure of the simulated waste package, the WPR model computes releases of individual radionuclides from the waste package. Releases are given both in terms of a fractional release rate and as a cumulative release over time.

Individual waste package releases are integrated by the ESR model. Releases of individual radionuclides can be adided to produce an estimate of

(a) It is convenient to use the term "module" to refer to the computer code that implements a particular model. 
total release from an individual waste package. Moreover, individual waste package releases can be integrated with respect to the waste package failurem time distribution to obtain a stochastically generated estimate of total release from the repository system (i.e., an estimate of the repository sourceterm). In this way the expected ranges of repository and waste package parameters, as determined from preliminary information and designs for U.S. sites, are translated into probabilistic assessment of EBS performance.

\subsection{DESIGN OBJECTIVES}

The AREST model has been developed to support the need of the DOE OGR to inake quantitative assessments of the performance of the EBS and its components, relative to regulatory requirements, for a variety of barrier materials and repository and waste package design configurations. To satisfy this need, the AREST model must be generally applicable and must have a sufficiently flexible logical structure to allow modifications. Moreover, the AREST code must be numerically accurate and computationally efficient, and capable of incorporating new information and/or improved process models that may become available in the future. Consequently, AREST has been designed to possess the following features:

- AREST is a probabilistic model. Every input to the AREST code can be regarded as a realization of some random variable or stochastic process, and all input variables can be assigned values in accordance with user-selected probability distributions. The probability distributions are typically chosen to describe a particular repository site or environmental situation. In practice, many input values may be fixed for a particular simulation; a fixed value is simply represented by a degenerate probability distribution, that is, by a distribution that has all its mass concentrated at a single point.

- AREST is modular. The modular structure of the AREST code makes it comparatively easy to expand the model or to incorporate new process models and input distributions. Moreover, the modular structure of 
the code facilitates debugging and documentation, and allows the various AREST modules, such as the WPC and the WPR modules to be used separately.

- AREST is general. The logic of AREST has been developed, insofar as possible, to accommodate models of all processes which can reasonably be considered to affect release rates. Although the current AREST code has been developed primarily to model radionuclide releases from spent fuel, the programming logic and models of the waste package environment are quite adequate for modeling releases from other waste forms as well. Moreover, attempts are made to use physical and chemical models derived from basic principles, rather than empirical models, or models that apply only to a specific repository site or environment.

- AREST is flexible. The generalized logic and modular structure of AREST combine to make it a very adaptable: model. The modular structure of the AREST code frees it from dependence on any particular process model. Several models of uniform corrosion have been encoded, for example, and the user can either select from among these models or choose to encode some other model. Because of the modular structure, new models can be incorporated with comparative ease. Likewise, a variety of input distributions have been encoded. The user can select an appropriate distribution from this "library" to generate values for AREST input and control variables. The ability to choose different distributions and modules from one simulation to another makes it relatively easy to perform comparative parallel performance assessments with AREST.

- AREST is computationally efficient. Codes that implement detailed models of physical, chemical, and nuclear processes (research codes) are often too complex and require too much computing time to include in AREST. Rather than substituting simplified models of questionable accuracy into AREST in those cases, the research codes are used in a "support" mode. The research codes are used to make required calculations external to AREST, and the results of these calculations are 
provided as inputs to AREST. Waste package thermal histories (temperature expressed as a function of time), for example, are computed externally by thermal support codes and results are input to AREST in tabular form. The use of external support codes enables AREST to be computationally efficient without requiring an unacceptable sacrifice of modeling accuracy. Moreover, the use of research codes to support AREST in this fashion means that AREST is free of any particular research code.

Although AREST is general in scope and function, the code has been designed to model repository sites currently being investigated by the OGR. For this purpose, the code contains modules and input distributions for simulating specific sites, in particular those where the host material is salt, basalt, tuff, and crystalline rock. To simulate a particular repository site, the user selects those modules and distributions appropriate to the site.

\section{4 "MODEL" VERSUS "EXPERIMENT"}

The theoretical modeling concepts developed by Ziegler and Oren provide one framework for stochastic modeling (Ziegler 1976; Oren and Ziegler 1979). Within this framework, a fundamental distinction is made between the system model (model) and the experimental frame (experiment). This distinction is clearly explained in the documentation for SIMAN, a simulation language based on the principles of Oren and Ziegler and discussed by Pegden (1985, p.1):

\footnotetext{
"The system model defines the static and dynamic characteristics of the system. In comparison, the experimental frame defines the experimental conditions under which the model is run to generate specific output data. For a given model, there can be many experimental frames resulting in many sets of output data. By separating the model structure and the experimental frame into two distinct elements, different simulation experiments can be run by changing only the experimental frame. The system model remains the same."
}

In this context, "experiment" does not refer to one that is performed in a laboratory in the classical sense, but rather to an experiment performed with the aid of computer simulation. The experiment (experimental frame) is determined by the selection of values for control parameters and of distributions 
for input variables. The game of chess provides a concrete example of the distinction between model and experiment: The board, playing pieces, and rules of chess define a "model," but each individual game can be considered an "experiment."

It is also useful to make the distinction between model and experiment when discussing AREST. The purpose of this report is to describe the model, its structure and characteristics. Except to identify what input is needed, no particular experiment will be described. It is, however, necessary to describe the experimental frame for any particular application of AREST. The second volume of this report describes several experimental frames selected to assess the performance of spent fuel as a nuclear waste form.

The distinction between model and experinent is made because the evaluation of a given model is a separate issue from the evaluation of (the results) any particular experiment. The output of a $s^{-i m u l a t i o n ~ e x p e r i m e n t ~ m a y ~ n o t ~ b e ~}$ meaningful in a given context if incorrect or inappropriate input values are used, but the choice of incorrect inputs does not imply that the model is invalid. (Chess is not necessarily a defective game because one "experiment" is inconsistent or inadequate). A wide range of input values can be chosen to illustrate and test AREST, but these values need not describe any particular repository site or host medium. Because the purpose of this volume is to describe the AREST model and code, no attempt is made to describe any particular experiment. The second volume of this report describes experiments conducted with AREST to evaluate the performance of spent fuel as a waste form. 


\subsection{THE AREST MODEL}

Section 2.0 discusses the structure of AREST, the waste package environment, the waste package containment, the waste package release, the containment-release prograin logic, and the engineered system release.

\subsection{THE STRUCTURE OF AREST}

The three major submodels of AREST are described briefly in Section 1.0 and shown in Figure 1.1. Figure 2.1 shows these submodels in relationship to the process models that describe the waste package environment, the various input variables and modules, and the support codes required to run the AREST code. As noted in Section 1.0, the WPC model simulates waste package containment performance, the WPR model computes radionuclide releases from the individual waste packages, and the ESR model integrates waste package releases relative to simulated failure times to produce an estimate of total repository release. The ESR model also controls exchanges of information among the WPC model, the WPR model, and inodels of the waste package environment.

Waste package containment and release cannot be modeled without information about the environment in which these processes occur. Consequently, AREST contains models that describe the physical and chemical environments of the repository and waste package. Included in AREST are modeis of the thermal, geochemical, hydrological, radiation, and mechanical environments of the simulated waste package. At this time, the thermal and geochemical models are most fully developed. The thermal model provides temperatures as required by other components of AREST; temperatures are updated at each time step during simulation. The geochemical model provides the values of variables used to describe groundwater composition in the vicinity of the waste package. Groundwater variables, like temperature, are updated at each time step. The hydrologic model provides the time until resaturation of the waste package following emplacement and repository closure. The radiation model describes radiation doses to which the waste package is exposed, and the mechanical model describes the mechanical stresses to which the metallic barriers are subjected. To date, 


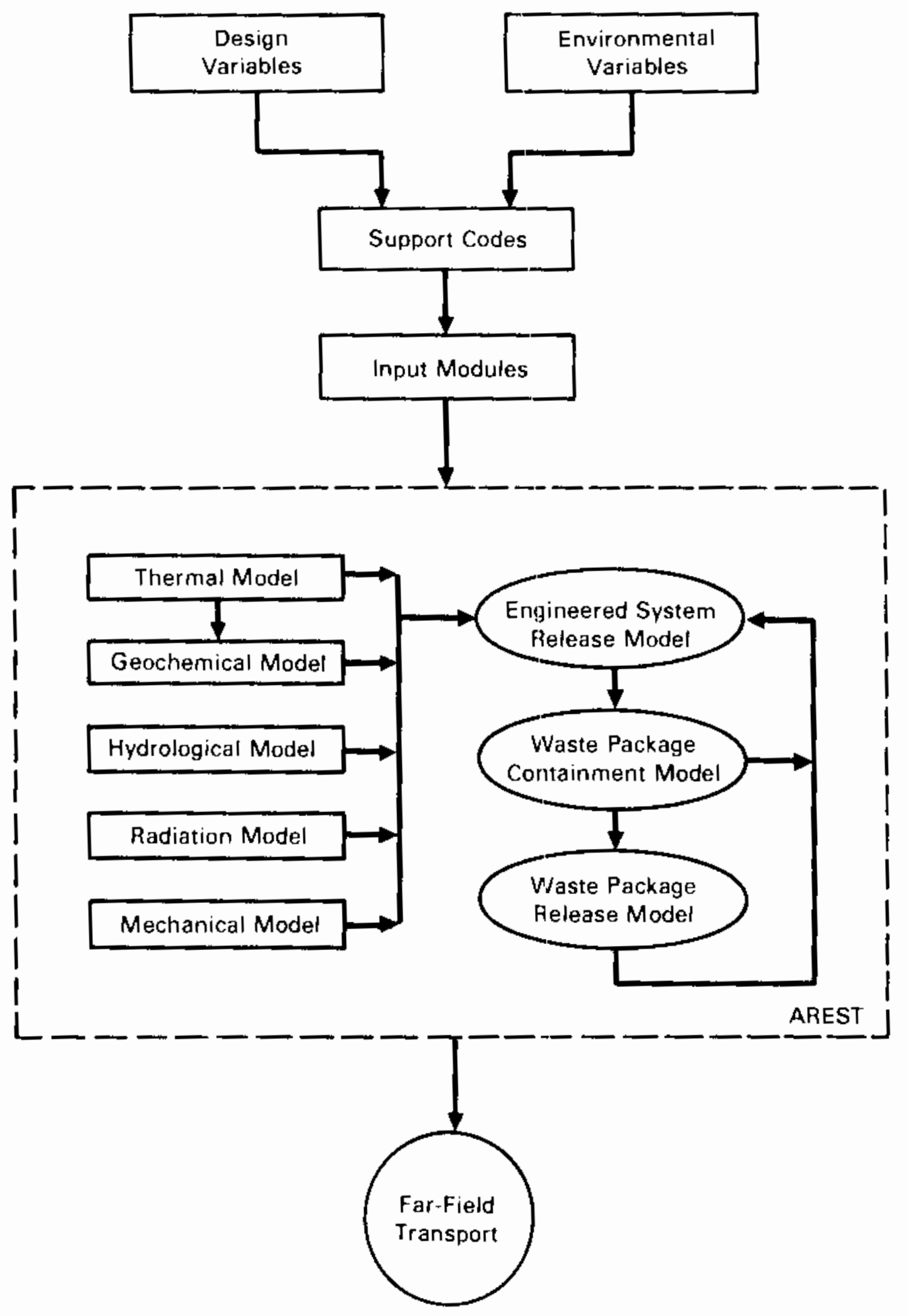

FIGURE 2.1. Relationships Among AREST Submodels and Various Process Models, Input Variables, and Support Codes 
only rudimentary mechanical and radiation inodels have been developed for AREST. The effect of radiolysis is incorporated indirectly by means of the groundwater geochemistry model.

Inputs to AREST include the values assigned to waste package and repository design variables, and to variables that describe the physical and chemical environments of the repository and waste package. Inputs also include the output from support codes that perform calculations too lengthy to be done in AREST, as well as user-selected modules that simulate physical and chemical degradation processes.

Waste-package and repository-design variables are those variables subject to human control that pertain to the design of the repository and the waste package; examples include container thickness and spacing. Environmental variables are those not normally regarded as controllable, such as geochemical variables, that describe the initial environment of the waste package and the repository site.

The AREST model requires information about a number of physical, chemical, and nuclear processes. The research/scientific codes that implement detailed models of those processes are of ten too complex and require too much computing time for them to be included directly into the AREST code. In these cases, the research/scientific codes are used to make the necessary calculations external to AREST, and the results of these calculations are then provided as inputs to AREST. Values of the variables that describe the geochemical environment of the repository site, for example, are computed by support codes and supplied as inputs to AREST. Likewise, required site-specific thermal histories are derived from a detailed thermal analysis and tabulated for use by the AREST code. The use of external research/scientific codes in this fashion preserves the computational efficiency of the AREST code without requiring an unacceptable loss of modeling accuracy (the adoption of simplified models solely to reduce computing time is avoided). The use of external support codes not only preserves computational efficiency and accuracy, but also enhances flexibility because AREST is not tied to a particular support code.

Finally, the AREST code is designed to accept modules that simulate various physical and chemical processes. This feature gives the AREST code great 
flexibility and enables the simulation of waste package containment and release under a wide variety of assumptions. Uniform corrosion, pitting corrosion, and stress corrosion are currently simulated by means of input modules. The site environmental assessments (DOE 1986a, 1986b, 1986c) contain models of uniform corrosion of the waste package container. All of these, as well as the models; described in Appendix A, have been coded for use by the AREST code. The user selects one of the available modules at the time of simulation. Existing modules can be updated as necessary, and additional modules can be added with relative ease; therefore, as with support codes, AREST is not limited to any particular model. The availability of multiple models for a given process not only enhances the flexibility of the AREST code, but also facilitates the evaluation of model uncertainty. Simulations can be performed with each available process model to assess the effect of model choice (for the process or processes in question) on release.

\subsection{WASTE PACKAGE ENVIRONMENT}

The AREST model contains various models that describe the environment of the simulated waste package. Models that describe the thermal, geochemical, hydrological, radiation, and mechanical environments of the waste package are discussed in this section.

\subsubsection{Thermal Model}

For modeling temperature-sensitive processes within AREST, it is necessary to know or be able to compute waste package temperatures. The AREST thermal model uses the following information to compute container temperatures at times of interest within the simulation period:

- the temperature history of a reference or design-basis waste package container

- the average temperature of the repository host rock at the midplane of the waste packages for all times in the simulation period

- the distribution of heat generation rates, at the time of emplacement, of nuclear wastes received at the repository. 
To date, the thermal model has been implemented only for spent fuel. Reference temperature calculations are based upon the design-basis spent fuel description: 10-year old, 33,000 MWd/MTU exposure pressurized-water reactor (PWR) fuel. The thermal model is quite general, however, and can easily be modified for other waste forms, provided that temperature histories and initial heat generation rate characteristics are available.

The average repository temperature and reference waste package container temperature histories are calculated with a supporting heat transfer code. As described in Appendix B, the general purpose finite element code, ANSYS is currently used to calculate the waste package container and average repository host rock temperature histories. Calculations depend upon material thermal properties, repository and waste package design parameters, and the decay heat generation rate for the repository system. The resulting time-dependent temperature histories are tabulated for input to AREST.

The initial heat generation rate distribution of the spent fuel at the time of emplacement is calculated using a supporting logistics code. The Waste System Transportation and Economic Simulation--Version 11 (WASTES II) code is used to calculate the initial heat generation rate characteristics of spent fuel received at and emplaced in the first geologic repository. The initial heat generation rate distribution depends upon waste acceptance schedules at the repository and spent fuel discharge projections for the spent fuel management system. The initial heat generation rate distribution of spent fue? receipts is tabulated in cumulative form for input to AREST. Elements of the thermal model are shown in Figure 2.2 in relation to the other components of AREST.

From the input information described above, the temperature of the simulated container is computed within the AREST code at each time step. At any time after emplacement, the temperature of a simulated container is computed with the aid of the following equation:

$$
\frac{H_{s}(0)}{H_{r}(0)}=\frac{T_{s}(t)-T_{a}(t)}{T_{r}(t)-T_{a}(t)}
$$




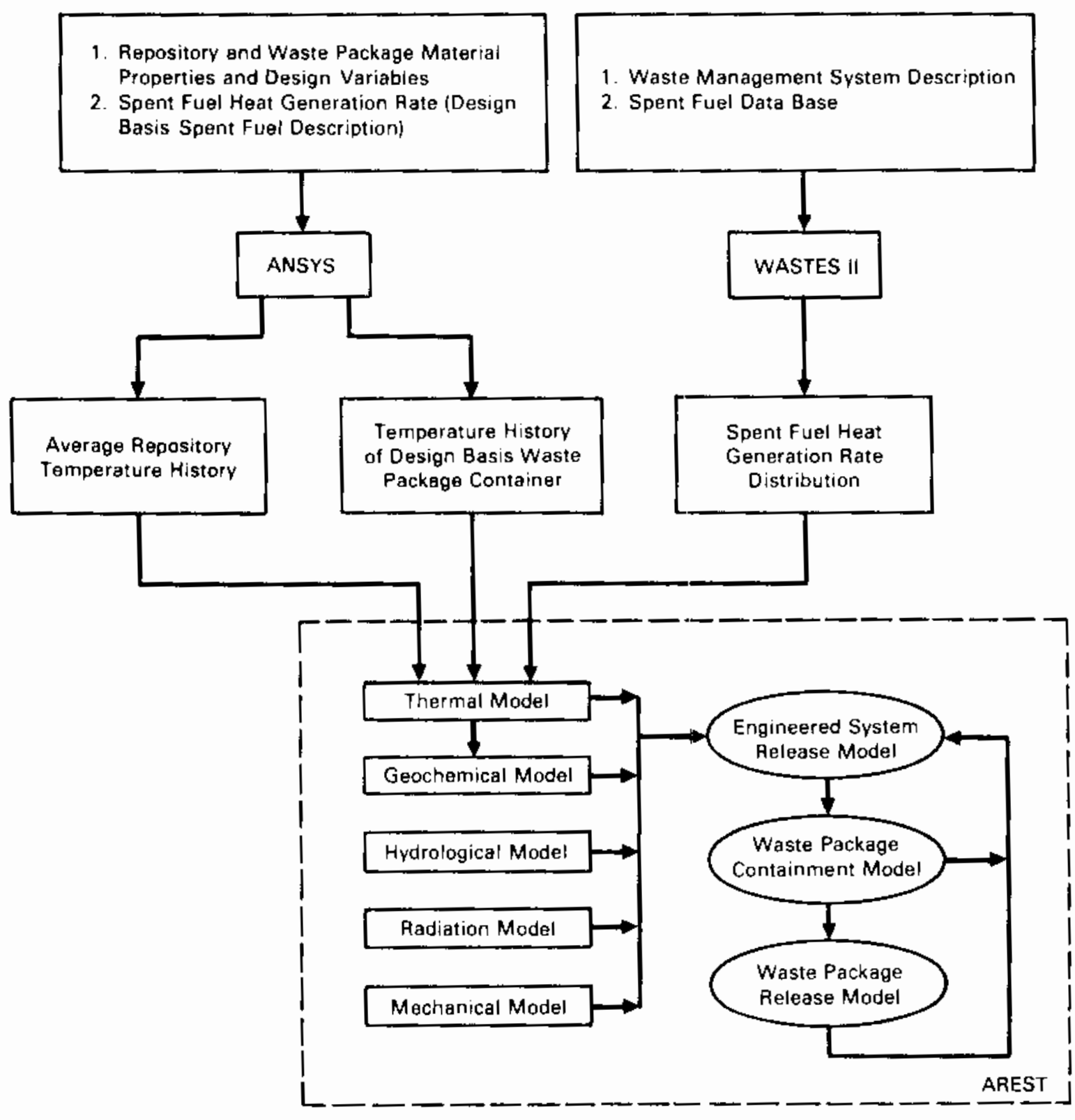

FIGURE 2.2. The AREST Thermal Model

or equivalentiy,

$$
T_{s}(t)=\frac{H_{s}(0)}{H_{r}(0)}-\left[T_{r}(t)-T_{a}(t)\right]+T_{a}(t)
$$

where $T_{S}(t)=$ temperature of the simulated container at time $t$ (in $\left.{ }^{\circ} \mathrm{C}\right)$ $T_{r}(t)=$ temperature of the reference container at time $t$ (in ${ }^{\circ} \mathrm{C}$ ) 


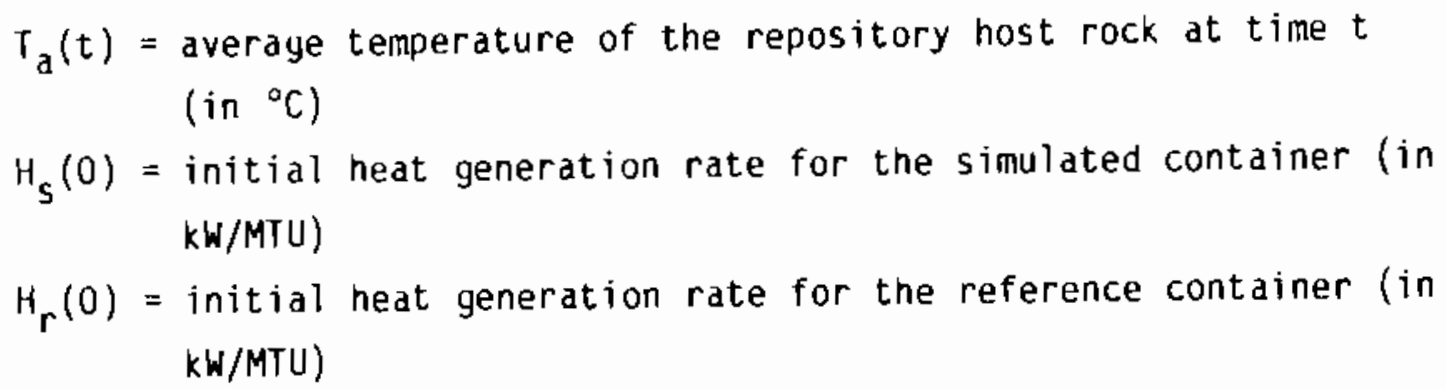

For times $t$ other than those at which reference container and average repository temperatures have been tabulated, $T_{r}(t)$ and $T_{S}(t)$ are determined by linear interpolation. The simulation of waste package temperature histories is shown graphically in Figure 2.3. Using the initial heat generation rate distribution (from WASTES II, see Appendix B), a uniformly distributed random number (U) is converted into an initial heat generation rate $\mathrm{H}_{\mathrm{s}}(0)$ for the (contents of the)

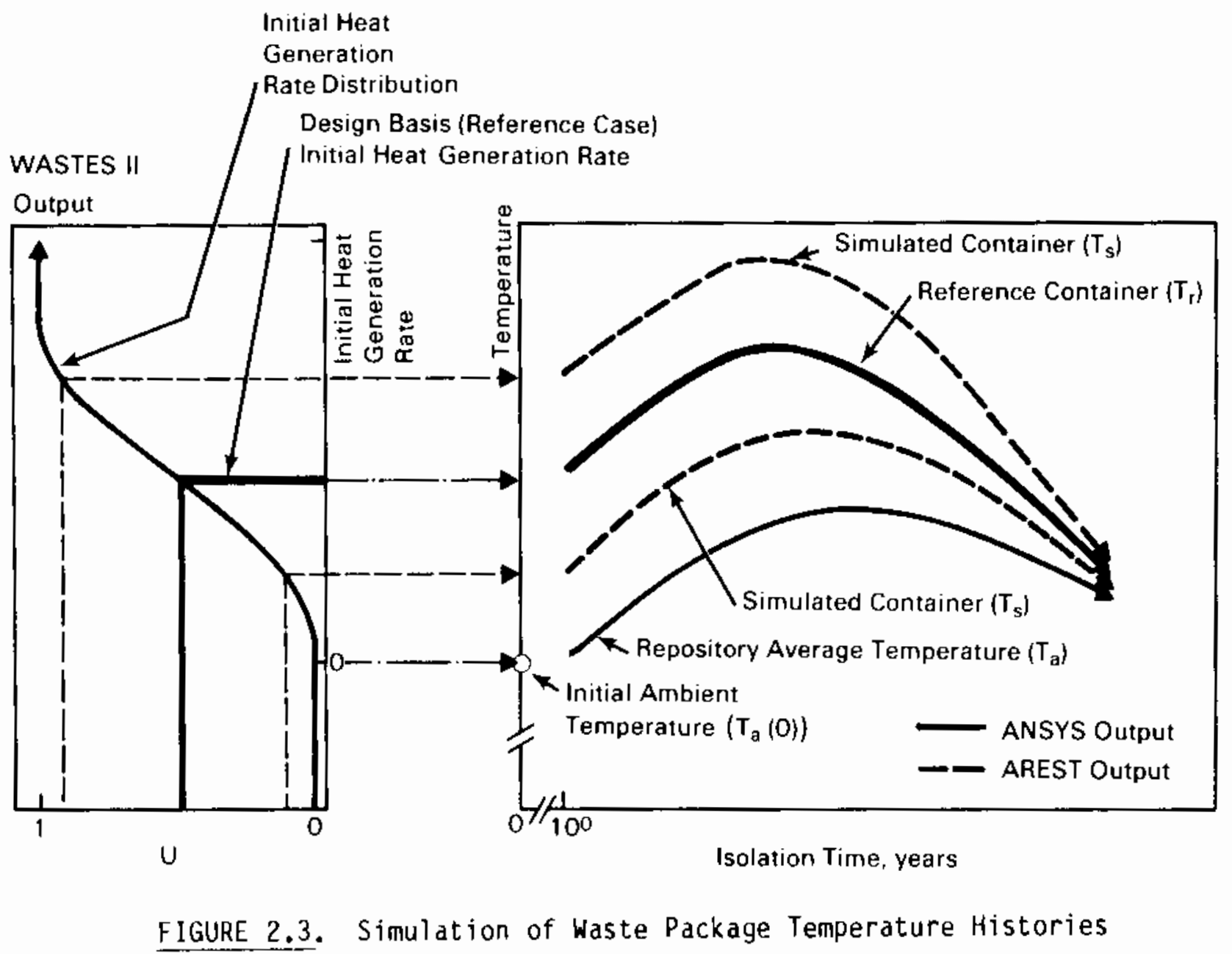


waste package. This initial heat generation rate is used in Equation (2.2) to compute temperatures $T_{s}(t)$ for the simulated container at times $t$ of interest.

In AREST, the (simulated) initial heat generation rate $\mathrm{H}_{\mathrm{s}}(0)$ is used to determine the temperature of the container at all subsequent time steps in tre simulation of a waste package. Thus, if the initial simulated value of $T_{s}$ is such that $\left[T_{s}(t)-T_{a}(t)\right]$ is greater (by $10 \%$, for example) than $\left[T_{r}(t)-T_{a}(t)\right]$. at any time $t$, then a similar offset $(10 \%)$ relative to reference temperature is used at all other times. This procedure contrasts with that where a new temperature is simulated from a suitable distribution of temperatures at each time step. Rather than simulating a new temperature at each time step, AREST randomly selects one function $T_{S}$ from a class of possible temperature-tine functions at the first time step. The selected function is used to compute temperatures at all subsequent time steps.

Equations (2.1) and (2.2) are obtained by assuming that at all times, the difference between the temperature of a simulated container and repository average temperature $\left[T_{S}(t)-T_{a}(t)\right]$ is proportional to the difference between the temperature of the reference container and repository average temperature $\left[T_{r}(t)-T_{a}(t)\right]$. The constant of proportionality is the ratio $H_{s}(0) / H_{r}(0)$ of the initial heat loadings for the two containers. Implicit in Equations (2.1) and (2.2), and consequently in the AREST thermal model, are the assumptions that container diameter and waste package emplacement density are constant throughout the engineered system.

To date, the thermal inodels for spent fuel nave been developed for the candidate first repository conceptual designs as described in the final Environmental Assessments (DOE 1986a, 1986b, 1986c) and the authorized 1985 Mission Plan system description (DOE 1985). Details of this procedure and its limitations are given in Appendix B. Despite the limitations, this model provides reasonable estimates of the time and spatially dependent container temperatures throughout the engineered barrier system.

\subsubsection{Geochenical Model}

The geochemical input to AREST includes information relevant to changes in groundwater composition at different spatial positions within a repository. 
Geochemical processes that are responsible for changes in the elemental composition of the groundwater involve mass transfer reactions between the groundwater and solids in the host rock, packing material, canister, and waste form. These processes are affected by factors that include temperature, groundwater composition, solubility of the solid phases in contact with the groundwater, and distribution of the aqueous mass between various species in solution.

The geochernical input to AREST is obtained by using an equilibrium speciation/solubility code and the reported composition of groundwaters (DOE 1986a, 1986b, 1986c) to calculate the aqueous equilibria for hypothetical conceptual models of basalt and high-level waste (HLW) repositories. A speciation/solubility support code, EQ3NR (Wolery 1983), is used to generate repository groundwater compositions that were tabulated for input to AREST (see Figure 2.4). In the case of a bedded salt repository, limitations introduced by the lack of thermodynamic data relevant to brines at high temperatures precluded the use of the EQ3NR code to predict compositions at elevated temperatures. These compositions were approximated, however, using experimental data. The geochemical parameters are user-generated and subject to frequent changes, so for convenience and flexibility, geochemical values were input to AREST in tabular form. Appendix $C$ contains a discussion of the simplified conceptual models and results of the calculations that are currently used in the AREST code.

\subsubsection{Hydrological Model}

The National Academy of Sciences (NAS) reviewed the expected hydrological conditions and waste package designs at several candidate sites for nuclear waste disposal, including the currently nominated repository sites in basalt, salt, and tuff (NAS 1983). The NAS report presents evidence that diffusive transport is the expected mechanism for nuclide migration within waste packages at these sites. Diffusive transport is the first hydrological property of repositories that is critical to the performance assessment of such locations. Evidence in the environmental assessment reports for the repository sites further confirms this assertion (DOE 1986a, 1986b, 1986c). In a review of mass transfer theory applied to waste package performance assessment Pigford and Chambré (1986) asserted that in most of the repository designs, the groundwater 


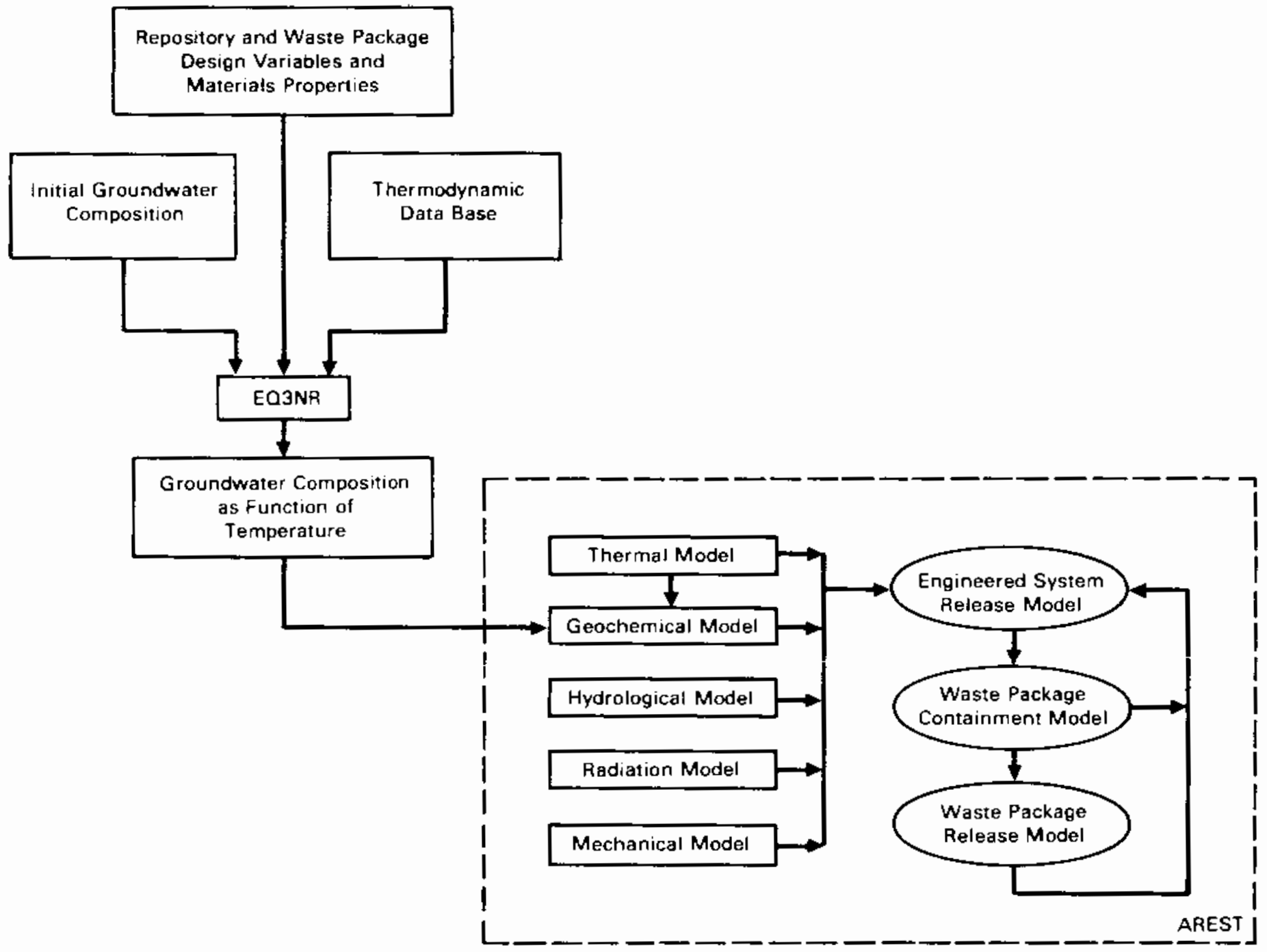

FIGURE 2.4. The AREST Geochemical Model 
pore velocity is so low that convective transport of nuclides within the waste package will be negligible. Accordingly, it is assumed in the AREST model that transport of both stable and radioactive species is diffusion-controlled for all waste package designs.

A second hydrological property of repositories, which is relevant to the performance assessment of EBS, is the degree of saturation. The degree of saturation is a field measure of the percent volume of voids (pores) that are filled with groundwater. Calculations of radionuclide release rates rely directly on interconnected pathways of water-filled pores in barrier materials (see Appendix E). Therefore, the degree of saturation represents a correction factor to mass transfer calculations. Radionuclide release rates calculated in AREST are normalized by this factor to account for the decreased number of pathways by which nuclides can migrate.

A third important aspect of repository hydrology is the time to achieve resaturation at the waste package, following its emplacement and subsequent repository closure. Emplacement of nuclear waste packages in water-bearing rock at atmospheric pressure will necessarily result in localized boiling of groundwater and the generation of stear. The dried rock mass and packing immediately surrounding the waste container then become unsaturated regions with pore pressures much lower than ambient groundwater pressure. Repository groundwaters will generally flow toward this unsaturated region, heating up and turning to steam. This process will continue until all pores are saturated and pressurized to the point that trapped steam converts to water. This process is called resaturation.

Resaturation is a complex phenomenon that involves the intricate coupling of separate processes, including thermal conduction, rock creep, reestablishment of ambient repository pressure, groundwater boiling, fracture sealing, and many others. Therefore, development of a general model for calculating the time of resaturation is beyond the scope of AREST at this time. For this reason, the approach taken for the AREST code is to use simplified bounding calculations to determine the time to resaturation (Pruess and Bodvarsson 1982). 
For ductile, plastic host rocks such as salt, rock creep drives repressurization of the region surrounding the waste cortainer. This repressurization is assumed to result in resaturation on a time scale that is instantaneous (less than 10 years), relative to the time scale of interest for nuclear wastes containment and release. For the case of unsaturated rock media, such as tuff, resaturation can be modeled by assuming a constant pressure of approximately 1 atm and then calculating the time for the waste package environment to cool below the boiling point of water (approximately $100^{\circ} \mathrm{C}$, depending upon ambient pressure). For the case of a competent, saturated host rock, such as basalt or granite, it is assumed that fluid flow into the unsaturated voids is inversely proportional to the rock mass permeability. The following relationship between resaturation time and host rock permeability has been calculated (Pruess and Bodvarsson 1982):

$$
\log t_{R}=-1.06 \log k_{r}-17.8
$$

where $t_{R}$ is resaturation time (in years) and $k_{r}$ is host rock permeability (in $\mathrm{m}^{2}$ ). Figure 2.5 shows the calculated relationship graphically. Pruess and Bodvarsson (1982) also showed the dependence of resaturation time on other repository parameters.

\subsubsection{Radiation Model}

The two principal effects that radiation may have on performance of waste package materials are physical damage resulting in degradation of function arid chemical reactions resulting in changed environnental conditions. In this section, both of these potential effects are briefly addressed as they relate: to the modeling of the containment and slow release of radionuclides in AREST.

At all potential repository sites, damage to metal-based container materials by neutrons and ionizing radiation has been found to be insignificant for candidate waste forms (DOE 1986a, 1986b, 1986c). Irradiation damage to packing and host rock materials is also expected to be agligible, with the possible exception of gamma-irradiated salt (Levy 1983; Pedersen et al. 1984). If reciistic garma doses and dose rates are found to lead to significant degradatior of salt, it is anticipated that changes in contajner design le.g., new or 


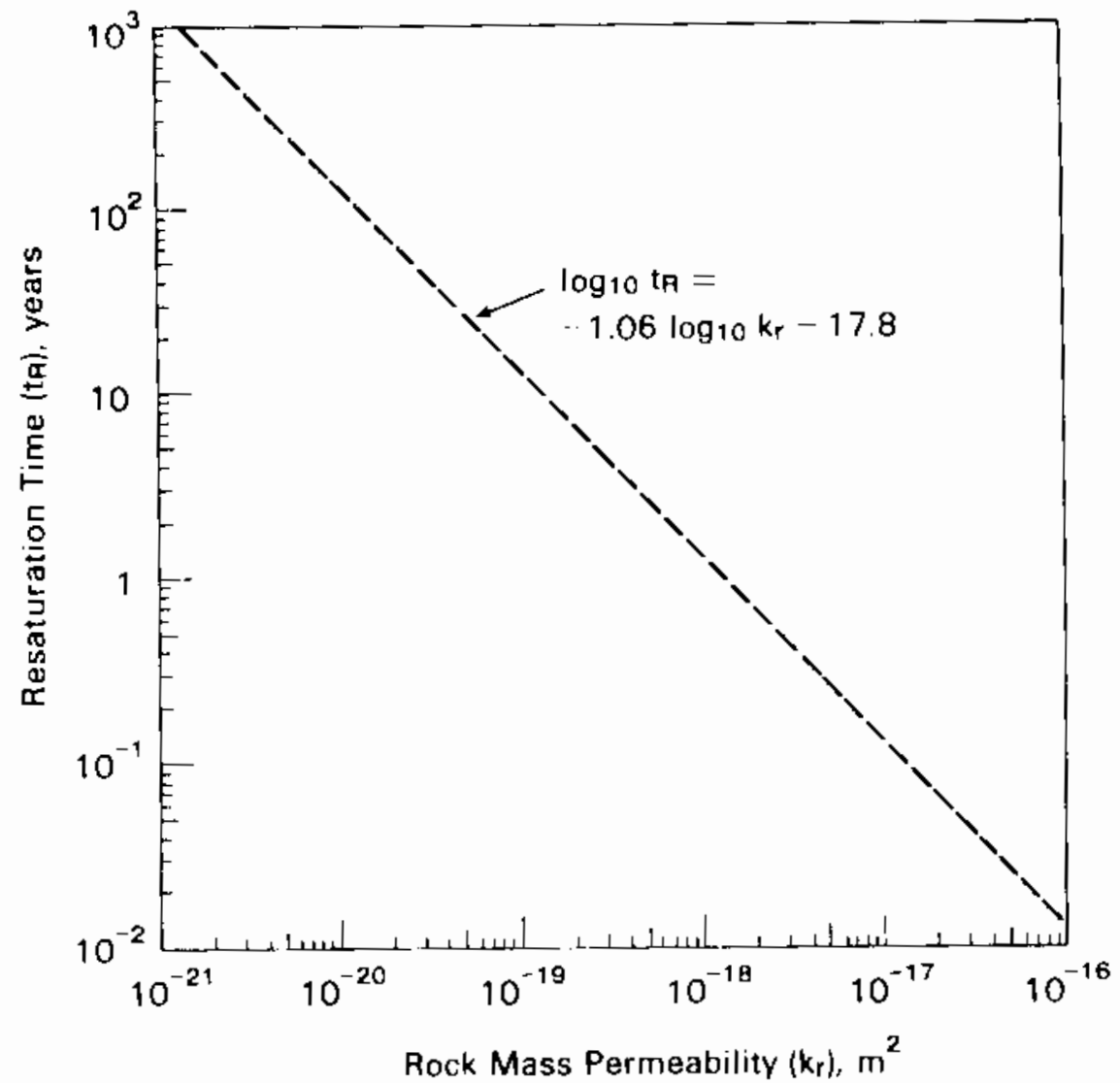

FlGURE 2.5. Relationship Between Resaturation Time and Rock Mass Permeability

thicker material) would be employed to eliminate this deleterious effect. As for physical damage to waste forms, the release rate models in AREST are functionally dependent on chemical solubilities of radionuclide-bearing solids. The solubilities of either primary or secondary (precipitated) crystalline solids are not expected to be affected by radiation damage because of the continued dissolution/precipitation reactions occurring at equilibrium solubility conditions. Therefore, the effects of radiation damage on predictions of containment and release rate performance are expected to be minimal, and are not currently modeled in AREST.

Of more general concern is the potential for gamma and/or alpha radiolysis of groundwater within the waste package region (Neretnieks 1984; Christensen and Bjergbakke 1986). Several gamma irradiation tests of simulated groundwaters have shown the production of certain chemical species (Gray 1984) that could be deleterious to waste package performance. More relevant tests of 
groundwater-plus-barrier materials, however, indicate that the presence of reactive solids typically suppresses reactions observed in tests only involving groundwater. Corrosion tests conducted under conservatively high gamma irrajiation (McCright, Van Konynenburg, and Ballou 1984; Westerman et al. 1984) have confirmed measurable increases in corrosion rates, generally by factors of 2 to 5, attributable to radiolytic production of oxidizing species. Studies of the reaction of radioactive waste forms with groundwater have shown measurable changes in dissolution rate (Bibler, Wicks, and Oversby 1985) and solubility (Rai and Ryan 1984) attributable to the generation of radiolytic species.

It is more suitable, therefore, that the effect of radiolysis be incorporated into AREST through the existing groundwater geochemistry model (Section 2.2.2 and Appendix (), rather than by means of a separate radiolysis analysis. Realistic modeling of the coupled effects of radiolysis and geochemical reactions within the waste package region cannot be achieved at this time, however. Data on the kinetics of geochemical reactions of compositionally complex groundwaters are poorly known; the kinetic data on radiolysis of such groundwaters are essentially unknown. In addition to the lack of rate constants, the effective reactive surface area of solids, grouridwater volume, buffering capacity of solids, and mass transport constraints have yet to be evaluated. At this time, the AREST code address can be used to address potential radiolytic effects by the bracketing of changes in geochemical parameters, notably Eh and $\mathrm{pH}$, arising from radiolysis. It is expected that the tremendous mass and buffering capacity of barrier materials, including waste forms, will completely attenuate radiolytic changes in geochemical parameters.

\subsubsection{Mechanical Model}

The AREST model currently contains a rudinentary mechanical model that supplies the input variables needed by the stress corrosion cracking model described in Appendix A. Inputs to the stress corrosion model include values for the yield stress of the waste package container.

Currently, the same (initial) stress yield value is supplied by the mechanical model to the stress corrosion module at each time step. Because stress. relaxation occurs with time, the current model predicts excessively rapid penetrations of the waste package container. A refinement of the mechanical 
model, whereby the yield stress is allowed to change with time, is planned to make the mechanical model more realistic.

\subsection{WASTE PACKAGE CONTAINMENT}

The integrity of engineered barriers will play an important role in determining the extent to which radionuclides are contained in a geologic repository. Currently, metallic containers are the primary engineered barrier for meeting the NRC containment performance objectives. Because corrosion is a primary degradation mechanism for the metallic containers, corrosion rate estimates are required for performance and safety assessment.

Corrosion describes a wide variety of complex phenomena involving both chemical and electrochemical interactions between a metal and its environment. These phenomena are extremely material- and environment-specific. Classifications of the corrosion process include uniform corrosion, localized corrosion, stress corrosion cracking, and galvanic corrosion. In practical situations, such distinctions may be difficult because the processes may operate concurrently and the interactions may exhibit many variations. A comprehensive corrosion model is unlikely because of the complexity of the corrosion processes and because not all the mechanisms associated with corrosion are completely understood. Furthermore, the environments into which the barrier materials will be placed have not yet been completely quantified.

Corrosion models may be entirely empirical or they can be based on a reaction mechanism. The latter will, of course, depend on an empirical data base and will be strictly valid over the range of conditions for which it was derived. But, since the mechanistic models are based on a deeper understanding of the chemical origins of the corrosion processes, they can, in principle, be extended to other conditions where similar reaction mechanisms are known to occur. The corrosion models being developed at the candidate repository sites are empirical and based upon data from relatively short-term (less than 5 years) corrosion tests. The DOE OGR, however, has recently expressed interest in developing a mechanism-based model for corrosion. Such an approach is complementary to corrosion modeling being done at the repository sites. 
Ultimately mechanistic modeis must rely on the validity and comprehensiveness of the empirical data on which they are based. Unfortunately, the data bases for most types of corrosion are not sufficiently detailed to permit the development of reliable mechanistic models that are applicable over a wide range of conditions and environments. For this reason, both empirical and mechanistic models must be considered at this time. As the corrosion data base is expanded and a more complete understanding of the chemical interactions and their dependence on enviromental conditions is achieved, it is expected that more comprehensive mechanism-based corrosion models will be developed.

Elements of the WPC model are shown in Figure 2.6. Included are module's for uniform corrosion, pitting corrosion, and stress corrosion. The modules are both empirical and mechanism-based. When running the AREST code, the user selects one of the available preprogrammed models for corrosion. The flexib-1ity of AREST is enhanced by the inclusion of multiple models of important corrosion processes.

\subsubsection{Uniform Corrosion}

The model for uniform corrosion described in Appendix A is largely empirical and based on a model developed by Sastre, Pescatore, and Sullivan (1986) at Brookhaven National Laboratory (BNL). The model is applicable to carbon steel corrosion in low-magnesium brine environments. The model appears to work well for predicting corrosion rates between 1 and 6 months of exposure at $150^{\circ} \mathrm{C}$ $(423 \mathrm{~K})$. Applying the model to other conditions should be done with caution. In particular, the model shows severe limitations at very short times (less than 1 day) or at temperatures other than $150^{\circ} \mathrm{C}(423 \mathrm{~K})$.

Several predictive models of the rate of uniform corrosion, in addition to the generalized mechanistic model described in Appendix A, have been programmed for use in AREST. These include the Basalt Waste Isolation Project (BWIP) model of uniform corrosion of the waste package container (Anantatmula, Delegard, and Fish 1984) and a model of uniform corrosion developed for the Salt Repository Project (SRP) (Westerman et a1. 1984). Both models are empir. ical and both predict the rate of uniform corrosion of a steel container. The BWIP model takes different forms in aqueous and steam environments. 


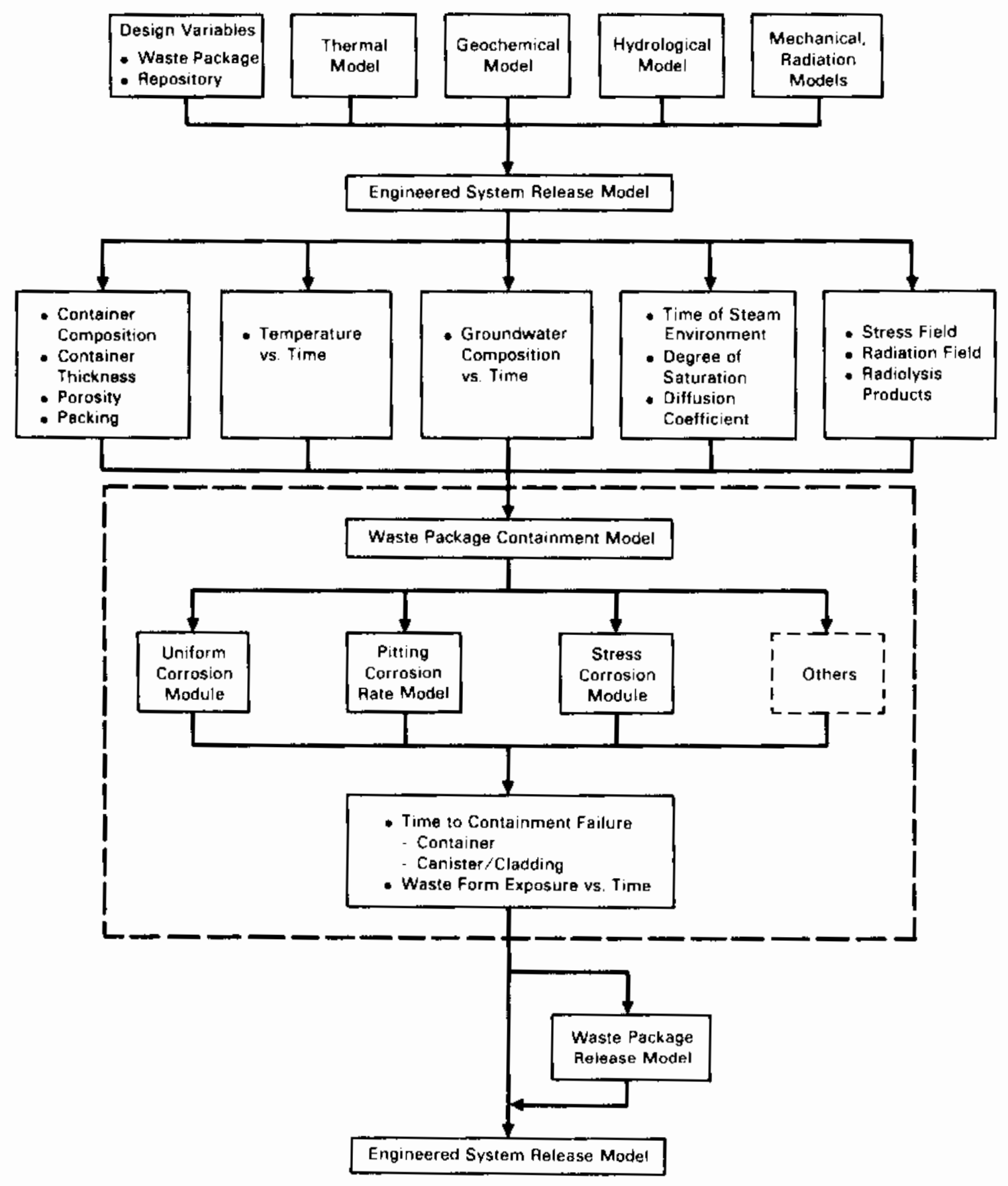

FIGURE 2.6. The Waste Package Containment Model

Models for uniform corrosion under other conditions will be incorporated in the AREST code as they become available. In particular, as the data base becomes large enough to prevent the development of reliable mechanistic models, these will be incorporated as additional uniform corrosion modules. 


\subsubsection{Pitting Corrosion}

The pitting corrosion model in AREST is essentially a probabilistic model that involves the calculation of a pit growth rate at each time step. The model is quite similar to a model contained in an Aerospace Corporation report prepared for the NRC (Stephens 1985). The model is applied to both the container and cladding. For each waste package container, pitting corrosion is simulated as follows:

- At the start of simulation, a threshold container surface area that constitutes failure by pitting, $A_{f}$, is determined. The quantity $A_{f}$ is such that when the total surface area of the pits penetrating the container exceeds $A_{f}$, the container is considered to have failed by pitting corrosion. The area, $A_{f}$, is computed as follows:

$$
A_{f}=A * P_{f} \text {, }
$$

where $A$ is the total inner-wall surface area of the container and $P_{f}$ is the percentage $P_{f}$ the percentage of total surface area that defines failure by pitting. The percentage $P_{f}$ is an input value based upon the work of Kim, Chambré, and Pigford (1986).

- For each waste package, $i$, the number of potential pit sites, $N_{j}$, is simulated initially. The variable, $N_{j}$, is assumed to follow a Poisson distribution. A pitting rate, such as the average number of potential pit sites per container, or the average number of pits per unit volume, is required to simulate $N_{j}$. The potential pit sites are assumed to be distributed uniformly throughout the volume of the container (or cladding).

After $\mathbb{N}_{i}$ has been simulated, the following calculations are done at each time step:

- Potential pit sites are checked for initiation of pitting. A pit initiates at a given site at a given time step if the pit site lies in the shell of container (cladding) material that is removed by uniform corrosion, and the pitting rate exceeds the rate of uniform 
corrosion. The pitting rate equation described in Appendix $A$ is currently used for this purpose. The rate of uniform corrosion is calculated in the uniform corrosion module selected by the AREST user. The number of pit sites is the shell of material removed by uniform corrosion is computed as the product of $N_{j}$ and the proportion of the container (cladding) volume that is removed by uniform corrosion during the time step in question.

- Upon initiation of pitting at a potential pit site, the increase in pit depth is computed at each time step. Once a pit develops, it is assumed to have a cylindrical shape of constant cross-sectional area, $A_{p}$, which does not change with the depth of the pit.

- Let $D(t)$ denote the depth of a pit at time $t$. Then, at each time step, the distribution, $F_{t}(d)$, of $D(t)$ is computed:

$$
F_{t}(d)=F(d ; D, t)=\operatorname{Pr}[D(t)<d] .
$$

where the notation $\operatorname{Pr}[A]$ is used to denote the probability of the event $A$.

It is convenient to compute the distribution of $D(t)$, either directly or by simulation, outside of AREST. At present, $D(t)$ is treated deterministically, so that $F_{t}$ is a unit step function [that is, $F_{t}(d)=0$ for all values of $d$ less than some value $d^{\prime}$ and $F_{t}(d)=1$ for all values greater than or equal to $\left.d^{\prime}\right]$. In order to link the simulations of uniform and pitting corrosion, pitting depths are always given relative to the actual surface of the container, rather than to the original surface:

- The distribution, $G(t)$, of the time, $t_{p}$, that a pit penetrates the container is computed from $F_{t}(d)$ as follows:

$$
G(t)=\operatorname{Pr}\left[t_{p}<t\right]=\operatorname{Pr}\left[D(t)>d_{0}-d_{u}\right]=1-F_{t}\left(d_{0}-d_{u}\right)
$$


where $d_{0}$ is the original thickness of the container (or cladding) and $d_{u}$ is the thickness of the container that has been removed by uniform corrosion.

- The average number of pits required for failure by pitting, $k_{f}$, is computed. In general, computation of $k_{f}$ requires the distribution of the cross-sectional areas of the pits, a distribution that may change with time. It is currently assumed that all pits have (constant) cross-sectional area, $A_{p}$, so $k_{f}$ is computed as follows:

$$
k_{f}=A_{f} / A_{p}
$$

- Let $K$ denote the total number of pits that have penetrated the container at the end of the current time step. Then, the probability that the container has failed by pitting corrosion, ${ }_{f}$, is computed as follows:

$$
\begin{aligned}
P_{f} & =\operatorname{Pr}\left(K>k_{f}\right)=\sum_{j=k_{f}}^{N_{i}}\left(\begin{array}{l}
N_{i} \\
j
\end{array}\right)[G(t)]^{j}[1-G(t)]^{N_{j}-j} \\
& \left.=\sum_{j}^{N} \sum_{k}^{i}\left(\begin{array}{l}
N_{i} \\
j
\end{array}\right)\left[1-F_{t}\left(d_{o}-d_{u}\right)\right]^{j}\left[F_{t}\left(d_{o}-d_{u}\right)\right]\right]^{N_{j}-j}
\end{aligned}
$$

- If $P_{f}$ exceeds some (small) predetermined probability, then the container is considered failed by pitting corrosion. The current cutof $f$ value in AREST is 0.1 , so that failure by pitting corrosion occurs when $P_{f}>0.1$.

\subsubsection{Stress Corrosion}

Stress corrosion does not occur unless both stresses and some form of corrosion mechanism are present. A mechanistic model for predicting the rate of stress corrosion cracking of the waste package container (Newman 1981) is described in Appendix A. In this model, stress corrosion is regarded as a 
step-like process whereby a tensile stress causes fracture of a relatively brittle, passive film on the material, followed by rapid dissolution of the metal. As the anodic dissolution of the metal proceeds, a new passive layer is built up at the crack tip. The stress again fractures the layer, and the process repeats itself. Stress corrosion can therefore be considered as a repetitive occurrence of passive layer fracture followed by healing. The rate at which stress corrosion occurs depends upon the stress level to which the material is subjected and the passivation rate of the material in the given environment.

The stress corrosion model in Appendix A has been coded as an AREST module. The module is used to predict the rate of stress corrosion, specifically the crack-tip velocity at a point of stress cracking, at each time step. The crack tip velocity is a function of the stress level supplied by the mechanical model of the waste package environment. Currentiy, the same (initial) stress intensity is used at each time step. The rate of penetration is highly dependent upon the assumed stress intensity, and stress relaxation occurs with time, so the present model predicts more rapid-than-expected penetrations. Equivalently the present model, which ignores stress relaxation, predicts earlier failures than would be expected from a more realistic model under similar conditions.

Because the stress corrosion model in Appendix A has been developed for highly caustic environments, there is some question concerning its applicability in the environments of the candidate repository sites. Moreover, stress corrosion is a highly random phenomenon, so it would be reasonable to incorporate a stress corrosion rate model into a stochastic framework much like that for pitting corrosion. Both considerations are the subject of further investigation.

\subsection{WASTE PACKAGE RELEASE}

The NRC has established quantitative performance objectives for the allowable slow release rate of radionuclides from an EBS once substantially complete containment has been lost (10 CFR 60, 1983; NRC 1986). Although the EBS has been defined by the NRC ( 10 CFR 60, 1983; NRC 1986), uncertainty remains in the 
interpretation of this definition. In particular, two items are at issue: the exact location of the EBS boundary, and the question of whether the EBS includes a portion of the enclosing host rock.

In order to avoid confusion and to retain technical conservatism, it was decided to assesses fractional radionuclide release rates from the waste package (WP) subsystem of the EBS, which has a clear, well-defined boundary. This decision is reasonable because the WP is the principle subsystem of the EBS that controls release rates and is consistent with programmatic guidance fror the DOE on WP design analysis (DOE 1984b). It nust be stressed, however, that releases from the actual EBS can be no greater, and may be significantly lower, than the release rates calculated for the WP subsystem (Yung et a1. 1987). The WPR model of the AREST code can also be used to calculate the cumulative release of radionuclides from the WP subsystem. These cumulative releases are then normalized to the limits set by the EPA (40 CFR 191, 1985). In a strict sense, the EPA limits on cumulative release are imposed far from the WP subsystem at the accessible environment; however, comparison of WP subsystem performance with the overall system requirements for a repository is a valid, useful, and complementary approach for safety assessment. Further rationale for the assumptions presented here are provided in Section 2 of the second volume of this report.

Figure 2.7 presents the general structure of the WPR model. It is impor.tant to note that the WPR model requires as input from the WPC model the fail.. ure time of each simulated container. However, the AREST code is set up so that the WPR code can be run together with the WPC code (Section 2.3) or separately with the aid of a user-defined fallure time distribution. This capability is discussed in Section 2.5. The quartitative calculations of radionuclioe release rates are based on two mass transfer models, one for solubility-limited releases and one for inventory-limited releases. These are shown in Figure 2.7.

Section 2.4 .1 briefly reviews the application and advantages of mass transfer theory in calculating radionuclide relecse rates. A more detailed review of this topic can be found in the publications of Chambré, Pigford, and coworkers (Pigford and Chambré 1985; Zavoshy, Chambré, and Pigford 1985; 


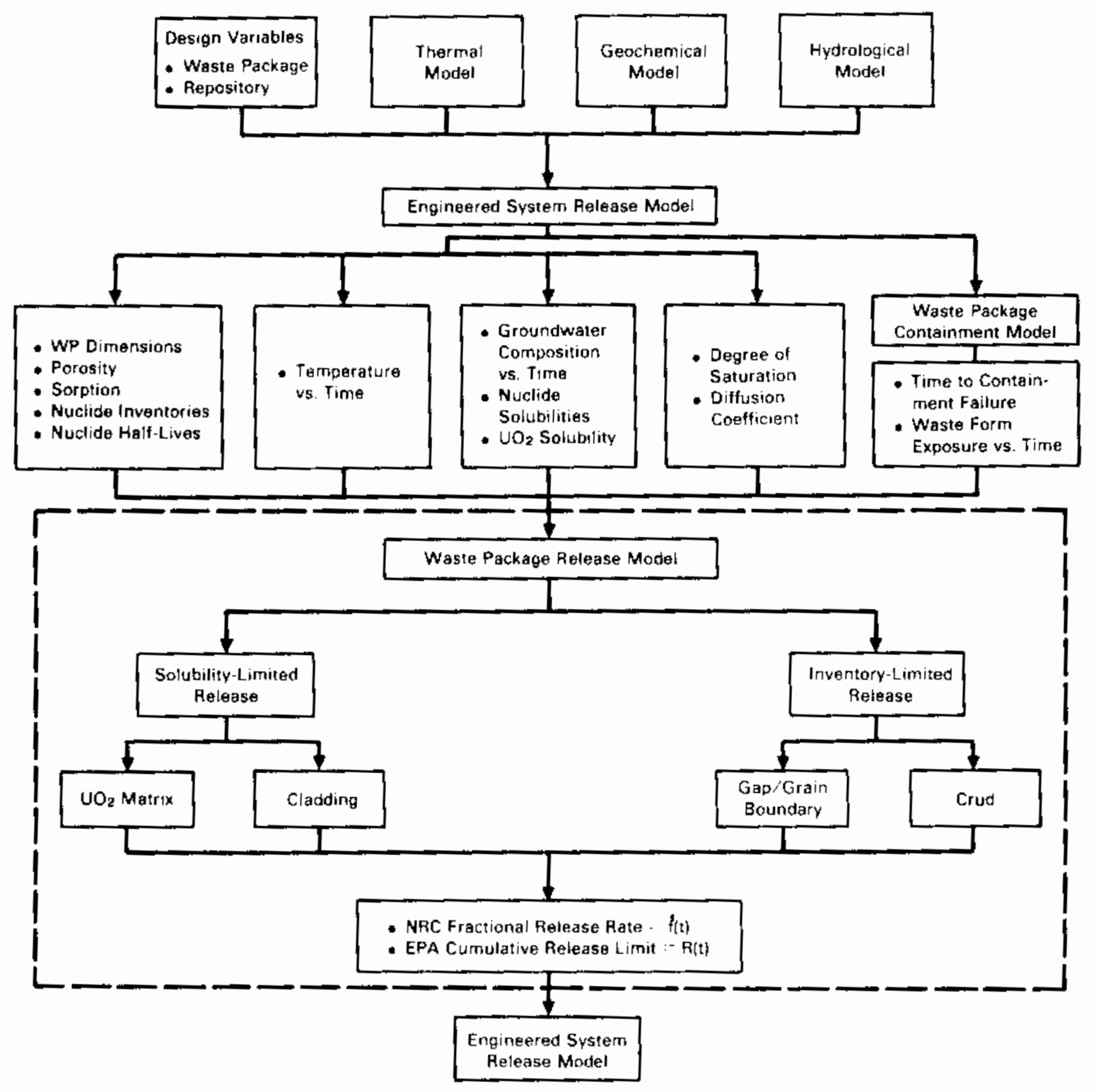

FIGURE 2.7. The Waste Package Release Model

Chambré, Pigford, and Zavoshy 1982; Kim, Chambré, and Pigford 1986). Section 2.4.2 describes the specific andytical solutions used for calculation time-dependent, solubility-limited fractional release rates for both the waste form and waste package (Chambré et al. 1985). Included in this section is a discussion of solubility control imposed by separate radionuclide-bearing solids (i.e., incongruent or apparently incongruent dissolution) and solubility control imposed by the congurent dissolution of the primary waste matrix (e.g., 
$\mathrm{U0}_{2}$ ). For highly soluble radionuclides, Section 2.4 .3 presents a mass transfer equation for calculating the time-dependent, fractional rates of release from the waste package ( $\mathrm{Kim}$, Chambré, and Pigford 1986). Specific applications of the WPR model to the assessment of spent fuel as a waste form are briefly reviewed in Section 2.4.4. Section 2.4.5 contains a discussion of the current limitations of mass transfer theory as applied to WP and waste form performance assessment.

\subsubsection{Mass-Transfer Analysis of Release Rate}

The quantitative mass transfer rate $(\dot{M})$ of radionuclides from the WP subsystem is evaluated in the WPR model by a mass transfer approach, based on the consideration of waste package design, host rock characteristics, and data or chemical and transport processes. The application of mass transfer theory tc waste package performance has been extensively developed in the United States by Chambre, Pigford, and coworkers. This group has derived several different analytical solutions for various aspects of waste form/waste package performance, including radioactive decay, nonlinear sorption, temperature-dependent solubility, diffusivity and retardation coefficient, presence of packing (backfill) material, transport through small container holes, and waste package geometry, (Pigford and Chambré 1985; Zavoshy, Chambré, and Pigford 1985; Kim, Chambré, and Pigford 1986; Chambré, Pigford, and Zavoshy 1982). Limited experimental validation of portions of their mass transfer work has been obtained (McGrail, Chick, and McVay 1985). The same basic approach was adopted by the National Research Council's Waste Isolation System Panel (NAS 1983) and advocated by the Performance Assessment National Review Group in its review of the DOE's Repository Projects (Lieberman et a1. 1985). Criticisms (Cohen 1985) of this mass transfer analysis as applied to waste package assessment have been reviewed and found invalid (Pigford 1984).

Mass transfer rates, as a function of distarce from the waste form surface

$(r)$ and time after repository closure $(t), \dot{M}(r, t)$ are related to $N R C$

(10 CFR 60,1983 ) fractional release rates, $\dot{f}(r, t)$, by the following relationship: 


$$
\dot{f}(r, t)=\frac{\dot{M}(r, t)}{I(1000)}, t>t_{f}>0
$$

where $t_{f}$ is the time of containment failure (i.e., initiation of release) and $I(1000)$ is arbitrarily defined as the inventory of a given radionuclide 1000 years after permanent closure of the repository. A related parameter, the instantaneous fractional release rate, $\dot{F}(r, t)$, can also be defined:

$$
\begin{aligned}
& \dot{F}(r, t)=\frac{\dot{M}(r, t)}{I(t)} \\
& t=t_{f}+t_{r}, t>0
\end{aligned}
$$

where $t_{r}$ is the time elapsed since the initiation of release, and $I(t)$ is the inventory of a given radionuclide at time $t$. The (time-dependent) inventory at time $t$ can be related to the 1000 -year inventory by

$$
I(t)=I(1000) \exp \left[(1000-t) /\left(t_{\frac{1}{2}} / 1 n 2\right)\right]
$$

where $t \frac{1}{2}$ is the half life in years of the radionuclide.

Combining Equations (2.10) and (2.11) gives

$$
\dot{f}(r, t)=\frac{I(t)}{I(1000)} \dot{F}(r, t)
$$

Substituting from Equation (2.13) into Equation (2.14) gives

$$
\dot{f}(r, t)=\left[(1000-t) /\left(t_{\frac{1}{2}} / \ln 2\right)\right] \dot{F}(r, t)
$$

which relates the $\mathrm{NRC}$ release rate to the instantaneous fractional release rate. 
Release rate calculations based on mass transfer theory have several advantages over previous approaches based on reaction kinetics and bulk-flow saturation models (Pigford and Chanbré 1986). Mass transfer theory provides the following advantages:

- It is a mechanistic theory based upon well-understood governing equations and conservatively bounding boundary conditions.

- It is reliable and technically defensible approach for extrapolating future release rates.

- It places no reliance on adjustable coefficients nor arbitrary parameters to empirically "fit" data.

- It provides a clear demonstration of what experimental data are required (e.g., radionuclide saturation concentrations, diffusion coefficients, porosity, groundwater approach velocity, waste package configuration), and the functional relationships among these terms.

This functional relationship can be an important guide for determining which chemical, physical, and design parameters are the most important with respect. to minimizing release rate. This direct insight is not evident from other approaches to release rate calculations.

In the specific mass-transfer application used in the WPR model, a waste package is assumed, in some cases conservatively, to be surrounded by wet, porous host rock. This report considers the case in which nuclide transport in both the waste package and host rock is 1 imited by diffusion control, based on the anticipated events and processes at all the repository sites (NAS 1983; DOE 1986a, 1986b, 1986c). Mass transfer mode1s based on combined advective and diffusive transport are available (Chambré and Pigford 1984) but are not included in the AREST code at this time. Depending on the failure mode of the containment barrier (see Section 2.3), groundwater is assumed to contact one or more of the separate nuclide sources. For example, for the case of spent fuel, separate nuclide sources in the matrix, gap, anc cladding are distinguished and individually evaluated (see Appendix 0).

Note that the mass transfer equations of the WPR model can be used to calculate release rates both from the waste form into the packing (backfi11) 
material and from the packing into the host rock. It is this latter release rate that corresponds to the NRC release rate performance objective (10 CFR 60 , 1983; NRC 1986). It must be stressed that no performance objective is specifically imposed on the release rate from the waste form per se. Attempts to evaluate compliance with respect to the release rate performance objective on the basis of results from waste-form tests alone are misleading and potentially invalid from both a regulatory and scientific viewpoint. It is clear, however, that evaluation of release behavior of the waste package/engineered barrier system is directly coupled to the release rate of nuclides from the waste form.

\subsubsection{Solubility-Limited Release Model}

Mass transfer theory has been used to derive equations for the timedependent, diffusive mass transport of a radionuclide from a waste package (Chambré et a). 1985). Specifically, a mass transfer rate, $\dot{M}(r, t)$, is calculated as a function of time and location within the waste package. The exact mathematical form of these mass transfer rate equations as applied in the WPR model are reviewed in Appendix $E$. Section 3.4 discusses the input parameters required for release rate calculations by this model.

These equations are based on a model that assumes that the waste package geometry consists of a three nested regions (Figure 2.8). The innermost region is assumed to be a spherical waste form having an area equal to the surface area of the actual cylindrical waste form container. Mass transfer calculations of release rates from spherical and prolate spheroid (closely approximating the actual cylindrical geometry of a waste package) geometries have been made (Chambré et a1. 1985). Comparison of these results confirms that steadystate radionuclide release rates are approximately equal for the two geometries when the waste form surface areas are equal. Section 3.4 addresses the actual transformation of dimensions from the actual cylindrical geometry of a waste form container to the spherical geometry used in this model. The potential void space that may result from incomplete filling of the waste container with a particular waste form can be estimated and included in specifying an outer boundary through which mass-transfer rates are calculated.

This waste form is assumed to be surrounded by a spherical porous shell, typically a packing material. The thickness of this annular region is set 


$$
\text { [O }
$$


equal to the thickness of the primary barrier between the waste form and the host rock for the actual cylindrical geometry. Both the waste form and packing (or equivalent material) are assumed to be embedded in host rock extending infinitely in all directions, as shown in Figure 2.8.

The mass transfer rate, $\dot{M}(r, t)$, calculated from this solubility-limited model is a function of at least twelve parameters that are described more fully in Section 3.4 and in Appendix $E$. These include:

- radial dimensions of the waste form and packing thickness $\left(R_{0}, b\right)$

- porosity of the (altered) packing and the host rock $\left(\varepsilon_{1}, \varepsilon_{2}\right)$

- bulk density of packing and the host rock $\left(p_{1}, p_{2}\right)$

- degree of saturation ( $\phi)$

- percentage of waste form surface area exposed $(\theta)$

- inventory of nuclides 1000 years after permanent closure ([1000])

- nuclide radioactive decay constant ( $\lambda=\ln 2 /$ half-life)

- nuclide diffusion coefficient $\left(D_{f}\right)$

- retardation coefficients for the packing and the rock $\left(k_{1}, k_{2}\right)$

- nuclide concentrations at the waste form surface $\left(C_{5}\right)$

- time of containment failure after permanent closure $\left(t_{f}\right)$

- temperature at time $t_{f}(T)$

In addition, the release rates calculated by the WPR model can also be normalized to account for the effect of degree of hydrologic saturation and the limited exposure of spent fuel surface area (Pigford and Chambré 1986).

An initial boundary condition is imposed that fixes the surface concentration of a given radionuclide, $\left(C_{s}\right)_{j}$. This value can be assumed to be a solubility-limited concentration, $\left(C^{*}\right)_{i}$ imposed by a discrete radionuclide-bearing solid (Chambré et al. 1985). This assumption has been evaluated for glass (Zavoshy, Chambré, and Pigford 1985) and spent fuel (Appendix D) waste forms under expected waste package conditions and found to be realistic and justified. In general, the $C_{s}$ values for different nuclides cannot be assumed equal or correlated to each other. Because of this, the mass transfer rates $\left(\dot{M}_{j}\right)$ of nuclides from the waste form surface will be unequal (incongruent). 
An alternative case can be postulated in which a compositionally homogeneous waste form dissolves congruently. By definition, congruent dissolution requires that the instantaneous fractional release rates at the waste form surface are equal for all components (Appendix E). This is true for the components of the waste form matrix and all included nuclides.

In this congruent case, the surface concentration of $i,\left(C_{s}\right)_{i}$, is no longer equal to a solubility limit imposed by a nuclide-bearing solid, as in the incongruent case. Instead, $\left(C_{s}\right)_{j}$ is directly proportional to the solubility of waste form matrix (assuming that such a solubility can be determined), the time-dependent stoichiometric proportion of $i$ in the matrix, and a time-dependent function related to the relative mass transfer rates of $i$ and the matrix components through the waste package. If the $\left(C_{s}\right)_{j}$ calculated for the congruent case is less than the $\left(C^{*}\right)_{j}$ value used in the incongruent case, then the congruent mass transfer rate also will be lower. This relationship applies even to that proportion of highly soluble nuclides that may be uniformly distributed (although not necessarily chemically bound) within a waste form matrix that is dissolving congruently.

Figures 2.9 and 2.10 show the time-dependent concentration and mass transfer rates (normalized to its solubility concentration) for a given nuclide from individual waste packages, as calculated by the WPR model. These results have been verified against calculations first made with the same model by Chambre et al. (1985).

\subsubsection{Inventory-Limited Release}

Mass transfer equations have been derived (Kim, Chambré, and Pigford 1986) to describe the release of highly soluble, inventory-limited radionuclides from a waste package. Appendix $E$ summarizes the exact equations used in the WPR model for inventory-limited release calculations.

These equations are based on a planar geometry, including a waste form, a water-filled void volume $\left(V_{v}\right)$ over the waste form, a porous layer of packing (or equivalent), and the host rock (Figure 2.11). Over the time scale of interest, groundwater is assumed to immediately fill the void volume. A certain mass of nuclide is also conservatively assumed to dissolve from the waste 


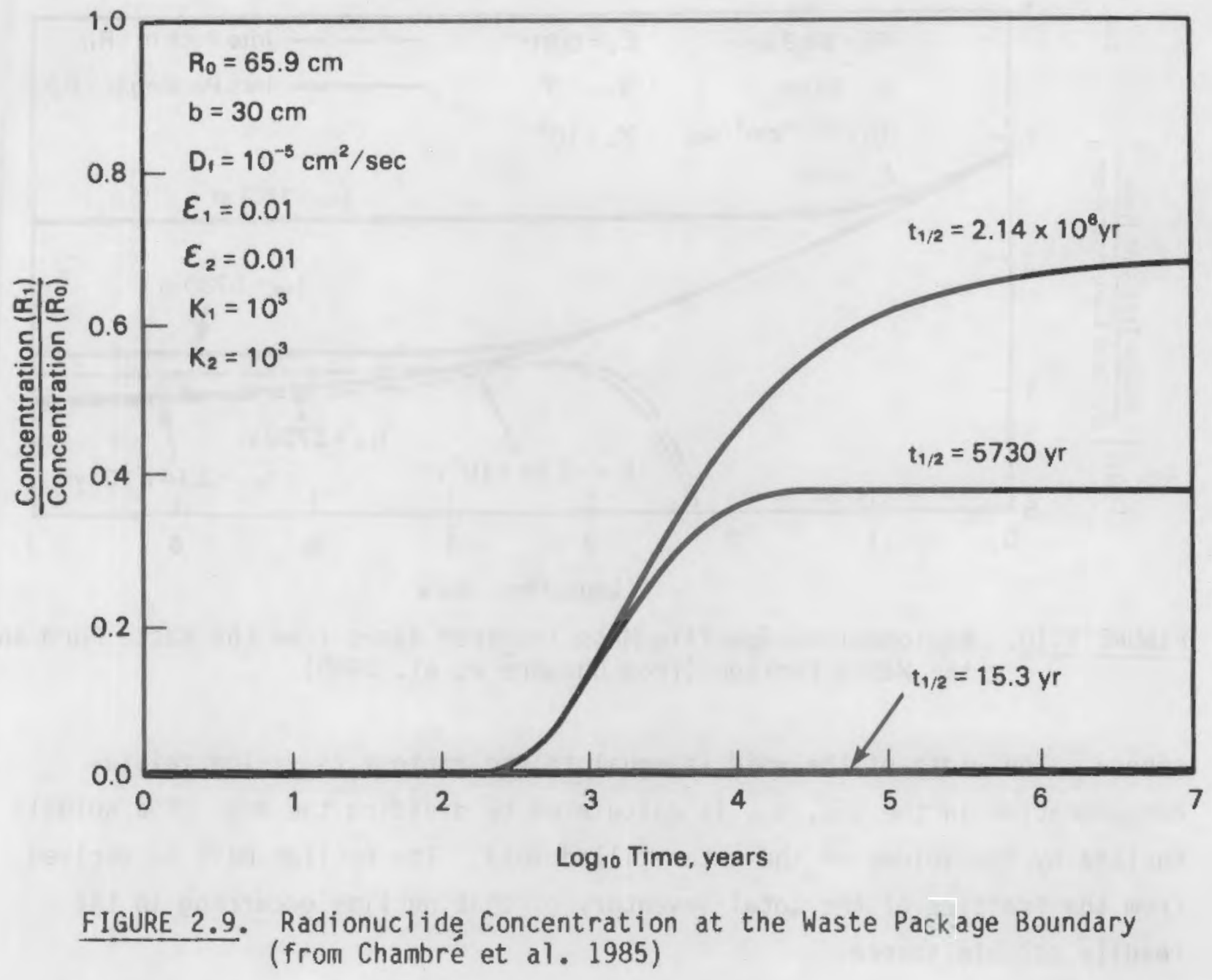

form into this water-filled void volume at the same instant, providing an initial concentration of the nuclide. Subsequent transport is assumed to be diffusion controlled through the porous barriers of the waste package and into the surrounding porous host rock.

The dimensions of the barriers in this planar model are transformed from the actual cylindrical geometry of a given waste package, as shown schematically in Figure 2.11 (also see Appendix E). The volume of the void, $v_{y}$, is equal to the difference in the volumes of the cylindrical waste form container and the total volume of enclosed spent fuel rods. The surface area, $S_{v}$, is the surface area of the cylindrical waste form container. This parameter is identical to the surface area used in the "solubility-limited" model for transforming the actual cylindrical geometry of the waste form into an equivalent 


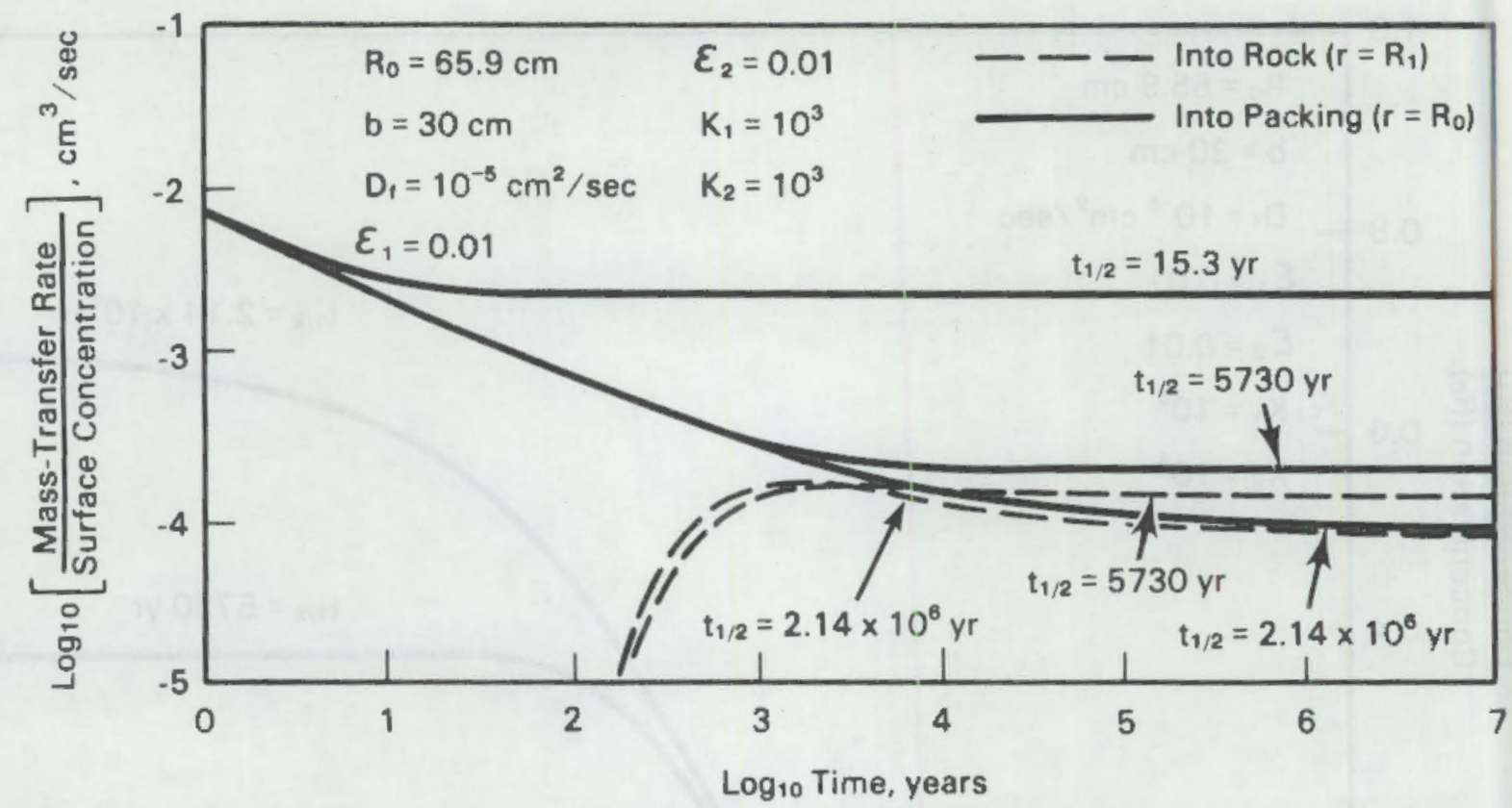

FIGURE 2.10. Radionuclide-Specific Mass Transfer Rates from the Waste Form and the Waste Package (from Chambré et al. 1985)

sphere. The width of the void is equal to the ratio $v_{v} / S_{v}$. The initial concentration in the gap, $N_{0}$, is calculated by dividing the mass of a soluble nuclide by the volume of the water-filled void. The nuclide mass is derived from the fraction of the total inventory of that nuclide occurring in the readily soluble source.

The following input parameters are required for the inventory-limited mass transfer calculations:

- initial concentrations of nuclide in water-filled void $\left(\mathrm{N}_{0}\right)$

- radioactive decay constants $(\lambda=\ln 2 /$ half-life $)$

- volume and outer surface area of void $\left(V_{v}, S_{v}\right)$

- thickness of packing (b)

- diffusion coefficient $\left(D_{f}\right)$

- nuclide retardation coefficients on the packing and host rock $\left(k_{1}, K_{2}\right)$

- porosity of the packing and host rock $\left(\varepsilon_{1}, \varepsilon_{2}\right)$.

These parameters are discussed more fully in Section 3.4.

This inventory-limited model incorporates decreasing mass flux (release rate) from both radioactive decay of the source and depletion of the 

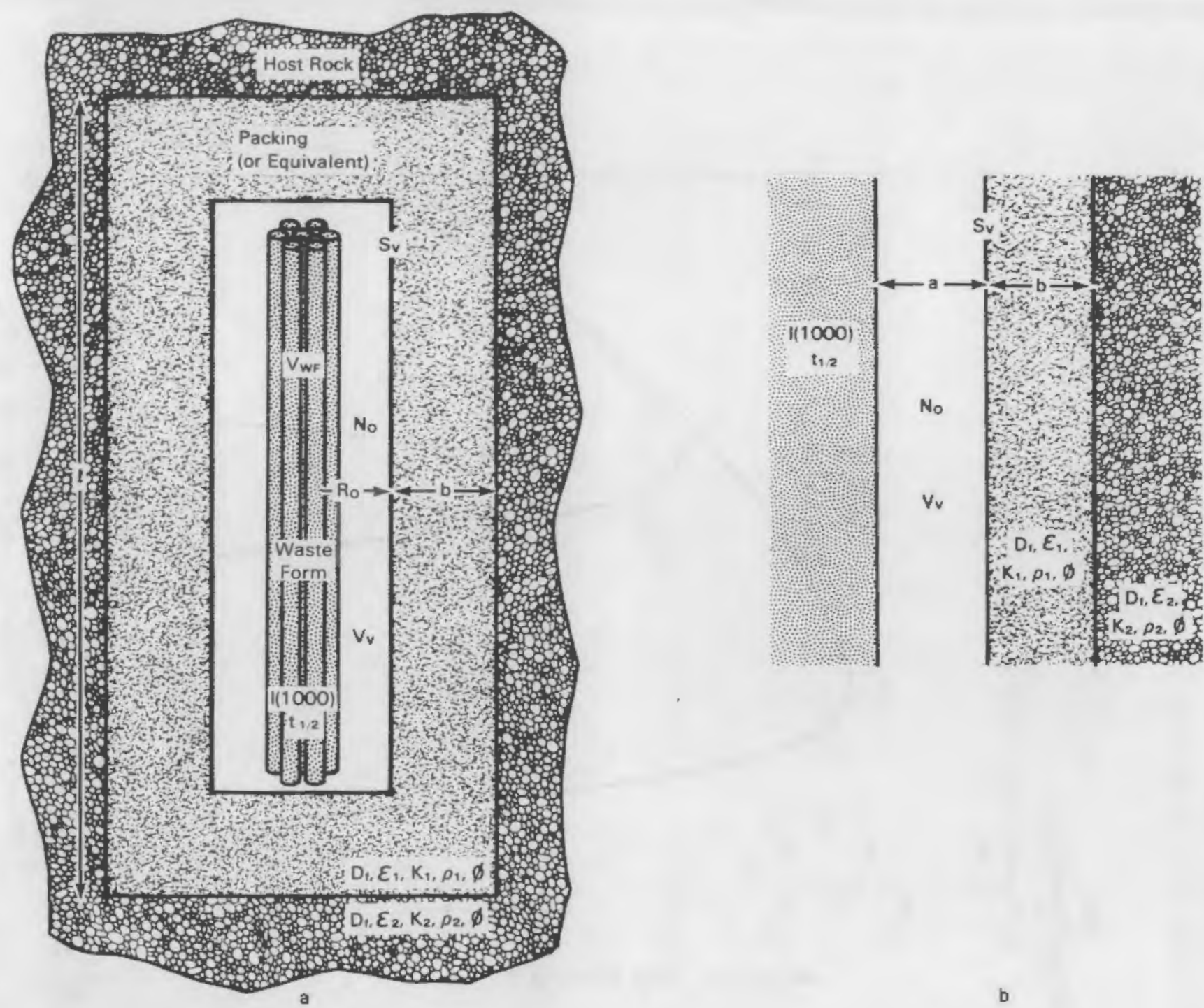

FIGURE 2.11. Waste Package Geometry for Inventory-Limited Release (a) Actual Waste Package Configuration, (b) Equivalent Planar Configuration 
radionuclides because of the nuclide diffusion out of the region of fixed initial inventory. Figure 2.12 shows an example of inventory-1imited release calculations by the WPR model for three nuclides having different half-lives and sorption behavior. These releases calculated by AREST have been verified against calculations first made by Kim, Chambré, and Pigford (1986).

NRC

Release Rate Limit

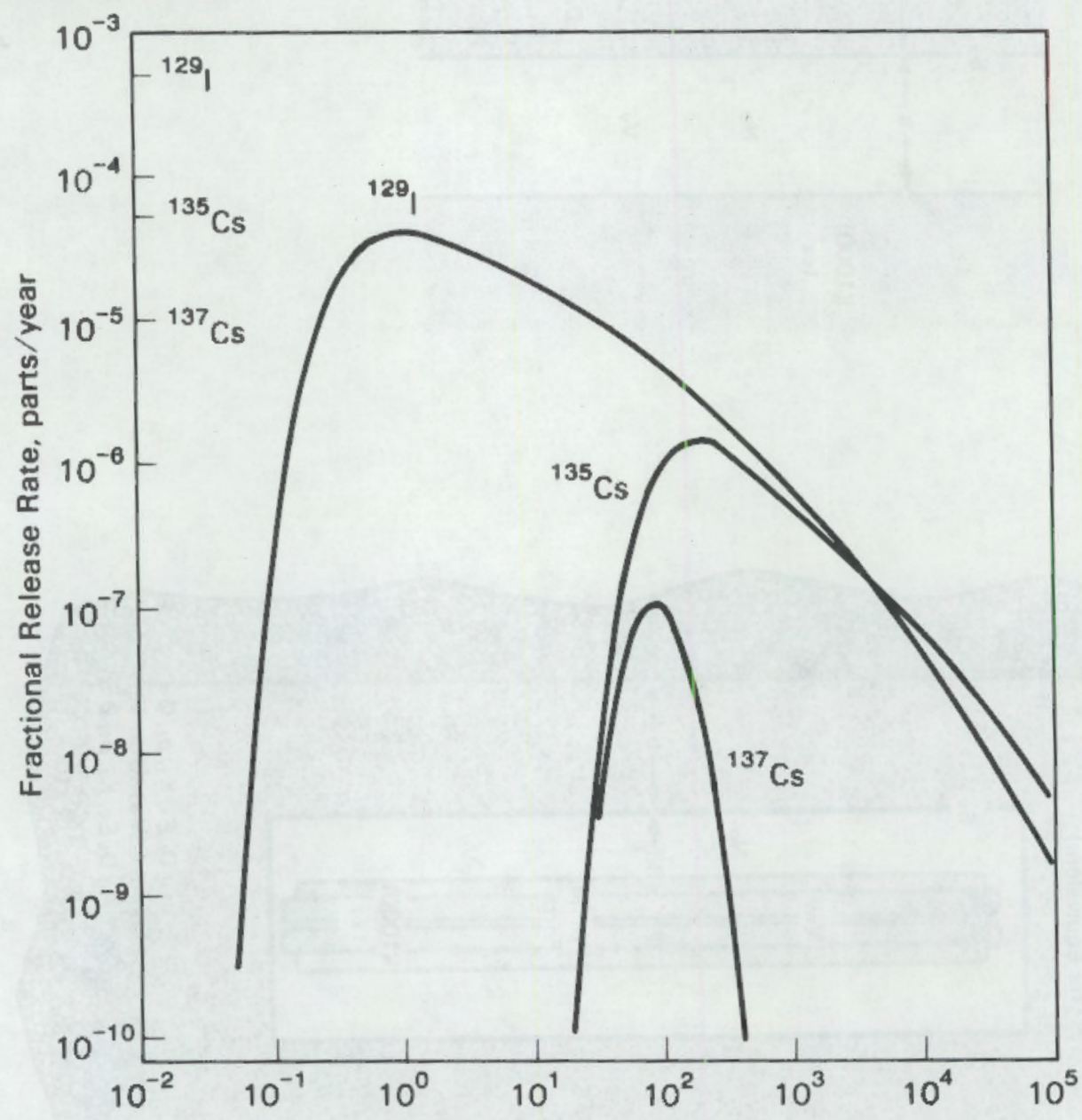

Time, years

FIGURE 2.12. Example of Release Rate for Gap Model. Assumes 1000 years of containment before release begins (from Kim, Chambre, and Pigford 1986). 


\subsubsection{WPR Modeling of Spent Fuel}

Spent fuel can be divided into at least three separate radionuclide sources, specifically the $\mathrm{UO}_{2}$ matrix, the cladding (including "crud" layer), and the gap region between the matrix and cladding. In this analysis, the grain boundary region of spent fuel is assumed to have the same nuclides and instantaneous release to groundwater as the gap, and is, therefore, included with the gap source. This division is based on the different interactions of spent fuel components with groundwater and the different radionuclide inventories in these components. Appendix $D$ contains further explanation for this division for spent fuel. Other source-term modeling approaches have adopted a similar approach for spent fuel (Johnson, Garisto, and Stroes-Gascoyne 1985; Garisto et al. 1986; Werme and Grambow 1987; Oversby 1987). The capability of AREST to model multiple radionuclide sources from a single waste form represents a necessary refinement over previous source-term codes used for the analysis of monolithic waste forms, such as borosilicate glass (INTERA 1983).

Appendix $D$ includes a calculation demonstrating that under expected repository conditions the release of radionuclides from the $\mathrm{UO}_{2}$ matrix of spent fuel and the cladding itself will be transport-controlled (i.e., solubilitylimited) rather than controlled by the rate of surface reaction. Therefore, the mass transfer rates (hence, fractional release rate) of nuclides contained in the $\mathrm{UO}_{2}$ matrix and the cladding can be modeled by the solubility-limited model described in Section 2.4.2 and Appendix E. Both incongruent and congruent release scenarios can be considered for the $\mathrm{UO}_{2}$ matrix. The gap and crud layer on the cladding, however, contains limited inventories of highly soluble radionuclides. Fractional release rates of gap and crud radionuclides are, therefore, modeled by the mass transfer equations described in Section 2.4.3 and Appendix E.

For the purposes of Volume 2 of this report on the assessment of spent fuel as a waste form, the WPR model can be further subdivided into four parallel submodels that correspond to the release of radionuclides from the $\mathrm{UO}_{2}$ matrix, the gap (and grain boundaries), the cladding, and the crud layer. This division is similar to the source-term modeling approach of others (Johnson et al. 1985; Garisto et al. 1986; Wuertz and Ellinger 1986). The approach is 
based upon the different radionuclide inventories and interactions with water of these separate components, as described in Appendix D.

One aspect in which spent fuel is different from reprocessed waste forms is that the metal cladding encasing the primary waste form is itself radioactive. The likely release mechanisms of radionuclides, particularly ${ }^{14} \mathrm{C}$, from spent fuel cladding are reviewed in Appendix D. Two separate release rate cases are used in the WPR model, depending on whether water or steam is present at the time of container failure. If steam conditions prevail at the time of container failure, a significant amount of ${ }^{14} \mathrm{C}$ from the crud layer on the outer surface of the cladding can be released as $\mathrm{CO}_{2}$ gas (Van Konynenburg et al. 1985). There is uncertainty in assessing the total amount of ${ }^{14} \mathrm{C}$ existing in the cladding (thus, the proportion released) and the distribution of ${ }^{14} \mathrm{C}$ throughout the cladding (Appendix D). At this time the WPR model assumes that only the ${ }^{14} \mathrm{C}$ estimated (Croff and Alexander 1980; Barner 1984) to be in the crud layer is released as $\mathrm{CO}_{2}$ gas upon container failure during steam conditions. A modified version of the inventory-limited model is used, in which gaseous diffusion coefficients are substituted for aqueous diffusion coefficients. The remainder of the ${ }^{14} \mathrm{C}$ inventory calculated to be in the cladding itself is assumed not to be released under steam conditions. As better information is acquired about the amount and distribution of ${ }^{14} \mathrm{C}$ in cladding, this assumption can be made more realistic.

\subsubsection{Limitation of Mass Transfer Analysis}

There are several limitations to radionuclide release rate calculations based on currently implemented mass transfer models. The inability of such models to account for spatial inhomogeneities is a key limitation. For example, assume that a cylindrical waste package is capped by a porous region with significantly different properties (e.g., porosity) than the host rock surrounding the rest of the package. Finite-element analysis of such a configuration has shown that radionuclide release can be preferentially channeled through this cap (Yung et al. 1987). Such a preferential release from the waste package indicates the important effect of programmatic and regulatory definitions on design and performance assessment. The present WPR model assumes a set of concentric, overlapping shells of uniform properties. It may 
be possible, however, that the quantitative evaluation of spatial heterogeneities by mass transfer analysis can be investigated separately, as have been temperature (time)-dependent solubilities (Chambré et al. 1985), small apertures in container/cladding materials (Pigford and Chambré 1986), nonlinear sorption (Chambré et al. 1985) and other potential effects.

A second limitation of the present WPR models is that colloidal transport of radionuclides is not explicitly considered. This limitation, however, stems from the lack of suitable data on the characteristics (e.g. size-spectrum, sorption/filtration effects, agglomeration rates) of potential colloids. With appropriate data, analogous to those used to model release of dissolved nuclides, mass transfer analysis is equally well suited to predict colloid release rates.

Diffusion through groundwater, neglecting the effect of tortuosity, is assumed as the limiting transport mechanism. Mass transfer models based on advection and diffusion are available for WPR rate calculations, but it is assumed that such conditions are not anticipated with the waste package environment for any of the currently nominated U.S. repository sites (NAS 1983). Surface diffusion along clay mineral surfaces has been proposed to represent a faster pathway of release for some radionuclides; if this mechanism for preferential transport can be confirmed under realistic repository conditions (i.e., not eliminated because of presence of nonclay minerais, competing effects of multiple radionuclides, consideration of the free water volume versus total porosity, etc.), the mass transfer equations used will remain suitable for release rate calculations, albeit by means of revised effective-diffusion coefficients.

The effect of adjoining waste packages is also not presently considered in the WPR model. It is assumed that ignoring this effect is conservative. For calculation of release rates by mass transfer analysis, the presence of radionuclides from previous waste package releases can only decrease the release rates for subsequently failed waste packages. Natural groundwater contains trace concentrations of stable isotopes of some radionuclides contained in spent fuel. This existing concentration of nuclides in groundwater can only decrease the chemical concentration gradients driving diffusional transport and 
release. It should be noted that this effect can be readily included if data on the concentrations of naturally occurring stable isotopes and nuclides from previously failed waste packages can be obtained. It was desirable and necessary, for example, to consider the role of groundwater containing appreciable amounts of nonradiogenic carbon as carbonate on the release of ${ }^{14} \mathrm{C}$.

The use of reversible $k_{d}$ sorption coefficients assurning equilibrium to calculate retardation coefficients of nuclides is clearly an expedient method for incorporating many separate chemical interactions. It has not been demonstrated that such an approach is conservative. It must also be noted, however, that with the exception of extremely short-lived nuclides, reversible sorption of nuclides within the WP subsystem does not affect the steady-state fractional release rates of nuclides. Furthermore, irreversible sorption (ion exchange) has not been included in these models, although such a process could greatly attenuate releases from the WP subsystem (Barney and Reed 1986).

Finally, the current mass transfer equations used in the WPR model are simplified with respect to more detailed analyses. More complex mass transfer models lead to more realistic, and usually more favorable, estimates of expected performance. An important future activity is to compare results from the analytic release models in the AREST code with the results from other codes that use finite element methods. However, the desire for more realisin must be balanced by the availability of information, uncertainties in data, and the subsequent loss of reliability. In addition, simple, defensibly conservative models are required for flexibility in iterative calculations, especially for stochastically addressing the combined system performance of thousands of separately evaluated waste packages.

\subsection{CONTAINMENT-RELEASE PROGRAM LOGIC}

Containment and release have been discussed separately in previous sections of this report, but they are inextricably related. The logic that guides the modeling of containment and release for an individual waste package is one 
of the most fundamental structural aspects of AREST. Figure 2.13 shows the global containment-release logic of the AREST code in detail as it has been implemented for spent fuel.

The time of resaturation, i.e., the time at which the waste package environment returns from steam to aqueous conditions, is calculated at the start of each waste package simulation. The hydrological model is used for this purpose. If the initial time step is less than the time of resaturation, $t_{R}$, then simulation first proceeds along the steam branch of the logic diagram in

Figure 2.13. Appropriate modules are called upon to simulate the corrosion and degradation of the waste package container in a steam environment. Currently, AREST is capable of simulating uniform corrosion, pitting corrosion and stress corrosion in steam.

Simulation proceeds from one time step to the next until either container failure is indicated or until resaturation occurs. If container failure occurs during the steam phase (prior to resaturation), then the release of ${ }^{14} \mathrm{C}$ as $\mathrm{CO}_{2}$ gas from the zircaloy cladding is simulated. Thereafter, degradation of the cladding is simulated until resaturation occurs, or until cladding failure is indicated, whichever occurs first. If the cladding fails before resaturation occurs, all simulation of corrosion processes ceases and the code simply steps through time until the steam phase is completed. Thereafter, release from the waste form is simulated for an aqueous environment as shown in the water branch of Figure 2.13. As with the container, three types of degradation can be simulated for zircaloy: uniform corrosion, pitting corrosion, and stress corrosion.

If the container failure does not occur during the steam phase, then simulation of the degradation of the container in steam continues until resaturation occurs. Thereafter, simulation of each degradation process continues with the aid of modules appropriate for an aqueous environment. Simulation of waste form performance commences at the time container failure is indicated. For spent fuel, this involves simulation of uniform pitting and stress corrosion of the zircaloy cladding. Pitting corrosion and stress corrosion are simulated until cladding containment failure is indicated. Simulation of uniform corrosion of the cladding continues at all time steps because release calculations 


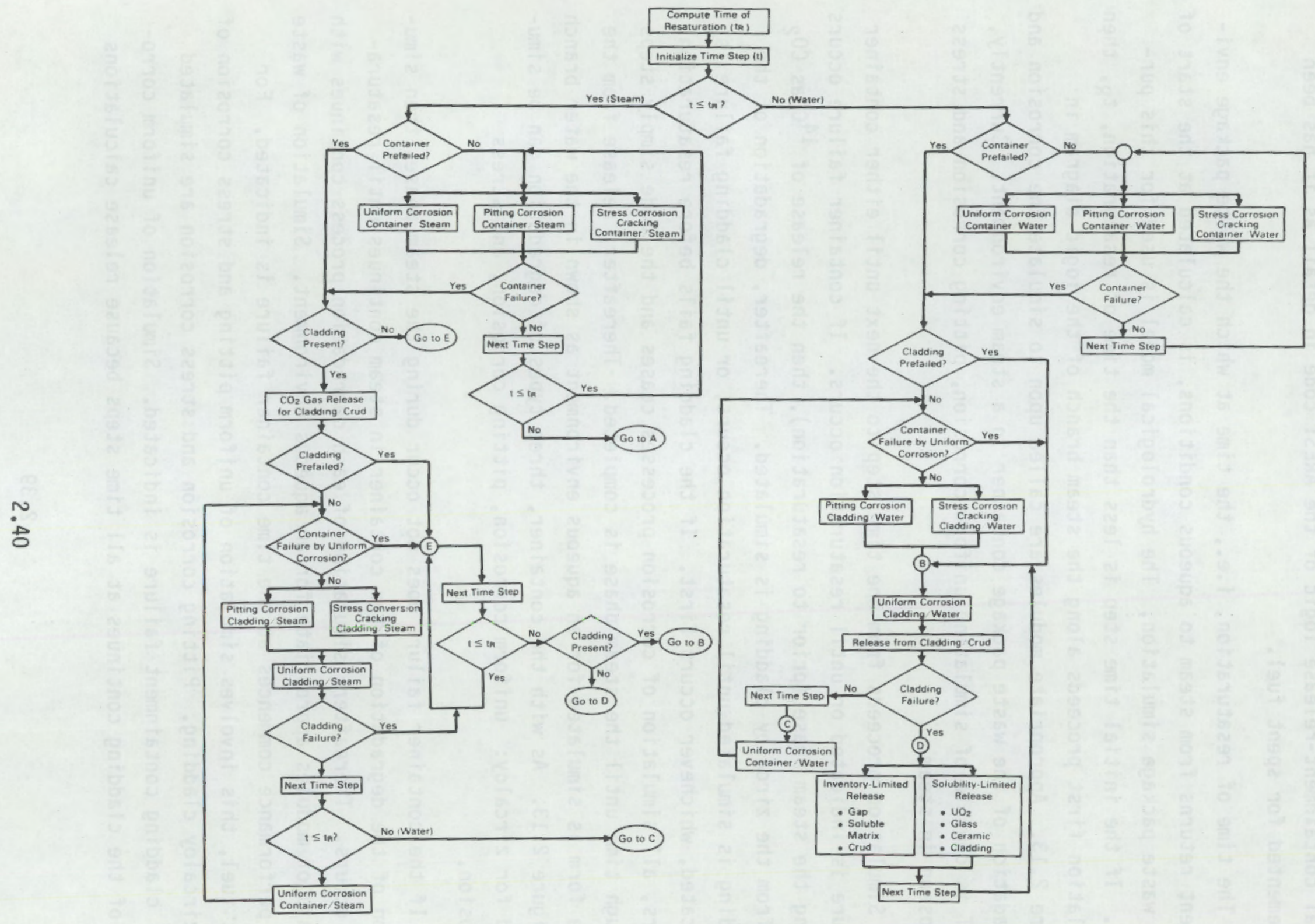

FIGURE 2.13. AREST Containment-Release Logic 
depend, in part, upon the rate of uniform corrosion. The release of radionuclides from the zircaloy cladding is simulated for each time step following container containment failure. Radionuclide releases from the gap and the $\mathrm{UO}_{2}$ matrix are computed for each time step following cladding failure.

It should be noted that the cladding may serve a containment function subsequent to failure of the waste package container by either pitting or stress corrosion. When the corrosion allowance is depleted by uniform corrosion, however, it is assumed that the container loses its structural integrity, i.e., collapses, and that this collapse in turn causes cladding failure. For this reason, uniform corrosion of the container is simulated beyond the time of indicated failure by some other mechanism.

The assumption that the cladding fails when the container fails by uniform corrosion is conservative in the sense that no containment credit is taken for cladding beyond the time of such failure. Likewise, the zircaloy cladding may contain defects that developed either before or after emplacement of the spent fuel in a waste container. These defects could diminish or eliminate the containment function of the cladding. For performance assessment purposes, it is conservative to assume no containment credit for cladding, relying instead on the container to assure compliance with NRC requirements for substantially complete containment. This option can be simulated in AREST by assuming that part or all of the cladding has "prefailed," i.e., has failed prior to the time of container failure.

Except for several that involve time, most of the boxes in Figure 2.13 describe various physical and chemical processes. The boxes identify program modules or subroutines that simulate the indicated processes. Corresponding to the box "Uniform Corrosion, Container/Water," for example, is an AREST subroutine (module) for simulating the uniform corrosion of a steel container in an aqueous environment. Deterministic or mechanistic models are used whenever possible. Variability is introduced during simulation by selecting values for input variables (model parameters) from suitable probability distributions. Ideally, the probability distributions are determined from relevant experimental data. When experimental data are inadequate, probability distributions must be determined by other means, such as with the aid of expert judgment. In 
some cases, the probability distributions may be selected without regard to their physical basis, but rather to evaluate the sensitivity of model output to the variable(s) in question.

The modular nature of the AREST code facilities modification when additional data become available or improved process models are developed. As described in Section 2.3, the module for a given corrosion process can be replaced without changing the basic structure (logic) of AREST. The AREST user can, for example, select one of several previously programmed models of uniform corrosion when the code is run, or he can supply a completely different model if he wishes. This feature means that the AREST user need not be dependent upon any particular process model. Moreover, the availability of multiple modules for a particular corrosion process is expected to be extremely useful when AREST is used to address questions of model uncertainty.

Despite the logical interdependence between containment and release modeling for a single waste package, the AREST code has been structured so that it is possible to "decouple" the WPC and WPR models. When used in a "stand-alone" mode, the WPC code can be used to generate a series of container failure times that may be used to estimate the distribution of failure times under a specified set of (input) conditions. Similarly, the WPR model can accept a hypothetical failure distribution that is not generated by the WPC model (appropriate values of other WPR input variables must be supplied, of course). Regardless of the mode of use, however, the basic logic of Figure 2.13 applies.

To date, the development of AREST has focused upon its use to assess the performance of spent fuel as a waste form. The logic of Figure 2.13 will require only minor modifications, however, when AREST is expanded to model other waste forms, such as vitrified glass. The incorporation into AREST of corrosion and release modules suitable for other waste forms is one of several improvements planned for the future. 


\subsection{ENGINEERED SYSTEM RELEASE}

The ESR model has two primary functions: to monitor and control the flow of information among components of the AREST code, and to integrate individual - waste package releases to obtain estimates of total release from the entire EBS.

\subsubsection{Program Control}

One function of the ESR model is to direct the exchange of information among the components and modules of the AREST code. Ensuring that updated information is received by the WPC and WPR models from the waste package environment models at each time step is a key aspect of program control. In particular, current temperatures and groundwater compositions are required at each time step. The ESR model also controls inputs to the environment models, and ensures that these are updated as necessary. Finally, the ESR model controls and directs the output of information from the WPC, WPR, and waste package environment models. To the extent possible, information monitoring and exchange tasks have been localized in the ESR code, both to preserve modularity and to minimize the amount of code that must be rewritten when the interdependence among components of AREST is increased.

\subsubsection{Integrated Release}

The second major function of the ESR model is to combine estimated releases from individual waste packages into an estimate of total EBS release. For this purpose, the ESR model uses both the failure times from the WPC model and the corresponding releases estimates from the WPR model. The WPR model calculates both fractional release rates and cumulative releases of individual radionuclides for each simulated waste package; cumulative releases are estimated by integrating cumulative release rates.

Using output from the WPC and WPR models, the ESR model can produce estimates of release for individual waste packages or for the entire repository, as well as estimates of average waste package release. Moreover, the release estimates may be calculated either for individual radionuclides or for several radionuclides jointly. The type of output and its form (graphical or tabular) are selected by the user. 
Release rates for individual waste packages and radionuclides are calculated in the WPR module at selected time points and tabulated for access by the ESR model. A sufficient number of time points are used to provide accurate estimates of release for time periods as small as one year. Linear interpolation is used to estimate release at time points for which it has not been tabulated.

The numerical methods used to combine release estimates from individual waste package simulations are quite general and can be applied to arbitrary release functions. In particular, the methods are used in the case of inventory-controlled release, where release is a function of inventory. For the solubility-controlled case, in which mass transfer rates are independent of the inventory of radionuclides present, the numerical methods used in the AREST code are standard and widely used. These numerical methods are essentially the same as those used by Sagar, Eslinger, and Boca (1984a, 1984b) and further described in an Aerospace Report to the NRC (Stephens 1985). Computational details are given below.

Let $\dot{M}(r, t)$ be the estimated mass transfer rate for an individual radionuclide for a single waste package as defined by Equation (2.10). In Equation (2.10), $t$ is an arbitrary time, and $r$ is the distance from the waste package to the flux boundary. If a simulated container fails at some time $\tau_{j}=t_{f, j}$, then the cumulative release from the waste package at time $t, t>{ }^{\tau} j$,

$$
R_{j}(t)=\int_{\tau_{j}}^{t} \dot{M}\left(r, t^{\prime}\right) d t^{\prime}
$$

For a series of simulated waste packages that fail at times $\tau_{1}, \tau_{2}, \ldots$, the the total cumulative release at time $t$ is

$$
R(t)=\sum_{j} R_{j}(t)=\sum_{j} \int_{\tau_{j}}^{t} \dot{M}\left(r, t^{\prime}\right) d t^{\prime}
$$

Average total cumulative release is computed by dividing $R(t)$ by the number of simulated waste packages that have contributed to the sum in Equation (2.17). 
Equations (2.16) and (2.17) may be applied to mass transfer rates for individual radionuclides or to combined transfer rates for several radionuclides.

In the solubility-limited case, $\dot{M}(r, t)$ depends upon the elapsed time since failure, and not upon the time of failure itself. In other words, $\dot{M}(r, t)$ is independent of $\tau$ and depends solely on $t-\tau$. In this case, Equations (2.16) and (2.17) can be written respectively as follows:

$$
\begin{aligned}
& R_{j}(t)=\int_{0}^{t-\tau_{j}} \dot{M}\left(r, t^{\prime}\right) d t^{\prime} \\
& R(t)=\int_{j} \int_{0}^{t-\tau_{j}} \dot{M}\left(r, t^{\prime}\right) d t^{\prime}
\end{aligned}
$$

The assumption that release depends only upon the elapsed time since failure is equivalent to assuming that the shape of the release function does not change with time. Computationally, this means that the release function must be evaluated only once. Thereafter, releases are calculated by evaluating this single function at the various elapsed times $t-\tau_{j}$. Without making this or some other simplifying assumption, the release must be calculated anew for each waste package. In this regard it should be noted that to avoid the need to calculate release rates for individual waste packages, the assumption was made at the outset that the mass transfer rate $\dot{M}(r, t)$ does not differ from one waste package to another.

Because the waste package failure times $\tau_{1}, \tau_{2}, \ldots$, are randomly generated realizations of a waste package failure-time distribution, they differ from one simulation run to the next. By making assumptions about the distribution of failure times, it is theoretically possible, using probability theory, to derive the complementary cumulative distribution function (ccdf) of $R(t)$ analytically. The complexity of the release rate functions in the WPR model precludes this possibility in practice, so it is necessary to estimate the ccdf of $R(t)$ empirically. One way to do this is to simulate the "repository" 
repeatedly under a fixed set of initial conditions using Monte Carlo methods until sufficiently many realizations of $R(t)$ are obtained using standard statistical methods. Estimates of the ccdf of $R(t)$ can then be obtained using standard statistical methods. 


\subsection{MODEL INPUTS AND DATA REQUIREMENTS}

The AREST code has been set up so that nearly every input, either to one of the modules of AREST itself or to one of its process modules, can be regarded as a random variable. Input variables are of two types: continuous and discrete. Continuous variables are those that can assume all values in some interval or range of interest. Oiscrete variables are those that can assume any value in some discrete (usually finite) set of possible values. A fixed value can be regarded as a discrete variable for which the set of possible (input) values contains a single point. Examples of continuous variables are environmental parameters such as initial temperature, resaturation time, Eh (redox potential), and $\mathrm{pH}$. Examples of discrete variables include design parameters such as the number and dimensions of waste packages and the spacing of waste packages within the repository.

Variables that pertain to repository or waste package design tend to be discrete. The values of design variables are set at the beginning of a simulation run and remain constant for all simulated waste packages. Container thickness, for example, is set at the start of a run and remains constant throughout the run. Values may or may not be site-specific. Typically, specified values are selected from the waste package reference design for one of the three repository candidate sites (DOE 1986a, 1986b, 1986C). However, some other value may be used if needed. For example, if the user were studying the effect of container thickness on the failure-time distribution, then values other than those for the reference designs of the candidate sites would be specified.

Values of continuous variables are typically simulated for each simulated waste package. However, the distribution from which the values of a continuous variable are simulated is selected at the start of a run, and all simulated values are generated in accordance with the selected distribution. Like the value of a discrete variable, the distribution of a continuous variable may be, but need not be, site-specific. When distributions can be derived from sitespecific data, they have been included in the list of distributions available to the AREST user (DOE 1986a, 1986b, 1986c). 
The AREST model has been designed to include those factors known to have a significant effect on waste package performance, but the AREST code does not explicitly take account of all the factors that may potentially affect waste package performance. Some of these factors can be implicitly modeled, however, by selecting an appropriate experimental frame; distributions for input variables are chosen to reflect variability in the unmodeled factor of interest. One example is the spatial variability of waste package temperatures. The current AREST code does not explicitly model spatial variability. However, spatial variability can be implicitly modeled by choosing distributions for temperature-dependent AREST input variables that include the effect of spatial variability.

Values for a number of important input variables to AREST are obtained with the aid of simulation codes that are external to AREST. One example is the groundwater composition variables described in Appendix $C$. With the aid of the geochemical code EQ3NR, the initial groundwater at the site is caused to react with appropriate manmade and natural barrier materials at elevated repository temperatures. The results are tabulated at discrete temperature steps for access by AREST. As another important example, the temperature-time histories for both a reference case waste package container and the repository average temperature are calculated by the ANSYS code and tabulated for input to AREST. Temperature calculations are discussed in detail in Appendix B.

It is convenjent to regard AREST, taken together with its supporting codes, as an "extended" AREST performance assessment model. Although the extended model contains various support models such as EQ3NR and ANSYS, AREST is not dependent upon any particular support ccde. Thermal calculations can be derived from some other source than ANSYS and input values for geochemical variables can likewise be obtained by some other means than EQ3NR. Ideally, the values of input variables would be simulated from distributions that have been rigorously derived from valid experimental data. 


\subsection{WASTE PACKAGE ENVIRONMENT}

This section discusses the component models of the waste package environment: the thermal model, the geochemical model, the hydrological model, the mechanical model, and the radiation model.

\subsubsection{Thermal Model}

The thermal model described in Section 2.2.1 provides temperatures to other AREST submodels as needed. To compute the temperature of a simulated waste package at a given time step, the thermal model requires the following information:

- the temperature of a reference or design-basis waste package, both at the time of emplacement and at the specified (post-emplacement) time

- the average repository host rock temperature, at the time of emplacement and at the specified time

- the initial heat generation rate for the simulated waste package at the time of emplacement.

The required temperatures are taken from tables that contain temperature-time histories for the design-bases waste package and average repository temperature. Temperature-time histories are computed outside of AREST at a series of preselected time points, and the results are tabulated for use in AREST. At times which have not been tabulated, temperatures are determined by linear interpolation. The initial heat generation rate for a simulated waste package is obtained by sampling the distribution of initial waste package heat loadings. This distribution is also calculated external to AREST and is derived from expected spent-fuel receipt characteristics (see Appendix B). For purposes of spent-fuel analysis, input values to ANSYS are derived from information found in the waste package reference designs and environmental assessments for the three potential repository sites (DOE 1986a, 1986b, 1986C).

Temperature calculations are necessarily site-specific because temperatures depend not only upon spent-fuel characteristics, but also upon repository and waste package destgn parameters and thermal properties of the host rock. In the case of spent fuel, the number of fuel rods in each waste package is an 
important design consideration. The general-purpose, finite-element code ANSYS is used to calculate the temperature histories required by the AREST thermal mode1. From the inputs described here, the AREST thermal model calculates waste package temperatures according to the alyorithm described in Section 2.1. The repository and waste package design parameters, material thermal properties and heat generation rate data required to run ANSYS are discussed in Appendix B.

The distribution of initial heat generation rates is determined from an analysis of spent-fuel receipt characteristics. The analysis is done using the WASTES II code and is based upon the repository receipt scenario described in the 1985 DOE Mission Plan for the OCRWM Program (DOE 1985). Details are presented in Appendix B. To date, the thermal model in AREST has been fully implemented only for spent fuel.

\subsubsection{Geochemical Model}

Section 2.2.2 and Appendix $C$ describe the geochemical model and how it supports both the WPC and WPR modeTs of AREST. The equilibrium geochemical code EQ3NR (Wolery 1983) is used as the geochemical model to support AREST. The most basic input to the EQ3NR is the thermodynamic data base that it contains. Reviews of these data have been presented elsewhere (Jacobs and Watley 1985; Wolery 1983) and are beyond the scope of this report.

The key user-defined repository-specific variables in the geochemical model are the initial groundwater chemistry, $\left[x_{w}\right]_{0}$, the type and composition of natural and engineered barrier materials, $\left[x_{S}\right]_{0}$, and the waste package temperature expressed as a function of time, $T(t)$. The reactive chemical components of the waste package environment are determined by $\left[x_{w}\right]_{0}$ and $\left[x_{S}\right]_{0}$. In addition, $\left[x_{5}\right]_{0}$, and to a more limited degree $\left[x_{14}\right]_{0}$, determine which buffering reactions control important parameters such as pH and Eh (Appendix $C$ ). The temperature data are required to express the equilibrium constants for reactions as a function of waste package temperature.

This method of determining input values for the geochemical model permits considerable flexibility. For example, new or revised reference repository groundwater compositions, $\left[x_{w}\right]_{0}$, can be accommodated and their effect can 
easily be assessed. The potential effects of radiolysis on variables such as ph and Eh can be tested by artificially imposing buffering reactions/solids, $\left[x_{S}\right]_{0}$. In this manner the potential effects of radiolysis might be simply simulated without radiolysis modeling of natural groundwaters.

In some cases, flexibility with respect to input is needed because of the limitations of the geochemical model (Appendix $C$ ). Because the model cannot as yet handle chemically complex, high ionic-strength brines, for example, the input for $\left[x_{w}\right]_{0}$ must be reduced to its simplest and most dominant components, $\mathrm{Na}$ and $\mathrm{Cl}$. Similarly, the formation of metastable (rather than equilibrium) reaction products may require that $\left[x_{S}\right]_{0}$ input be modified to reflect their occurrence. The user-defined input variables, therefore, may often be assigned artificial values required to assess model sensitivity, rather than "realistic" simulation values.

\subsubsection{Hydrological Model}

Hydrologic parameters used as inputs to AREST include the degree of saturation $(0<\phi \sim 1.0)$, nuclide diffusion coefficient $\left(D_{f}=10^{-5} \mathrm{~cm}^{2} / \mathrm{sec}\right)$, and the time of resaturation $\left(t_{R}\right)$. The calculation of $t_{R}$ for ductile, plastic rock media and competent rock media is reviewed in Section 2.2.3. Such calculations require as inputs either waste package temperature-time profiles or data on host rock permeability. If these input variables are selected from suitable distributions, then resaturation times will be distributed as well.

\subsubsection{Mechanical Model}

The potential time- and spatial-variation of stresses in the waste package environment are not explicitly modeled in the current version of AREST. For each repository site, hydrostatic and lithostatic pressures are assumed to be equal to the reference values given by the repository projects (DOE 1986a, $1986 \mathrm{~b}, 1986 \mathrm{c}$ ). These pressures are used by the repository projects (and AREST) to assess the structural thickness of container materials necessary to prevent containment failure by crushing.

The stress corrosion module (see Section 2.3.3 and Appendix A) simulates the crack-tip velocity at a point of stress cracking. The crack-tip velocity 
is a function of the stress level to which the material is subjected. The initial stress level is input to the mechanical model, from which it is passed to the stress corrosion module.

\subsubsection{Radiation Model}

AREST does not contain a radiation model. As discussed in Section 2.2.4, the potential effect of radiolysis on chemical reactions within the waste pack- . age can be incorporated into the geochemical rodel. Specifically, pH and Eh are two key chemical parameters that may be affected by radiolysis reactions. For anticipated conditions, it is assumed that chemical buffering of groundwater by solid phases dominates the effects of radiolysis. This assumption requires further confirmation.

\subsection{WASTE PACKAGE CONTAINMENT}

This section discusses the three types of corrosion affecting waste package containment: uniform corrosion, pitting corrosion, and stress corrosion.

\subsubsection{Uniform Corrosion}

The uniform corrosion model in AREST employs a model of the rate of uniform corrosion. The corresponding module incorporates multiple uniform corrosion rate modules, one of wich is selected by the user at the time of simulation. Inputs to the uniform corrosion model therefore depend upon the choice of a rate module. Furthermore, there are constraints to the ranges of the inputed values and these are also module-specific. The inputs for the uniform corrosion module described in Appendix A are listed in Table 3.1.

TABLE 3.1. Inputs for the Uniform Corrosion Module

\begin{tabular}{lll}
\multicolumn{1}{c}{ Input } & Units & \multicolumn{1}{c}{ Suggested Range } \\
\cline { 1 - 2 } Temperature & $\mathrm{K}$ & Near $150^{\circ} \mathrm{C}(432 \mathrm{~K})$ \\
Chloride concentration & $\mathrm{ppm}$ & 70 to 191,000 \\
Oxygen concentration & $\mathrm{ppm}$ & 0.1 or below \\
Time of exposure & $y r$ & Greater than 1 day
\end{tabular}


Empirical coefficients, determined by fitting a mathematical model to a reference set of steel corrosion data, are also required. Application of the model to a different set of conditions or materials would require the calculation of new fitting coefficients.

Inputs to the BWIP model of uniform corrosion of the waste container (Anantatmula, Delegard, and Fish 1984) depend upon the time for resaturation to occur. In the presaturation period, inputs to a steam corrosion model are time (years) and temperature $\left({ }^{\circ} \mathrm{C}\right.$ ). The post-saturation aqueous corrosion mode 1 requires the time, the temperature, and an empirical radiation enhancement factor as inputs. The BWIP model also requires several additional empirically derived input values that depend upon environmental conditions. Inputs to the SRP model (Westerman et a1. 1984) include temperature, the area of the exposed surface, and the irradiation rate of the container material. Coefficients are fitted using experimental data.

All the uniform corrosion modules in AREST contain variables whose values must be assigned by the user. By assigning suitable probability distributions to input variables, all models can be used in a stochastic framework, but only the model of Appendix A explicitly incorporates a factor (term) to account for model uncertainty. Values for the factor are simulated from a lognormal distribution that approximates the distribution that of the residuals obtained by fitting a mathematical model to the reference corrosion data.

\subsubsection{Pitting Corrosion}

The AREST model for pitting corrosion is a probablistic model that incorporates a model for calculating the rate of pit depth growth at each time step (see Section 2.3.2). The stochastic component of the model requires the following inputs:

- the inner-wall surface area of the container (A)

- a percentage $\left(P_{f}\right)$ of $A$ such that when the total surface area of pits penetrating the container exceeds $\left(P_{f}\right)$, the container is considered to have failed by pitting corrosion 
- the average number of sites per contajner at which the potential for pit development exists

- the distribution of pit depths at each time, $t$, or equivalently, the distribution of times at which pits penetrate the container.

Although the stochastic component of the pitting corrosion model is quite general, pitting is a complex phenomenon that is not well understood. It appears unlikely, therefore, that it will be possible in the near future to adequately determine such inputs as the average number of potential pitting sites or the distribution of pit depths as a function of time.

Two pit depth growth rate models are available to the AREST user. The mechanistic model described in Appendix A requires the following inputs:

- the molecular weight of the metal (gm/mole)

- the density of the metal $\left(\mathrm{gm} / \mathrm{cm}^{3}\right)$

- the diffusivity of the metal cation in the pit $\left(\mathrm{cm}^{2} / \mathrm{s}\right)$

- the concentration of the cation at the pit opening (mole $/ \mathrm{cm}^{3}$ )

- the proton charge on the constituents of binary electrolyte (equivalents)

- the potential drop along the pit depth (volts)

- temperature $\left({ }^{\circ} \mathrm{K}\right)$

The second pit growth rate model is that proposed by scientists at BNL (Sastre, Pescatore, and Sullivan 1986). Except for a pit growth enhancement factor, the model is identical to the BNL model of uniform corrosion discussed in Appendix $A$. The enhancement factor is a randomly generated value between 1 and 6 . Other inputs are, of course, identical to those for the uniform corrosion model.

\section{2 .3 Stress Corrosion}

The mechanistic model of stress corrosion given in Appendix A predicts the crack-tip velocity at a point of stress cracking. Crack-tip velocity, in turn, is a function of stress intensity. Stress intensity values are supplied as inputs to the stress corrosion model by the mechanical model. Currently, the 
same (initial) stress intensity value is used at each time step. Because stress relaxation occurs with time and the time-dependence of stress intensity is not being modeled, the stress corrosion model as currently implemented predicts more rapid penetrations (or earlier failures) than would be predicted by a model which took account of stress relaxation.

\subsection{WASTE PACKAGE RELEASE}

The two models for waste package release, solubility-limited release and inventory-limited release, are discussed in this section.

\subsubsection{Solubility-Limited Release}

As discussed in Appendix E, the WPR model contains a set of equations that describe the time-dependent, solubility-limited, mass transfer rate (i.e., fractional release rate) for radionuclides diffusing from a waste package. The time-dependent release rate of a radionuclide is a function of following parameters:

- radial dimensions of the waste form and packing thickness $\left(R_{0}, b\right)$

- porosity of the (altered) packing and the host rock $\left(\varepsilon_{1}, \varepsilon_{2}\right)$

- bulk density of packing and the host rock $\left(\rho_{1}, \rho_{2}\right)$

- degree of saturation $(\phi)$

- percentage of waste form surface area exposed $(\theta)$

- inventory of nuclides 1000 years after permanent closure (I[1000])

- nuclide radioactive decay constant ( $\lambda=\ln 2 /$ half-life)

- nuclide diffusion coefficient $\left(D_{f}\right)$

- retardation coefficients for the packing and the rock $\left(k_{1}, k_{2}\right)$

- nuclide concentrations at the waste form surface $\left(C_{s}\right)$

- time of containment failure after permanent closure $\left(t_{f}\right)$

- temperature at time $t_{f}(T)$

These inputs can be grouped into three categories: WP design parameters, physical parameters, and chemical characteristics of the waste form and included radionuclides. 


\section{Waste Package Design Parameters}

The key input parameters from WP design are those related to the dimensions of the various barrier materials that compose the WP. These include conntainer radius $\left(r_{0}\right)$, container length $(\ell)$, borehole radius $\left(r_{1}\right)$, and packing or equivalent material) thickness $\left(b=r_{1}-r_{0}\right)$, as shown in figure 3.1. The cylindrical geometry of an actual waste package is then transformed into an equivalent spherical geometry for computational purposes (Chambré et al. $1985)$. In particular, the cylindrical interior volume of the container $\left(V_{C C}\right)$ is set equal to the volume of a sphere $\left(V_{C S}\right)$, and a new spherical container radius $\left(R_{0}\right)$ is calculated:

$$
\begin{gathered}
V_{C C}=V_{C s} \\
\pi\left(r_{0}\right)^{2} \ell=(4 \pi / 3)\left(R_{0}\right)^{3} \\
R_{0}=\left[0.75\left(r_{0}\right)^{2} g\right]^{\frac{1}{3}}
\end{gathered}
$$

The spherical waste container is surrounded by a spherical shell of porous material, typically packing (formerly called "backfill") material, although porous barrier materials consisting of metal corrosion products, consolidated host rock, or even a water-filled void can be used. The thickness of this spherical shell (B) is set equal to the thickness of the packing (b) or the thickness of the any other porous harrier under consideration. Both waste form and porous shell are assumed to be imbedded in porous host rock extending infinitely in all directions. The transformed cesign parameters of the spherical waste package are shown in Figure 3.1.

\section{Physical Parameters}

The diffusion coefficient $\left(0_{f}\right)$, bulk density $\left(\rho_{1}, \rho_{2}\right)$ and porosity $\left(\varepsilon_{1}\right.$, $\varepsilon_{2}$ ) of the packing and host rock are key physical parameters affecting release rates that must be specified. The diffusion coefficient for each nuclide in 

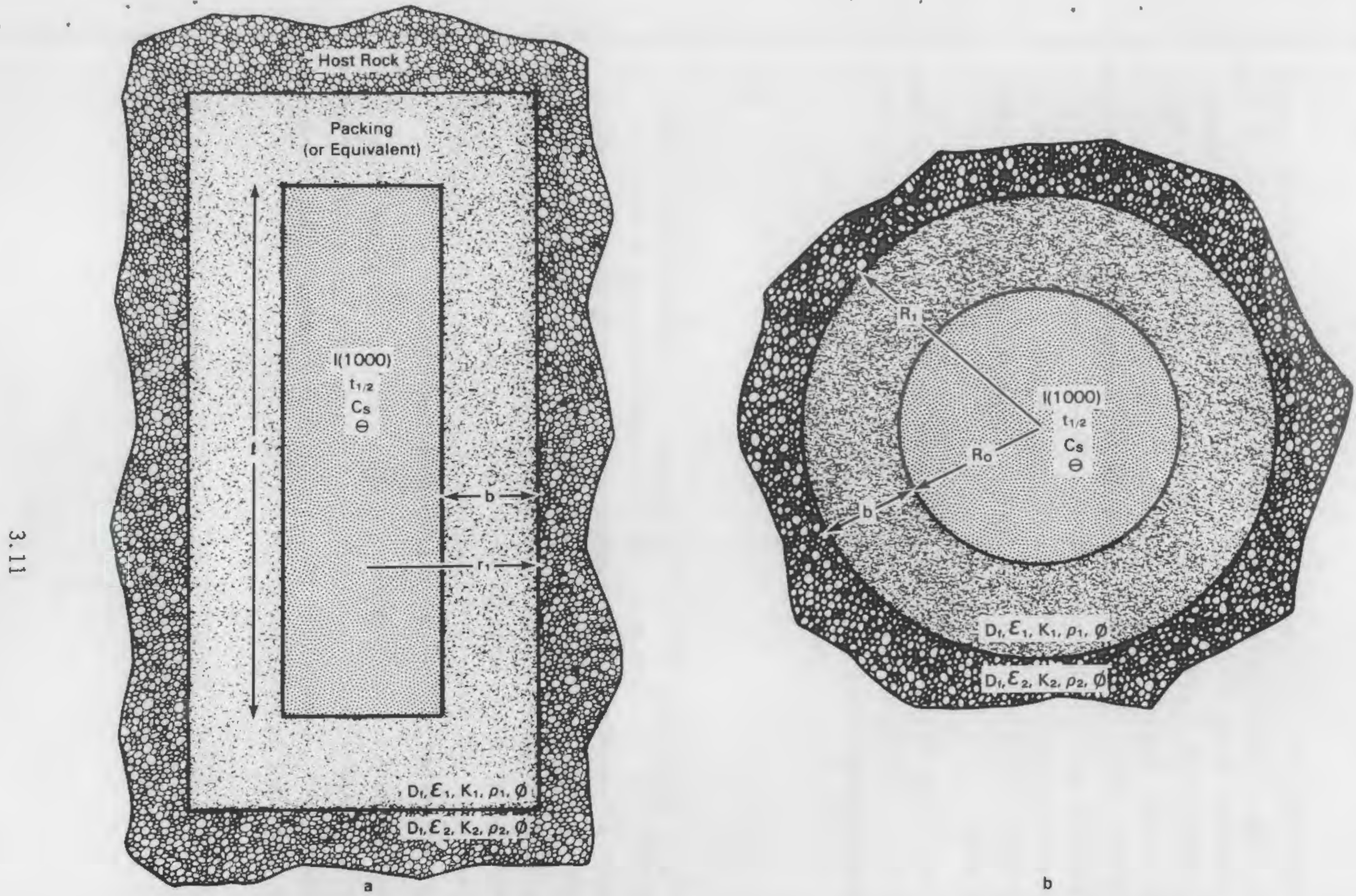

FIGURE 3.1. Waste Package Geometry for Solubility-Limited Release (a) Actual Waste Package Configuration, (b) Equivalent Spherical Configuration 
each porous material is conservatively assumed to be equal to the approximate value of the diffusion coefficient through water. That is, no credit is taken for tortuosity of the diffusional path of the nuclide through porous media, which could reduce the effective diffusion coefficient by as much as a factor of 100 to 1000 (Pigford and Chambre 1986). The slight dependence of $D_{f}$ on temperature is also ignored in these calculations. Relatively low waste package temperatures $\left(<120^{\circ} \mathrm{C}\right)$ prevail 300 to 1000 years after repository closure. The relative increase in $D_{f}$ at these elevated temperatures is expected to be for less than the decrease in $D_{f}$ because of tortuosity (Chambré et a1. 1985; Lerman 1979).

The release rate can also be scaled for unsaturated rock media (see Section 2.4.2). The degree of unsaturation $(\phi)$ is used to adjust the calculated fractional release rate $(\dot{f})$ according to the following equation:

$$
\dot{f}_{u}=\phi \dot{f}_{s}
$$

Where $\dot{f}_{u}$ is $f_{\text {unsaturated }}$ and $\dot{f}_{s}$ is $f_{\text {saturated. This approximation is made }}$ necessary by the lack of an exact theory for unsaturated system transport. It represents a bounding estimate, assuming all water in the unsaturated region provides an interconnected pathway for diffusion. This assumption ignores that portion of the groundwater that is physically isolated and, therefore, unable to serve as a diffusion pathway. Obvious boundary conditions are met by this relationship; at $\phi=0$ there is no water and thus no fractional release while at $\phi=1$ the unsaturated case becomes the fully saturated case.

The release rates calculated by the WPR model can also be normalized to account for the effect of limited exposure of waste form surface area (Pigford and Chambré 1986). One possible relationship between release rate and exposed surface area based on that study is as follows:

$$
\dot{f}_{a}=\left\{\begin{array}{c}
230 \\
\theta \dot{f}_{b}, \theta<0.00435 \\
\dot{f}_{b}, \theta>0.00435
\end{array}\right.
$$


where $\dot{f}_{a}$ is $\dot{f}_{\text {apertures, }}$ the fractional release rate from a waste form encased in a container/canister assumed to have apertures $1 \mathrm{~mm}$ in radius; $\theta$ is the fraction of the total surface area of waste form exposed; and $\dot{f}_{b}$ is $\dot{f}_{\text {bare, the }}$ calculated fractional release rate from a bare waste form with no container/ canister present. Note that under the assumptions made by Pigford and Chambré (1986) it has been demonstrated that the fractional release rate, $\dot{f}_{a}$, is not directly proportional to the percentage of the surface area of the waste form exposed, $\theta$. This is because enhanced diffusional transport at the edges of apertures in the container/canister causes small apertures to act effectively as larger apertures with respect to mass transfer.

\section{Chemical Parameters}

The chemical characteristics of individual radionuclides required for calculating solubility-limited releases include radionuclide concentration at the waste form surface $\left(C_{s}\right)$, radioactive decay constant ( $\lambda=\ln 2 /$ half-life), retardation coefficients (or sorption coefficients, $k_{D}$ ) on the packing and the rock $\left(K_{1}, K_{2}\right)$, and the inventory of the waste form 1000 years after closure of the repository [I(1000)]. Retardation coefficients are typically derived from experimental sorption coefficients $\left(k_{D}\right)$ for individual radionuclides as follows:

$$
K=1+\frac{\rho k_{D}}{\rho k_{D} / \varepsilon}
$$

where $\rho$ is the bulk density of the porous material, and $\varepsilon$ is its porosity of either the packing (or equivalent) or host rock.

Two basic options for defining $C_{s}$ are discussed in Section 2.4.2 and Appendix E: incongruent release, using individual solubilities of nuclidebearing solids; or congruent release, using the product of the solubility of the waste matrix $\left(\mathrm{e} . \mathrm{g} . \mathrm{UO}_{2}\right)$ and the stoichiometric proportion of a nuclide in the matrix. For incongruent release, the dependence of $C_{S}$ on temperature, $T$, and groundwater composition, $x_{w}$, is not calculated for any component. Two major reasons for this limitation are the dearth of accepted thermodynamic data on solids and solution species of many radionuclides and the meager amount of 
direct experimental data on the actual radionuclide-bearing solids obtained under repository-relevant test conditions.

For congruent release, the solubility of uranium as $\mathrm{UO}_{2}$ at the time of containment failure, $t_{f}$, is calculated as a function of both temperature and groundwater composition at $\mathrm{t}_{f}$. The $\mathrm{UO}_{2}$ solubility is calculated using a "solubility function" developed by the Atomic Energy of Canada, Limited for use . with their SYVAC performance assessment code (Garisto and Garisto 1985). In addition to temperature, the primary inputs to this solubility function include, $\mathrm{pH}, \mathrm{Eh}$, and the concentration of complex-forming anions (carbonate, phosphate, sulfate, chloride) that are obtained through the geochemical model (Appendix C). Note that in AREST groundwater composition is also treated as temperature-dependent. The applicability of this solubility function is restricted to a region of $\mathrm{pH}$-Eh values over which $\mathrm{UO}_{2}$ and $\mathrm{U}_{4} \mathrm{O}_{9}$ are the thermodynamically stable solids (see shaded area of Figure 3.2). As long as a reduced form of iron is present, either as aqueous $\mathrm{Fe}^{+2}$ or solid $\mathrm{Fe}^{0}$, the oxidation of spent fuel $\mathrm{UO}_{2}$ to solids more oxidized than $\mathrm{U}_{4} \mathrm{O}_{9}$ has not been observed. Moreover, the values calculated from this solubilities function compare favorably with temperature- and groundwater-solubilities of $\mathrm{UO}_{2}$ calculated by the AREST geochemical support code EQ3NR.

\subsubsection{Inventory-Limited Release}

The WPR model also contains a set of equations that describe the timedependent, inventory-limited, mass transfer rate (i.e., fractional release rate) for radionuclides diffusing from a waste package. These equations are more fully discussed in Appendix $E$. The parameters required for the calculation of inventory-limited fractional release rates include:

- water-filled volume $\left(V_{v}\right)$

- surface area of void $\left(S_{v}\right)$

- porosity of the packing and the host rock $\left(\varepsilon_{1}, \varepsilon_{2}\right)$

- bulk density of packing and the host rock $\left(\rho_{1}, \rho_{2}\right)$

- degree of saturation $(\phi)$

- inventory of nuclides 1000 years after repository closure (I[1000])

- nuclide radioactive decay constants ( $\lambda=\ln 2 /$ half-life) 


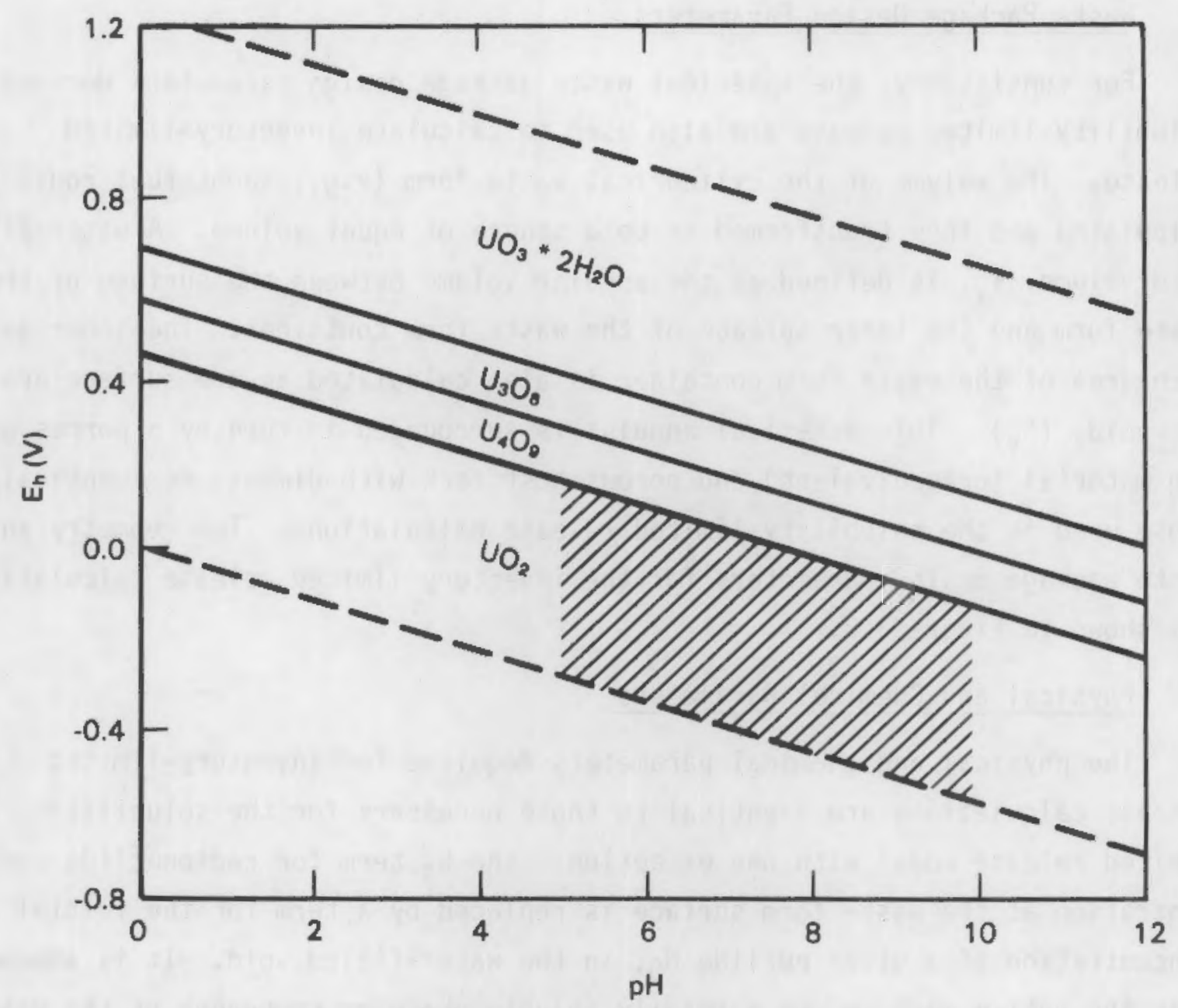

FIGURE 3.2. Stability Diagram for U-H-0 System at $25^{\circ} \mathrm{C}$

- nuclide diffusion coefficient $\left(D_{f}\right)$

- nuclide retardation coefficients for the packing and rock $\left(K_{1}, K_{2}\right)$

- initial concentration of nuclide in void $\left(\mathrm{N}_{0}\right)$

- time of containment failure after permanent closure $\left(t_{f}\right)$.

As with the solubility-limited release equations described in Section 3.3.1, inputs for this portion of the WPR model can be grouped into three categories: WP design parameters, physical parameters, and chemical parameters of the waste form and included radionuclides. 


\section{Waste Package Design Parameters}

For consistency, the spherical waste package design parameters derived for solubility-limited release are also used to calculate inventory-limited release. The volume of the cylindrical waste form (e.g., spent-fuel rods) is . calculated and then transformed in to a sphere of equal volume. A water-filled void volume, $v_{v}$, is defined as the annular volume between the surface of the . waste form and the inner surface of the waste form container. The inner surface area of the waste form container is also calculated as the surface area of the void, $\left(S_{v}\right)$. This spherical annulus is surrounded in turn by a porous packing material (or equivalent) and porous host rock with dimensions identical to those used in the solubility-limited release calculations. The geometry and waste package design parameters for the inventory-limited release calculation are shown in Figure 3.3 .

\section{Physical and Chemical Parameters}

The physical and chemical parameters required for inventory-limited release calculations are identical to those necessary for the solubilitylimited release model with one exception: the $c_{5}$ term for radionuclide concentration at the waste form surface is replaced by a term for the initial concentration of a given nuclide $\mathrm{N}_{0}$, in the water-filled void. It is assumed that the entire mass, $m$, of a readily soluble phase or component of the waste form immediately dissolves into the void volume, $v_{v}$ when groundwater first contacts the waste form. Thus, the initial concentration of a given radionuclide, $\mathrm{N}_{0}$, is calculated as follows:

$$
N_{0}=\frac{m}{V_{v}}
$$

For a given radionuclide, the value of m may be defined as a specific mass, or as any fraction of the total 1000-year inventory [I(1000)]. Because $m$ is not a function of temperature and groundwater composition, $\mathrm{N}_{0}$, and hence release rate, will also be independent of these parameters. Moreover, if a given 

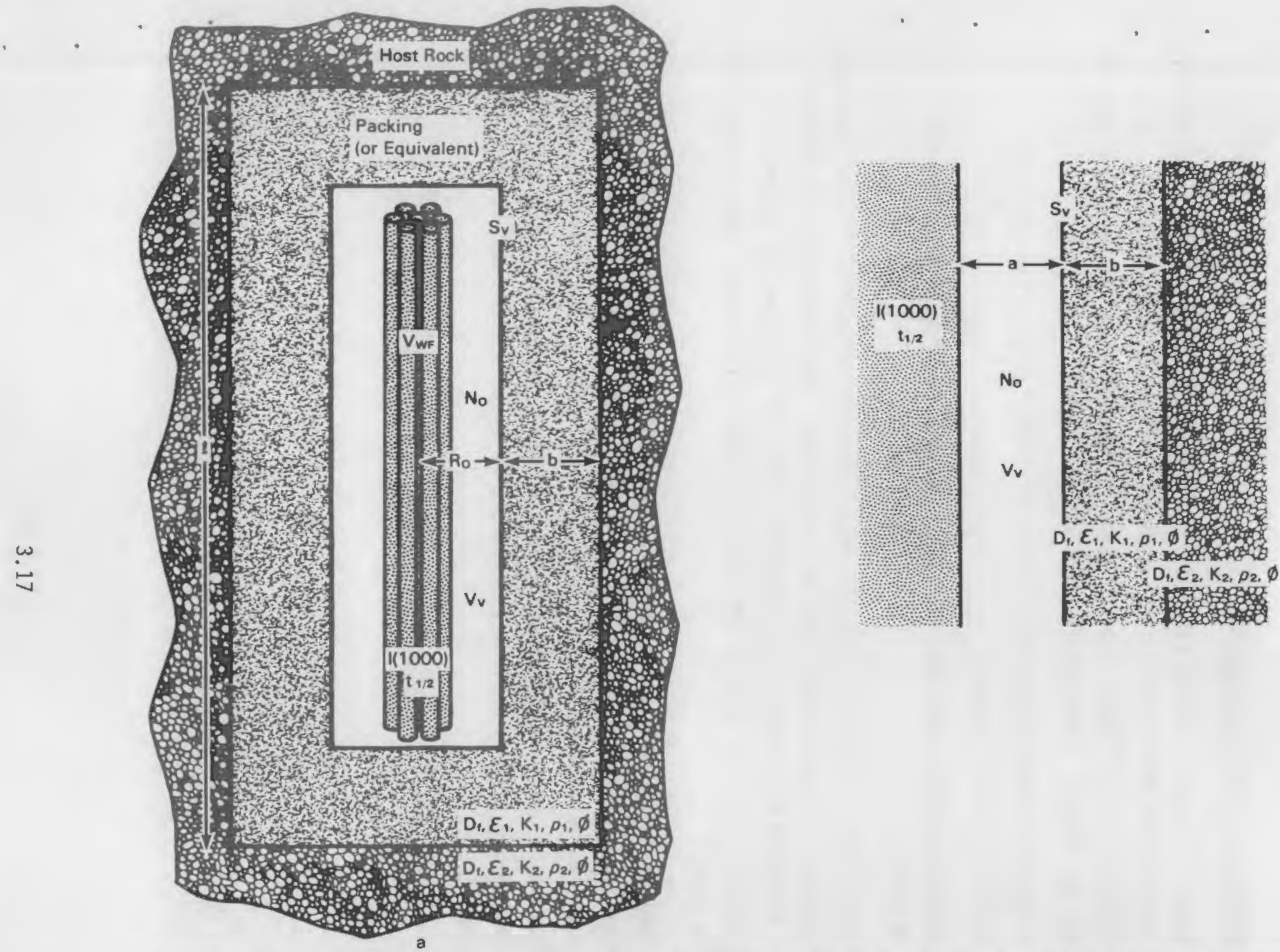

FIGURE 3.3. Waste Package Geometry for Inventory-Limited Release (a) Actual Waste Package Configuration, (b) Equivalent Planar Configuration 
radionuclide has a half-life considerably longer than 10,000 years, $N_{0}$ will be approximately independent of the time at which release begins.

\subsection{ENGINEERED SYSTEM RELEASE}

A major function of the ESR model is to compute estimates of total repository release from the simulated releases of individual waste packages. For this purpose, the ESR model requires two inputs, one from the WPC model and one from the WPR model. These inputs are, respectively,

- a series of waste package failure times (the failure time for each simulated waste package)

- radionuclide releases for each waste package (expressed as a function of time).

From this input information, the ESR model computes estimates of total or repository-scale release as described in Section 2.6. The nature of the desired output from the ESR model i.e., fractional release rates or cumulative releases, dictates the form of the required input (fractional, cumulative) from the WPR model.

Typically, the simulated waste package failure times are supplied by the WPC model and release functions are provided by the WPR model. However, the ESR model can be used in a "stand alone" as described in Section 2.5. In order to accommodate user-supplied failure and release information, the ESR model has been designed to accept arbitrary failure-time distributions and release functions. 


\subsection{AREST CODE OUTPUT}

The nature and form of output from AREST is controlled by the ESR model. In particular, performance results for individual waste packages, generated by the WPC and WPR models, are integrated in the ESR model to provide total system performance measures as output. Output from AREST can be further categorized according to whether it pertains to measurement indices for "Containment" or "Release."

\subsection{CONTAINMENT OUTPUT}

Several types of information relating to waste package containment are compiled by the ESR model for output in either tabular or graphical form. The most important of these is the distribution of containment failure times. At the option of the user, the containment failure distribution may be obtained for the container barrier alone or for both the container and any additional barriers that provide containment (e.g., spent-fuel cladding, overpack). Moreover, the distribution of containment failure times can be partitioned according to the indicated failure mechanism. In the hypothetical sample output shown in Figure 4.1a, failures resulting from uniform corrosion and pitting corrosion have been plotted separately. Failures from the two sources are combined to produce an estimate of the (total) containment failure-time distribution. Distributions of failure times for uniform and pitting corrosion have been combined to produce the cumulative distribution of containment failure times shown in Figure $4.1 b$.

The calculated distributions of containment failure times reflect parameter uncertainty, produced by random sampling from the distribution of input variables. Although some aspects of model uncertainty, such as parameter uncertainty and the effect of using competing modules for corrosion processes, can currently be addressed, a thorough analysis of model uncertainty involves code verification and validation, benchmarking, and uncertainty analysis. Evaluation of AREST model uncertainty is one of the pianned future activities discussed in Section 5.0 . 


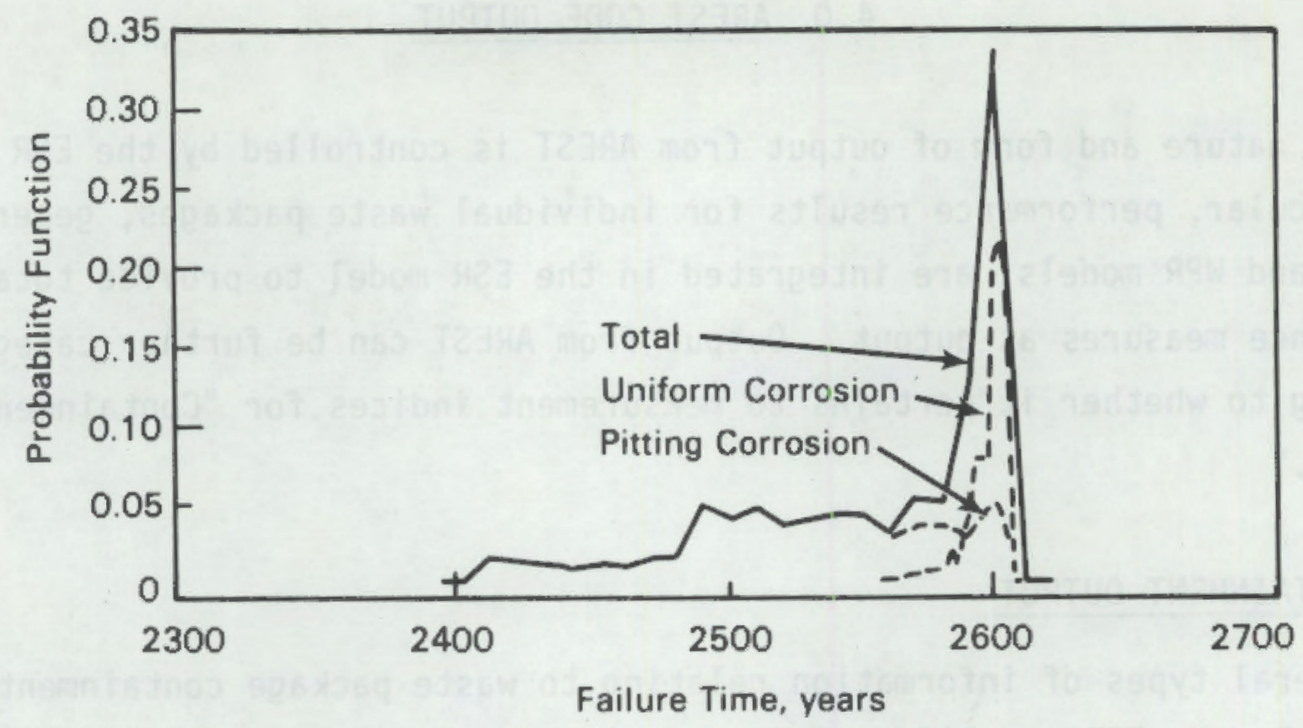

(a)

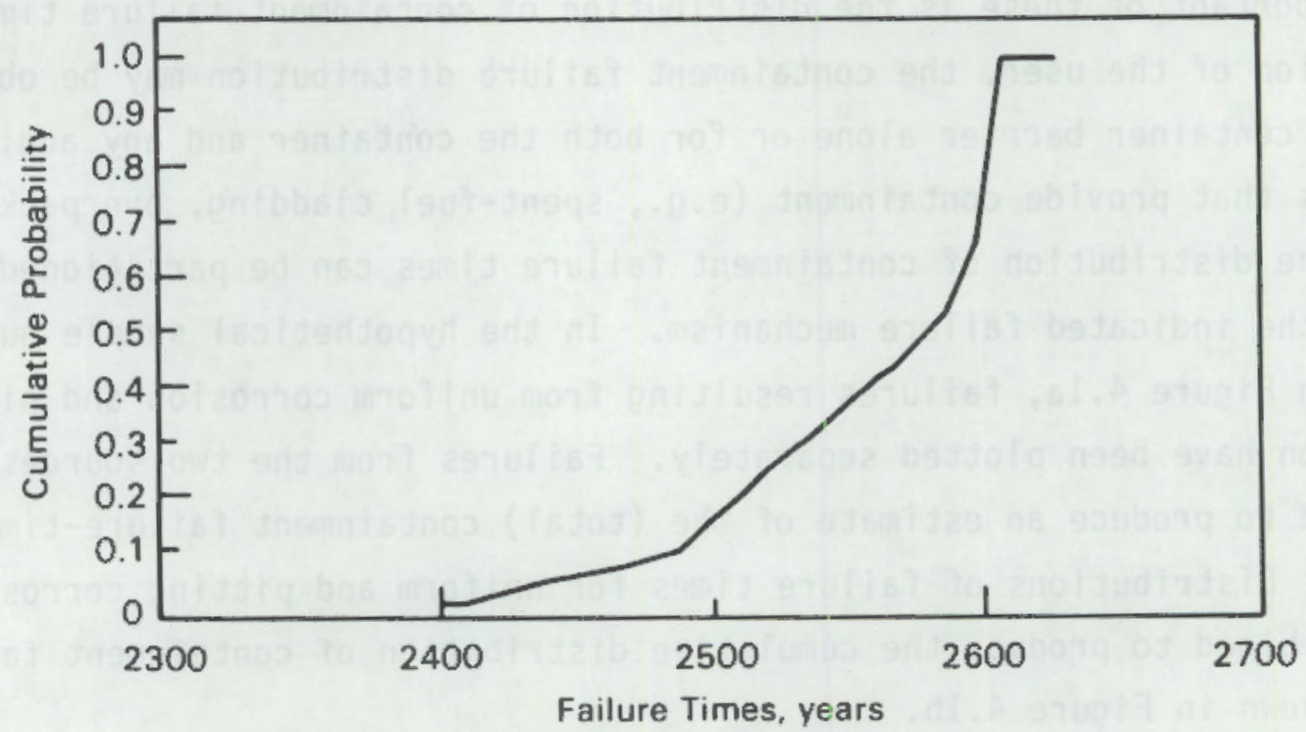

(b)

FIGURE 4.1. Distribution of Containment Failures by Uniform and Pitting Corrosion, (a) Frequency Distribution, (b) Cumulative Distribution

Data on variables that affect containment failure can also be tabulated for output by the ESR model. These include the waste package temperature and the composition of the groundwater within the waste package at the time of failure, and the solubility of $\mathrm{UO}_{2}$ (assuming certain geochemical conditions are met, see Appendix D) at the time and temperature of failure. The distributions of these variables over the entire post-closure time period can also be obtained. Because these variables are evaluated to support release rate 
calculations, rather than for any specific regulatory requirement, they are currently tabulated but they are not routinely plotted.

\subsection{RELEASE OUTPUT}

The key release outputs from the WPR and ESR models are radionuclide mass - transfer rates for individual waste packages. As explained in Section 2.4 and Appendix $E$, these mass transfer rates can be converted either to fractional release rates, based on limits imposed by the NRC $(10$ CFR 60, 1983), or cumulative releases, based on limits set by the EPA (40 CFR 191, 1985). In the ESR model, the averages of these converted release values for the entire repository system are tabulated. Figure 4.2 shows an output example in which fractional release rates are plotted against the time since repository closure. The values shown were calculated for a hypothetical case in which a single waste package containing spent fuel lost containment 1,000 years after repository closure. Figure 4.3 presents the same data but expressed in terms of radionuclide-specific cumulative releases normalized to the EPA limits. The

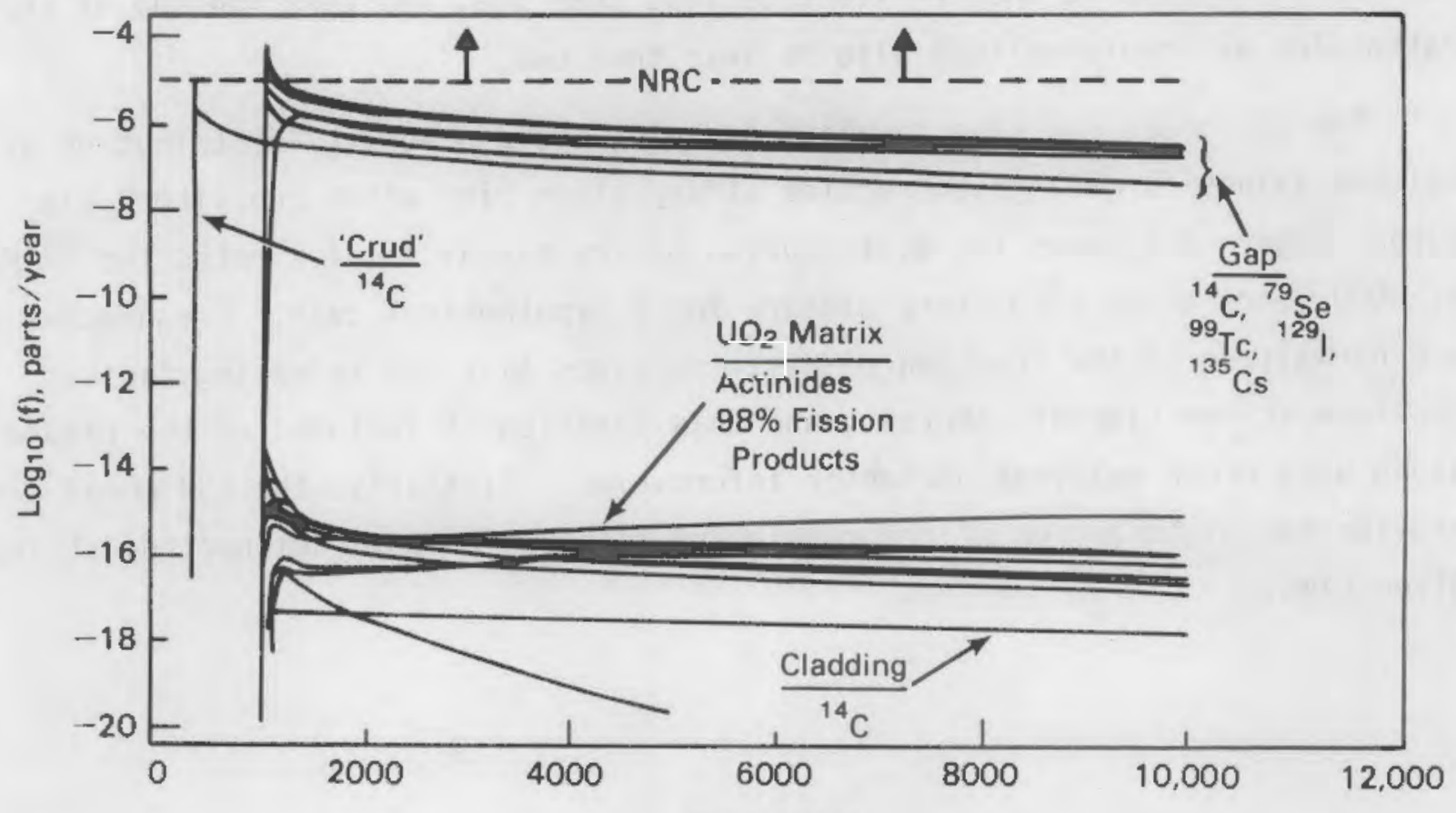

Time, years

FIGURE 4.2. Sample Plot of Fractional Release Rates Versus Time 


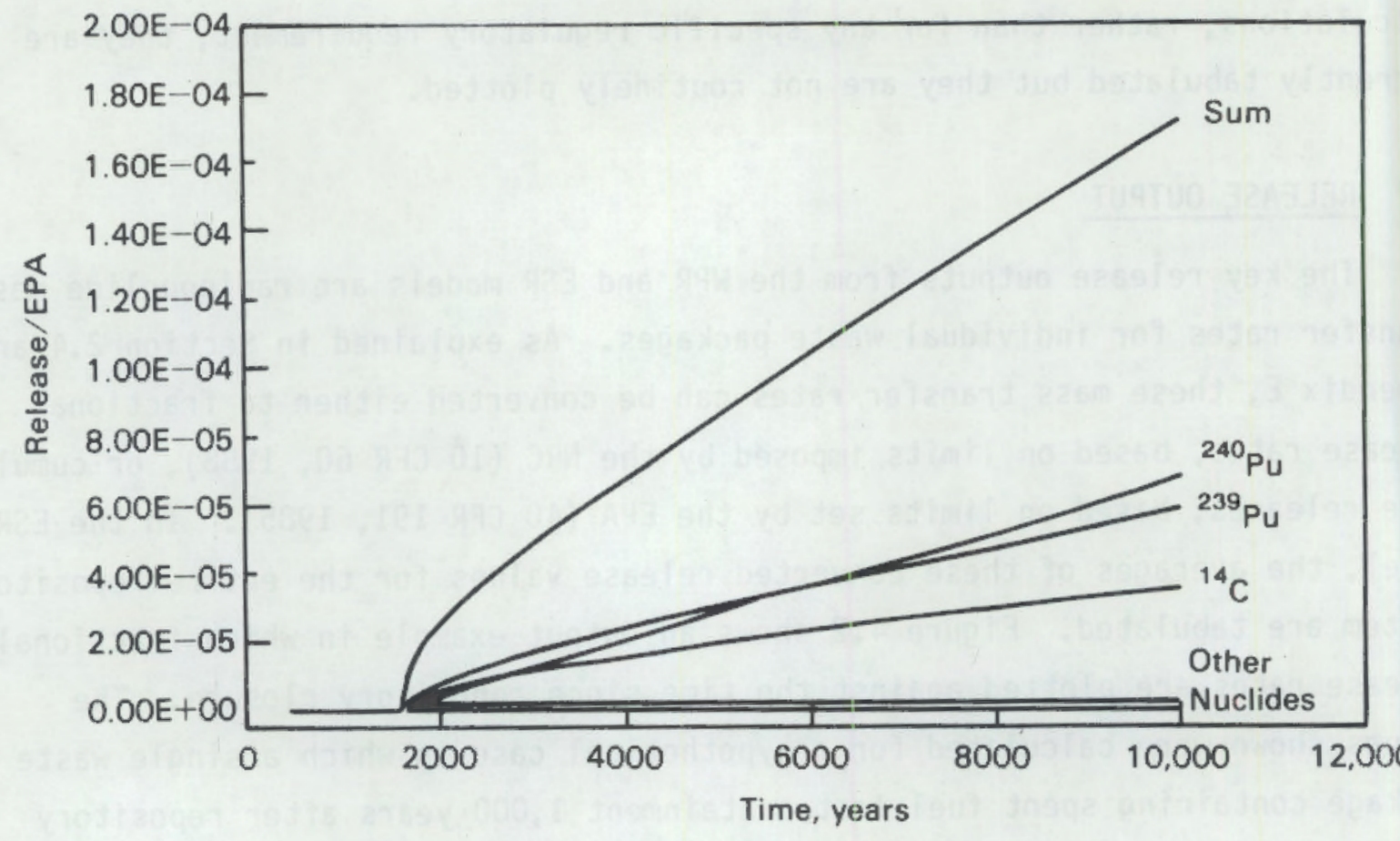

FIGURE 4.3. Sample Plot of Cumulative Releases Normalized by EPA Limits

EPA performance requirements state that for each nuclide, the ratio of total cumulative release to the EPA limit be less than one, and that the sum of these ratios for all radionuclides also be less than one.

The ESR model can also tabulate and plot the probability distribution of release values for any given nuclide at any given time after repository closure. Figure 4.4 shows the distribution of fractional release rates for ${ }^{237} \mathrm{~Np}$ at 5000 years after repository closure for a hypothetical case. Frequencies are normalized to the fraction of waste packages that are releasing radionuclides at the time of interest, and this fraction is included on the figure along with other relevant parameter information. Similarly, the ESR model can provide the distribution of the cumulative release for any radionuclide at any given time. 


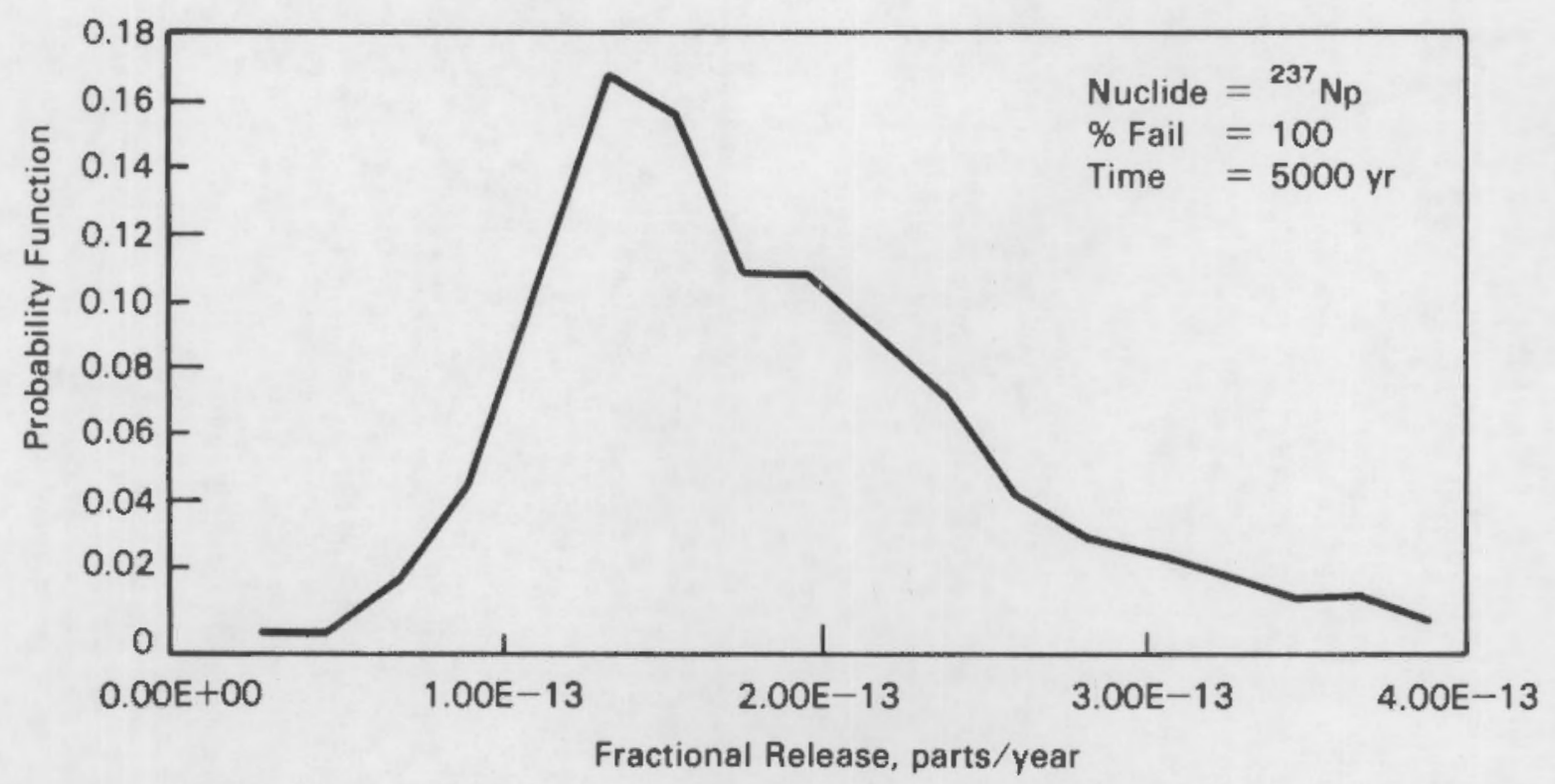

FIGURE 4.4. Sample Plot of ${ }^{237} \mathrm{~Np}$ Release Rate Distributions 5000 Years After Repository Closure 


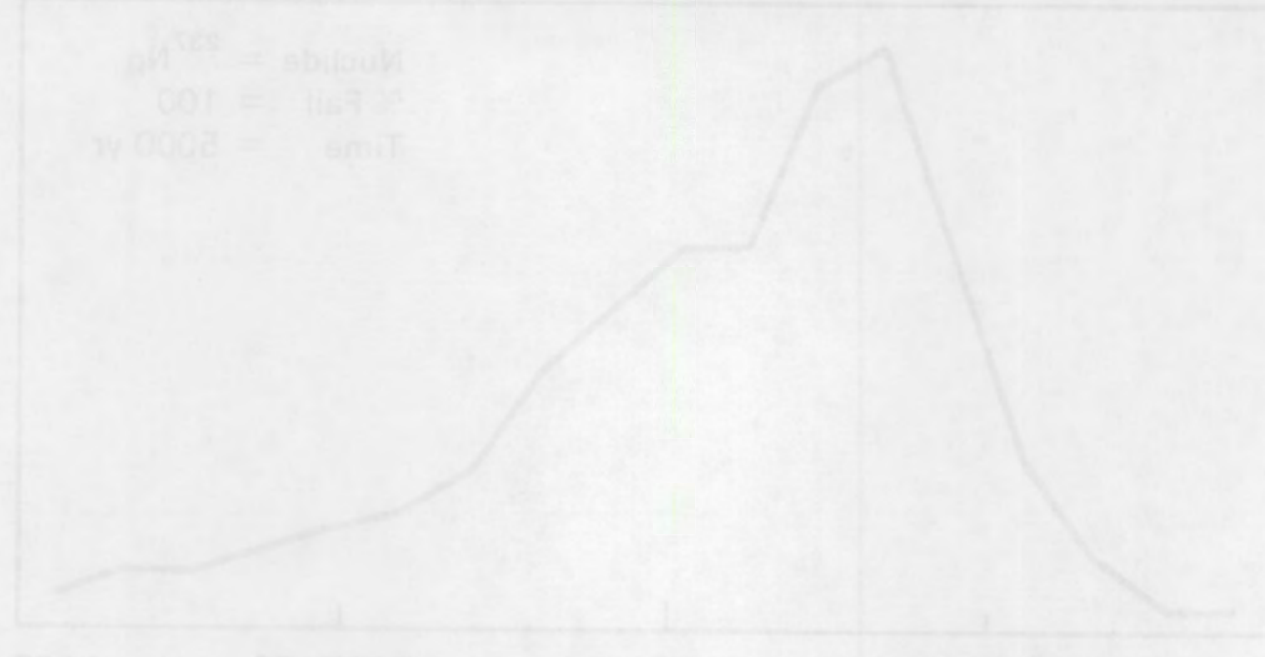




\subsection{FUTURE DEVELOPMENTS}

The AREST model is currently in a developmental stage. Consequently, the need to enhance existing and develop additional capabilities in order for AREST to realize its full potential is recognized. Links among existing components and submodels need to be included in some cases and improved in others. The temperature module in the AREST code, for example, should be linked to the modules for all temperature-dependent processes where no links currently exist. Submodels are needed to simulate the effects of geologic hazards such as earthquakes and volcanic eruptions. In its present form, the AREST code deals only with spent fuel releases. Further work is required if AREST is to be extended to other waste forms such as borosilicate glass. The existing models for waste package degradation and failure can be enhanced and additional models can be developed. In this section, areas where AREST can be significantly improved or expanded are identified and discussed.

\subsection{STOCHASTIC SUBMODELS}

The current version of AREST contains a rudimentary stochastic model of pitting corrosion. Because pitting corrosion is a chemically and statistically complex process, the model requires further development to make it more realistic. The present stochastic structure is quite general, but additional work is required to determine distributions for the frequency and location of pits. Moreover, the pitting corrosion model presented in Section 2.3 and the pitting rate model in Appendix $A$ should be refined as necessary to incorporate recent modeling developments.

To date, the development of AREST has focused on the use of the code to assess the spent fuel as a waste form under anticipated conditions. Consequently, no capability to model disruptive geologic events such as earthquakes, floods, and volcanic eruptions has been implemented. Such capability is essential, however, if AREST is ever to be used for licensing assessments (Stephens 1985). The authors plan to include the necessary probabilistic structure in AREST to model the effect of disruptive geologic events on release. The 
general capability to model disruptive events will also make it possible to model certain human intrusion scenarios, provided that they can be describec in terms of existing AREST input variables.

\subsection{WASTE FORM RELEASE}

The containment-release logic of AREST has been implemented for spent fuel, but the logic has been designed to apply to other waste forms as well. Because commercial and defense wastes are also expected to be placed in a geologic repository, it would be desirable to use AREST to model the dissolution of, and release from, these waste forms. Computer codes are available (e.g., Grambow 1985) to aid in the understanding of the dissolution processes that occur when glass waste forms come in contact with water. Such codes, together with support geochemical codes, can be used to generate the information needed for AREST to model the dissolution of, and subsequent release from, glass waste forms.

When AREST is expanded to model release from other waste forms, it will be necessary to expand the thermal data base as well. The distribution of waste package temperature histories is determined from the expected receipt charac. teristics of the waste form in question. Thus, it will be necessary to determine the thermal histories of the additional waste forms for a variety of possible receipt scenarios.

In addition to expanding AREST to simulate other waste forms, AREST will be updated as necessary to include any improvements made by Pigford, Chambré and colleagues in their present mass transfer models. Several potential areas for advanced modeling exist: ingrowth of nuclides with radioactive-decay precursors, colloid transport of nuclides, effects of multiple regions with different properties affecting transport, irreversible sorption, and the radiolysis effects of $\mathrm{Eh}, \mathrm{pH}$, and groundwater chemistry.

\subsection{CONTAINMENT}

The current version of AREST employs models for the rates of uniform corrosion, pitting corrosion, and stress corrosion cracking. All the models of 
corrosion and degradation used in AREST have been taken from existing literature. Some of the models are empirical, but others attempt to describe in mechanistic terms the corrosion and degradation of metallic waste containers.

Depending on possible changes in waste package design, existing models may require extension to nonferrous and nonmetallic materials. Current research may identify additional corrosion modes and degradation mechanisms that significantly affect containment times. Extension of the present AREST model will be required to accormodate models of these processes. In particular, models of transport controlled corrosion, stress corrosion cracking, and galvanic corrosion will be considered for possible inclusion in AREST. Efforts to improve the modeling of waste package containment will, of course, focus on materials that are actively being considered for components of the EBS and on mechanisms that are expected to result in the shortest containment times.

\subsection{THERMAL MODEL ING}

Current inputs to the AREST thermal model are based upon certain simplifying assumptions about variables such as emplacement geometry and heat conduction. These assumptions lead to values that tend to overestimate both the magnitude and range of container temperatures. Additional work is required to incorporate the effects of these variables into the thermal calculations performed for AREST. Further, the age and heat generation rate distributions of wastes received at the repository must be developed on the basis of current assumptions about waste management systems and receipt scenarios. Moreover, these distributions must be updated as necessary. In particular, age and heat generation rate distributions are required for glass waste forms.

Within the AREST code, the thermal module is not fully linked to other temperature-dependent process modules and variables, such as nuclide solubilities (except $\mathrm{UO}_{2}$ ), sorption coefficients, and diffusion coefficients. In particular, when modeling release, the conservative assumption is made: temperature remains unchanged at all times subsequent to containment failure. While this assumption may be reasonable for late failures, it may lead to excessively high estimates of release for early failures. The models and 
variables in AREST must be evaluated for their sensitivity to temperature, and linked to the thermal model as necessary.

\subsection{SPATIAL MODELING}

Although some spatial aspects of the repository are modeled implicitly via the selection of appropriate distributions for input variables (e.g., degree of . resaturation) or via thermal calculations (container spacing is one of the parameters upon which thermal inputs to AREST are based), the geometry of th: repository is not explicitly modeled in the current version of AREST. Releases from the indjuidual waste packages are summed by the ESR model to produce an estimate of total repository release, but the spatial distribution of individual releases from failed waste packages is not explicitly taken into account. Potential sources of spatial variability that significantly impact waste package performance must be identified. These should be modeled appropriately, either by explicitly incorporating geometric models of the phenomena into AREST or by incorporating the effects into the distributions of relevant input variables.

\subsection{BENCHMARKING AND VERIFICATION}

At its present stage of development, the AREST code has not been thoroughly verified or benchmarked against other, similar codes. These steps must be completed before AREST can be used for sensitivity studies and uncertainty analysis. When AREST reaches a suitable stage of development, comparison with other probabilistic performance assessment codes for nuclear waste management (for example, the Vault submodel of SYVAC) will be conducted. Such comparisons are especially important if AREST is to be combined with a far-field transport model to assess the performance of the overall geologic repository system. 


\section{REFERENCES}

Alexander, D. H., M. J. Apted, A. M. Liebetrau, A. E. Van Luik, R. E. Williford, and P. G. Doctor. 1985. "Conceptual Model for Deriving the Repository Source Term." In Scientific Basis for Nuclear Waste Management VIII, eds. C. M. Jantzen, J. A. Stone, and R. C. Ewing, pp. 439-450. Materials Research Society, Pittsburgh, Pennsylvania.

Anantatmula, R. P., C. H. Delegard, and R. L. Fish. 1984. "Corrosion Behavior of Low-Carbon Steel in Grande Ronde Basalt Groundwater in the Presence of Basalt-Bentonite Packing," In Scientific Bas is for Nuclear Waste Management VII, ed. G. L. McVay, Pp. 113-120. Elsevier, Amsterdam, Netherlands.

Apted, M. J., D. H. Alexander, A. M. Liebetrau, A. E. Van Luik, R. E. Williford, and P. G. Doctor. 1985. "A Conceptual Model for Repository Source-Term Evaluation," in Proceedings of the Workshop on the Source Term for Radionuclide Migration from High-Level Waste or Spent Fuel Under ReaTistic Repository Conditions, eds. T. Hunter and A. Mutler, pp. 125-136. SAND85-0380, Sandia National Laboratory, Albuquerque, New Mexico.

Barner, J. 0, 1984. LWR Spent Fuel Approved Testing Materials for Radionuclide Release Studies. PNL-4686, Pacific Northwest Laboratory, Richland, Washington.

Barney, G. S., and D. T. Reed. 1986. "Effects of Sorption Hysteresis on Radionuclide Releases from Waste Packages." In High-Level Nuclear Waste Disposal, ed. H. C. Burkholder, pp. 701-711. Battelle Press, Columbus, Ohio.

Bibler, N. E., G. G. Wicks, and V. M. Oversby. 1985. "Leaching Savannah River Plant Nuclear Waste Glass in a Saturated Tuff Environment." In Scientific Basis for Nuclear Waste Management VIII, eds. C. M. Jantzen, J. A. Stone, and R. C. Ewing, pp. 247-256. Materials Research Society, Pittsburgh, Pennsylvania.

Chambré, P. L., T. H. Pigford, and S. Zavoshy. 1982. "Solubility Limited Dissolution Rate in Ground Water." Transactions of the American Nuclear Society $41: 153$.

Chambré, P. L., and T. H. Pigford. 1984. "Prediction of Waste Performance in a Geologic Repository." In Scientific Basis for Nuclear Waste Management VII, ed. G. L. McVay, pp. 985-1008. Elsevier, Amsterdam, Netherlands.

Chambré, P. L., T. H. Pigford, W. W.-Lee, J. Ahn, S. Kajiwara, C. L. Kim, H. Kimura, H. Lung, W. J. Williams, and S. J. Zavoshy. 1985. Mass Transfer and Transport in a Geologic Environment. LBL-19430, Lawrence Berkeley Laboratory, Berkeley, California.

Christensen, H., and E. Bjergbakke. 1986. "Alpha-Radiolysis of Aqueous Solutions." In Scientific Basis for Nuclear Waste Management X, ed. L. 0 . Werme, pp. 401-408. Materials Research Society, Pittsburgh, Pennsylvania. 
Cohen, B. I. 1985. "Critique of the National Acadeny of Sciences Study of the Isolation Systems for Geologic Disposal of Radioactive Waste." Nuclear Technology $70: 433$.

Croff, A. G., and C. W. Alexander, 1980. Decay Characteristics of OnceThrough LWR and LMFBR Spent Fuels, High-Level Wastes, and Fuel-Assembly Structural Material Wastes. ORNL/TM-7431, 0ak Ridge National Laboratory, 0ak Ridge, Tennessee.

Disposal of Nuclear Radioactive Waste in Geologic Repositories, 10 CFR Part 61), Vol. 46, No. 130 (1983). (Cited in text as 10 CFR 60, 1983.)

Environmental Radiation Protection Standards for Management and Disposal of Spent Nuclear Fuel, High-Level and Transuranic Radioactive Wastes. Title 40, Part 191 (1985). (Cited in text as 40 CFR 191, 1985).

Garisto, F., and N. C. Garisto. 1985. "A U0 2 Solubility Function for the Assessment of Used Nuclear Fuel Disposal." Nucl. Sci. Eng. 90:103-110.

Garisto, N. C., K. B. Harvey, F. Garisto, and L. H. Johnson. 1986. "Source Term Models for the Assessment of Nuclear Fuel Waste Disposal in Canada." In Waste Management '86: Proceedings of the 1986 Symposium on Waste Management, ed. R. G. Post, pp. 397-401. University of Arizona, Tucson, Arizona.

Grambow, B. 1985. "A General Rate Equation for Nuclear Waste Glass Corrosion." In Scientific Basis for Nuclear Waste Management VIII, eds. C. M. Jantzen, J. A. Stone and R. C. Ewing, pp. 15-27. Materials Research Society, Pittsburgh, Pennsylvania.

Gray, W. J. 1984. "Ganma Radiolysis Effects on Grande Ronde Basalt Groundwater." In Scientific Basis for Nuclear Waste Management VII, ed. G. L. McVay, pp. 147-152. Elsevier, Amsterdam, NetherTands.

INTERA Environmental Consultants, Inc. 1983. WAPPA: A Waste Package Performance Assessment Code. Report DNWI-452, Office of Nuclear Waste Isolation, Battelle Memorial Institute, Columhus, Ohio.

Jacobs, G. K., and S. K. What ley, eds. 1985. Conference on the Application of Geochemical Models to High-Level Nuclear Waste Repository Assessment. NUGEG/CP-0062, ORNL/TM-9585, U.S. Nuclear Regulatory Commission, Washington, D.C.

Johnson, L. H., N. C. Garisto, and S. Stroes-Gascoyne, 1985. "Used-Fuel Dissolution Studies in Canada." In Waste Management '85: Proceedings of the 1985 Symposium on Waste Management, ed. R. G. Fost, Vol. 1, pp. 479-482. The University of Arizona Press, Tucson, Arizona.

Kim, C. L., P. L. Chambré, and T. H. Pigford. 1986. Mass-Transfer-Limited Release of a Soluble Waste Species. LBL-20899, Lawrence Berkeley Laboratory, Berkeley, California. 
Lerman, A. 1979. Geochemical Processes, Water and Sediment Environments. John Wiley and Sons, New York.

Levy, P. W. 1983. "Radiation Damage Studies on Natural Rock Salt from Various Geological Localities of Interest to the Radioactive Waste Disposal

Program." Nuclear Technology 60:231-243.

Lieberman, J. A., S. N. Davis, D. R. F. Harleman, R. L. Keeney, D. C. Kocher, D. Langmuir, R. B. Lyon, W. W. Owens, T. H. Pigford, and W. W. L. Lee. 1985. Performance Assessment National Review Group. RFW-CRWM-85-01, Roy F. Weston, Washington, D.C.

Liebetrau, A. M., and M. J. Apted. 1985. "A Generalized Waste Package Containment Model." Waste Management '85: Proceedings of the 1985 Symposium on Waste Management, ed. R. G. Post, pp. 253-257. University of Arizona, Tucson, Arizona.

McCright, R. D., R. A. Van Konynenburg, and L. B. Ballou. 1984. "Corrosion Test Plan to Guide Canister Materials Selection and Design for a Tuff Repository." In Scientific Basis for Nuclear Waste Management VII, ed. G. L. McVay, pp. 309-318. Elsevier, Amsterdam, Netherlands.

McGrail, B. P., L. A. Chick, and G. L. McVay. 1985. "Initial Results for the Experimental Evaluation of a Nuclear Waste Repository Source Term Mode1." Nuclear Technology 69:114-118.

National Academy of Sciences (NAS). 1983. A Study of the Isolation System for Geologic Disposal of Radioactive Wastes. National Academy Press, Washington, D.C.

Neretnieks, I. 1984. "The Impact of Alpha-Radiolysis on the Release of Radionuclides from Spent Fuel in a Geologic Repository." In Scientific Basis for Nuclear Waste Management VII, ed, G. L. McVay, pp. 1009-10̄22. Elsevier, Amsterdam, Netherlands.

Newman, J. F. 1981. "The Stress Corrosion of Steel in Sodium Hydroxide Solution: A Film Rupture Model." Corrosion Science 21(7):487-503.

Oren, T. I., and B. P. Ziegler. 1979. "Concepts for Advanced Simulation Methodologies." Simulation 32(3):69-82.

Oversby, V. M. 1987. "Spent Fuel as a Waste Form: Data Needs to Allow LongTerm Performance Assessment Under Repository Disposal Conditions." In Scientific Basis for Nuclear Waste Management, Vol. X, ed. J. K. Bates and W. B. Seefeldt, pp. 87-101. Materials Research Society, Pittsburgh, Pennsylvania.

Pederson, L. R., D. E. Clark, F.N. Hodges, G. L. McVay, and D. Rai. 1984. "The Expected Environment for Waste Packages in a Salt Repository." In Scientific Basis for Nuclear Waste Management VII, ed. G. L. McVay, pp. 417426. Elsevier, Amsterdam, Netherlands. 
Pegden, C. D. 1985. Introduction to SIMAN" Systems Modeling Corporation. State College, Pennsyivania.

Pigford, T. H. 1984. Response to B. L. Cohen's Criticism of the Report: "A Study of the I solation System for Geologic Disposal of Radioactive Wastes, Nat. Acad. Press, 1985. UCB-NE-4052, University of California at Berkeley, Berkeley, California.

Pigford, T. H., and P. L. Chambré. 1985. Mass Transfer in a Salt Repository. LBL-19918, Lawrence Berkeley Laboratory, Berkeley, California.

Pigford, T. H., and P. L. Chambré. 1986. "Reliable Predictions of Waste Performance in a Geologic Repository." in High.-Level Nuclear Waste Disposal, ed. H. C. Burkholder, pp. 163-186. Battelle Press, Columbus, Ohio.

Pruess, K., and G. Bodvarsson. 1982. Hydrothermal Conditions and Resaturation Times in Underground Openings for a Nuclear haste Repository in the Umtanum Flow at the Basalt Waste Isolation Project. LBL-18451, Lawrence Berketey Laboratory, Berkeley, California.

Rai, D., and J. L. Ryan. 1984, "Solubility Constraint: An Important Consideration in Safety Assessment of Nuclear Waste Disposal." In Scientific Basis for Nuclear Waste Management VII, ed. G. L. McVay, pp. 805-815. Elsevier, Amsterdam, Netherlands.

Sagar, B., P. W. Eslinger, and R. G. Baca. 1984a. Probabilistic Modeling of Radionuclide Release at the Waste Package Subsystem Boundary of a Repository in Basalt. SO-BWI-TA-012, Rockwell Hanford operations, Richland, Washington.

Sagar, B., P. W. Eslinger, and R. G. Baca. 1984b. Probabilistic Modeling of Radionuclide Release at the Waste Packages Engineered Boundary of a Repository in Basalts. Draft RHO-BW-ST-689, Rockweli Hanford Operations, Richland, Washington.

Sastre, C., C. Pescatore, and T. Sullivan. 1986. Waste Package Reliability. NUREG/CR-4509, U.S. Nuclear Regulatory Commission, Washington, D.C.

Stephens, K. 1985. Methodologies for Assessing Long-Term Performance of HighLevel Radioactive Waste Packages. ATR-85 (5810-01)-1ND, The Aerospace Corporation, Washington, D.C.

U.S. Department of Energy (DOE). 1984a. General Guidelines for the Recommendation of sites for the Nuclear Waste Repositories. Nuclear Waste Policy Act of 1982; 10 CFR Part 960. Final Siting Guideline, Federal Register, Vol. 49, pp. 47714-47770, December 6, 1984, Washington, D.C.

U.S. Department of Energy (DOE). 1984b. Generic Requirements for a Mined Geologic Disposal System. DOE/OGR/B-2, Washington, 0.C. 
U.S. Department of Energy. 1985. Mission Plan for the Civilian Radioactive Waste Management Program. DOE/RW-0005, Volume 1, Office of Civilian Radioact ive Waste Management, Washington, D.C.

U.S. Department of Energy (DOE). 1986a. Environmental Assessment: Deaf Smith County, Texas. D0E/RW-0069, Vol. 2 of 3, Office of Civilian Radioactive Waste Management, Washington, D.C.

U.S. Department of Energy (DOE). 1986b. Environmental Assessment: Reference Repository Location, Hanford Site, Washington. DOE/RW-0070, Vol. 2, Office of Civilian Radioactive Waste Management, Washington, 0.C.

U.S. Department of Energy (DOE). 1986c. Environmental Assessment: Yucca Mountain Site, Nevada Research and Development Area, Nevada. O0E/RW-0073, Vo1. 2 of 3, Office of Civilian Kadioactive Waste Management, Washington, D.C.

U.S. Nuclear Regulatory Commission (NRC). 1986. Disposal of High-Level Radioactive Wastes in Geologic Repositaries; Conforming Amendments. Federal Register, Vol. 51, pp. 22288-22301.

Van Konynenburg, R. A., C. F. Smith, H. W. Culham, and C. H. Otto, Jr. 1985. "Behavior of Carbon-14 in Waste Packages for Spent Fuel in a Repository in Tuff." In Scientific Basis for Nuclear Waste Management VIII, eds. C. M. Jantzen, J. A. Stone, and R. C. Ewing, pp. 405-412. Materials Research Society, Pittsburgh, Pennsylvania.

Werme, L. 0., and B. Grambow. 1987. "Development, Application, and Validation of Models for Waste Package Long-Term Performance: Current Irends." In Scientific Bas is for Nuclear Waste Management, Vol. X, ed. J. K. Bates and W. B. Seefeldt, pp. 29-43. Materials Research Society, Pittsburgh, Pennsylvania.

Westerman, R. F., J. L. Nelson, S. G. Pitman, W. L. Kuhn, S. J. Basham, and D. P. Moak. 1984. "Evaluation of Iron-Base Materials for Waste Package Containers in a Salt Repository." In Scientific Basis for Nuclear Waste Management VII, ed. G. L. McVay, pp. 427-436. Elsevier, Amsterdam, Netherlands.

Wolery, T. J. 1983. EQ3NR, A Computer Program for Geochemical Aqueous Speciation-Solubility Calculations: User's Guide and Documentations. UCRL-53414, Lawrence Livermore National Laboratory, Livermore, California.

Wuertz, R., and M. Ellinger. 1986. "Source Term for the Activity Release from a Repository for Spent Fuel." In Scientific Basis for Nuclear Waste Management IX, ed. L. 0. Werme, pp. 393-400. Materials Research Society, Pittsburgh, Pennsylvania. 
Yung, S. C., C. F. Mclane, R. P. Anantatmula, R. T. Toyooka, and W. K. Terry. 1987. Waste Package Preliminary Reliability Analysis Report. SD-BW1-TI-?87, Basalt Waste Isolation Project, Rockwell Hanford Operations, Richland, Washington.

Zavoshy, S. J., P. L. Chambré, and T. H. Pigford. 1985. "Mass Transfer in a Geologic Environment," In Scientific Basis for Nuclear Waste Management VIII, eds. C. M. Jantzen, J.A. Stone and R. C. Ewing, pp. 311-322. Mate.riaTs Research Society, Pittsburgh, Pennsylvania.

Ziegler, B. P. 1976. Theory of Modeling and Simulation. John Wiley, New York, New York. 
APPENDIX A

CORROSION MODELS 
APPENDIX A

\section{CORROSION MODELS}

The integrity of engineered barriers will play an important role in determining the extent to which radionuclides are contained in or released from a waste repository. Currently, metallic container materials are the primary engineered barriers that meet the U.S. Nuclear Regulatory Commission (NRC) containment performance objectives at all U.S. repository projects. Because corrosion is the principal mode mechanism of degradation for the metallic containers, corrosion rate estimates are required for performance and safety assessment. This appendix describes models that estimate corrosion rates of metallic barriers in important repository-type environments.

\section{A.1 INTRODUCTION}

The term "corrosion" describes a wide variety of complex phenomena involving both chemical and electrochemical interactions between a metal and its environment. Corrosion phenomena depend heavily upon the material and its environment. As a result, the mechanisms of corrosion and the morphology of the corrosion products are very diverse. Corrosion can be uniform or localized, result from applied or residual stresses, or occur because of galvanic coupling with dissimilar materials. Systems which give rise to corrosion products with similar morphologies may also corrode according to very different rate laws because the chemical species involved in corrosion and their reactivities differ. Because of this diversity, it is highly unlikely that a comprehensive corrosion rate equation will be developed. Even the development of a corrosion model for a single material-repository system is not trivial since the environments into which the metallic barriers will be placed have not yet been completely quantified, nor is it well established what they will be like after the hundreds and thousands of years of the repository lifetime. 
The current published approaches to corrosion modeling at all U.S, repository projects are based on empirical models fit to relatively short-term (less than 5-year) corrosion tests. Recently, the technical staff at the NRC (McNeil 1983) and others (Steinler 1986) have questioned whether empirical models will provide a satisfactory basis for performance assessment of the long-term (greater than 100 years) containment/corrosion processes of a nuclear waste package. Because of this reservation and the fact that others are developing empirical corrosion models, the Performance Assessment Scientific Support (PASS) program was requested by the U.S. Department of Energy's (DOE) Office of Geologic Repositories (OGR) to describe the degradation processes with emphasis placed on mechanistic models. With the data base currently available, this approach was found to be more appropriate to some types of corrosion than to others. Mechanistic models ultimately rely on the validity and comprehensiveness of the empirical data on which they are based. Unfortunately, the data bases for most types of corrosion are not sufficiently detailed to permit the development of reliable mechanistic models, particularly models which are applicable to a wide range of conditions and environments.

The models presented here were taken from the literature. The empirical models are, of course, appropriate only to the conditions and environments for which they were developed. The mechanistic models are most accurate when applied to the conditions for which they were derived. But since they are based on a deeper understanding of the chemical origins of the corrosion process (than that obtained on empirical grounds alone), these models can, in principle, be extended to other conditions and environments where similar reaction mechanisms are known to occur. Unfortunately, the current lack of data for requisite mechanistic model parameters in repository situations required that some of these models be modified and that some of the parameters be fitted to empirical data. For these reasons the applicability of the mechanistic models in their present form is probably no more broad than could be expected for empirical corrosion rate equations. However, the statistical approach of the AREST code allows the inclusion of some of the uncertainty inherent in the models themselves by stochastic input of the fitted 
parameters. The sensitivity of the models (and AREST) to the data deficiencies and the importance of these deficiencies can be determined by how the input uncertainties affect the results.

Three specific types of corrosion were considered: uniform corrosion, pitting corrosion, and stress corrosion cracking. Galvanic corrosion, crevice corrosion, hydrogen embrittlement, microbial corrosion, and other possible forms of degradation were not considered at this time. The types of corrosion that were considered were chosen because they represent the most likely modes of degradation in a repository. Other modes may be possible and can be added to the AREST code when necessary. The materials that were considered were limited to low-carbon steels, stainless steels, and zircaloy.

Section A.2 describes the approach taken to describe uniform corrosion. Section A.3 considers pitting corrosion, and Section A.4 deals with stress corrosion cracking. Approximations and limitations for each model are delineated.

\section{A.2 UNIFORM CORROSION MODELS}

Uniform corrosion proceeds to a greater or lesser extent for most metals in most environments. Factors influencing the rate of corrosion include, but are not limited to, the composition of the material under consideration, the environment into which it is placed, the by-products of the corrosion process, and the temperature. The interrelationships between these factors and their effect on the actual chemical process responsible for corrosion are extremely complex. For this reason, it is unlikely that a model for uniform corrosion, based on purely mechanistic grounds could be developed which would be comprehensive enough to include all metals in all environments. Rather, a family of uniform corrosion models might be developed with each member of the family appropriate for a specific set of conditions and environments. Some of these models will be empirical and (where sufficient modeling work has been performed) some will be based on chemical mechanisms. The specific model chosen for corrosion rate estimation would be appropriate for the set of repository conditions under study. As corrosion research under repository conditions continues, resulting models (both empirical and mechanistic) will be 
incorporated into AREST as appropriate. Inclusion may result in the additior of new corrosion modules or modification of existing modules to make them more comprehensive.

The most reliable uniform corrosion rate models currently available are empirical models. A number of these have been ideveloped for carbon steel in chloride-containing environments. Since carbon steel is currently being considered as a candidate for metal barriers for nuclear waste in salt-containirg repositories, a model for the reactions of this metal/environment system should be included in the AREST code as a module for uniform corrosion. In this section, two important empirical models for the corrosion of carbon steel in chloride-containing environments will be discussed. The similarity between these models will be shown and they will be used to develop a uniform corrosion model appropriate for one set of repository conditions. Finally, the relaticnship between this model and an important mechanistic model developed by Chao, Lin, and MacDonald (1981) will be suggested.

\section{A.2.1 Empirical Models}

Posey and Palko (1979) at Oak Ridge National Laboratory published a report on the corrosion of ferrous materials in synthetic geothermal brines. Using a specially designed flow-through autoclave systen, they investigated the influence of $\mathrm{pH}$ (from neutral to moderately acidic) and temperature (up to $200^{\circ} \mathrm{C}$ ) on the corrosion behavior of carbon steel in concentrated chloride solution (4M $\mathrm{NaCl}$ ). The following empirical two-term expression was derived for the corrosion rate:

$$
\begin{aligned}
& { }^{j} \operatorname{corr}=1.90 \times 10^{5} \exp \left(-3.98 \times 10^{3} / \mathrm{T}\right) \\
& +4.19 \times 10^{6}\left(10^{-\mathrm{pH}}\right) \exp \left(-2.10 \times 10^{3} / \mathrm{T}\right)
\end{aligned}
$$

where $j_{\text {corr }}$ is the corrosion rate in mils per year (mpy), and $T$ is the absolute temperature. In the region of near-neutral pH, from about $\mathrm{pH} 5$ to 9 (at $25^{\circ} \mathrm{C}$ ), the corrosion rate is relatively independent of $\mathrm{pH}$ and Equation (A.1) reduces to the following: 


$$
j_{\text {corr }}=1.90 \times 10^{5} \exp \left(-3.98 \times 10^{3} / \mathrm{T}\right)
$$

However, Equation (A.2) is found to give corrosion rates higher than those found by other workers. At $150^{\circ} \mathrm{C}(423 \mathrm{~K})$, for example, Equation (A.2) predicts a corrosion rate equal to 15.6 mpy. This value is significantly larger than corrosion rates determined for carbon steel in similar brine environments by Westerman et al. (1986). At $150^{\circ} \mathrm{C}(423 \mathrm{~K})$, Westerman et al. (1986) found the corrosion rate of A216 steel in anoxic PBB-2 brine(a) equal to 0.575 mpy. The reason for this disparity is probably that the corrosion rates were determined at different times after the experiments were initiated. In general, corrosion rate is a function of time, typically exhibiting large values shortly after the experiment is initiated and decreasing to smaller values over longer time periods. Data collected by Westerman et al. (1986) were taken after $4480 \mathrm{~h}$ $(0.511 \mathrm{yr})$, while the time interval used by Posey and Palko (1979), although unspecified, seems to have been much shorter (less than $8 \mathrm{~h}$ ). Clearly, a more complete corrosion rate equation should include a functional dependence on time.

An empirical equation for calculating corrosion depth that contains an explfcit time dependency was developed by Sastre, Pescatore, and Sullivan (1986) at Brookhaven National Laboratory (BNL). This equation was developed from data for carbon steels over a range of temperatures, brine compositions, and times. While being far from complete, the data base was adequate for generating an approximate corrosion equation which was a function of temperature (between $25^{\circ}$ and $250^{\circ} \mathrm{C}$ ), chloride concentration (between 70 and $169,416 \mathrm{ppm}$ ), oxygen concentration (between 0.03 and $3.0 \mathrm{ppm}$ ), and time (between 0.083 and $16 \mathrm{yr}$ ). This equation, which has been differentiated with respect to time to give an expression for corrosion rate, is shown below:

$$
j_{\text {corr }}=0.689 t^{-0.531} \exp (-1402 / T)(C 1)^{0.543}(0)^{0.2} d
$$

(a) A syntbetic low-magnesium brine containing predominantly NaC1 at 191,000 ppm chloride. 
where $\mathrm{t}=\mathrm{t}$ ime in years

$\mathrm{T}=$ absolute temperature

(C1) = chloride concentration in ppm

(0) = oxygen concentration in ppm

$d=$ experimental parameter which can vary between 0.00147 and 676 .

The wide range for $d$ suggests that the corrosion mechanisms vary widely over the experimental conditions studied. The equation should therefore be used with caution. It is useful however to consider what value of $d$ is required to $f i t$ the equation to data collected recently by Westerman et al. (1986) and Morgan. (a)

Using the corrosion rate found by Westerman et a1. (1986) for A216 steel in PBB-2, and taking $T=432 \mathrm{~K},(\mathrm{Cl})=191,000 \mathrm{ppm},(0)=0.1 \mathrm{ppm}$ for "anoxic" brine, and $t=0.511 \mathrm{yr}$, $d$ is calculated to be 0.0368 . This value is within the range specified by the BNL model. Using this value for d, Equation (A.3) reduces to the following:

$$
j_{\text {Corr }}=0.0254 \mathrm{t}^{-0.531} \exp (-1402 / T)(\mathrm{C} 1)^{0.543}(0)^{0.2}
$$

Under the conditions used by Westerman et a1. (1986), at $423 \mathrm{~K}$, Equation (A.4) reduces further to the following:

$$
j_{\text {corr }}=0.429 \mathrm{t}^{-0.531}
$$

Equation (A.5) is plotted in Figure A.l over a time interval of $1 \mathrm{yr}$.

Recently, corrosion rates were determined by Morgan(a) for A216 steel in PBB-1 (b) brine at $150^{\circ} \mathrm{C}$. These data were obtained at 1,3 , and 6 months. Some

(a) Morgan, L. G. 1987. "Waste Package Program Monthly--Report April 10, 1987," internal report, Pacific Northwest Laboratory, Richland, Washington.

(b) Similar to PBB-2 brine but containing slightly higher levels of contaminants including magnesium. 


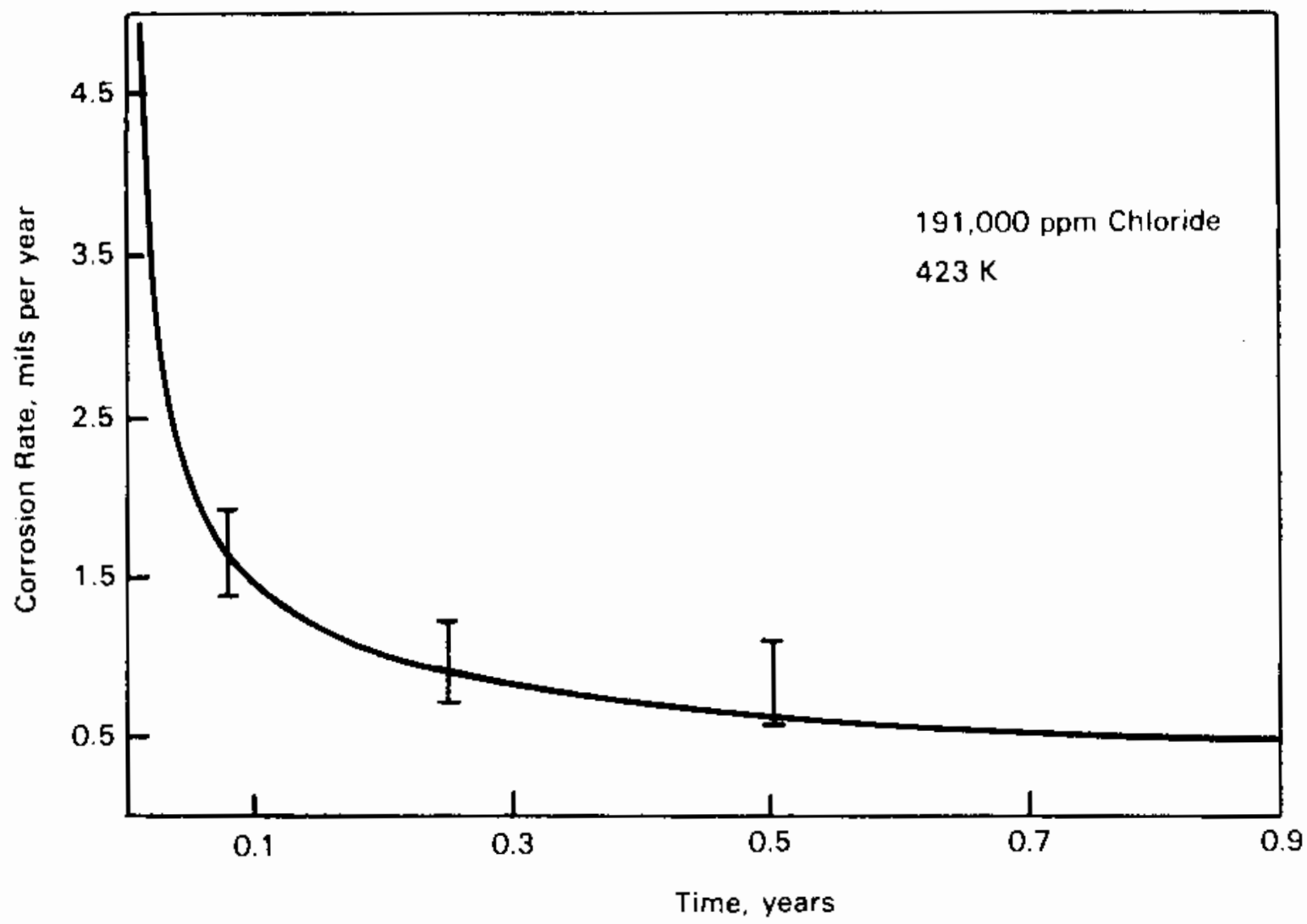

FIGURE A.1. Corrosion Rate for Carbon Steel in Brine Solution

variation in the corrosion rate with material condition (e.g., normalized versus as-cast, lot number, etc.) was observed, but in general the corrosion rate decreased with time over 6 months. "Bars" corresponding to the range of data observed at each time interval are plotted in Figure A.1. The data are consistent with the values predicted by Equation (A.5) between 1 and 6 months.

It is also of interest to determine whether Equation (A.4) is consistent with corrosion data obtained by other workers. In particular, it is important to find out whether the equation is valid at different times and different temperatures. Although $t$ was not specified by Posey and Palko (1979), their data probably were obtained at much shorter times than data collected by Westerman et al. (1986) and Morgan.(a) According to Equation (A.2), Posey and Palko (1979) determined that the corrosion rate of carbon steel in $4 \mathrm{M} \mathrm{NaCl}$ was

(a) Morgan, L. G. 1987. "Waste Package Program Monthly Report--April 10, 1987," internal report, Pacific Northwest Laboratory, Richland, Washington. 
15.6 mpy at $423 \mathrm{~K}$. Using this value for $j_{\text {Corr }} i n$ Equation (A.5) gives $t$ equal to $8.36 \times 10^{-4} \mathrm{yr}$ or $7.3 \mathrm{~h}$. Although $t$ was not specified by the authors, this value is not unrealistic since the data were probably collected over the course of one working day.

Braithwaite and Molecke (1980) reported on corrosion studies conducted at Sandia Laboratories. They found that the corrosion rate of 1018 mild steel at $250^{\circ} \mathrm{C}(532 \mathrm{~K})$ in low-magnesium brine containing $175,000 \mathrm{ppm}$ chloride was 2.75 mpy after 28 days $(0.0767 \mathrm{yr})$. Equation $\left(\mathrm{A}_{\mathrm{A}} 4\right)$ predicts a corrosion rate equal to 3.01 mpy for these conditions. This value is very close to the empirical corrosion rate suggesting that Equation (A.4) is valid at temperatures up to $250^{\circ} \mathrm{C}(523 \mathrm{~K})$ for exposure times of about 1 inch.

For shorter times at temperatures other than $423 \mathrm{~K}$, the empirical model appears to breakdown. Equation (A.2) predicts a corrosion rate equal to $0.301 \mathrm{mpy}$ at $298 \mathrm{~K}$. Assuming $t$ is equal to $7.3 \mathrm{~h}\left(8.36 \times 10^{-4} \mathrm{yr}\right)$ as suggested above, Equation (A.4) predicts a corrosion rate equal to 3.89 mpy. If $t$ were shorter than the assumed $7.3 \mathrm{~h}$, the variance is even greater. At $4 \mathrm{~h}(4.57 \mathrm{x}$ $10^{-4} \mathrm{yr}$ ), Equation (A.4) gives a corrosion rate of $5.36 \mathrm{mpy}$. The error is over an order of magnitude, which suggests the model should not be applied to conditions of both a lower temperature and a shorter time period. The corrosion mechanisms are clearly different in this situation. At $250^{\circ} \mathrm{C}(523 \mathrm{~K})$, Equation (A.2), also predicts a corrosion rate very different than Equation (A.4). The Posey and Palko model (1979) gives a corrosion rate equal to 92.2 mpy while Equation (A.4) gives a value of $29.5 \mathrm{mpy}$ after $7.3 \mathrm{~h}\left(8.36 \times 10^{-4} \mathrm{yr}\right)$. While the percent error is not as significant as for the lower temperature, it is large enough to suggest the model is inadequate at shorter times at any temperature significantly different than $150^{\circ} \mathrm{C}(423 \mathrm{~K})$. Equation (A.4) appears to predict a higher-than-actual corrosion rate at temperatures below $423 \mathrm{~K}$ and a lower-than-actual corrosion rate at temperatures above $423 \mathrm{~K}$.

The discussion above suggests that Equation (A.4) contains an inaccurate dependence on temperature at short time intervals. The model might be made more accurate by expressing d as a function to $T$ in Equation (A.3); however, at this time data are insufficient to do this reliably. 
The use of Equation (A.4) to calculate corrosion rates at significantly longer time intervals (greater than 1 year) has not been completely validated. Sastre, Pescatore, and Sullivan (1986) reported data collected over time intervals up to $16 \mathrm{yr}$, but the long-term data suffered from inconsistencies including the occurrence of pitting corrosion in some samples. Equation (A.4) should therefore be used with caution when applied to time intervals greater than 1 year. However, it seems likely that any model for uniform corrosion which has a logarithmic or negative-exponential relationship with time will give very small corrosion rates at sufficiently long times. For example, using conditions simflar to Westerman et al. (1986) at $100 \mathrm{yr}$, Equation (A.4) predicts a corrosion rate equal to 0.037 mpy.

\section{A.2.2 Mechanistic Models}

The development of a mechanistic model for calculation corrosion rates involves the following steps:

- identify the parameters that effect the corrosion kinetics

- obtain experimental data that show how these parameters affect the corrosion kinetics and derive empirical models based on these relationships

- develop a mechanistic basis for these relationships and use it to develop a new model

- evaluate the mechanistic model by comparing it to empirical models under various experimental conditions

- modify the mechanism as required to make the mechanistic model more correct or more comprehensive.

As indicated previously, a comprehensive mechanistic model for uniform corrosion does not exist at this time. However, many models have been developed for uniform corrosion under very specific sets of conditions. For iron in chloride-containing aqueous environments alone, numerous mechanisms have been proposed to explain corrosion effects (Foley 1970), including the direct reaction between protective oxide films and chloride ions, the invoivement of 
chloride ions in the formation of colloidal corrosion product films, and competitive adsorption between chloride and less aggressive ions or more beneficial (passivating) ions.

Recently, a mechanistic model was developed by Chao, Lin, and MacDonald (1981) describing the growth of passive films. This model leads to a rate of growth equation (for films thicker than 5 angstroms) which has the following. general form:

$$
\text { rate }=[A(T) / T] \exp -B(T) / T]
$$

where $A$ and $B$ are temperature-dependent parameters that are functions of the properties of the passive $f i l m$ and the $f i l m / s o$ ution interface. While Equation (A.6) applies strictly to the rate of film growth, for metals with very low solubility, the rate of film growth may approximate the corrosion rate. This would especially be the case shortly after corrosion is initiated when the passive film is in the process of forming and the corrosion is dominated by faradaic processes and not by dissolution.

Equation (A.6) jllustrates how Equation (A.4) will probably have to be modified to extend its application to shorter time intervals. A more explicit temperature-dependency for the preexponential and also (probably) for the exponential term will have to be incorporated in the corrosion rate expression. of course, to accomplish this with reasonable certainty, a more extensive data base is required.

\section{A.2.3 Uncertainties and Limitations}

The primary limitation to the empirical model discussed above is the lack of an extensive data base. The model is strictly valid only over the range of experimental conditions used in its derivation. The model should be used with caution, in particular it should be determined whether the conditions of interest are sufficiently similar to those in the or: ginal experiments.

Other uncertainties in the model are that the ranges and the distribution of values for the numerical constants in Equation (A.4) are not known at 
present. Morgan (a) indicated that some variation in measured corrosion rates can be expected for the same material (different lot numbers) under the same conditions. Statistical analysis of this variation still remains to be performed.

In addition, the complexity of the corrosion process suggests that other factors may also influence the corrosion rate. Tests using brines with high concentrations of $\mathrm{Mg}^{2+}$ show a dramatic increase in corrosion rate over tests done with low concentrations of $\mathrm{Mg}^{2+}$ (Westerman et al. 1986). The role of specific ions other than $\mathrm{Cl}^{-}$must therefore be addressed. Chemistries associated with a waste repository may also influence the process. Radiation can cause alteration of the groundwater chemistry and result in enhanced corrosion rates (Westerman, Pitman, and Nelson 1982). Modification of the present model may be required to account for these additional effects.

\section{A.3 PITTING CORROSION}

Pitting corrosion is a local phenomenon that can cause rapid penetration of a metallic specimen. Pitting corrosion is initiated by local variations in either the material or the solution in contact with the material. Differences in microstructure of the material, such as grain boundaries or inclusions of second phase particles, are likely spots for the initiation of pitting corrosion. Welds or discontinuous joints in the material may cause the solution to stagnate and may promote crevice corrosion, which is similar in nature to pitting corrosion. Once a pit is initiated, the conditions necessary for pit propagation are sustained and the process becomes autocatalytic. The time and location of pit initiation and growth are essentially random phenomena.

During the formation of a pit, a local environment is produced and sustained that may be very different than that of the bulk solution. The concentrations of reactants and products produces a situation different from that of uniform corrosion. The pit is primarily a site for anodic dissolution of

(a) Morgan, L. G. 1987. "Waste Package Program Monthly Report--April 10, 1987," internal report, Pacific Northwest Laboratory, Richland, Washington. 
the metal, while large portions of the canister may act as a cathode. The very large ratio of cathodic to anodic areas results in rapid metal dissolution.

The model chosen to describe this process is the one given by Stahl and Miller (1985). This model is a simple treatment of a very complex environment within the pit itself. Pitting is treated as a one-dimensional transport process. The corrosion rate is assumed to be limited by the diffusion of the metal cation through a dilute binary electrolyte. The diffusion is driven tiy both concentration and potential gradients. Reactions and reaction rates within the pit are neglected, as is transport of material between the pit ard the environment. The resulting equation is as follows:

$$
\left.\mathrm{dh} / \mathrm{dt}=\frac{\text { M.W. }}{\rho}\left[\left|\frac{z_{+}}{\mathrm{z}}\right|+1\right] 0 \frac{\mathrm{C}_{+}(0)}{\mathrm{h}} \mid \exp \left(\frac{\mathrm{z}-\mathrm{F}}{\mathrm{RT}} \Delta \phi\right)-1\right\}
$$

where $\mathrm{dh} / \mathrm{dt}=$ the rate of pit depth increase $(\mathrm{cm} / \mathrm{s})$

$h=$ the pit depth $(\mathrm{cm})$

M.W. = the molecular weight of the metal $(\mathrm{gm} / \mathrm{mole})$,

$p=$ the density of the metal $\left(\mathrm{gm} / \mathrm{cm}^{3}\right)$

$D=$ the diffusivity of the metal cation in the pit $\left(\mathrm{cm}^{2} / \mathrm{s}\right)$

$z_{+}, z_{-}=$the proton charge on the constituents of the binary electrolyte (equivalents)

$C_{+}(0)=$ the concentration of the cation at the pit opening (mole $/ \mathrm{cm}^{3}$ )

$F=$ the Faraday constant $(96,500$ coulombs/equivalent $)$

$R=$ the ideal gas constant $\left(8.314\right.$ joules/mole- $\left.{ }^{\circ} \mathrm{K}\right)$

$T=$ the temperature $\left({ }^{\circ} \mathrm{K}\right)$,

$\Delta \phi=$ the potential drop along the pit depth (volts)

In the above equation, all of the parameters are defined physical quantities except for $\Delta \phi$ and $C_{+}(0)$. Since the pit solution is markedly different from the bulk solution, a direct connection between $\Delta \phi$ and the environment is difficult to make. In this model, it is assumed to be a constant which may take on a range of values. A suitable value for this quantity is suggested by voltage drop measurements done by Postlethwaite and Onofrei (1979), in which a potential drop of about $20 \mathrm{mV}$ was measured during the pitting of both zircaloy 
and stainless steel. This is of the same order of magnitude as the $9 \mathrm{~m} V$ calculated in a semi-theoretical approach done by Vetter and Strehblow (1974).

The quantity $C_{+}(0)$ will likely depend upon the bulk solution. It will depend in part upon the rate at which this ion is transported away from the pit mouth or is consumed by secondary reactions. Specific aggressive species also play an important role. The assumed form for this quantity will be:

$$
\left.C_{+}(0)=\alpha(1+E h)+\beta[C]^{-}\right]
$$

where $\left[\mathrm{Cl}^{-}\right]$is the concentration of chloride ions in moles $/ \mathrm{cm}^{3}$. The form for the term dependent upon Eh (redox potential) is chosen to insure that $C_{+}(0)$ remains positive. Other specific ions could be added to Equation (A.8) and may be necessary as more data become available.

The form of Equation (A.7) indicates that the pit depth increases as the square root of time for a given set of conditions. Such a dependence is indicative of a diffusion-controlled process and is similar to the $t^{0.49}$ dependence reported by Marsh (1983). Table A.1 lists the numerical values used by the mode1. Ranges for the parameters are estimates based on the fact that pitting rates may vary by an order of magnitude or more.

\section{A.3.1 Uncertainties and Limitations}

The limitations associated with the pitting corrosion model are primarily because of the lack of an adequate data base. One thing that hinders the acquisition of such a data base is the fact that pitting is primarily a statistical phenomenon. As such, sinall-sample, short-term tests may not show a propensity for pitting when in fact it may be a possibility. Furthermore, rates determined from tests on small samples may not be accurate when applied to large-scale structures. Longer-term tests on full-scale specimens must be done to get a better indication of the possible distribution functions associated with pit initiation and extent.

The present model also represents a very simplified method for treating the pitting phenomena. The single species, one-dimensional transport theory, may represent an oversimplification of the actual processes. Multidimensional 
TABLE A.1. Values Used in Pitting Corrosion Model for Ferrous Materials

$$
\begin{aligned}
& \frac{d h}{d t}=\frac{M_{\cdot} W_{0}}{p}\left[\mid \frac{z_{+}}{z_{-}}+1\right] D \frac{a(1+E h)+\beta[C 1-]}{h}\left\{\exp \left(\frac{z_{-} F}{R T} \Delta \phi\right)-1\right\} \\
& \text { M.H. }=55.8 \mathrm{gm} / \mathrm{mole}(\mathrm{Fe}) \\
& \rho=7.86 \mathrm{gm} / \mathrm{cm}^{3}(\mathrm{Fe}) \\
& D=5.0 \cdot 10^{-6} \mathrm{~cm}^{2} / \mathrm{sec}\left(\mathrm{Fe}^{2+} \text { in } 1 \mathrm{~N} \mathrm{H}_{2} \mathrm{SO}_{44}\right)^{(\mathrm{a})} \\
& z_{+}=2\left\langle\mathrm{Fe}^{2+}\right\rangle \\
& z_{-}=-1\left(\mathrm{Cl}^{-}\right) \\
& \Delta \phi=-0.02 \text { volts }(b) \text { (estimated range: }-0.01 \text { to }-0.04 \text { volts) } \\
& \alpha=2.47 \cdot 10^{-5(c)}
\end{aligned}
$$

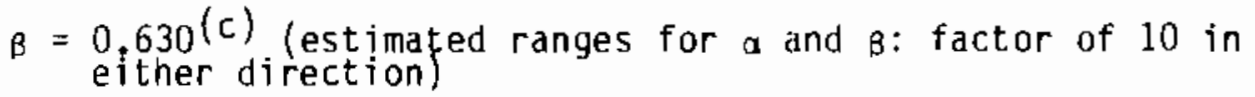

(a) Vetter and Strehblow (1974).

(b) Postlethwaite and Onofrei (1979).

(c) Calculated from pitting data in Miller and Stahl (1984) and Marsh (1983).

transport theories with secondary reactions (e.g., Sharland and Tasker 1985), would probably give a better indication of the actual pitting rates to be expected, but such complications are difficult to quantify at present.

Certain threshold values govern the pitting process, including a certain electrochemical potential or a minimum concentration of some active anion such as chloride. Since these quantities are $i 11$ defined with respect to repository conditions, it is conservatively assumed that pitting proceeds under all conditions.

The numbers presented apply to a generic steel and do not make a distinction between a low-carbon steel and a stainless steel, even though stainless steel is less susceptible to pitting. The values calculated for the required parameters are based on a very limited data base. Because pitting corrosion data show such wide variations, ranges were estimated for some of the parameters to partially account for this phenomenon. Pitting data were not available for zircaloy, so no numbers can be given for this case. However, it can be pointed out that zircaloy is not overly susceptible to pitting in most 
applications. This is not to suggest that pitting will not occur in zircaloy under repository conditions, but indicates that it may be less likely in this material than in a steel.

\section{A.4 STRESS CORROSION CRACKING}

The stress corrosion cracking (SCC) process occurs under the combined influence of both a corrosive environment and a tensile stress. Tensile stresses are likely to occur in a repository because of lithostatic or hydrostatic loads, residual stress developed during fabrication, or stresses that may be imposed on the material by accident.

The process of SCC is modeled as a step-like process whereby a tensile stress causes fracture of a relatively brittle, passive film on the material, followed by rapid dissolution of the metal. As the anodic dissolution of the metal proceeds, a new passive layer is built up at the crack tip. The stress again fractures the layer, and the process repeats itself. Thus, SCC can be considered to be a repetitive occurrence of passive layer fracture and healing. The rate at which SCC occurs is dependent upon the stress level to which the material is subjected and also the passivation rate of the material in the given environment.

A general form for the SCC rate equation is given below:

$$
v=L_{f} / t_{f}=p Q_{f} / t_{f}
$$

where $v=$ the crack tip velocity $(\mathrm{m} / \mathrm{s})$,

$L_{f}=$ the depth of metal lost between oxide rupture events $(m)$,

$t_{f}=$ the time between oxide rupture events $(s)$,

$Q_{f}=$ the amount of electric charge associated with $L_{f}$ (coulombs $/ m^{2}$ ), and

$p=a$ Faradaic constant $\left(\mathrm{m}^{3} /\right.$ coulomb)

Different interpretations of these parameters result in various theories for predicting the rate of SCC. A development in terms of stress intensities 
is used here (Newman 1981). An alternate approach in terms of strain rates was used by ford (1982), but calculation of strain rates would be even more dif $i$ cult than estimating stress levels.

Newman's (1981) work indicates that $Q_{f}$ is relatively insensitive to the? environment but depends upon the level of stress. $A \cong^{-1}$ dependency can be predicted ( $\cong$ is the stress intensity) on the basis of a simple linear elast $c$. analysis of the crack tip. The quantity $t_{f}$ is environmentally dependent, as it is a function of the passivation rate of the material.

The prediction of a crack tip velocity is accomplished by the following process. The amount of charge accumulation between oxide rupture events at a given stress intensity is determined experimentally. For a specific set of environmental conditions, the time required for a charge of this amount to accumulate is also determined. These two quantities then give the crack tif velocity by insertion into Equation (A.9).

The functional dependence of the crack tip velocity versus the stress intensity predicted by this model is of a form commonly encountered in SCC as shown in Figure A.2. A rapid increase in crack tip velocity is noted for small increases in stress intensity until a plateau is reached. At still higher stress intensities, the crack tip velocity again increases rapidly as the strength limits of the material are reached.

The model also indirectly predicts a threshold stress intensity below which crack propagation does not occur. This point is defined to be the point where the crack tip velocity is equal to the rate of uniform corrosion for the given conditions. If the crack tip velocity is found to be below the rate of uniform corrosion, then the passive film will be physically healed faster than it could be fractured and the crack tip will not advance.

Table A.2 indicates the values used for the SCC model. These values are appropriate for the conditions used by Newman (1981) and may not be representative of a repository environment. Figure A.3 shows the crack depth as a function of time for $3 \% C_{r}-M o$ steel at a constant applied stress leve 1. 


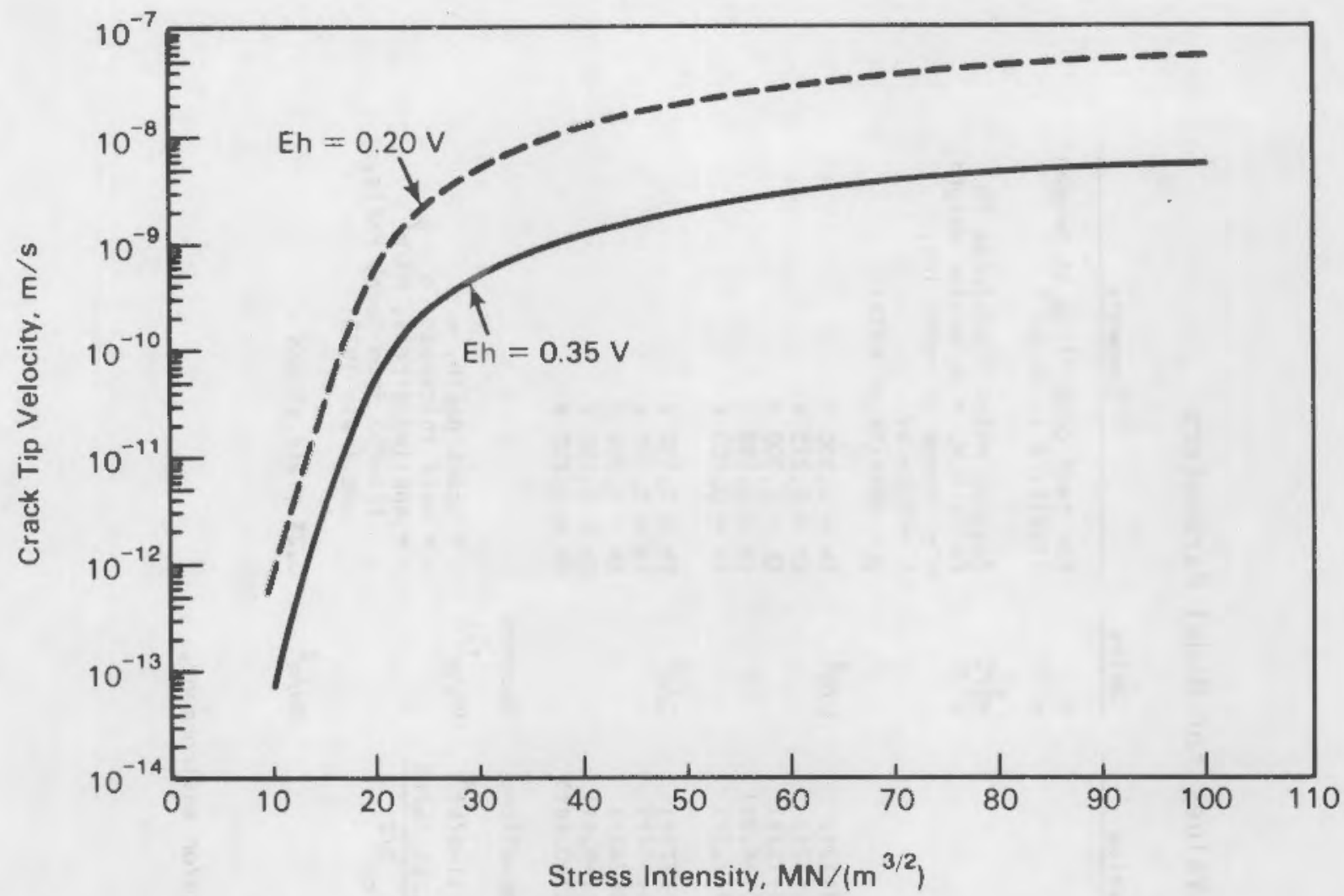

FIGURE A.2. Variation in Crack Tip Velocity with Changes in Stress Intensity

\section{A.4.1 Uncertainties and Limitations}

The primary inadequacy of the proposed model is the lack of repositoryspecific data. The possibility of SCC has been demonstrated by the work of Tashiro (1982), who found some evidence of SCC in certain stainless steels when chloride concentrations were found in the test solution. Zircaloy is known to be susceptible to SCC in the presence of iodine (Hofmann and Spino 1983) and ferric chloride (Hamner 1974). The SCC of zircaloy has not been quantified in this effort.

The specific numerical values given for this model (Newman 1981) are from a caustic solution known to produce SCC in ferrous materials and may therefore overestimate the susceptibility of the materials to SCC. The values may also overestimate the crack propagation rate. Data are needed, primarily for the rate of charge accumulation under the specific repository conditions as a 
TABLE A.2. Numerical Values for Model Parameters

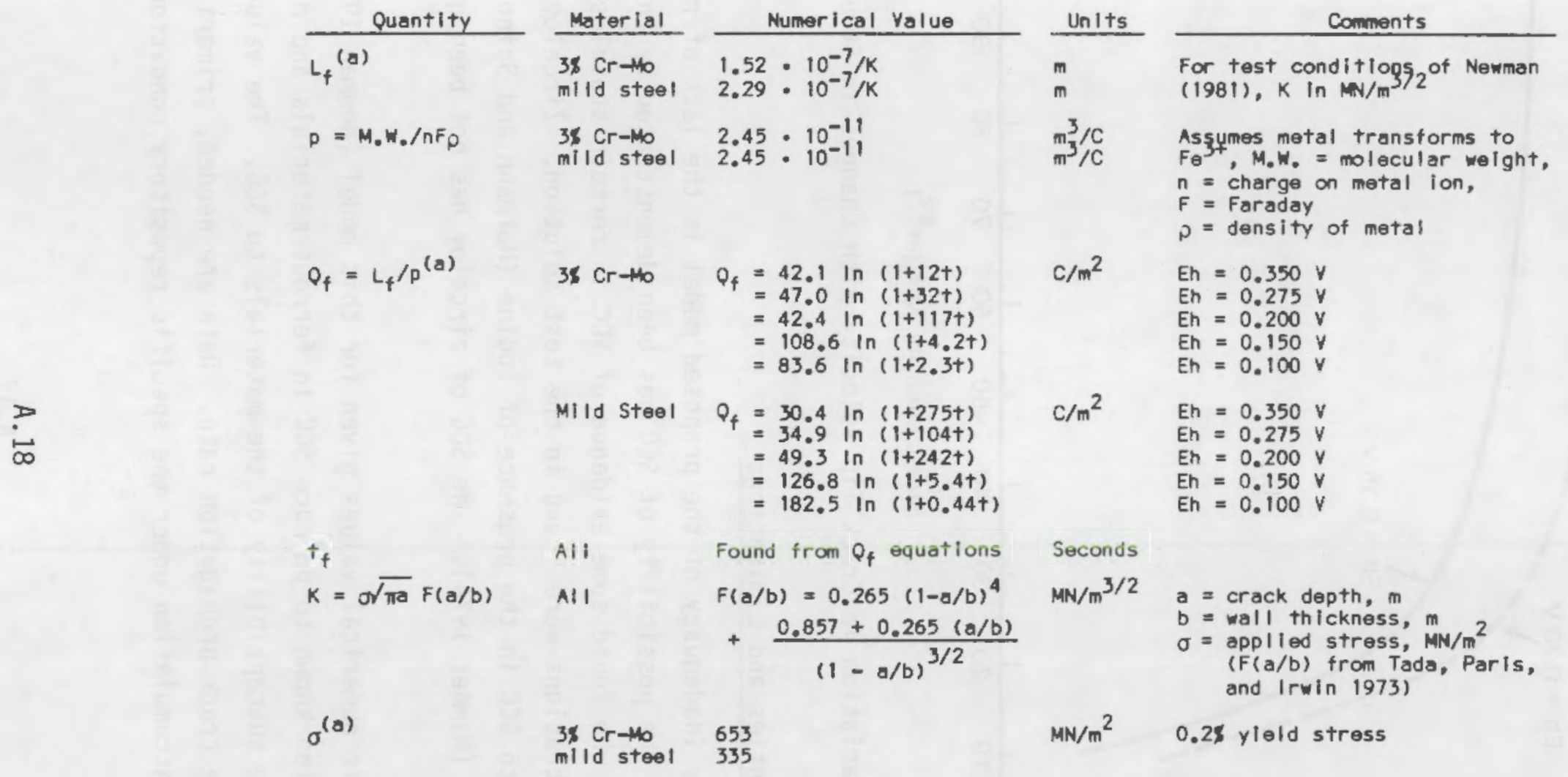

(a) These quantities will vary with material and/or environment. 


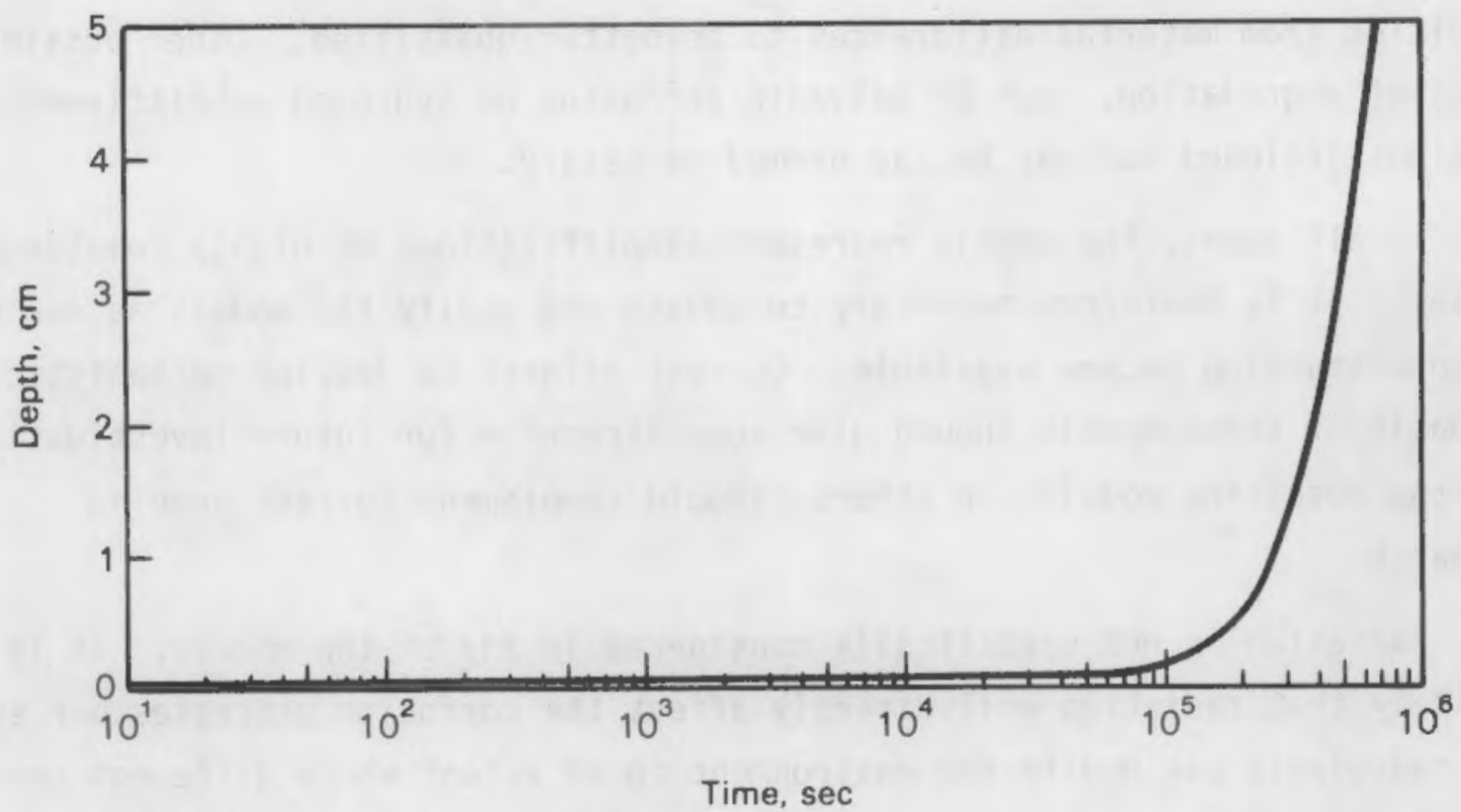

FIGURE A.3. Predicted Crack Depth as a Function of Time for $3 \% \mathrm{Cr}-$ Mo in a Caustic Environment

function of Eh. Such data would serve to validate the applicability of the model. An estimate of the time-dependent stress levels which may be expected would also benefit the model.

A distinction is not made in this model between intergranular and transgranular SCC. Deep cracks may be under a diffusion-controlled mechanism as noted by Ford (1982). The relationship between SCC and pitting corrosion has not been adequately delineated by the model. These comments suggest directions for future improvement of the model.

\section{A.5 SUMMARY}

The models described above represent attempts to estimate the rate at which waste package canisters may degrade by various modes. The types of degradation considered were uniform corrosion, pitting corrosion, and SCC. Data were not available to quantify all of the models with respect to the three materials considered (low-carbon steel, stainless steel, and zircaloy). However, additional data would allow extension of the models to consider other materials. Such information would also enable corrosion rate variations 
resulting from material differences to be better quantified. Other possible modes of degradation, such as galvanic corrosion or hydrogen embrittlement, were not included but may be, as deemed necessary.

In all cases, the models represent simplifications of highly complex processes. It is therefore necessary to update and modify the models as new data or understanding become available. Current efforts to develop mechanistic emphasis of these models should give some direction for future investigations and the resulting models, or others, should complement current ongoing research.

Radiation is not specifically considered in any of the models. It is unlikely that radiation will directly affect the corrosion processes per se, but radiolysis can modify the environment to an extent where different corrosion rates are observed. The assessment of the effects of radiation is an important step in the analysis of the corrosion of waste package canisters.

The models are presently not coupled. Such coupling complicates the statistical treatment of the canister degradation. However, a synergistic relationship between the various forms of corrosion may exist and the presence of one type of degradation may inhibit or enhance other types of corrosion. Such a complex issue is not resolved easily, but the consequences of such relationships deserve some attention.

The primary emphasis in future work should be the acquisition of repository-specific data. In many instances, it is difficult to apply the models presented here to the existing data because the parameters specific to the models are generally not reported. Tests should be developed using models of the corrosion process as guidance in an effort to increase basic understanding as well as to provide a more defensible position concerning corrosion estimates.

\section{A.6 REFERENCES}

Braithwaite, J. W., and M. A. Molecke. 1980. "Nuclear Waste Canister Corrosion Studies Pertinent to Geologic Isolation", Nuclear and Chemical Waste Management 1:37-50. 
Chao, C. Y., L. F. Lin, and D. D. McDonald. 1981. "A Point Defect Model for Anodic Passive Films, I. Film Growth Kinetics." Electrochemical Science and Technology 128(6): 1187-1194.

Foley, R. T. 1970. "Role of the Chloride Ion In Iron Corrosion." Corrosion $26(2): 58-79$.

Ford, F. P. 1982. Mechanisms of Environmental Cracking in Systems Peculiar to the Power Generation Industry. EPRI NP-2589, Electric Power Research

Institute, prepared by General Electric, Schenectady, New York.

Hamner, N. E. 1974. Corrosion Data Survey: Metals Section. 5th ed. National Association of Corrosion Engineers (NACE), Houston, Texas.

Hofmann, P., and J. Spino. 1983. Stress Corrosion Cracking Failure Behavior of Zircaloy-4 Tubing at Elevated Temperatures. KfK 3506, Kraftwerk Union, Erlangen, Federal Republic of Germany.

Marsh, G. P. 1983. "Carbon Steel Canister for the Containment of Nuclear Wastes," in Transactions of the American Nuclear Society 45:292 (Abstract).

McNei1, M. B. 1983. "Fundamental Problems in General and Pitting Corrosion of Iron and Low-Carbon Steel Containers Under Conditions Expected in Basalt and Salt HLW Repository Environments," Transactions of the American Nuclear Society 45:292-293 (Abstract).

Miller, S., and D. Stahl. 1984. Long-Term Performance of Materials Used for High Level Waste Packaging, NUREG/CR-3427, VoT. 3., U.S. Nuclear Regulatory Commission, Washington, D.C.

Newman, J. F. 1981. "The Stress Corrosion of Steel in Sodium Hydroxide Solution: A Film Rupture Model." Corrosion Science 21(7):487-503.

Posey, F. A., and A. A. Palko. 1979. "Corrosivity of Carbon Steel in Concentrated Chloride Solution." Corrosion 35(1):38-43.

Postlethwaite, J., and M. Onofrei. 1979. "Hydrogen Evolution and Anodic Disintegration During Electrochemical Pitting of Zirconium in AlkalineChloride Solutions." Corrosion 27(4):185-189.

Sastre, C., C. Pescatore, and T. Sullivan. 1986. Waste Package Reliability. BNL-NUREG-51953, Brookhaven National Laboratory, Upton, New York.

Sharland, S. M., and P. W. Tasker. 1985. A Mathematical Model of Crevice Corrosion DOE/RW/85/112, Department of the Environment, Theoretical Physics Division, Harwell Laboratory, United Kingdom.

Stahl, D., and N. E. Miller, compilers. 1985. Long-Term Performance of Materials Used for High-Level Waste Packaging. NUREG/CR-3900, VoT. 4, U.S. NucTear Regulatory Commission, Washington, D.C. 
Steinler, M. (Chairman, Materials Review Board) 1986. Review of Repository Projects Corrosion Programs, Ad-Hoc Committee for Corrosion. U.S. Department of Energy, Washington, D.C.

Tada, T., P. Paris, and G. Irwin. 1973. The Stress Analys is of Cracks Handbook. Del Research Corporation, St. Louis, Missouri.

Tashiro, S., ed. 1982. Progress Report on Safety Research of High-Level Waste Management for the Period April 1981 to March 1982. JAERI-M 82-145, Division. of Environmental Safety Research, Tokai Research Establishment, Japan Atomic Energy Research Institute.

Vetter, K., and H. Strehblow. 1974. "Pitting Corrosion in an Early Stage and Its Theoretical Implications." Localized Corrosion, Vol. 3, pp. 240-251. National Association of Corrosion Engineers (NACE) Houston, Texas.

Westerman, R. E., S. G. Pitman, and J. L. Nelson. 1982. General Corrosion, Irradiation-Corrosion, and Environmental-Mechanical Evaluation of Nuclear Waste Package Structural Barrier Materials. PNL-4364, Pacific Northwest Laboratory, Richland, Washington.

Westerman, R. E., J. H. Haberman, S. G. Pitman, B. A. Pulsipher, L. A. Sigalla. 1986. Annual Report--FY 1984. Corrosion and EnvironmentMechanical Characterization of Iron-Base Nuclear Waste Package Structural Barrier Materials. PNL-5426, Pacific Northwest Laboratory, Richland, Washington. 
APPENDIX B

THERMAL MODELS FOR SPENT FUEL 
APPENDIX B

\section{THERMAL MODELS FOR SPENT FUEL}

Spent-fuel thermal models have been developed to estimate the timedependent behavior and distribution of container temperatures for each of the repository designs. A three-step approach is used to separately evaluate the time-dependent behavior and spacial variability.

First, spent-fuel container temperatures are evaluated with multidimensional heat conduction models for each of the conceptual repository designs. Second, spent-fuel receipt characteristics are evaluated with a spent-fuel management system logistics model for an assumed repository receipt scenario. Third, the distributions of container temperatures are evaluated with the AREST model.

The AREST model bases the distribution of container temperatures on the initial heat-generation rate distribution of spent-fuel receipts and the difference between container and repository average temperatures. This approach provides a simple approximation for the container temperature distributions based on the design's spent-fuel description. An important assumption is that the design of the waste package or underground facility is not changed to accommodate spent-fuel of variable heat-generation rates. In addition, this approach does not account for many other important factors which impact both the magnitude and distribution of spent-fuel container temperatures in the repository. More rigorous approaches were judged to be inappropriate for the current version of the AREST model. The container temperature distributions, however they are generated, are easily incorporated into the AREST model. The following provides a detailed description of the spent-fuel thermal models and recommendations for further study.

\section{B.1 SPENT-FUEL CONTAINER TEMPERATURES}

The spent-fuel container temperature histories are evaluated with waste package and repository scale models using the ANSYS finite element code 
(Swanson Analysis Systems, Inc. 1986). ANSYS is a widely used, general purpose finite element code with both structural and thermal capabilities. The code is able to treat steady-state as well as transient-loading conditions and temperature-dependent material properties. Three-dimensional waste package scale models are used to estimate near-term (i.e. less than 1000 years) temperatures. One-dimensional repository scale models are used to estimate the repository average temperatures. The repository average temperatures are linked to the container temperatures to estimate long-term (i.e. greater than 1000 years) temperatures. This approach has been used by the Basalt Waste Isolation Program (BWIP) (Altenhofen 1981) to estimate long-term temperatures of the waste package component in support of design development, material testing and site characterization activities.

\section{B.1.1 Assumptions}

Several assumptions for developing the waste package and repository scale models are important for estimating the time-dependent behavior of container temperatures. For the waste package scale model, adiabatic conditions can be modeled at the midplanes between emplacement rooms and between individual boreholes. Modeling of adiabatic conditions, coupled with the symmetry of the cylindrical waste containers allows the use of a quarter symmetry waste package scale model of the container and the surrounding rock. For the repository scale model, a one-dimensional grid simulates an infinite array of emplaced waste packages in semi-infinite media.

The first assumption is that the spent fuel containers have the same heatgeneration rate characteristics throughout the repository. For the repository scale model, it is important that the spent-fuel heat generation rate is based on the average age and exposure characteristics of the spent-fuel receipts such that average repository temperatures are produced. In this case, spent-fuel from a pressurized water reactor (PWR) aged 10 years and an exposure of 33,000 MWd/MTU is used. Simultaneous emplacement of the waste package containers and room backfill is assumed although under the current emplacement schedule, the spent fuel is emplaced over a 25-year period.

The key assumption for developing container temperature distributions is that the container diameter and emplacement density are fixed throughout the 
repository. Constant waste loading allows the AREST model to base the distribution of container temperature on the initial heat generation rate distribution of spent-fuel receipts and the difference between container and repository average temperatures. Given a wide variation in spent-fuel receipt characteristics, the repository designers may choose to vary the container diameter and emplacement density to improve costs. This assumption tends to overestimate the distribution of temperatures if the design is constrained by limiting temperature requirements.

In most cases, the assumptions used in this analysis tend to overestimate the magnitude and distribution of container temperatures. The assumptions are needed to simplify the approach such that it can be applied to each of the repository media. The development of three-dimensional room and repository scale models are required to eliminate many of these assumptions. Given the current input data needs for the AREST model, these simplifying assumptions appear to be reasonable.

\section{B.1.2 Data}

The data used in to estimate spent-fuel container temperatures are based on the best available information cited in the literature ${ }^{(a)}$ (Gilbert/ Commonwealth, Inc. 1986; 0'Neal et al. 1984). Some of the draft literature will soon be released. The repositories are in various stages of advanced conceptual design. The conceptual design parameters, material thermal properties, and heat generation rate data used in the thermal analysis are given in Tables B.1 through B.3.

\section{B.1.4 Methodology}

The finite element grids for the three-dimensional waste package scale model are shown in Figures B.1 and B.2 for each of the repository waste emplacement concepts. The grid for the waste package scale model is the smal1est volume element that is representative of the waste package emplacement

(a) Westinghouse Electric Corporation. 1986. Waste Package Conceptual Designs for a Repository in Salt. Draft Report BMI/ONWI-517, prepared for 0ffice of Nuclear Waste Isolation, Battelle Memorial Institute, Columbus, Ohio. 
TABLE B.1. Repository Material Properties

\begin{tabular}{|c|c|c|c|}
\hline Item & $\begin{array}{l}\text { Density, } \\
\mathrm{kg} / \mathrm{m}\end{array}$ & $\begin{array}{c}\text { Conductivity, } \\
w / \pi^{\circ} \mathrm{C}\end{array}$ & $\begin{array}{c}\text { Speclf Ic Heat, } \\
\mathrm{kJ} / \mathrm{kg}^{\circ}{ }^{\circ} \mathrm{C}\end{array}$ \\
\hline \multicolumn{4}{|l|}{ Basalt Model } \\
\hline Basalt & 2840.0 & 1.60 & 0.837 \\
\hline Backfill & 1800.0 & 0.55 & 0.615 \\
\hline Contalner & 5000.0 & 0.58 & 0.3 \\
\hline & & 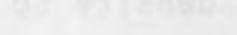 & \\
\hline \multicolumn{4}{|l|}{ Tuff Model } \\
\hline Tuff & 2244.0 & 1.80 & 0.971 \\
\hline BackfIII & 1500.0 & 0.65 & 0.689 \\
\hline Container & 5000.0 & 0.58 & 0.3 \\
\hline \multicolumn{4}{|l|}{ Salt Model } \\
\hline Salt & 2190.0 & 4.00 & 0.912 \\
\hline Backfill & 1519.0 & 0.40 & 0.912 \\
\hline Container & 5000.0 & 0.58 & 0.3 \\
\hline
\end{tabular}

TABLE B.2. Repository Waste Package Design Parameters

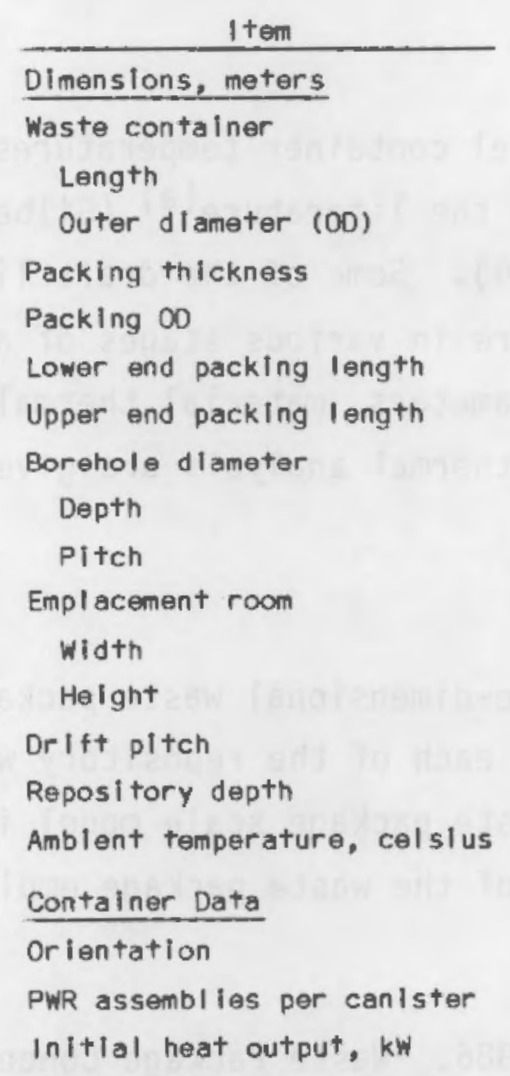

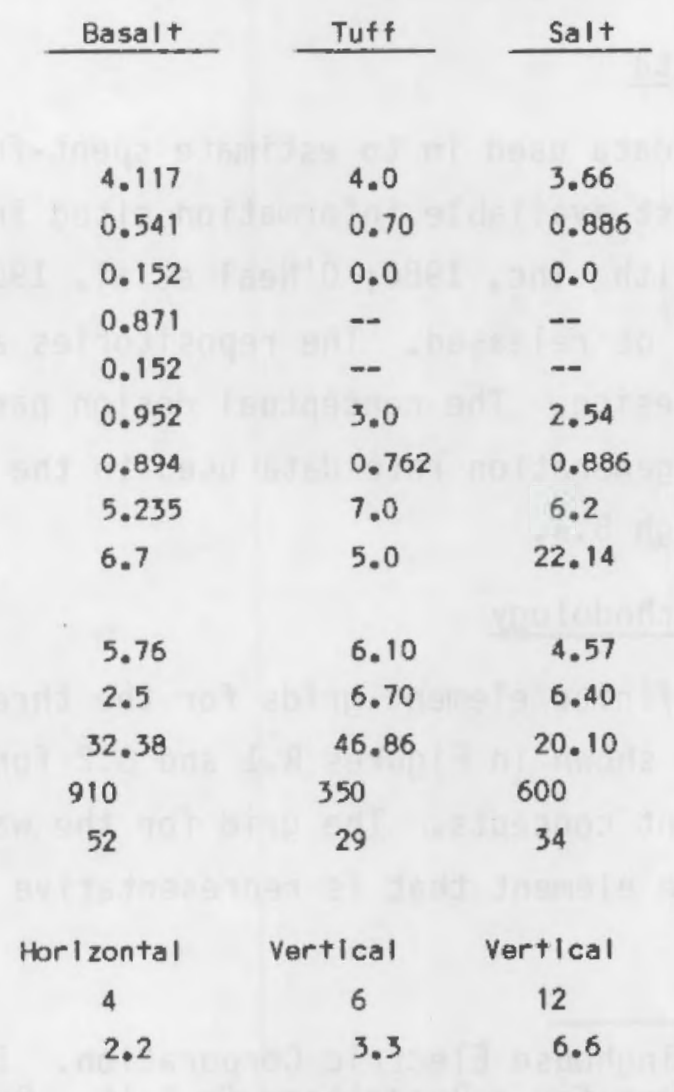


TABLE B.3. Normalized Decay Heat Data for Consolidated Spent Fuel (10 years out of reactor).

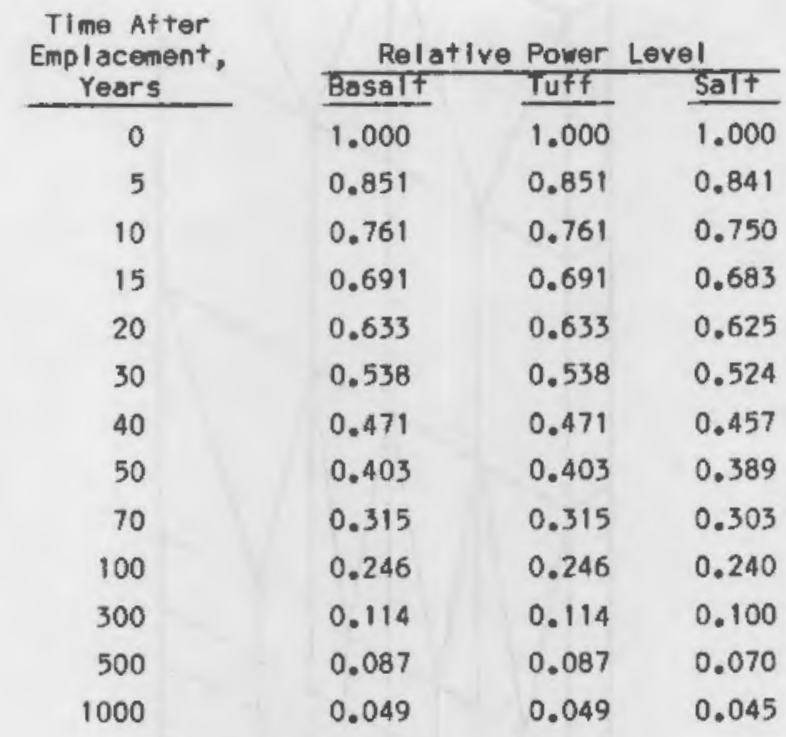

concept. The spent fuel and container are homogenized into a single region with equivalent material thermal properties and thermal load characteristics. Depending on the emplacement geometry, the unit cell encompasses a fraction of a waste package container with adiabatic boundary conditions imposed at the midplanes of symmetry.

The waste package scale models used a technique known as finite element substructuring to include the thermal effects of the far-field regions of the repository, but focus the detailed thermal calculations on the area around the canister. Substructuring is a matrix condensation technique that reduces the computational time required. Since the transient thermal problem requires an iterative solution, the time savings is compounded by the number of iterations required. By suhstructuring the repository models, they could be reduced to a manageable size and still provide an accurate thermal solution near the borehole.

In each of the waste package scale models, the area away from the canister was defined as a substructure. A substructure is similar to a normal finite element model in that it is constructed of many elements. However, before the detailed thermal calculations are made, an intermediate run is required to 


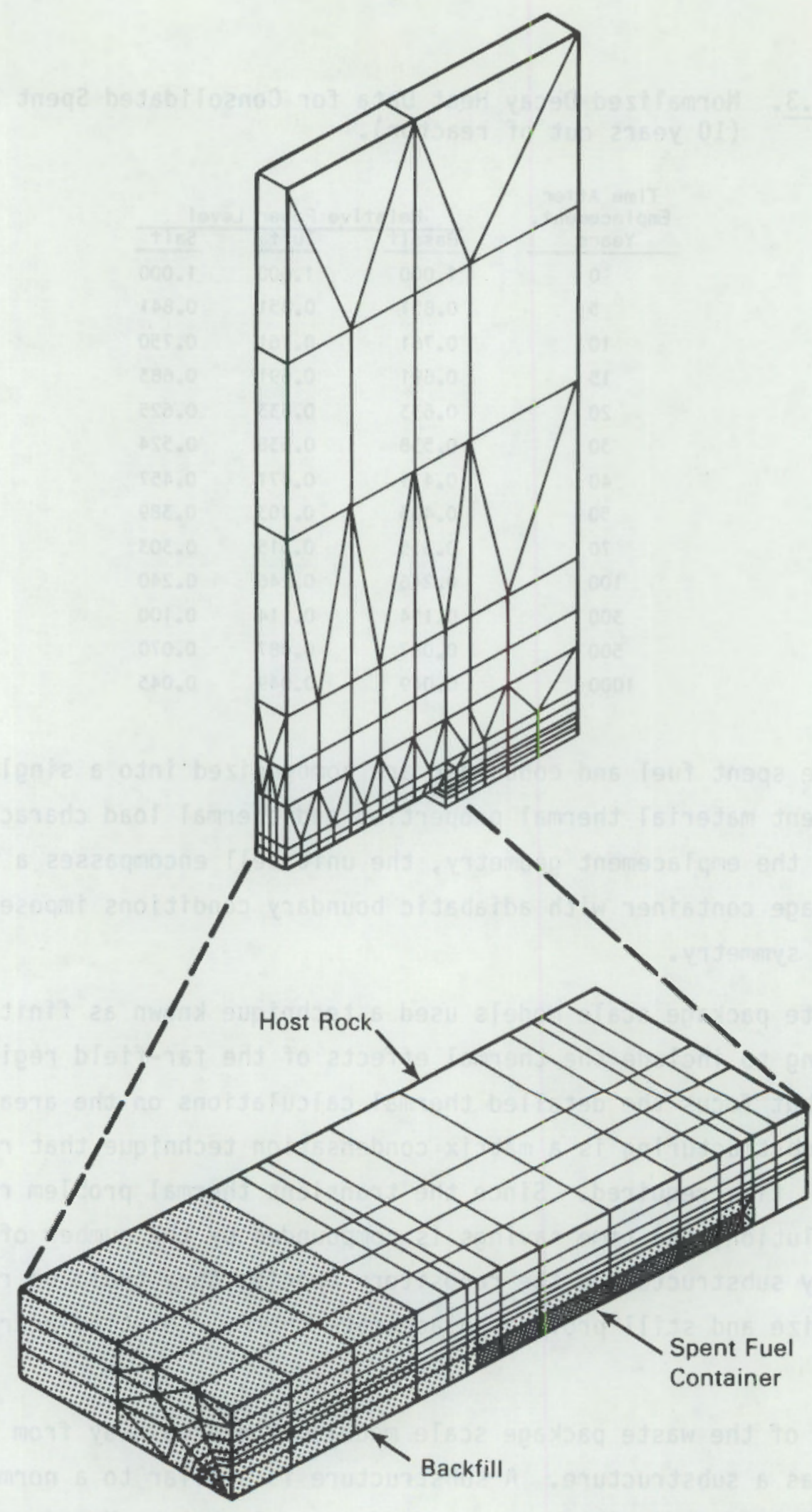

FIGURE B.1. Waste Package Scale Finite Element Model Grid for BWIP Reference Design - Horizontal Emplacement Concept 


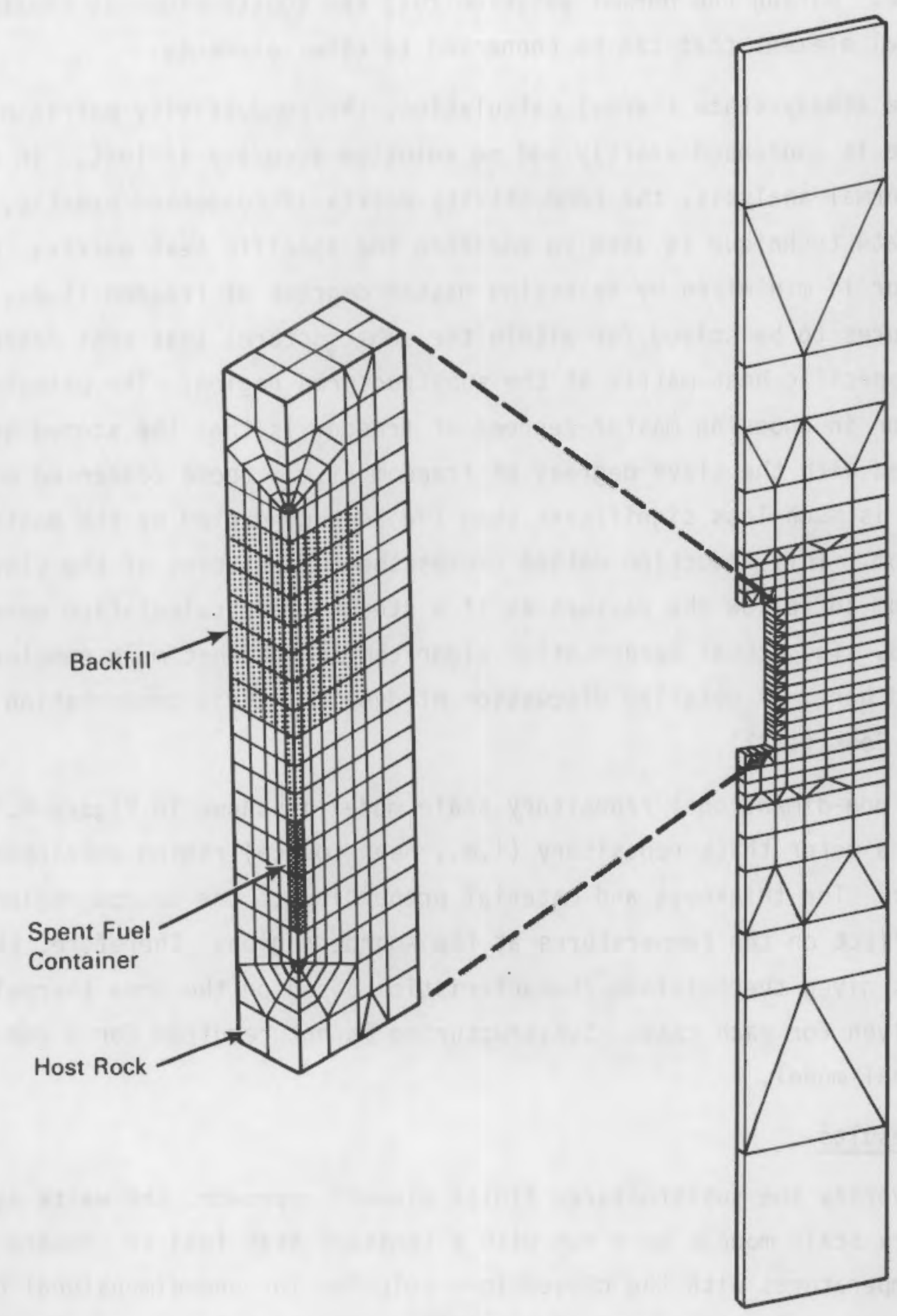

FIGURE B.2. Waste Package Scale Finite Element Model Grid for the Nevada Nuclear Waste Isolation Project (NNWSI) and the Salt Repository Project (SRP) Reference Designs - Vertical Emplacement Concept 
reduce the number of internal degrees of freedom to be solved within the substructure. During the normal solution run, the substructure is treated as an individual element that can be connected to other elements.

In a steady-state thermal calculation, the conductivity matrix of the sub- structure is condensed exactly and no solution accuracy is lost. In a transient thermal analysis, the conductivity matrix is condensed exactly, but an approximate technique is used to condense the specific heat matrix. Calculation error is minimized by selecting master degrees of freedom (i.e., those temperatures to be solved for within the substructure) that best describe the reduced specific heat matrix of the substructured region. The principal assumption in choosing master degrees of freedom is that the stored heat associated with the slave degrees of freedom (i.e., those condensed out of the problem) is much less significant than the heat conducted by the master degrees of freedom. This reduction method causes the temperatures of the slave degrees of freedom to follow the masters as if a steady-state calculation were being performed. The actual condensation algorithm is somewhat more complex than is indicated here. A detailed discussion of dynamic matrix condensation can be found in Cook (1981).

The one-dimensional repository scale model is shown in Figure B.3 and consists of a meter thick repository (i.e., heat source) region enveloped by the host rock. The thickness and material properties of the source region have little effect on the temperatures at the source region. Therefore, the source region is given thermal-load characteristics based on the area thermal-load values given for each case. Substructuring is not required for a onedimensional model.

\section{B.1.5 Results}

To verify the substructured finite element approach, the waste package and repository scale models were run with a constant heat load to compare the farfield temperatures with the closed form solution for one-dimensional heat flow in a half plane (Carlslaw and Jaeger 1959). Figure B.4 compares the temperature rise of the two finite element models (assuming a constant heat flux) with the theoretical solution at a distance 20 meters above the centerline of the waste canister. Figure B.4 shows that the finite element solutions give 


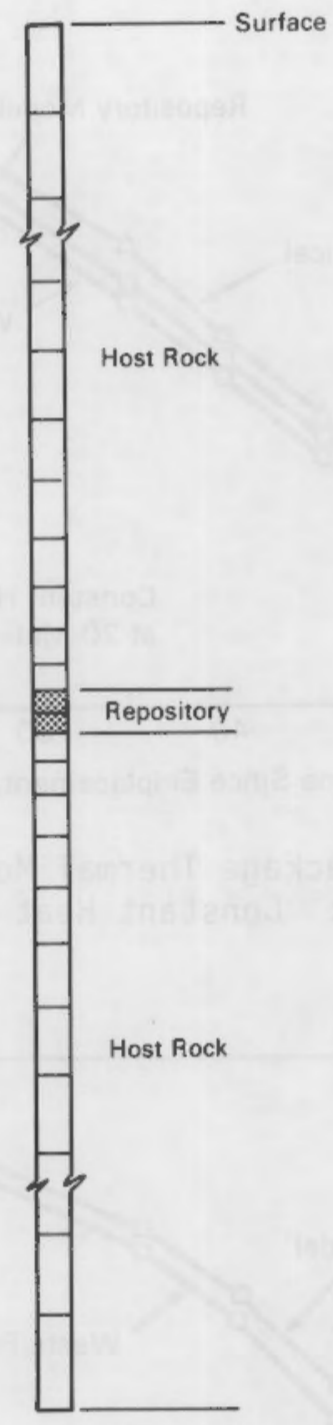

FIGURE B.3. Repository Scale Finite Element Grid

results within $10 \%$ of the theoretical solution. Figure $B .5$ compares the two finite element models under the transient heat load conditions from the spent fuel data. This level of agreement verifies the substructured finite element approach used to model the waste package.

The results of the waste package and repository scale models are shown in Figures B. 6 through B. 8 for each of the repository media. These results are in reasonable agreement with the waste package temperature estimates reported by 


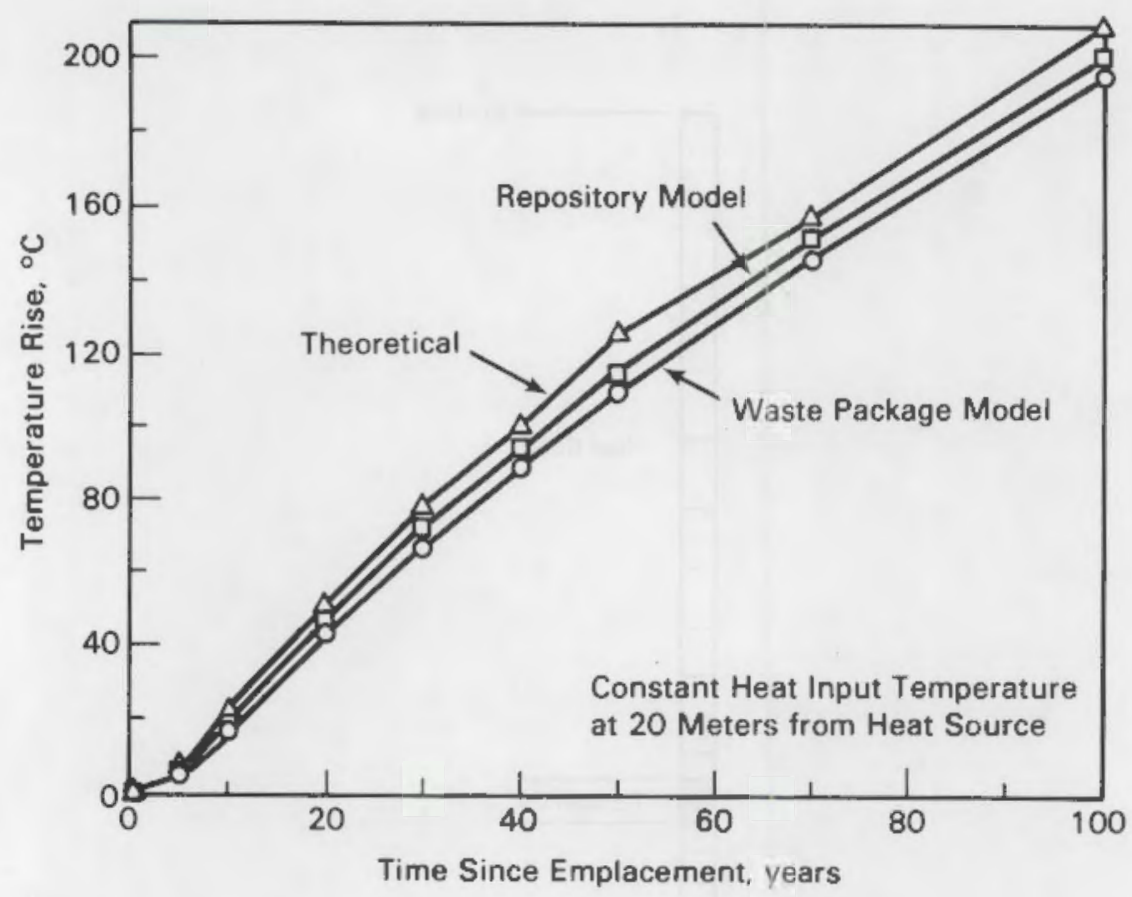

FIGURE B.4. Waste Package Thermal Model Verification Test Results: Constant Heat Input

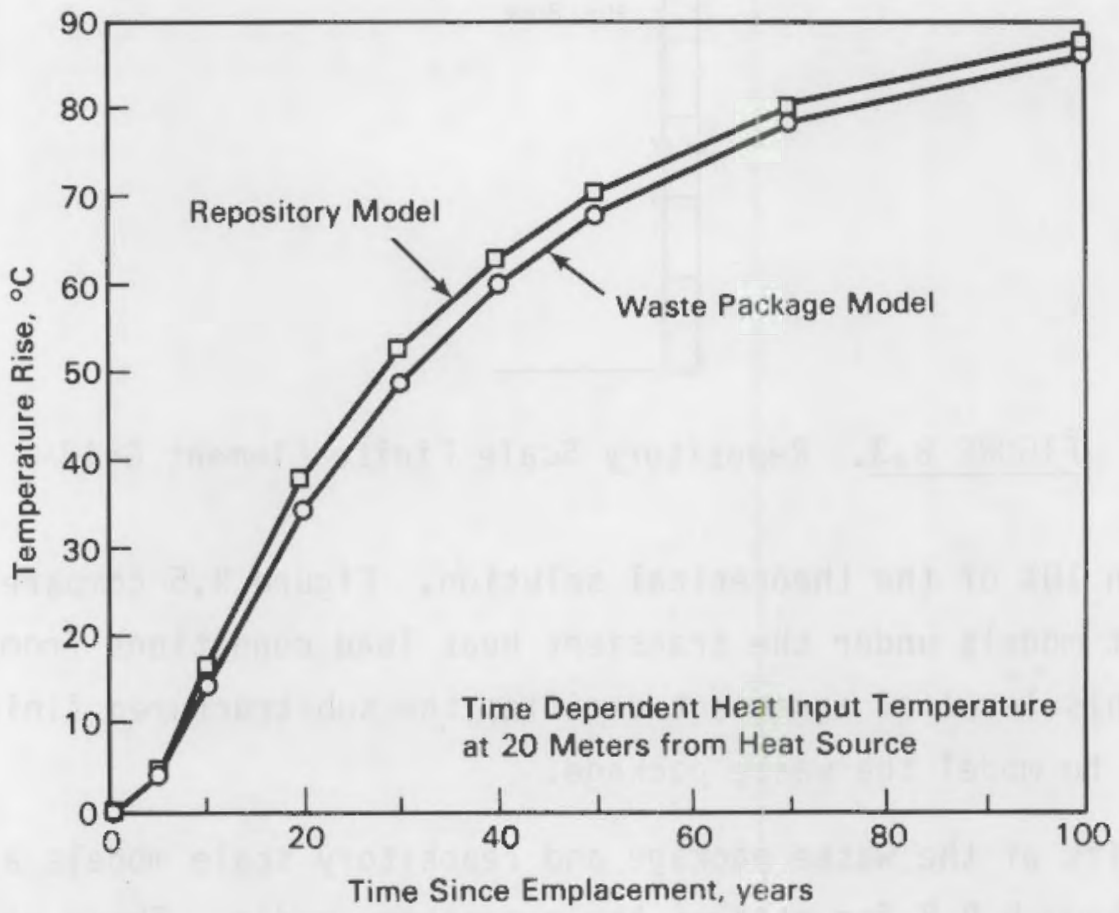

FIGURE 8.5. Waste Package Thermal Model Verification Test Results: Time Dependent Heat Input 


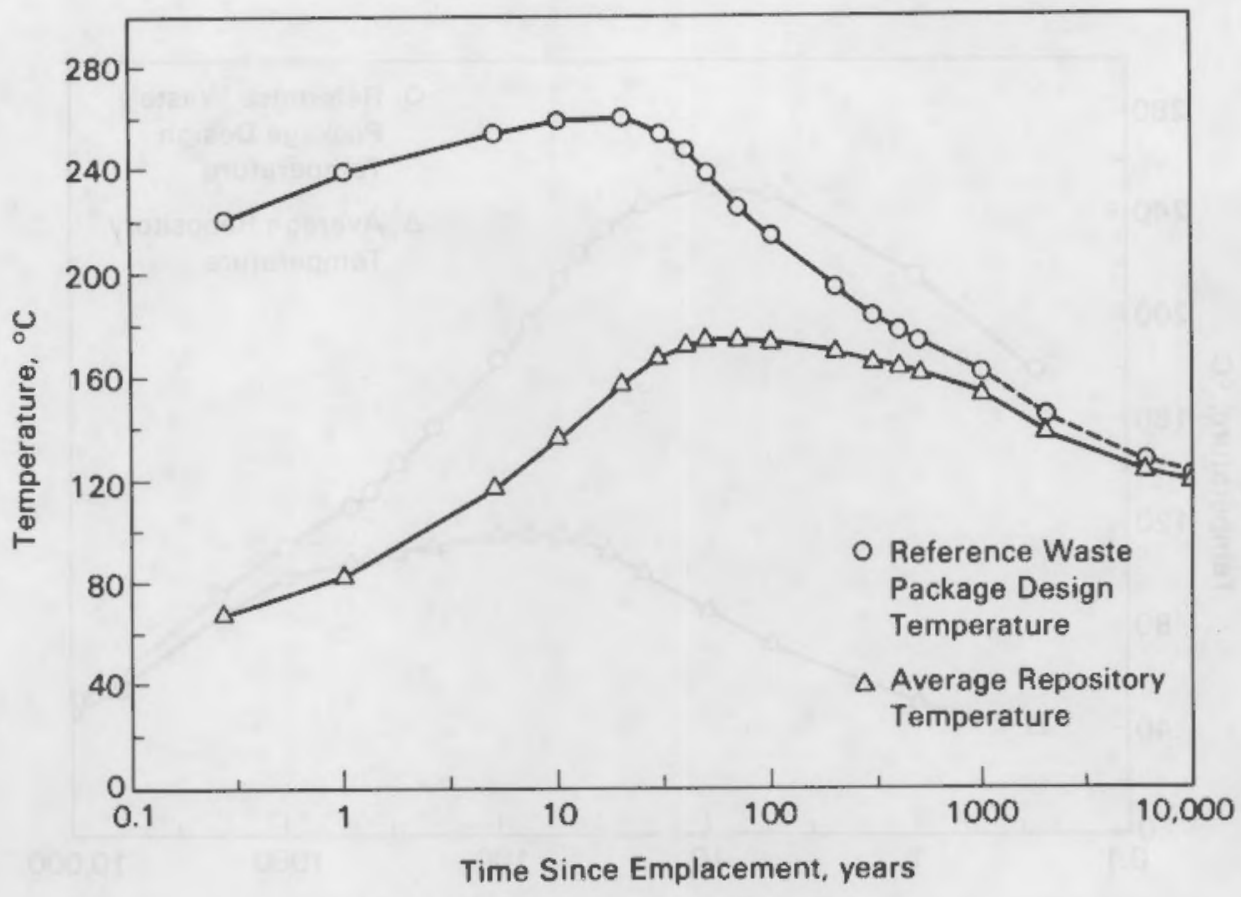

FIGURE B.6. Waste Package Container and Repository Average Temperatures for the Reference BWIP Design

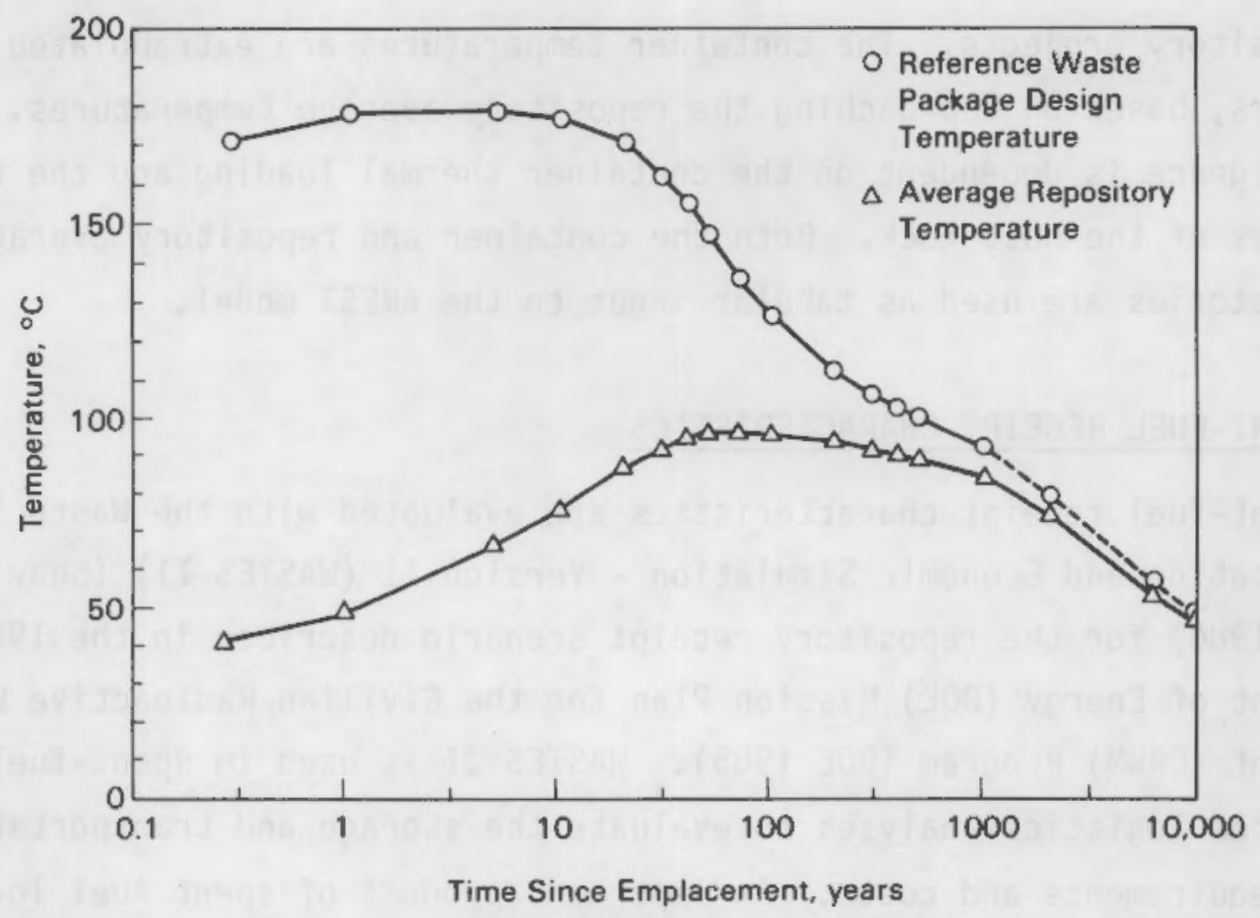

\section{FIGURE B.7. Waste Package Container and Repository Average Temperatures for the Reference SRP Design}




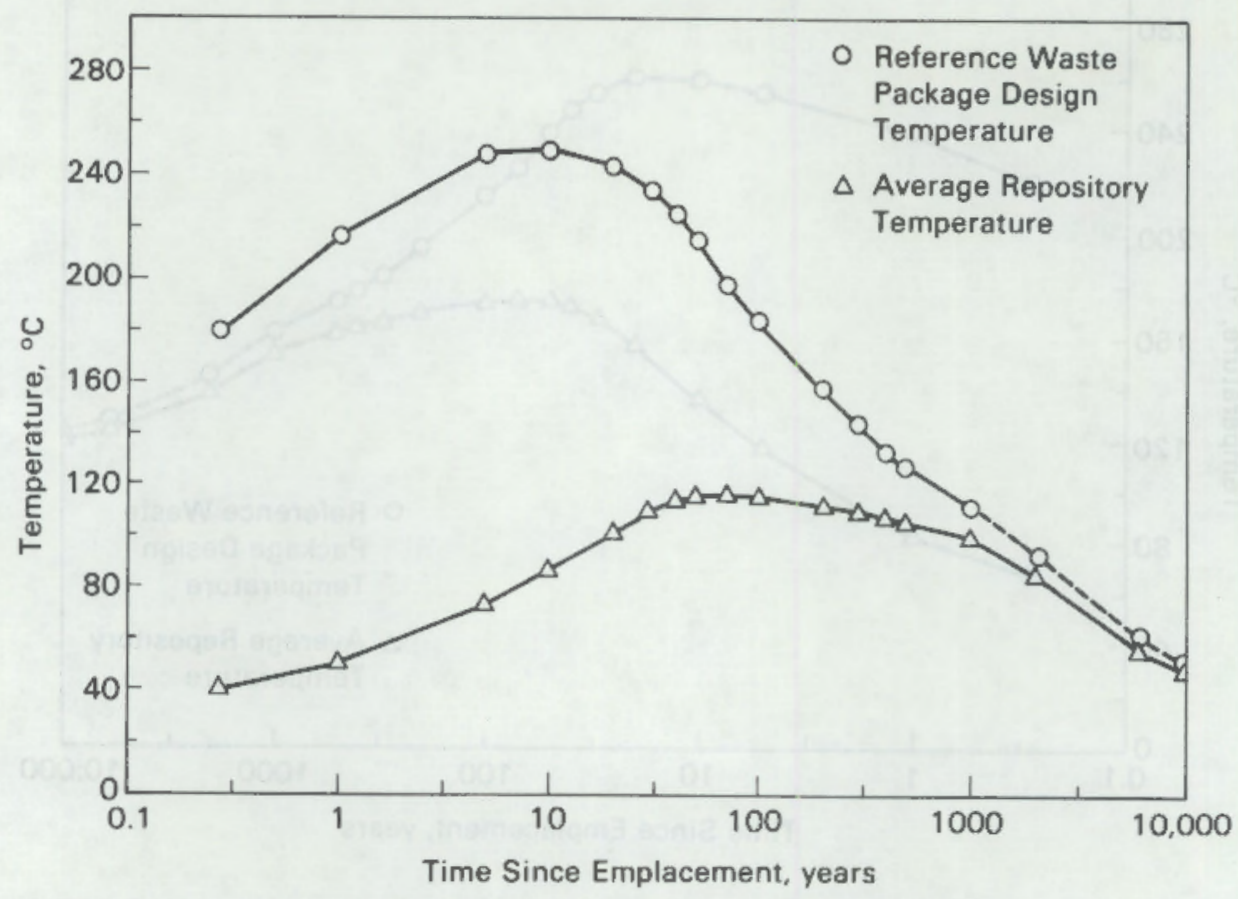

FIGURE B.8. Waste Package Container and Repository Average Temperatures for the Reference NNWSI Design

the repository projects. The container temperatures are extrapolated beyond 1000 years, based on approaching the repository average temperatures. The rate of convergence is dependent on the container thermal loading and the thermal properties of the host rock. Both the container and repository average temperature histories are used as tabular input to the AREST model.

\section{B.2 SPENT-FUEL RECEIPT CHARACTERISTICS}

Spent-fuel receipt characteristics are evaluated with the Waste System Transportation and Economic Simulation - Version II (WASTES II) (Shay and Buxbaum 1986) for the repository receipt scenario described in the 1985 U.S. Department of Energy (DOE) Mission Plan for the Civilian Radioactive Waste Management (CRWM) Program (DOE 1985). WASTES II is used in spent-fuel management system logistics analyses to evaluate the storage and transportation system requirements and costs. An important product of spent fuel logistics analyses is the characterization of repository receipts. Pacific Northwest Laboratory's spent-fuel data base (Heeb, Libby, and Holter 1985) is used to 
provide WASTES II with reactor-specific discharge information based on the 1984 Energy Information Agency (EIA) middle case nuclear growth projection. WASTES II maintains the age and exposure of each discharged batch of assemblies throughout the simulation and calculates the heat generation rate of spent fuel received at each facility on an annul basis.

\section{- B.2.1 Assumptions}

The key assumptions used in this analysis are the waste management system description and the spent-fuel acceptance agreements between the DOE and nuclear utilities. For this analysis, the authorized two-repository system description is assumed. The 1985 Mission Plan describes both authorized and improved-performance waste management systems. The improved-performance system is a two-repository system with the addition of a monitored retrievable storage (MRS) facility as an integral part of the system. The second repository and MRS facility are subject to congressional authorization. The Mission Plan also identifies the 1984 EIA middle case nuclear growth projection as the baseline for DOE planning.

The spent-fuel acceptance agreements between DOE and the nuclear utilities are to be determined. Both the Mission Plan and the Standard Contract (10 CFR 961) specify that DOE will accept spent fuel on an oldest-first basis. However, an exception may be granted to reactors requiring additional storage capacity and reactors that are being decommissioned. The Mined Geologic Disposal System Requirements (MGDSR) Document (DOE 1984) requires the repositories to receive, handle and dispose of spent fuel aged as little as 5 years from reactor discharge on a routine basis. The amount of spent fuel less than 10 years old depends on the repository receipt scenario. For this analysis, spent-fuel acceptance is assumed to be based on a strict oldest first basis. The spent-fuel management system description and acceptance agreements have a significant impact on repository receipt characteristics.

\section{B.2.2 Data}

The waste acceptance schedules for the authorized single repository system is shown in Table B.4. For this study, the first repository has a receipt rate capacity of 3000 MTU per year and a total capacity of 62,000 MTU. Spent-fuel 
TABLE R.4. Waste Acceptance Schedule--Authorized Plan System

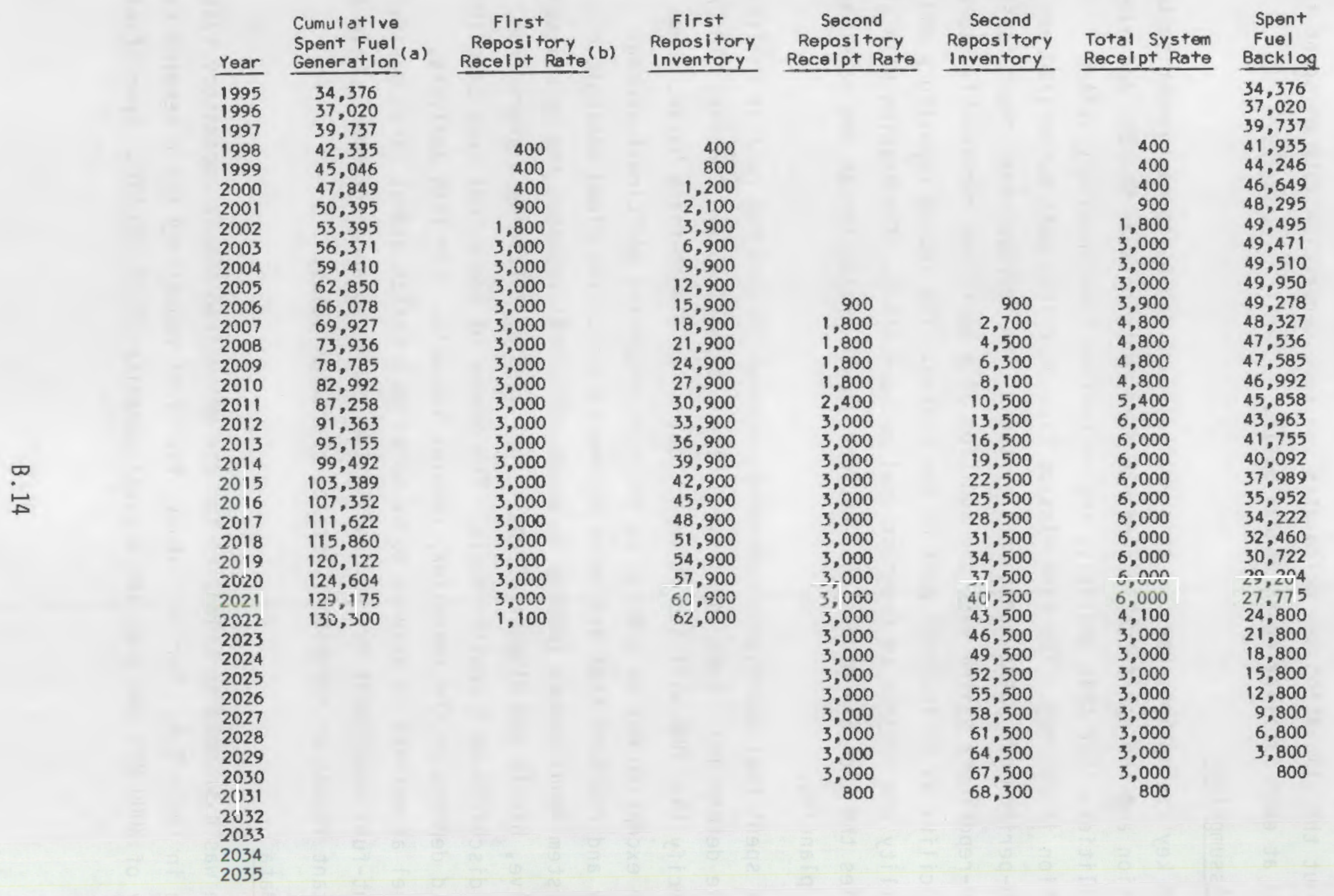

(a) Based on 1984 EIA mIddle case growth projection.

(b) Excludes high level waste acceptance. 
discharge information is based on the 1984 EIA middle case nuclear growth projection. The heat generation rate of spent fuel is dependent on its exposure level and the time out of reactor. Figure B.9 provides the WASTES II model heat generation rate data PWR spent fuel at exposure levels ranging from 10,000 to 40,000 MWd per MTU and decay times from 1 to 50 years after discharge.

B.2.3 Methodology

The WASTES II model simulates a user-defined system of nuclear spent-fuel generation, transportation, storage, and final disposal. The number of each type of facility, facility locations and capacities, and priorities for waste acceptance are all specified by the user. The simulation is initiated with reactor discharge and site characteristic information input data files that

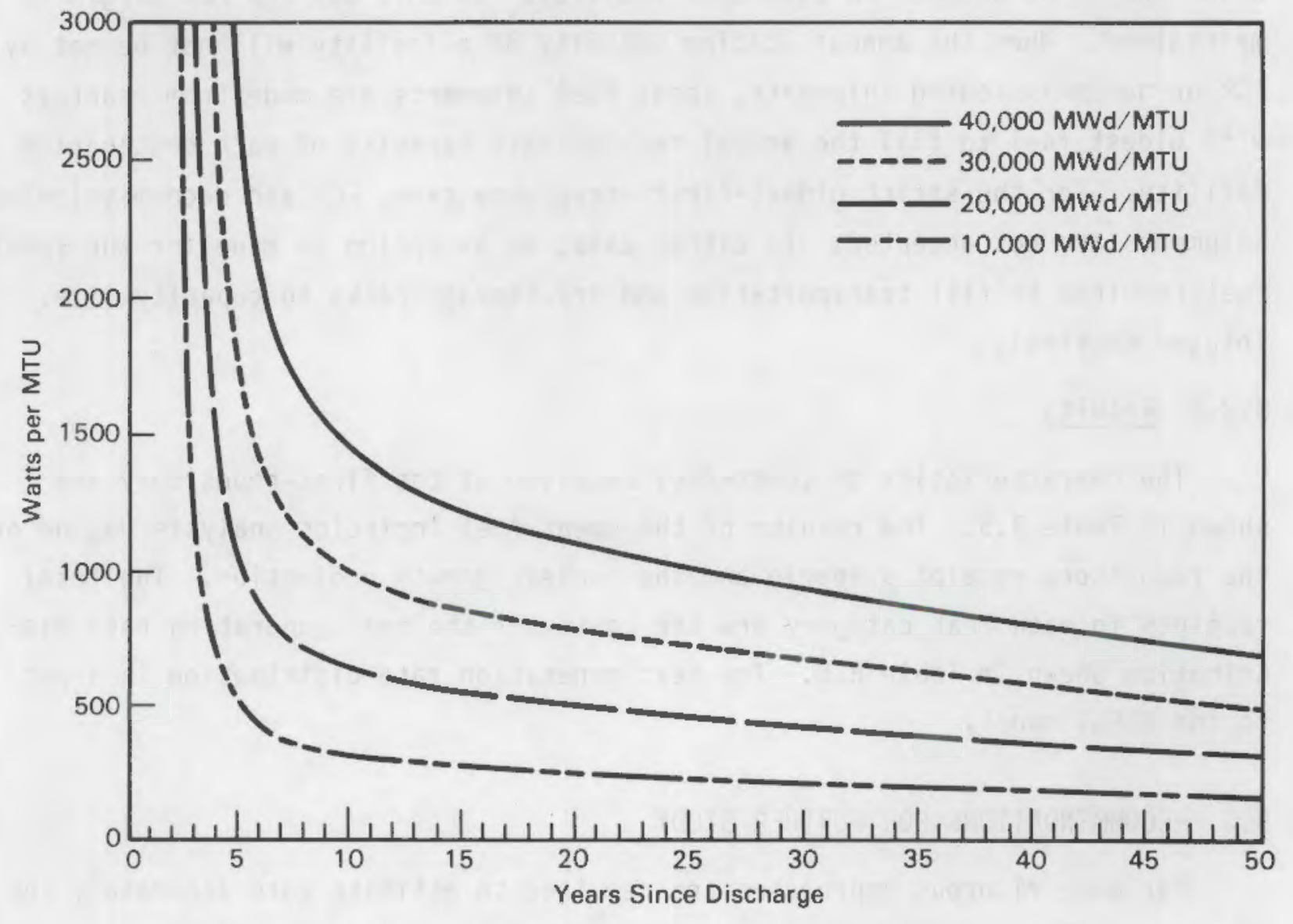

FIGURE B.9. PWR Spent Fuel Heat Generation Rate Data Used in Wastes Model Evaluations 
contain deterministic information on the date (year/month) and quantity of historical and projected spent-fuel discharges and reactor pool storage capacities. From this point, the model is controlled by a user-specified combination of source and destination originated transfers.

During the simulation, spent-fuel transfers occur when a reactor pool violates the full core reserve (FCR) storage margin or when the reactor is decommissioned. At these times, the source reactor checks destination facilities to see if they can accept spent fuel. The availability of destination facilities is determined by their annual loading capacity and the acceptance criteria for that facility. A dry storage facility is assumed to exist for each reactor site and is allowed to grow as necessary to contain spent fuel which cannot be shipped to any other facility. In this way the FCR margin is maintained. When the annual loading capacity of a facility will not be met by FCR or decommissioning shipments, spent fuel shipments are made from reactors with oldest fuel to fill the annual receipt rate capacity of each destination facility. For the strict oldest-first acceptance case, FCR and decommissioning shipments are not accepted. In either case, an exception is made for the spent fuel required to fill transportation and dry storage casks to capacity (i.e. integer casking).

\section{B.2.5 Results}

The characteristics of spent-fuel received at the first-repository are shown in Table B.5. The results of the spent fuel logistics analysis depend on the repository receipt scenario and the nuclear growth projection. The total receipts in each heat category are the basis for the heat generation rate distribution shown in Table B.6. The heat generation rate distribution is input to the AREST model.

\section{B.3 RECOMMENDATIONS FOR FURTHER STUDY}

Far more rigorous approaches are required to estimate more accurately the time-dependent distribution of container temperatures for each of the 
Receipts, of Fuel by Age MTU $(a)$

\begin{tabular}{|c|c|c|c|c|c|c|c|c|c|c|}
\hline Year & $0-5$ yr & $5-8 y r$ & $8-10 \mathrm{yr}$ & $10-12$ y & $12-15 \mathrm{yr}$ & $15-20 \mathrm{yr}$ & $\geq 20 \mathrm{yr}$ & Min & Avg & Max \\
\hline 1998 & 0 & 0 & 0 & 0 & 0 & 0 & 400 & 19.7 & 27.1 & 36.2 \\
\hline 1999 & 0 & 0 & 0 & 0 & 0 & 0 & 400 & 20.8 & 25.7 & 26.8 \\
\hline 2000 & 0 & 0 & 0 & 0 & 0 & 0 & 401 & 22.3 & 25.8 & 26.3 \\
\hline 2001 & 0 & 0 & 0 & 0 & 0 & 7 & 892 & 17.9 & 25.7 & 26.7 \\
\hline 2002 & 0 & 0 & 0 & D & 0 & 4 & 1,796 & 17.0 & 25.1 & 26.3 \\
\hline 2003 & 0 & 0 & 0 & 0 & 0 & 19 & 2,984 & 19.0 & 23.9 & 25.3 \\
\hline 2004 & 0 & 0 & 0 & 0 & 0 & 138 & 2,859 & 17.2 & 22.4 & 24.1 \\
\hline 2005 & 0 & 0 & 0 & 0 & 1 & 275 & 2,725 & 12.4 & 21.1 & 22.6 \\
\hline 2006 & 0 & 0 & 0 & 0 & 2 & 1,849 & 1,115 & 12.4 & 19.8 & 21.2 \\
\hline 2007 & 0 & 0 & 0 & 0 & 7 & 2,992 & 0 & 12.4 & 18.6 & 19.8 \\
\hline 2008 & 0 & 0 & 0 & 0 & 23 & 2,977 & 0 & 12.4 & 17.3 & 18.6 \\
\hline 2009 & 0 & 0 & 0 & 0 & 201 & 2,799 & 0 & 12.4 & 16.3 & 17.5 \\
\hline 2010 & 0 & 0 & 0 & 0 & 992 & 2,012 & 0 & 12.4 & 15.4 & 16.6 \\
\hline 2011 & 0 & 0 & 0 & 38 & 2,325 & 638 & 0 & 11.3 & 24.4 & 15.7 \\
\hline 2012 & 0 & 0 & 0 & 141 & 2,855 & 0 & 0 & 10.7 & 13.3 & 14.5 \\
\hline 2013 & 0 & 0 & 48 & 1,390 & 1,562 & 0 & 0 & 9.2 & 12.1 & 13.3 \\
\hline 2014 & 0 & 0 & 153 & 2,727 & 121 & 0 & 0 & 8.7 & 11.0 & 12.2 \\
\hline 2015 & 0 & 25 & 1,332 & 1,641 & 0 & 0 & 0 & 7.8 & 10.1 & 11.2 \\
\hline 2016 & 0 & 67 & 2,626 & 307 & 0 & 0 & 0 & 6.8 & 9.4 & 10.3 \\
\hline 2017 & 0 & 96 & 2,905 & 0 & 0 & 0 & 0 & 6.7 & 9.0 & 9.8 \\
\hline 2018 & 0 & 203 & 2,801 & 0 & 0 & 0 & 0 & 6.6 & 8.6 & 9.6 \\
\hline 2019 & 0 & 1,148 & 1,849 & 0 & 0 & 0 & 0 & 5.6 & 8.2 & 9.0 \\
\hline 2020 & 0 & 2,034 & 965 & 0 & 0 & 0 & 0 & 5.7 & 7.7 & 8.6 \\
\hline 2021 & 5 & 2,932 & 64 & 0 & 0 & 0 & 0 & 4.9 & 7.3 & 8.2 \\
\hline 2022 & 0 & 1,097 & 0 & 0 & 0 & 0 & 0 & 5.2 & 6.9 & 7.7 \\
\hline 2023 & 0 & 0 & 0 & 0 & 0 & 0 & 0 & 0.0 & 0.0 & 0.0 \\
\hline 2024 & $\underline{0}$ & $\underline{0}$ & 0 & 0 & $\underline{0}$ & 0 & $\underline{0}$ & 0.0 & 0.0 & 0.0 \\
\hline Total & 5 & 7,602 & 12,743 & 6,244 & 8,089 & 13,710 &, 608 & & & \\
\hline
\end{tabular}

Receipts, of Fuel by Heat MTU (a)

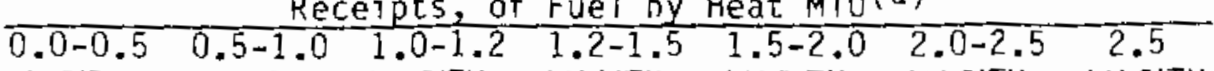

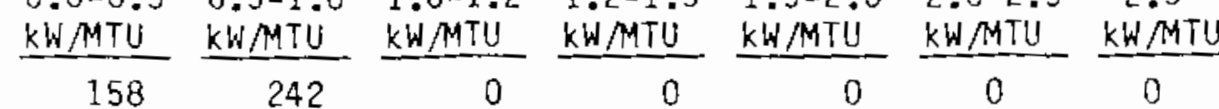

\begin{tabular}{rrrrrr}
228 & 172 & 0 & 0 & 0 & 0 \\
332 & 69 & 0 & 0 & 0 & 0 \\
696 & 203 & 0 & 0 & 0 & 0 \\
741 & 1,059 & 0 & 0 & 0 & 0 \\
501 & 2,493 & 7 & 0 & 2 & 0 \\
284 & 2,655 & 57 & 0 & 0 & 0 \\
242 & 2,547 & 198 & 14 & 0 & 0 \\
629 & 2,101 & 255 & 16 & 0 & 0 \\
290 & 2,271 & 438 & 0 & 0 & 0 \\
152 & 2,223 & 587 & 38 & 0 & 0 \\
117 & 2,119 & 719 & 45 & 0 & 0 \\
42 & 2,129 & 799 & 35 & 0 & 0 \\
48 & 1,892 & 850 & 210 & 0 & 0 \\
65 & 1,810 & 810 & 312 & 0 & 0 \\
4 & 1,238 & 1,240 & 517 & 0 & 0 \\
205 & 933 & 1,365 & 496 & 1 & 0 \\
227 & 815 & 1,390 & 555 & 11 & 0 \\
246 & 883 & 1,191 & 663 & 16 & 0 \\
468 & 891 & 968 & 576 & 98 & 0 \\
248 & 832 & 1,117 & 629 & 117 & 0 \\
127 & 792 & 1,012 & 865 & 201 & 0 \\
93 & 540 & 889 & 1,177 & 300 & 0 \\
63 & 456 & 735 & 1,406 & 336 & 5 \\
28 & 113 & 255 & 578 & 123 & 0 \\
0 & 0 & 0 & 0 & 0 & 0 \\
0 & 0 & -0 & 0 & 0 \\
\hline 6,234 & 31,478 & 14,942 & 8,132 & 1,205 & 5 \\
& & & & &
\end{tabular}

Min Avg Max $\begin{array}{lll}0.19 & 0.52 & 0.87\end{array}$ $\begin{array}{llll}0.22 & 0.46 & 0.81\end{array}$ $\begin{array}{llll}0.22 & 0.36 & 0.79 & 15\end{array}$ $\begin{array}{llll}0.22 & 0.41 & 0.75 & 18\end{array}$ $\begin{array}{lllll}0.23 & 0.54 & 0.92 & 23\end{array}$ $\begin{array}{llll}0.23 & 0.63 & 1.61 \quad 26\end{array}$ $\begin{array}{lllll}0.24 & 0.70 & 1.52 & 28\end{array}$ $\begin{array}{lllll}0.24 & 0.75 & 1.24 & 29\end{array}$ $\begin{array}{llll}0.24 & 0.73 & 1.27 & 28\end{array}$ $\begin{array}{lllll}0.25 & 0.81 & 1.56 & 30\end{array}$ $\begin{array}{llll}0.26 & 0.87 & 1.27 & 31\end{array}$ $\begin{array}{llll}0.27 & 0.89 & 1.31 \quad 31\end{array}$ $\begin{array}{llll}0.42 & 0.94 & 1.34 & 32\end{array}$ $\begin{array}{llll}0.28 & 0.97 & 1.43 \quad 33\end{array}$ $\begin{array}{llll}0.45 & 0.98 & 1.43 & 32\end{array}$ $\begin{array}{llll}0.46 & 1.03 & 1.52 & 33\end{array}$ $\begin{array}{llll}0.29 & 1.02 & 1.62 \quad 31\end{array}$ $\begin{array}{llll}0.30 & 1.03 & 1.64\end{array}$ $\begin{array}{llll}0.31 & 1 . .02 & 1.66 & 29\end{array}$ $\begin{array}{llll}0.31 & 0.96 & 1.67 & 27\end{array}$ $\begin{array}{llll}0.32 & 0.99 & 1.82 & 28\end{array}$ $\begin{array}{llll}0.33 & 1.06 & 1.88 & 29\end{array}$ $\begin{array}{llll}0.33 & 1.13 & 2.06 & 30\end{array}$ $\begin{array}{llll}0.35 & 1.19 & 2.06 & 30\end{array}$ $\begin{array}{llll}0.34 & 1.24 & 2.12 & 31\end{array}$ $\begin{array}{lllll}0.00 & 0.00 & 0.00 & 0\end{array}$ $\begin{array}{llll}0.00 & 0.00 & 0.00 & 0\end{array}$
TABLE B.5. Characteristics of Spent Fuel Receive at First Repository
A .

(3)

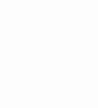

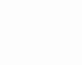


TABLE B.6. Spent Fuel Thermal Receipt Characteristics at the First Repository (based on the 1985 DOE Mission Plan authorized system description and 1984 EIA Middle Case Nuclear Growth Projection)

\begin{tabular}{c}
$\begin{array}{c}\text { Heat Generation, } \\
\text { Rate kW/MTU }\end{array}$ \\
\hline 0.0 to 0.2 \\
0.2 to 0.5 \\
0.5 to 1.0 \\
1.0 to 1.2 \\
1.2 to 1.5 \\
1.5 to 2.0 \\
2.0 to 2.5 \\
$>2.5$ \\
Total
\end{tabular}

Total

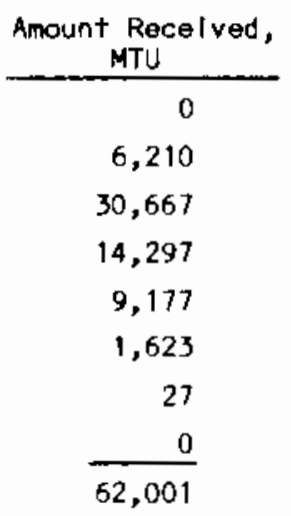

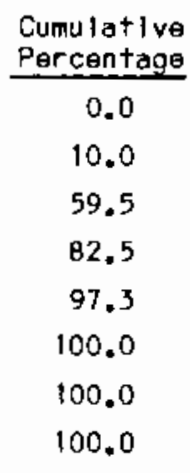

0.0
10.0

49.5

23.1

14.8

2.6

0.0

\begin{tabular}{|c|c|}
\hline tage & $\begin{array}{l}\text { Cumulative } \\
\text { Percentage } \\
\end{array}$ \\
\hline 0 & 0.0 \\
\hline 0 & 10.0 \\
\hline 5 & 59.5 \\
\hline 1 & 82.5 \\
\hline 8 & 97.3 \\
\hline 6 & 100.0 \\
\hline 0 & 100.0 \\
\hline 0 & 100.0 \\
\hline
\end{tabular}

repository designs. There are many important factors that the AREST model does not account for which contribute to both the magnitude and distribution of container temperatures.

In terms of spent-fuel receipt characteristics, the receipt scenario has an important impact on the age and heat generation rate of spent-fuel receipts. The AREST model is a more reasonable approximation when the initial heat generation rate distribution solely results from exposure variations and not from age variations. The effect of increasing exposure is shown to have a nearly proportional effect on the heat generation rate. The effect of increasing age, however, is nonlinear and changes the time-dependent behavior of the heatgeneration rate curve. As a result, spent-fuel age affects the time-dependent behavior of the container temperature. Further study is required to evaluate the separate effects of age and exposure variations on container temperatures.

Material properties are important because of the potential variability and the effects of temperature-dependent properties. Variability of host rock thermal properties could have been factored into the analysis if more data had been available. The effect of temperature-dependent thermal conductivity, as in the case of salt, should be studied further.

Repository operations such as emplacement, ventilation, and backfilling are important for near-term temperature estimates. The effect of repository 
operating conditions on container temperatures deserves further study because of the relatively long operating period of the repository.

Alternative strategies for packaging and emplacing spent fuel with variable heat generation rate characteristics have not been established in the conceptual repository designs. Because of the high cost of the waste packages and an underground facility, there is an incentive to tailor the design to accommodate different spent-fuel characteristics. Variable container diameters and emplacement densities are strategies that should be evaluated for the effects on container temperature.

In most cases, the AREST model tends to overestimate both the magnitude and the distribution of container temperatures. The container temperature results may be conservative or nonconservative with respect to performance assessment. In terms of preclosure safety, this approach ensures that repository and waste package component temperatures are within their respective 1 imiting temperature requirements. In terms of containment, the impact on container lifetimes depends on the effect of temperature on the corrosion rates. In terms of isolation, the impact on radionuclide release rates container failure distribution and on radionuclide solubility. For these reasons, it is recommended that that AREST model be also run for selected fixedtemperature histories over the range of container temperatures predicted by the model. The results of these runs would serve to bound the estimates of performance for the sake of conservatism.

\section{B.4 REFERENCES}

Altenhofen, M. K. 1981. Waste Package Heat Transfer Analysis: Model Development and Temperature Est imates for Waste Packages in a Repository Located in Basalt. RHO-BWI-ST-18, Rockwell Hanford Operations, Richland, Washington.

Carlslaw, H. S., and J. C. Jaeger. 1959. Conduct of Heat in Solids. 2nd ed. Oxford University Press, Oxford, England.

Cook, R. D. 1981. Concepts and Applications of Finite Element Analysis. 2nd ed. John Wiley and Sons Inc., New York, New York. 
Gilbert/Commonwealth, Inc. 1986. Site Characterization Plan Conceptual Design Report for Basalt Waste Isolation Project High Level Nuclear Wastes. SD-BWICDR-005, prepared for Basalt Waste Isolation Project, Rockwell Hanford Operations, Richland, Washington.

Heeb, C. M., R. A. Libby, and G. M. Holter. 1985. Reactor Specific Spent Fuel Discharge Projections: 1984 to 2020. PNL-5396, Pacific Northwest Laboratory, Richland, Washington.

O'Nea1, W. C., D. W. Gregg, J. N. Hockman, E. W. Russe1, and W. Stein. 1984. Preclosure Analysis of Conceptual Waste Package Designs for a Nuclear Waste Repository in Tuff. UCRL -53595 , Lawrence Livermore National Laboratory, Livermore, California.

Shay, M. R., and M. E. Buxbaum. 1986. WASTES II: Waste System Transportation and Economic Simulation - Version II. Users Guide. PNL-5714, Pacific Northwest Laboratory, Richland, Washington.

Swanson Analysis Systems, Inc. 1986. ANSYS - Engineering Analysis System, Revision 4.2. Houston, Pennsylvania.

Standard Contract for Disposal of Spent Nuclear Fuel and/or High Level Waste. 10 CFR Part 961 (1982). (Cited in text as 10 CFR 961).

U.S. Department of Energy (DOE) . 1984. Generic Requirements for a Mined Geologic Disposal System. OOE/RW-005, office of Civilian Radioactive Waste Management, Washington, D.C.

U.S. Department of Energy (DOE). 1985. Mission Plan for the Civilian Radioactive Waste Management Program. DOE/RW-005, Office of Civilian Radioactive Waste Management, Washington, D.C. 


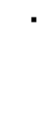


APPENDIX C

GROUNOWATER/GEOCHEMICAL VARIABLES 
APPENDIX $C$

\section{GROUNDWATER/GEOCHEMICAL VARIABLES}

A simplified conceptual model was used to derive the geochemical input to the AREST code. For this model, the repository is divided into a series of zones, each representing a separate closed system. An assumption used in this approach is that each of these systems is "closed"; in other words, a set of relevant chergical reactions is allowed to occur within a zone in the absence of influences from the neighboring zones.

In general, three zones were considered: 1) the host rock, 2) the outer part of the waste package, and 3) the spent-fuel waste form. The known compositions of the groundwaters for the basalt and tuff repositories used in the calculations were GR-4 and $J-13$ compositions (Table $C .1$ ) respectively. For the salt repository site, the intrusion brine, PBB-l was selected (Table C.1). The composition of the groundwater representative of each zone was calculated up to $250^{\circ} \mathrm{C}$ using the geochemical code EQ3NR (Wolery 1983) or, in the code of the salt repository, using relevant experimental data. These data were incorporated into a series of reference (look-up) tables that are accessed by the AREST code at execution time.

\section{C.I ASSUMPTIONS/LIMITATIONS OF THE ANALYSIS}

Several assumptions were made in the conceptual model that affect the calculations. These assumptions are outlined briefly below, and an expanded discussion follows.

- The starting groundwater compositions assumed were those reported in the 1iterature, i.e., GR-4, 3-13, and PBB-1 (McGrail 1985; Ogard and Kerrisk 1984; DOE 1986a)

- Available experimental data for equilibrium $\mathrm{NaCl}$ solubility and for PBB-1 were used to estimate the alteration of the brine. 
TABLE C.1. Compositions of Repository Groundwaters(a) Used in the AREST Coide $(\mathrm{mg} / \mathrm{L})$

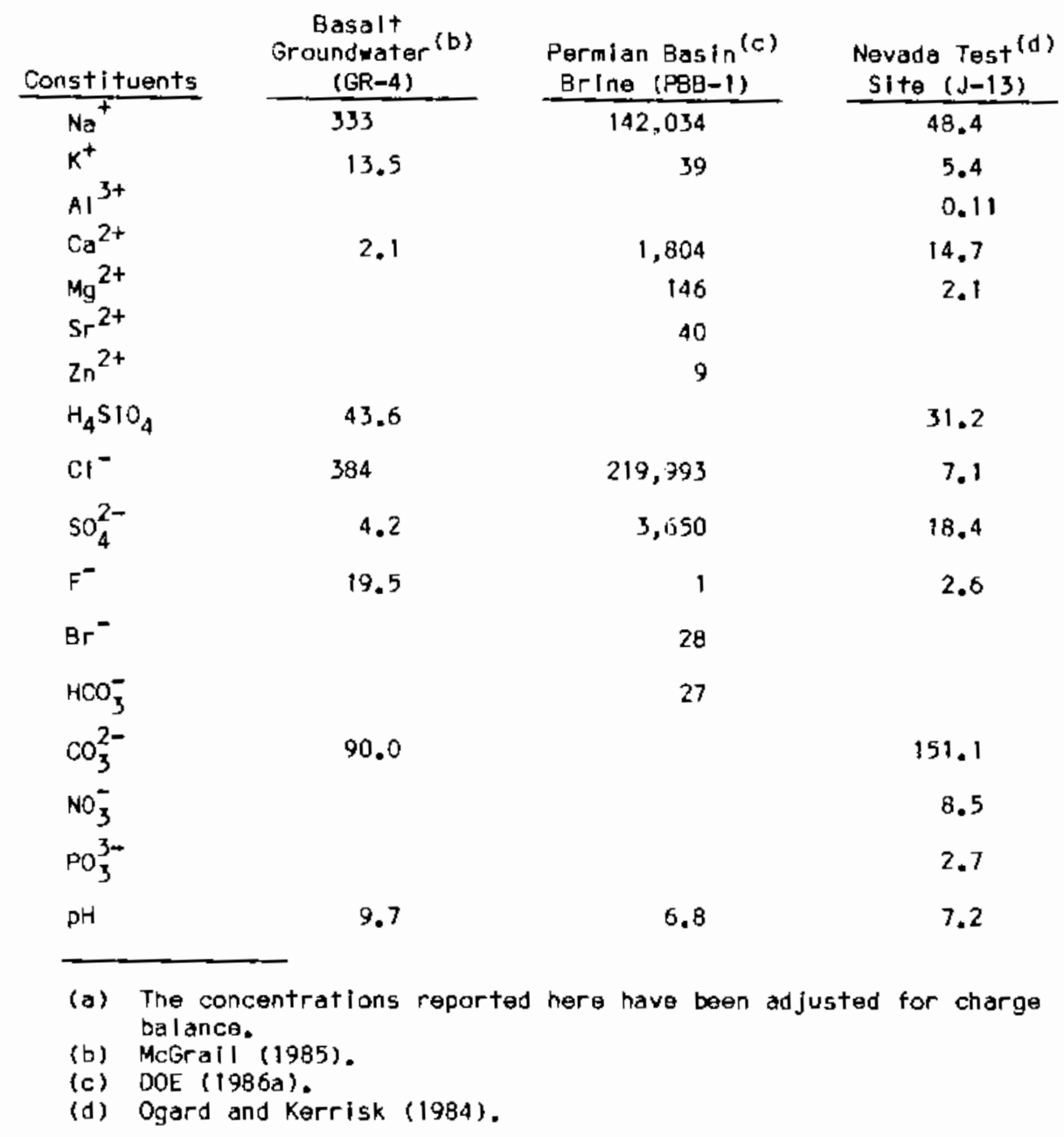

- For a given set of chemical reactions in tuff, thermodynamic equilibrium was assumed, and kinetic constraints were not taken into account.

- All groundwater compositions were assumed not to change by reaction with the steel container and the spent fuel cladding.

- Sorption of radionuclides was not considered.

The first assumption essentially states that because the groundwater has been in contact with the host rock for many years (in most cases tens of thousands of years) the composition is fixed by the rock at the horizon 
temperature. Data from hydrothermal experiments with the basalt and the tuff horizon (Apted, Meyers, and Mazer 1983; Oversby 1984) suggest that the compositions of these solutions in contact with the rock do not change dramatically with increasing temperature. Therefore, use of the reported groundwater compositions as the starting compositions for the repositories in basalt and tuff for input to the EQ3NR code represents a good starting point for the calculations. These starting compositions were then speciated as a function of temperature, and the total concentrations of the dissolved constituents were kept constant. The total concentration of sulfur, for example, in the groundwater remained constant, while the individual concentrations of $\mathrm{SO}_{4}^{2-}, \mathrm{S}^{2-}, \mathrm{H}_{2} \mathrm{SO}_{4}$, etc. varied with temperature.

The second assumption concerns the EQ3NR code, which also has the capability of calculating equilibria in high-ionic-strength solutions pertinent to salt sites using Pitzer's equations. That option could not be exercised in this study because of current limitations in the data base. The version of EQ3NR used for the AREST code input (Version 3245) contains Pitzer's data at $25^{\circ} \mathrm{C}$ for major salt constituents and therefore could not be used to estimate the brine composition at high temperatures. An alternate approach was used in which the composition of $\mathrm{PBB}-1$ in equilibrium with $\mathrm{NaCl}$ was calculated using total solubility data as a function of temperature for halite from sylvester and Pitzer (1977). Future refinements of this geochemical input should include calculating the solubility of halite in PBB-1 brine using EQ3NR when the hightemperature data base becomes ayailable.

The third assumption concerns the chemical reactions in tuff. Because the groundwater will be moving very slowly, sufficient time should be available at any given spot in the waste package for the solution to reach equilibrium with its surroundings and for the dissolved constituents to be distributed according to the various thermodynamic equilibria. Therefore, any kinetic considerations would be transient and not contribute to the steady state. This assumption facilitates the calculations and avoids the problems of including precipitation and dissolution kinetics, for which there is a scarcity of data, in the calculations and in the reference tables. 
The fourth assumption states that steel container will react with the incoming solution to form magnetite $\left(\mathrm{Fe}_{3} \mathrm{O}_{4}\right)$ and/or hematite $\left(\mathrm{Fe}_{2} \mathrm{O}_{3}\right)$ corrosion products and $\mathrm{H}_{2}(\mathrm{~g})$. This set of reactions leads to a negligible change in the solution chemistry, most notably in the $\mathrm{pH}$. This assumption will fail when the . solution reacts with the steel to form other reaction products that remove significant quantities of dissolved constituents from solution. To date, signifi.. cant changes in solution chemistry have not been reported in published work. The solution composition changes little or not at all when corrosion occurs. Furthermore, corrosion will occur slowiy over a very long time, so that, again, any changes will be small.

The fifth assumption states that sorption is not considered for this aspect of AREST because the current version of EQ3NR does not contain a sorption model, existing sorption models do not appear to be adequate, and sorption equilibration is generally established within minutes at $25^{\circ} \mathrm{C}$ (unless it is diffusion-controlled). Including sorption would lead to initially lower values of dissolved uranium and other radionuclides tian those calculated from the dissolution of spent fuel. Once all of the sorption sites become equilibrated with the dissolved components, the solution concentrations will eventually be controlled by the solubilities of appropriated mineral phases.

Several other potential reactions and processes were not considered for various reasons. In the basalt and tuff repository designs, groundwater migrating toward the repository may reach temperatures that exceed the boiling point. Groundwater may exceed the boiling point in the tuff repository where ambient pressures prevail or during the preclos dre period in the basalt repository. Water vaporization may result in the precipitation of solid phases, but this process has not been considered because of the lack of experimental evidence verifying the identity of such precipitates.

AT1 of the calculations for the geochenical input to the AREST code have been performed using the equilibrium geochemical code EQ3NR (Wolery 1983). Reaction path calculations, i.e., the EQ6 code(a) have not been considered in

(a) Wolery, T. J. 1984. EQ6, A Computer Program for Reaction-Path Modeling of Aqueous Geochemical Systems: User's Guide and Documentation. UCLRDRAFT, Lawrence Livermore Laboratory, Livermore, California. 
this work. Reaction path calculations have been reported in the case of the J-13 water (Kerrisk 1983) and have been done in connection with hydrothermal experiments (Knauss, Oversby, and Wolery 1984). The calculations agree well with the observations, but the calculations were done using reaction progress coordinates, i.e. mass of rock dissolved per unit volume of solution, as opposed to actual time coordinates. Both experiments and calculations indicate small changes in solution composition. Because explicit kinetics could not be included and because of the small observed changes, it was decided that reaction path calculations would not add significantly to the estimations made here. The composition of the basalt and tuff groundwaters, were calculated using EQ3NR for the temperature range $25^{\circ}$ to $250^{\circ} \mathrm{C}$. Equilibrium constants for all the major solution species (i.e., those species comprising greater than $90 \%$ of total mass of the dissolved constituent) were available; however, a limitation of the calculations is that data for certain uranium solution species and pertinent uranium solids above $25^{\circ} \mathrm{C}$ are not available. Inconsistencies in the present calculations caused by this limitation are unknown at present. The current version of EQ3NR code also has the capability of calculating equilibria in high ionic strength solutions pertinent to salt sites using the Pitzer equations, but the data base is currently limited to major salt components at $25^{\circ} \mathrm{C}$. Therefore, this option of the EQ3NR code was not exercised in this study.

If the above assumptions are overconservative or invalid for any reason, the predicted chemistry of the groundwater may change dramatically. The effects on the release from spent fuel may be beneficial or detrimental. However, by using the reference tables approach, the AREST users may easily inject their own assumptions as reflected in new tables.

\section{C.2 ANALYSIS RESULIS FOR SPECIFIC REPOSITORIES}

Described below are the waste package concepts that are used in this version of the AREST reference tables. These descriptions are consistent with those described in the environmental assessments published for each of the leading candidate repositories (DOE 1986a, 1986b, 1986c). An example of such a reference table is shown in Table C.2. A table similar to this exists for each position considered, i.e., host rock, outer waste package, and spent fuel. 
Inclusion of a complete set of the reference tables in this report would no: add significantly to the understanding of the input to the AREST code. However, a complete set of data, is published in Volume 2 of this report.

\section{C.2.1 Basalt Waste I solation Project}

For the case of the Basalt Waste Isolation Project (BWIP), the candidate repository located at Hanford, Washington, and the rock is basalt. Basalt generally consists of plagioclase, pyroxene, titaniferous magnetite, mesostasis, and some other minor phases (Palmer et a1. 1982). Horizontal bore holes will be drilled into this rock from the repository tunnel access, and the waste package will be placed into these bore holes. The waste package will consist of a steel shell fitted with prefabricated rings of crushed basalt (75\%) and

\section{TABLE C.2. Example Reference Table}

\begin{tabular}{|c|c|c|c|}
\hline \multirow{2}{*}{$\frac{\text { Species }}{T\left(^{\circ} \mathrm{C}\right)}$} & \multicolumn{3}{|c|}{ Concentration $(\mathrm{M} / \mathrm{kg})$} \\
\hline & 55 & 60 & 65 \\
\hline $\mathrm{pH}(\mathrm{T})$ & 7.45 & 7.42 & 7.40 \\
\hline$E h(V)$ & -0.345 & -0.346 & -0.347 \\
\hline$\rho$ & 1.023 & 1.020 & 1.019 \\
\hline $\mathrm{Na}^{+}$ & $0.13980-01$ & $0.14660-0 "$ & $0.15710-01$ \\
\hline $\mathrm{Cl}^{-}$ & $0.10830-01$ & $0.10830-01$ & $0.10830-01$ \\
\hline $\mathrm{Al}(\mathrm{OH}\}_{4}$ & $0.94310-03$ & $0.16170-02$ & $0.26610-02$ \\
\hline $\mathrm{SlO}_{2}(\mathrm{~Bq})$ & $0.14450-02$ & $0.14390-02$ & $0.14360-02$ \\
\hline $\mathrm{HCO}_{3}^{-}$ & $0.14310-02$ & $0.1025 \mathrm{D}-02$ & $0.14300-02$ \\
\hline$F$ & $0.10250-02$ & $0.1025 \mathrm{D}-02$ & $0.10250-02$ \\
\hline $\mathrm{H}_{3} \mathrm{~S}^{10} \mathrm{O}_{4}^{-}$ & $0.10710-03$ & $0.11230-03$ & $0.11540-03$ \\
\hline $\mathrm{Ca}^{2+}$ & $0.51020-04$ & $0.50890-04$ & $0.50780-04$ \\
\hline $\mathrm{HS}^{-}$ & $0.41490-04$ & $0.41430-04$ & $0.41300-04$ \\
\hline $\mathrm{H}_{2} \mathrm{CO}_{3}$ & $0.19770-04$ & $0.20530-04$ & $0.21850-04$ \\
\hline $\mathrm{CO}_{3}^{2-}$ & $0.18770-04$ & $0.18600-04$ & $0.17970-04$ \\
\hline $\mathrm{OH}^{2}$ & $0.10840-04$ & $0.13660-04$ & D. 16690-04 \\
\hline $\mathrm{NaCl}$ & $0.10700-04$ & $0.10920-04$ & $0.11460-04$ \\
\hline NaF & $0.24060-05$ & $0.2703 \mathrm{D}-05$ & $0.3092 \mathrm{D}-05$ \\
\hline $\mathrm{NaCO}_{3}^{-}$ & $0.17830-05$ & $0.18990-05$ & $0.20060-05$ \\
\hline $\mathrm{H}_{2} \mathrm{~S}(a \mathrm{q})$ & $0.13130-05$ & $0.12720-05$ & $0.12720-05$ \\
\hline $\mathrm{CaHCO}_{3} 2-$ & $0.96150-06$ & $0.97830-06$ & $0.99410-06$ \\
\hline $\mathrm{CaCO}_{3}$ & $0.8683 \mathrm{D}-06$ & $0.90570-06$ & $0.91500-06$ \\
\hline $\mathrm{CaF}^{+}$ & $0.77610-06$ & $0.84800-06$ & $0.92320-06$ \\
\hline $\mathrm{SO}_{4}^{2-}$ & $0.17750-06$ & $0.2713 \mathrm{D}-06$ & $0.39970-06$ \\
\hline
\end{tabular}

$$
\text { C. } 6
$$


bentonite clay (25\%). A container of thick (approximately $75 \mathrm{~mm}$ ) A27 cast steel containing the spent fuel will be inserted into the hole in the basalt/clay rings. The spent fuel may be consolidated or unconsolidated.

Because the groundwater has been in contact with the basalt for a long period of time (more than 10,000 years), an analysis of the water might be expected to yield a composition which is at least stable with time, although not necessarily in equilibrium with the host rock. Results from the use of the GR-4 groundwater composition (MCGrail 1985) as input to the EQ3NR code indicated that several minerals were at various degrees of over-/undersaturation. Only quartz was common between the code output list and the minerals found in basalt by Palmer et al. (1982). Principally, this discrepancy exists because GR-4 contains no dissolved aluminum. Aluminum was probably below the limits of detection in all of the groundwaters that were analyzed and which led to the GR-4 composition. The GR-4 groundwater composition (Jones 1982) has been assumed to be the correct initial groundwater composition for use in the AREST mode 7 .

In hydrothermal experiments with basalt and synthetic groundwater at elevated temperatures (Apted, Myers, and Mazer 1983; Lane et a 1. 1984), elements such as $S i$ and $K$ are observed to increase from a factor of 2 to 7 above those in the starting synthetic groundwater, while other constituents, such as $\mathrm{F}^{-}$, $\mathrm{CO}_{3}^{2-}$, and $\mathrm{Cl}^{-}$, are observed to decrease or remain constant. This phenomenon can have a pronounced effect on the solubility of many solids through complexation. However, since it is difficult to calculate the observed changes using the reported phases (Palmer et al. 1982), many of which are not in the EQ3NR data base, the GR-4 groundwater was used as the initial groundwater composition. The EQ3NR code was then used to equilibrate GR-4 with magnetite/ hematite to establish the low observed Eh (redox potential) (Grandstaff et al. 1984) and speciate the water at elevated temperatures while maintaining the total dissolved constituents at a constant level.

Two documents support the selection of magnetite/hematite for Eh control. Water analyses of aqueous solutions taken from hydrothermal experiments have heen reported to cluster ahout the magnetite/hematite houndary (Grandstaff et a1. 1984). A recent document on the issue of redox chemistry in basalt 
groundwater at the Hanford Site leaves the question of sulfur speciation somewhat open, although it is clear from the speciation of dissolved Fe and $S$ that the waters are reducing ( $D i 11$ et a 1 1986). The requirement that the code maintain the aqueous phase in equilibrium with magnetite and hematite caused the resulting water to be rich in $\mathrm{HS}^{-}$. Dill et al. (1986) report data tha: suggest a high variability in the $50_{4}^{2-}$ concentrations from the wells at the Hanford Site, but the $\mathrm{SO}_{4}^{2-}$ appears to dominate the sulfur speciation. They also performed a limited sensitivity analysis wherein the [ $\mathrm{SO}_{4}^{2-} /\left[\mathrm{HS}^{-}\right]$was varied from $10^{+5}$ to $10^{-5}$ with only a $\pm 10 \%$ change in the calculated Eh. Using the equations from DitT et al. (1986), small changes in Eh $( \pm 0.03 \mathrm{~V})$ lead to large changes in the $\left[50^{2-}\right] /\left[\mathrm{HS}^{-}\right]$of $10^{2}$, and small changes in $\mathrm{pH}$ (+0.2 units) lead to large changes in the $\left.\left[\mathrm{SO}_{4}^{-}\right] / \mathrm{HS}^{-}\right]$of $30 \%$. Sulfur speciation data from a well near the proposed repository site suggest $50{ }_{4}^{2-}$ values of $0.01 \mathrm{mg} / \mathrm{L}$ and $10.8 \mathrm{mg} / \mathrm{L}$ (Dill et a1. 1986), also indicating a large variability in the analytical results.

Coupling these facts with the relative insensitivity of the uranium solubility, uranium dissolution kinetics (Torgerson et a1. 1984), and iron corrosion to the sulfur speciation, it was decided to leave the sulfur speciation as calculated by the code rather than changing either the redox condition or the phases to control the sulfur speciation toward a water that is dominated by $\mathrm{SO}_{4}^{2-}$. It should be noted that if pyrite/magnetite or pyrite/ hematite are used for redox control, the Eh values calculated for the GR-4 groundwater using EQ3NR are also near $-0.4 \mathrm{~V}$, but the sulfur speciation is dominated by $\mathrm{SO}_{4}^{2-}$. This suggests that the pyrite content of basalt. (PaImer et al. 1982) is not in equilibrium with the actual basalt groundwaters but is influencing the sulfur speciation in the actual groundwaters and the solutions taken from hydrotherinal experiments.

Use of hematite and magnetite for redox control aiso generated a small partial pressure of $\mathrm{CH}_{4}(\mathrm{~g})$ which is consistent with reports (Gray and McVay 1986; Apps et a1. 1979; Gephart et al. 1979; McGrail 1985) that $\mathrm{CH}_{4}(\mathrm{~g})$ is present in the groundwater. However, the calculated value is substantialiy less than those values indicated in the literature. 
Other effects that may occur as the groundwater migrates through the heated rock have not been included in this version of the AREST reference tables for BWIP. It is expected that, during the period of high temperature following emplacement, water will be evaporated from the surrounding rock, causing precipitation of solids that may redissolve as the waste package cools and fresh groundwater reenters the rock. Currentiy, these effects cannot be calculated without previous experience or the actual process being examined in the laboratory. In addition, the bulk of the water flow is expected to be into the rooms and drifts just after closure and before the packing is saturated. Therefore, these waters are not likely to come in contact with the waste package. Adding these uncertainties to the small changes that have been observed in the geological short term, laboratory hydrothermal experiments lend further support to the selection of a "known" groundwater composition, i.e., GR-4.

The main use of the EQ3NR code was to calculate the $\mathrm{pH}$, the Eh, and the chernical speciation as a function of temperature from $55^{\circ}$ to $250^{\circ} \mathrm{C}$ for the $G R-4$ groundwater. There are, however, limitations in these calculations, caused by the uncertainties and the accuracies of the high-temperature thermodynamic data base. In some cases, thermodynamic data at temperatures higher than $25^{\circ} \mathrm{C}$ have been estimated, and in other cases, they have been measured. Some data are valid only at $25^{\circ} \mathrm{C}$. As a result, calculations done for elevated temperatures must be viewed with caution, although the thermodynamic data for the major species and solids in EQ3NR are available for elevated temperatures and appear to be consistent and reliable. One of the advantages of using the reference table approach in the AREST code is the ease with which the user can recalculate the changes in the groundwater composition using other thermodynamic data or using selected data from laboratory experiments as input.

The packing material in a basalt repository will be a mixture of bentonite clay and crushed basalt (DOE 1986b). Currently, the design calls for the packing to be $25 \%$ bentonite and $75 \%$ crushed basalt. The main purpose of this packing material is to buffer groundwater chemistry and establish a low-flow rate environment around the waste container. A second purpose is to retard radionuclide migration by sorption of the nuclides on the packing. It is of inter est, therefore, to estimate the basic chemistry of the water when it reaches 
the steel container, as the corrosion rate may depend critically on the presence or absence of some chemical species.

Crushed basalt will dominate the mass fraction of material in the packing, so the assumption is made here that the Eh of the system will be dominated, in . the long term, by the basalt. Hence, the Eh of the system is again fixed at the magnetite/hematite boundary within the packing. The clay, however, should dominate the surface area and the cation exchange sites.

With respect to the packing/groundwater interaction, a possible calculation is to equilibrate the most active component of the bentonite, sodium montmorjllonite, with the groundwater that comes from the host rock. This calculation has been done and results in quite high $\mathrm{pH}$ values for the groundwater (Wanner 1985), which are not observed in experiments with bentonite (Hermansson et aI. 1986; Wood 1983; Wood, Aden, and Lane 1982). Bentonite/groundwater experiments that have been reported (Hermansson et al. 1986; Wood 1983; Wood et a1. 1982) indicate that the $\mathrm{pH}$ decreases when reacting bentonite with groundwater, and the $\mathrm{pH}$ decreases further with increasing temperature of the experiment (Wood 1983).

When dealing with a material with ion-exchangeable cations, there are effectively two nearly independent reactions for which equilibria need to be considered--jon exchange and matrix/solution/alteration product equilibration (Anderson 1983). This effect has been addressed by Grambow (1985) and can tee handled in two equivalent ways. One is to consider a hypothetical solid that controls the ratio of $\mathrm{Na}^{+}$to $\mathrm{H}^{+}$. The other method is to allow the code to equilibrate both the $\mathrm{Na}^{+}$and $\mathrm{H}^{+}$forms of the clay with solution. The latter method was used to generate the data in the AREST reference tables. The method that was used to obtain an equilibrium constant for the $\mathrm{H}^{+}$form of montmori1lonite was to use the value for the equilibrium constant of the $\mathrm{Na}^{+}$form that is in the MINTEQ data base (Felmy, Girvin, and Jenne 1984) and change it using the $\mathrm{Na}^{+} / \mathrm{H}^{+}$ion exchange constant of Grambow et ai. (1986). This change yielded thermodynamic data for $25^{\circ} \mathrm{C}$. These constants were then extrapolated up in temperature to $100^{\circ} \mathrm{C}$, using the van't Hoff equation. Extrapolation beyond $100^{\circ} \mathrm{C}$ was not considered to be valid, especially when the calculations indicated quite high $\mathrm{Na}^{+}$concentrations. In comparing the difference in the data 
between the $\mathrm{Na}^{+}$and $\mathrm{H}^{+}$forms of other di- and trioctahedral clays, it was noted that up to $100^{\circ} \mathrm{C}$, the difference was constant. This indicates that, to a first approximation, the $i$ on exchange constant is not a very sensitive function of temperature. The $\log (K)$ values for the phases of interest are shown in Table C.3 and are for the generalized reaction:

$$
\text { clay }+\mathrm{H}^{+}=\text {cations }+\mathrm{SiO}_{2}(\mathrm{aq})+\text { water }
$$

The net effect of having both phases present in the calculation is that the pH is buffered to a lower value. This is consistent with the observations of Wood, Aden, and Lane (1982) and those reported by Grambow et al. (1986). The bentonite that was used in these studies contained about 1 wt\% calcite plus gypsum. These relatively soluble minerals were not included in the calculations done here.

Corrosion of the spent fuel container under reducing conditions is assumed to produce magnetite and $\mathrm{H}_{2}(\mathrm{~g})$, but to have little other effect on the solution composition. For the short term, this assumption may be in error when iron corrosion products may react with the clay/basalt packing to form iron-rich smectites or other iron-bearing silicates. Formation of these products could change the groundwater chemistry, most notably $\mathrm{pH}$, but to a first approximation these will be slow reactions, and the effects may tend to be buffered by the remaining, unaltered clay. Once formed, these solids are not likely to

TABLE C.3. Values for $\log (K)$ of the Montmorillonites Used in this Study (a)

$$
\begin{aligned}
& \frac{\mathrm{C}^{\circ}}{0} \frac{\log \left(K_{1}\right)}{10.54} \quad \frac{\log \left(K_{2}\right)}{6.84} \quad \frac{\log \left(K_{3}\right)}{5.04} \\
& \begin{array}{llll}
60 & 3.60 & 3.95 & 2.15
\end{array} \\
& \begin{array}{llll}
100 & 0.21 & 2.54 & 0.74
\end{array}
\end{aligned}
$$

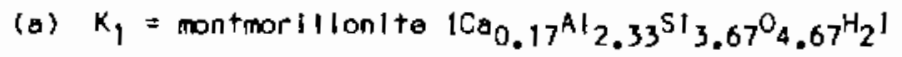

$$
\begin{aligned}
& K_{2}=\text { Wyoming montmorillonite }
\end{aligned}
$$

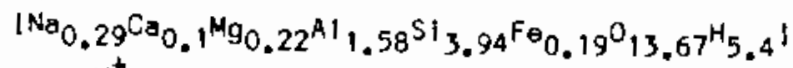

$$
\begin{aligned}
& \mathrm{K}_{3}=\mathrm{H}^{+} \text {-monitmorillanito }
\end{aligned}
$$

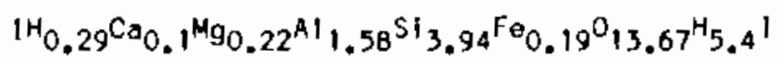


continue causing significant changes in the groundwater chemistry, and the water flowing from the packing to the spent fuel should be nearly unalterec. However, without good experimental evidence to confirm these changes in groundwater chemistry, there does not seem to be a compelling reason to calculate the effect of a suite of postulated reactions. Although Johnston et al. (1986) report the formation of siderite $\left(\mathrm{FeCO}_{3}\right)$ when mild steel corrodes in the presence of bentonite and GR-4 groundwater at $100^{\circ} \mathrm{C}$, there should be no eff $ə c \mathrm{ct}$ on the solubility of uraninite, because of the insignificant contribution by U(IV) complexes involving carbonate. Thus, the groundwater assumed to reach the spent fuel waste form is that which has been equilibrated with the clayi hasalt packing.

Under the reducing conditions, Eh $\simeq-0.4 \%$, calculated here using the equilibrium of magnetite and hematite or from the groundwater analyses (Di11 et a1. 1986), only U(IV)-containing phases should be stable, of which coffinite [USi0 $\left.0_{4}\right]$ and uraninite $\left[\mathrm{UO}_{2}\right]$ appear to be the most insoluble. Coffinite is nearly saturated when the solution is equilibrated with uraninite. Unfortunately the uranium-containing phase weeksite $\left[\mathrm{K}_{2}\left(\mathrm{UO}_{2}\right)_{2}\left(\mathrm{Si}_{2} \mathrm{O}_{5}\right)_{3} \cdot \mathrm{H}_{2} \mathrm{O}\right]$, which is often reported in hydrothermal experiments including U-bearing waste forms (Grandstaff et a T. 1984; Apted et al. 1983; Freeborn et al. 1980), was not present in the original EQ3NR data base, but estimated thermodynamic data at $25^{\circ} \mathrm{C}$ are available (Hemingway 1982). When Hemingway's value for the equilibrium constant of weeksite was put into the data base, the solution in equitibrium with uraninite was more than 10 orders of magnitude undersaturated with respect to weeksite. It is questionable whether this means that weeksite should control the $U$ concentration only at much higher temperatures or that the thermodynamic data are in error. This uncertainty lead to the selection of uraninite as the appropriate controlling solid phase for $U$.

Since the redox conditions of the water were not allowed to change during the reaction with the spent fuel and the $\mathrm{pH}$ only changed slightly, there were no changes expected by allowing the water equilibrated with the spent fuel to reequilibrate with the packing material. Sorption was not included in this study, mainly because a sorption model is not included in the current version of the EQ3NR code. However, sorption would be expected to lower the 
concentrations of radionuclides in solution below those calculated for solubility control. Thus, the approach taken here is considered to be conservative.

\section{C.2.2 Nevada Nuclear Waste Isolation Project}

At the Nevada Nuclear Waste Isolation Project (NNWSI) the repository will be placed in a tuffaceous rock consisting mainly of tridymite, quartz, cristobalite, and alkali feldspars (Bish, Ogard, and Vaniman 1984). The repository will be constructed above the local area water table. Because the tuff rock is very porous, the atmosphere in the repository after closure is projected to be oxidizing.

The groundwater from the local area is typified by the composition of the water J-13 drawn from a well, located approximately $6 \mathrm{~km}$ from the site (Ogard and Kerrisk 1984). Several hydrothermal experiments have been performed, on J-13 water and tuff rock. These experiments indicate that the changes in the J-13 composition are minor for the major components (Oversby 1984; Knauss and Beiriger 1984) and that these changes should not significantly alter the chemistry of the J-13 water. Thus, the composition of J-13 has been used in this work as the incoming water to the waste package and has only been speciated at temperature. Although dissolved oxygen measurements have been made on the samples of J-13 well water (8ish, Ogard, and Vaniman 1984; Tien et al. 1985), the Eh values are scattered $(+0.7 \mathrm{~V}$ to $+0.2 \mathrm{~V})$. These values are consistent with the projection that the atmosphere in the repository will be about the same as that found at the surface or $\mathrm{fo}_{2}=0.2$ atm (Bish, Ogard, and Vaniman 1984; DOE 1986c). At these redox conditions, the concentrations of elements in J-13 water, including uranium, are not very sensitive to changes in Eh. Therefore, a value of $0.4 \mathrm{~V}$ was selected for the Eh of $\mathrm{J}-13$ well water. This value is also an average value for surface waters (Lindsay 1979).

During the early phase of the repository lifetime, the temperature will he about $150^{\circ} \mathrm{C}$ and the ambient pressure will be 1 atm. Therefore, water that migrates into the repository will begin to boil when it encounters rock that is $95^{\circ} \mathrm{C}$ or greater. On the hasis of work by Knauss, Oversby, and Wolery (1984), it is known that, as the water evaporates/boils away, soluble suifates, nitrates, and chlorides as well as other minerals will precipitate and be left 
in the pores of the rock. The exact amount of these evaporite minerals and their identities are unknown. Therefore, as in the case of the basalt repository, it does not seen prudent to postulate these parameters and generate a set of data, which have no experimental basis, for the AREST reference tables.

In this repository, a 304L stajnless steel container will react with incoming water that contains oxygen. The reaction of the container to form $\mathrm{Fe}(\mathrm{OH})_{3}$ and other hydrated metal oxides will generate $\mathrm{H}_{2}(\mathrm{~g})$, but no acid or base:

$$
\mathrm{Fe}(\mathrm{s})+\mathrm{H}_{2} \mathrm{O}=\mathrm{Fe}(\mathrm{OH})_{3}+\mathrm{H}_{2}(\mathrm{~g})
$$

During the slow process of container corrosion, the $\mathrm{H}_{2}(\mathrm{~g})$ will diffuse away, and in the long term, J-13 water saturated with $\mathrm{Fe}$ (III), Cr(III), and Ni(II) will come in contact with the waste form. The assumption is made that no reaction will occur between the host rock and the precipitated, hydrated oxides, or that the reaction only generates small changes in the groundwater chemistry.

Because of the relatively high Eh of the water, uraninite (spent fuel) is calculated to be unstable with respect to solid phases that contain U(VI). Calculations with the EQ3NR code suggest that the following U-bearing phases are possible controls for dissolved $\mathrm{U}: \mathrm{y}-\mathrm{UO}_{3}, \mathrm{~s}_{\mathrm{i}}-\mathrm{UO}_{2}(\mathrm{OH})$, schoepite $\left[\mathrm{UO}_{3} \cdot 2 \mathrm{H}_{2} \mathrm{O}\right]$, rutherfordine $\left[\mathrm{UO}_{2} \mathrm{CO}_{3}\right]$, uranophane $\left[\mathrm{Ca}\left(\mathrm{H}_{3} \mathrm{O}_{2}\left(\mathrm{UO}_{2}\right)_{2}\left(\mathrm{SiO}_{4}\right)_{2} \cdot 3 \mathrm{H}_{2} \mathrm{O}\right]\right.$, and $\left(\mathrm{UO}_{3}\right)_{3}\left(\mathrm{PO}_{4}\right)_{2}$. Of these phases, schoepite was the least soluble and yielded total dissolved $U$ concentrations from $770 \mathrm{mg} / \mathrm{L}$ at $25^{\circ} \mathrm{C}$, in agreement with those calculated by Ogard and Kerrisk (1984), to $100 \mathrm{mg} / \mathrm{L}$ at temperatures between $55^{\circ} \mathrm{C}$ and $100^{\circ} \mathrm{C}$.

Experiments with spent fuel and $\mathrm{J}-13$ water, however, suggest that the concentration of $U$ in solution is controlled by a phase which is less soluble than schoepite. An uranium silicate, soddyite $\left[\left(\mathrm{UO}_{2}\right)_{2} \mathrm{SiO}_{4} \cdot 2 \mathrm{H}_{2} \mathrm{O}\right]$, has been suggested as the U-bearing phase controlling the concentration of dissolved 
uranium. (a) Hemingway (1982) has estimated the change in conductance of formation for soddyite. This mineral was added the EQ3NR data base and the total $U$ concentration calculated assuming that soddyite was the controlling phase. The concentrations of total dissolved $U$ that were calculated to be in equilibrium with soddyite were about $2 \mathrm{mg} / \mathrm{L}$ for temperatures between $25^{\circ} \mathrm{C}$ and $100^{\circ} \mathrm{C}$. Because the enthalpy and entropy data for soddyite were not estimated by Hemingway (1982), the EQ3NR code performs the calculations for elevated temperatures assuming that the equilibrium constant is independent of temperature. In addition, the equilibrium constant for the dominant complex $\left(\mathrm{UO}_{2}\right)_{2}\left(\mathrm{CO}_{3}\right)(\mathrm{OH})_{3}^{-}$is good only at $25^{\circ} \mathrm{C}$. Therefore, the calculations involving the solid phase and the dominant solution complex for $U$ should be viewed with caution. The calculated concentration at $25^{\circ} \mathrm{C}$ is in good agreement with that measured by Oversby and Wilson (1986) for crushed spent fuel in contact with J-13 water. Other U(VI)-containing phases such as schoepite, uranophane, and rutherfordine were calculated to be undersaturated by factors of $10^{2}$ to $10^{4}$ when soddyite was in equilibrium with $\mathrm{j}-13$ water.

Although soddyite is used in the current version of the AREST reference tables, it is also possible that uraninite will control the concentration of $U$ in J-13 water. Since the transition from U(IV) to U(VI) lies within the water stability field, $\mathrm{UO}_{2}$ should react with the dissolved oxygen, $0_{2}(\mathrm{aq})$, in $\mathrm{J}-13$ water to form U(VI) in solution and a U(VI) solid phase. There is, however, only a limited amount of $\mathrm{O}_{2}(\mathrm{aq})$ per liter of $\mathrm{J}-13$ water; $5.7 \mathrm{mg} / \mathrm{L}$ (0gard and Kerrisk 1984). If the reaction of $\mathrm{UO}_{2}$ were to consume all of the $\mathrm{O}_{2}(\mathrm{aq})$ the $U$ concentration would be about $85 \mathrm{mg} / \mathrm{L}$ at $25^{\circ} \mathrm{C}$. This concentration exceeds the solubility of some U(VI) phases, notably soddyite. Therefore, soddyite might precipitate and limit the maximum $U$ concentration. In an open system, the dissolution rate of $\mathrm{UO}_{2}$ would depend on the mass transport of $\mathrm{O}_{2}(\mathrm{aq})$ to the spent fuel; and the steady-state $U$ concentration would depend upon the relative rate of $\mathrm{UO}_{2}$ dissolution, the mass transport of $\mathrm{O}_{2}(\mathrm{aq})$, and the $U(V I)$ phase

(a) V.M. Oversby, from an unpublished report on the dissolution of spent fuel, presented at the Annual Spent Fuel Workshop, Stockholm, Sweden, September 1985. 
coexisting in equilibrium with $\mathrm{UO}_{2}$. The use of soddyite in the current version of the AREST reference tables probably represents an upper 1 imit to the $U$ concentration in $\mathrm{J}-13$ water.

\section{C.2.3 Salt Repository Project}

The approach used to estimate the change in composition of basalt and tuff groundwaters using the EQ3NR code was not used for salt brines for several reasons. Although EQ3NR can be used to calculate activities of salt constituents in brines using Pitzer's equations, the data in the current version of the code at the Pacific Northwest Laboratory (PNL) (Version 3245) are limited to major salt constituents at low temperatures (Jackson and Wolery 1985). Because of the lack of high-temperature thermodynamic data and the inability to treat some undissociated solutes in brines, the composition of brine was estimated to be a function of temperature. However, as the data base of the EQ3NR code is expanded, high-temperature calculationsinvolving the major brine constituents will become possible and the data in the AREST reference tables can be easily modified.

Fluids in a bedded salt repository are present in fluid inclusions and in fluids associated with hydrated clay and nonclay minerals. The small number of fluid inclusions present in Permian Basin bedded salt contain a high-magnesium brine. However, the Environmental Assessment Deaf Smith County Site, Texas (Environmental Assessment) (DOE 1986a) states that the main source of fluids into the host rock would come from a dissolution brine along with waters of hydration from clay and nonclay minerals. This composition was used in the geochemical input to the AREST code as the initial brine composition in a bedded salt repository.

The recipe used to synthesize PBB-1 brine in laboratory experiments (Gray and MCVay 1986) was used to calculate the representative PBB-1 molar (moles/ liter) composition. This brine is nearly identical in composition to the dissolution brine listed in the Environmental Assessment (DOE 1986a) except for the addition of several trace constituents (i.e., $\mathrm{Sr}^{2+}, \mathrm{Zn}^{2+}, \mathrm{F}^{-}, \mathrm{Br}^{-}, \mathrm{HCO}_{3}^{-}$). The molar composition of PBB-1 brine was first converted to the molal concentration scale using the measured density of this brine at $25^{\circ} \mathrm{C}\left(1.190 \mathrm{~g} / \mathrm{c}^{3}\right)$. The change in composition of the brine at temperature in contact with the host 
rock was approximated by assuming that the brine will be in equilibrium with halite and that no solids with retrograde solubilities precipitate (e.g., anhydrite). Stoichiometric amounts of halite were added to the PBB-l composition according to the halite molal solubility data given by Sylvester and Pitzer (1977) to obtain brine compositions between $50^{\circ}$ and $250^{\circ} \mathrm{C}$. This calculation ignores the effect of the other dissolved salt constituents on the mean molal activity of $\mathrm{NaCl}$; however, because $\mathrm{NaCl}$ comprises $98.5 \mathrm{~mole}$ of the dissolved solutes in PBB-1, the calculation should be an adequate approximation.

The lack of high-temperature thermodynamic data for electrolytes and the inability to theoretically treat many nonelectrolytes in high-ionic-strength solutions precluded calculating the change in composition of PBB-1 brine reacting with an iron canister. However, the rate of corrosion is calculated by the AREST code as described in an earlier section of this report. An alternative approach would be to estimate the amount of iron dissolved in brine used in corrosion experiments. Experimental data on corrosion rates of metallic canister materials in brines are available (Westerman and Pitman 1985) but the altered brine compositions are usually not reported. The effects of corrosion on brine composition will have to be added at a later date when more complete experimental data are available.

Accurate values for the concentration of uranium in solution resulting from dissolution of the spent fuel are also unavailable for halite-saturated PBB-1 brine at temperatures near $200^{\circ} \mathrm{C}$, although some data exist for the unsaturated brine at lower temperatures. Gray and McVay (1986) determined the concentration of uranium in $\mathrm{NaCl}$-undersaturated $\mathrm{PBB}-1$ brine at $30^{\circ}$ and $90^{\circ} \mathrm{C}$ resulting from the dissolution of spent fuel. In these experiments the uranium concentration was determined in $\mathrm{PBB}-1$ brine both with and without ductile iron present. For the reference tables, the uranium values for the tests including the ductile iron were used to account for the effects of the container on the concentration of uranium in solution. Because uranium values were reported for only two temperatures, it was further assumed that the concentration reported at $30^{\circ} \mathrm{C}(0.5 \mathrm{mg} / \mathrm{kg})$ is valid from $25^{\circ}$ to $75^{\circ} \mathrm{C}$, and the value reported at $90^{\circ} \mathrm{C}$ $\left(2.2 \mathrm{mg} / \mathrm{kg}\right.$ ) is valid between $100^{\circ}$ to $200^{\circ} \mathrm{C}$. The $\mathrm{pH}$ values reported in these experiments did not vary from the initial $\mathrm{pH}$ of the PBB-l brine, 6.8 (corrected 
for high ionic strength), by more than $0.4 \mathrm{pH}$ units; therefore, this value was used in the reference tables at all temperatures.

\section{C.3 SUMMARY}

The EQ3NR geochemical code was used to estimate the expected changes in groundwater compositions in high-level waste (HLW) repositories. The baseline compositions of the groundwaters for basalt, tuff, and bedded salt repositories were assumed to be represented by the GR-4, J-13, and PBB compositions, respectively. Hypothetical conceptual models were developed from current repository designs and available experimental data. Each repository was divided into a series of zones (host rock, outer waste package, spent fuel waste form) in which sets of mass transfer reactions were allowed to occur over the temperature range $25^{\circ} \mathrm{C}$ to $250^{\circ} \mathrm{C}$. Several limiting assumptions were made for this version of AREST, such as the solid phases that were allowed to equilibrate with the groundwater.

While the data base that was used is quite complete, the data contained therein have limited application in some cases, and some site-specific data are missing. The results of the calculations were incorporated into a set of reference tables that are accessed by the AREST code at execution time and can be easily changed by the user to incorporate new or revised information.

\section{C.4 FUTURE WORK}

The calculations summarized in this appendix represent a first approximation to estimating the compositional changes that may occur in groundwaters upon entering $H L W$ repositories. The simplified conceptual models used are, in part, the result of inadequate quantitative knowledge of the governing geochemical mechanisms controlling solution compositions. At present, it is not known how the predictions of the AREST code will be affected by the simplified conceptual geochemical mode1. Sensitivity calculations using the AREST code and the current set of reference tables are needed to determine whether refinements in the geochemical input are needed. If, from a sensitivity study, the geochemical input needs to be more exact, then studies such as those done by Knauss et al. (1985) and Jackson and wolery (1985) may need to be performed. 
Several of the assumptions made in the conceptual models could be improved with more complete experimental and thermodynamic data. The most important improvements are related to more complete thermodynamic data at high temperatures, especially for solids and aqueous species of uranium, and an evaluation of available high-temperature Pitzer interaction parameters for dissolved electrolytes. The high-temperature thermochemical data for uranium would allow more accurate calculations to be made of expected uranium concentrations resulting from dissolution of the spent fuel. This calculation also depends on the correct identity of the solubility control for uranium, which must be determined through careful experimental studies. The addition of hightemperature Pitzer coefficients would allow direct calculation of the changes in brine chemistry in equilibrium with a known salt assemblage and would circumvent the approximations used in this study.

Future corrosion work should include complete chemical analyses of the solution in order to test the assumption that corrosion of the canister does not appreciably change the solution properties. This, along with the identification of the solid phases, would greatly enhance the accuracy of the model used for predicting the waste package behavior for long periods of time.

The adequacy of the $\mathrm{Na}^{+} / \mathrm{H}^{+}$exchange model used in this version of AREST needs to be checked, not only for the temperature range discussed here $\left(100^{\circ} \mathrm{C}\right)$ but also for higher temperatures. The model used here included ion exchange for only $\mathrm{Na}^{+}$, but other ions need to be included, such as $\mathrm{Ca}^{2+}$ and $\mathrm{K}^{+}$.

Often reactions in these systems form solids that are metastable relative to a more thermodynamically stable phase assemblage. In natural systems, some of these metastable phases persist for hundreds of thousands of years without any ingrowth of the more thermodynamically favored phases. These phases are not well characterized in most cases; hence, the thermodynamic properties are not well known. Experiments need to be done to characterize these phases and determine whether there are natural analogs that would allow an estimate of the life time to be made. In some cases, the use of solid solution models, like the one that exists in the EQ3NR code, might be useful in estimating the thermodynamic properties. 
Usually the metastable phases form readily and hence exist because of kinetic reasons. The modeling that was done for this version of the AREST code assumed equilibrium, i.e., instantaneous kinetics. Use of the EQ6 code with the dissolution kinetics option might be useful in obtaining better estimates of the changes in the groundwater chemistry.

\section{C.5 REFERENCES}

Anderson, D. M. 1983. Smect ite Alteration. SKBF-KBS-TR-83-03, Swedish Nuclear Fuel Supply Co., Stockhoim, Sweden.

Apps, J., B. Doty, S. Doty, R. Galbraith, A. Kearns, B. Koht, J. Lons, A. Monroe, T. N. Narasimhan, P. Nelson, C. R. Wilson, and P. A. Witherspoon. 1979. Geohydrologic Studies for Nuclear Waste Isolation at the Hanford Reservation. LBL-8764, Lawrence Berke?ey Laboratory, BerkeTey, CaTifornid.

Apted, M. J., J. Meyers, and J. J. Mazer. 1983. Hydrothermal Reaction of Simulated Waste Forms with Barrier Materials Under Conditions Expected in a Nuclear Waste Repository in Basalt. SD-BWI-TI-141, Rockwell Hanford Operations, Richland, Washington.

Bish, D. L., A. E. Ogard, and D. T. Vaniman. 1984. "Mineralogy-Petrology and Groundwater Geochemistry of Yucca Mountain Tuffs." In Scientific Basis for Nuclear Waste Management VII, G. L. McVay, pp.283-291. Elsevier, Amsterdan, Netherlands.

Dill, J. A., T. E. Jones, A. D. Marcy, and M. H. West. 1986. Limitations in Determining Redox Chemistry in Basalt Groundwaters at the Hanford Site. RH0BW-ST-76P, RockwelT Hanford Operations, Richland, Washington.

Felmy, A. R., D. C. Girvin, and E. A. venne. 1984. MINTEQ: A Computer Program for Calculating Aqueous Geochenical Equilibria. EPA 600-3-84-032, Environmental Protection Agency, Washington, D.C.

Freeborn, W. P., M. Zolensky, B. E. Scheetz, S. Komarneni, G. J. McCarthy, and W. B. White. 1980. "Shale Rocks as Nuclear Waste Repositories: Hydrothermal Reactions with Glass, Ceramics, and Spent Fuel waste Forms." In Scientific. Bas is for Nuclear Waste Management, ed. C. J. M. Northrup, Jr., pp. 499506. PTenum Pubtishing Corp., New York.

Gephart, R. E., R. C. Arnett, R. G. Bacd, L. S. Leonhart, and F. A. Spane, Jr. 1979. Hydrologic Studies within the Columbia Plateau, Washington: An Integration of Current Knowiedge. RHO-BWI-5. Rockweil Hanford Operations, Richland, Washington. 
Grambow, B., E. 1985. "A General Rate Equation for Nuclear Waste GlassCorrosion." In Scientific Basis for Nuclear Waste Management VIII, eds. C. M. Jantzen, J. A. Stone, and R. C. Ewing, pp. 15-27. Materials Research Society, Pittsburgh, Pennsylvania.

Grambow, B. E., H.-P. Hermansson, 1. K. Björner, and L. Werme. 1986. "GlassWater Reaction in Presence of Granite and Bentonite - Experiment and Model." In Scientific Basis for Nuclear Waste Management IX, ed. 1. 0 . Werme, pp. 187-194. Materials Research Society, Pittsburgh, Pennsylvania.

Grandstaff, D. E., G. L. Mckeon, E. L. Moore, and G. C. UTmer. 1984. "Reactions in the System Basalt/Simulated Spent Fuel/water." In Scientific Basis for Nuclear Waste Management VII, ed. G. L. McVay, pp. 137-145. ETsevier, Amsterdam, Netherlands.

Gray, W. J., and G. L. McVay. 1986. FY-1984 Annual Report: Spent Fuel and $\mathrm{UO}_{2}$ Source Term Evaluation Results. PNL-5650, Pacific Northwest Laboratory, Richland, Washington.

Hermansson, H.-P., I.-K. Björner, H. Christensen, T, One, and L. 0. Werme. 1986. "Static Leaching of Fully Radioactive waste Glass at $90^{\circ} \mathrm{C}$ in the Presence of Bentonite, Granite, and Stainless Steel Corrosion Products." In Scientific Basis for Nuclear Waste Management IX, ed. L. O. Werme, pp. 179186. Materials Research Society, Pittsburgh, Pennsylvania.

Hemingway, B. S. 1982. Thermodynamic Properties of Selected Uranium Compounds and Aqueous Species at $298.15 \mathrm{~K}$ and 1 bar and at Higher Temperatures -Preliminary Models for the Origin of Coffinite Deposits, USGS open FiTe Report 82-619, U.S. Geological Survey, Reston, Virginia.

Jackson, K. J., and T. J. Wolery. 1985. "Extension of the EQ3/6 Computer Codes to Geochemical Modeling of Brines." In Scientific Basis for Nuclear Waste Management VIII, eds. C. M. Jantzen, J. A. Stone, and R. C. Ewing, pp. 507-514. Materials Research Society, Pittsburgh, Pennsyivania.

Johnston, R. G., R. P. Anantatmula, J. M. Lutton, and C. L. Rivera. 1986. Corrosion Phase Formation on Container Alloys in Basalt Repository Environments. RHO-BW-SA-535P, Rockwell Hanford Operations, Richland, Washington.

Jones, T. E. 1982. Reference Material Chemistry - Synthetic Groundwater Formulation. RHO-BW-ST-3T P, RockwelT Hanford Operations, Richtand, Washington.

Kerrisk, J. F. 1983. Reaction-Path Calculations of Ground-Water Chemistry and Mineral Formation of Ranier Mesa, Nevada. LA-9912-MS, Los ATamos National Laboratory, Los ATamos, New Mexico.

Knauss, K. G., and W. B. Beiriger. 1984. Report on Static Hydrothermal Alteration Studies of Topopah Spring Tuff Wafers in J-13 Water at $150^{\circ} \mathrm{C}$. UCRL-53576, Lawrence Livermore National Laboratory, Livermore, California. 
Knauss, K. G., V. M. Oversby, and T. J. Wolery. 1984. "Post Emplacement Environment of Waste Packages." In Scientific Basis for Nuclear Waste Management VII, ed. G. L. McVay, pp. 301-308. ETsevier, Amsterdam, Netherlands.

Knauss, K. G., J. M. Delany, W. J. Beiriger, and D. W. Peifer. 1985. "Hydrothermal Interaction of Topopah Spring Tuff with $\mathrm{d}-13$ Water as a Function of Temperature" In Scientific Bas is for Nuclear Waste Management. VIII eds. C. M. Jantzen, J. A. Stone, and R. C. Ewing, pp. 539-546. Materials Research Society, Pittsburgh, Pennsylvania.

Lane, 0. L., M. J. Apted, C. C. Allen, and J. Myers. 1984. "The Basalt/Water System: Considerations for a Nuclear Waste Repository." In Scientific Basis for Nuclear Waste Management VII, ed. G. L. McVay, pp. 95-103. ETsevier, Amsterdam, NetherTands.

Lindsay, W. L. 1979. Chemical Equilibria in Soils. John Wiley and Sons, New York.

McGrail, B. P. 1985. "Hydrotherinal Waste Package Interactions with MethaneContaining Basalt Groundwater." In Scientific Bas is for Nuclear Waste Management VIII, eds. C. M. Jantzen, J. A. Stone, and R. C. Ewing, pp. 459466. Materiais Research Society, Pittsburgh, Pennsylvania.

Ogard, A. E., and J. F. Kerrisk. 1984. Groundwater Chemistry Along the Flow Path Between a Proposed Repository Site and the Accessible Environment. LA10188-MS, Los ATamos National Laboratory, Los ATamos, New Mexico.

Oversby, V. M. 1984. Reaction of the Topopah Spring Tuff with J-13 Well Water at $90^{\circ} \mathrm{C}$ and $150^{\circ} \mathrm{C}$. UCRL-53552, Lawrence Livermore National Laboratory, Livermore, California.

Oversby, V. M., and C. N. Wilson. 1986. "Deviation of a Waste Package Source Term for NNWSI from the Results of Laboratory Experiments." In Scientific Basis for Nuclear Waste Management IX, ed. L. 0. Werme, Materials Research Society, Pittsburgh, Pennsylvania.

Palmer, R. A., G. D. Aden, R. G. Johnston, T. E. Jones, D. L. Lane, and A. F. Noonan. 1982. Characterization of Reference Materials for the Barrier Materials Test Program. RHO-BW-ST-27-P, Rock'well Hanford Operations, Richland, Washington.

Sylvester, L. F., and K. S. Pjtzer. 1977. "Thermodynamics of Electrolytes. 8. High-Temperature Properties, Including Enthalpy and Heat Capacity, with Application to Sodium Chloride." J. Phys. Chem., 81:1822-1828.

Tien, F.-L., C. D. Updegraff, K. K. Wahl, M. D. Siegel, and R. V. Guzowski. 1985. Repository Site Data Report for Unsaturated Tuff, Yucca Mountain, Nevada. NUREG/CR-4110 (SAND84-2668), Sandia Mational Laboratories, Albuquerque, New Mexico. 
Torgerson, D. F., N. N. Segert, D. W. Shoesmith, and P. Taylor. 1984. Underlying Chemistry Research for the Nuclear Fuel Waste Management Program. AECL-7786, Atomic Energy of Canada Limited, Pinewa, Manitoba, Canada.

U.S. Department of Energy (DOE). 1986a. Environmental Assessment Deaf Smith County Site, Texas. DOE/RW-0069. Department of Energy, Office of Civilian Waste Management, Washington, D.C.

U.S. Department of Energy (DOE). 1986b. Environmental Assessment Reference Repository Location, Hanford Site, Washington. DOE/RW-0070. Department of Energy, Office of Civilian Waste Management, Washington, D.C.

U.S. Department of Energy (DOE). 1986C. Environmental Assessment Yucca Mountain Site, Nevada Research and Development Area, Nevada. DOE/RW-0073. Department of Energy, Office of Civilian Waste Management, Washington, D.C.

Wanner, H. 1985. The Effect of Sodium Bentonite on the Chemical Composition of Groundwater. TM-45-85-03, Swiss Institute for Reactor Research, Wuerentingen, Switzerland.

Westerman, R. E., and S. G. Pitman. 1985. "Corrosion of Candidate Iron-Base Waste Package Structural Barrier Materials in Moist Salt Environments." In Scientific Basis for Nuclear Waste Management VIII, eds. C. M. Jantzen, J. A. Stone, and R. C. Ewing, pp. 279-285. Materials Research Society, Pittsburgh, Pennsylvania.

Wolery, T. J. 1983. EQ3NR, Computer Program for Geochemical Aqueous Speciation-Solubility CalcuTations: User's Guide and Documentation. UCLR-53414, Lawrence Livermore Laboratory, Livermore, California.

Wood, M. I. 1983. "Experimental Investigation of Sodium Bentonite Stability in Hanford Basalt." In Scientific Bas is for Nuclear Waste Management VI, ed. G. Brookins, pp. 727-734. Elsevier, Amsterdam, Netherlands.

Wood, M. I., G. D. Aden, and D. L. Lane. 1982. Evaluation of Sodium Bentonite and Crushed Basalt as Waste Package Backfill Materials. RHO-BW-ST-21 P, Rockwell Hanford Operations, Richtand, Washington. 
APPENDIX D

RADIONUCLIDE RELEASE FROM SPENT FUEL 
APPENDIX D

\section{RAOIONUCLIDE RELEASE FROM SPENT FUEL}

The processes controlling the release of radionuclides from waste forms, including spent fuel, are briefly sumarized in Section D.l as these relate to the conceptual basis for the waste package release (WPR) model of the AREST code. Particular emphasis is given to dissolution, precipitation, and transport processes in closed and open systems. Section 0.2 briefly reviews the separate sources of radionuclides within spent fuel as distinguished on the basis of physical form, radionuclide content, and processes controlling release.

\section{D.1 WASTE FORM/GROUNDWATER REACTION}

Waste packages can be viewed as thermodynamic open systems; that is, open to the transport of matter across the system boundary. This includes advective transport of water and/or diffusive transport of matter through water. The majority of waste-form testing, however, has been conducted under closed-system conditions because such tests are operationally less difficult and expensive than open-system tests. The reaction pathway and progress of solid/water interactions depend, in part, on whether the system is closed or open (Paces 1978; Wolery 1980). The relationship, therefore, between waste-form releases under open and closed conditions needs to be examined.

\section{D.1.1 Closed System}

Upon contact with groundwater in a closed system, a solid waste form such as spent fuel will imnediately undergo a dissolution reaction. The dissolution reaction is driven by the difference in chemical potentials of all chemical components between the solution and the waste form (Dibble and Tiller 1981; Rimstidt and Barnes 1980). Under closed-system conditions, two limiting cases to dissolution may prevail. In the first case, a saturation limit, $C_{5}$, is eventually exceeded and the dissolved components precipitate, some as major components of the precipitated solid, others as minor or trace components in 
the solid. In the second case, the initial solid phase dissolves completely without exceeding solution saturation levels leading to precipitation. Tha amount of waste component released is, therefore, inventory-limited.

For the saturation-limited case, the concentration of any given component in solution will be related to the stoichiometry and rates of dissolution and precipitation reactions. A net rate of reaction, $r_{\text {net }}$, defined as as the change in concentration over time, will be related to the relative rates of dissolution $\left(r_{+}\right)$and precipitation ( $\left.r_{-}\right)$reactions (Lasaga 1981):

$$
r_{\text {net }}=r_{+}-r_{-}
$$

In closed systems a condition of time-invariant concentration is often attained in which the net change in solution concentration for a given component is zero:

$$
\begin{gathered}
r_{\text {net }}=0 \\
r_{+}=r_{-} \neq 0
\end{gathered}
$$

For the equilibrium case the precipitating and dissolving phases are the same. A geologically common occurrence (Lasaga 1981) is the nonequilibrium case, called steady state, in which the dissolving phase and the precipitating phase(s) are different. In either case, time-invariant concentration does not imply that the dissolution and precipitation rates are zero, only that these rates are opposite and equal (Boudart 1976). Note that for steady-state, if the dissolution rate is much faster than the precipitation rate for equal surface areas of dissolving and precipitating phases, the solution concentration will approach the solubility of the dissolving solid. If precipitation is more rapid, the steady-state concentration of a giver component approaches the solubility of the precipitating solid.

If all of the chemical components in the solid are dissolved in their stoichionetric proportions, this is called "congruent dissolution" or alternately, "stoichiometric dissolution." "Incongruent dissolution" arises 
when certain components are preferentially dissolved, or leached, from the solid. Hydrogen ion exchange is an example of true incongruent dissolution. "Apparent incongruent dissolution" can arise from dissolution of more than one primary phase, or from congruent dissolution followed by precipitation of selected components. The distinction between true and apparent incongruent dissolution is key to modeling radionuclide release. True incongruency cannot be established from waste form tests by solution data alone; analysis of solid phases must also confirm that the incongruency observed in solution samples is not because of formation of precipitates or the presence of multiple dissolving phases.

\section{D.1.2 Open System}

For open-system conditions, there is an additional process to dissolution/ precipitation that will affect the release of radionuclides. This process is the diffusive/convective current (i.e., mass transfer rate) of dissolved components away from the waste form surface. Mass transfer is driven by diffusion, developed from gradients in chemical potential (concentration) surrounding the waste form, or diffusion combined with convective flow of groundwater. Within the engineered barrier systems at proposed repository sites, the groundwater flow is expected to be so low that the convective component of release from the waste form will be negligible (Pigford and Chambré 1986).

In open systems, therefore, these two processes are coupled in "series": the rate at which a waste component is released from spent fuel and the subsequent rate at which the released component moves away from the surface. The relative importance of these two processes at a hydrodynamic steady state has been evaluated (Zavoshy, Chambré, and Pigford 1985) by defining a mass flux ratio $(R)$, assuming diffusional transport, a zero-order forward rate of reaction and a first-order back reaction of a single dissolving phase:

$$
R=\frac{\text { forward reaction rate }}{\text { diffusive mass transfer rate }}=\frac{j_{0} r_{0}}{\varepsilon D C_{s}}
$$


where $j_{0}=$ the forward reaction rate normalized to surface area

$r_{0}=$ the radius of the waste form

$\varepsilon=$ the porosity of the surrounding medium

$D=$ the diffusion coefficient in the groundwater

$C_{s}=$ the saturation concentration of the dissolved species with respect to a given solid phase located at. the waste form surface.

At steady state, the concentration rate $\left(C_{S S} ;\right.$ and mass transfer rate $\left(j_{S S}\right)$ at the waste form surface are (Zavoshy, Chambré, and Pigford 1985)

$$
C_{S S}=C_{S} \frac{R}{1+R} \text { and } j_{s S}=\frac{j_{O}}{1+R}
$$

When $R \ll 1$, the dissolved waste components migrate away from the surface of spent fuel so rapidly that the surface concentration of such components cannot build up. At the spent fuel surface, the stated steady-state boundary condition requires that the concentration approach the value $\left(C_{s}, R\right)$ and the mass-transfer rate to approach the value $j_{0}$. In this case, the release rate can be called surface-reaction controlled (for a similar approach, see Berner 1978).

When the mass-flux ratio is large, (R $\gg 1)$, the concentration of dissolved waste components will build up at the surface of spent fuel, closely approaching a saturation/solubility value, $C_{S}$, identical to the closed-system case. This is a key rationale, linking the data requirements for modeling of an open-system waste package to the data that can be acquired from closedsystem testing on waste forms. The mass transfer rate will approach the value of $\left(j_{0} / R\right)$. The release rate in this case is transport-controlled.

Analogous to closed systems, certain highly soluble and/or inventorylimited nuclide-bearing solids may undergo total dissolution, and these nuclides will not be solubility-controlled under open-system conditions. The release rate of these species from a waste package can be controlled, however, by the rate of mass transfer through the waste package and surrounding host rock (Kim, Chambré, and Pigford 1986). 


\section{D.2 RADIONUCLIDE SOURCES FROM SPENT FUEL}

Studies of the spent fuel (Barner 1984) and interaction of spent fuel with groundwater solutions (Johnson, Garisto, and Stroes-Gascoyne 1985; Wilson and Oversby 1985; Gray and McVay 1984; Werme and Forsyth 1985) indicate that release of radionuclides from spent fuel can be divided into distinct sources: the matrix of $\mathrm{UO}_{2}$ grains, the cladding, the gap between the fuel and the cladding, and the boundaries between the $\mathrm{UO}_{2}$ grains (Figure 0.1 ). These sources can be distinguished on the hasis of different physical forms, radionuclide inventories of these sources, and processes controlling release.

\section{$0.2 .1 \quad \mathrm{U0}_{2}$ Matrix Dissolution}

More than $99 \%$ of the radionuclides in spent $\mathrm{vO}_{2}$ fuel are contained within the $\mathrm{UO}_{2}$ matrix grains; therefore, attention has been directed toward the matrix dissolution rate and the mechanism under which dissolution occurs under a variety of repository conditions. Recent spent fuel tests (Johnson, Garisto, and Stroes-Gascoyne 1985; Wilson and Oversby 1985; Gray and McVay 1984; Werme and Forsyth 1985) suggest that actinide elements ( $N p, P_{u}$, Am, and $\mathrm{Cm}$ ) and some fission products exhibit dissolution rates that are initially congruent with respect to calculated inventories and are released in fixed proportion to uranium dissolution rates. This concept is supported by chemical analysis of unreacted $\mathrm{UO}_{2}$ grains of spent light water reactor (LWR) fuel that showed essentially no compositional zonation for a wide variety of elements ( $\mathrm{Ba}, \mathrm{Ce}$, Cs, I, Pu, Ru, Tc, Te, and Zr) (Katayama, Bradley, and Harvey 1980).

To evaluate whether the steady-state mass transfer (i.e., radionuclide release rate) from $\mathrm{UO}_{2}$ is transport-controlled or surface-reaction-controlled, an estimate of the mass flux ratio (R) as described in Equation (D.4) can be made. An order-of-magnitude estimate can be made from the following assumptions:

- $j_{0}=5.0 \times 10^{-2} \mathrm{~g} /(\mathrm{m} 2$ - d) (Wilson and Oversby 1985; Gray and McVay 1984)

- $\quad D=5.2 \times 10^{-4} \mathrm{~m}^{2} / \mathrm{d}$ (Zavoshy, Chambré, and Pigford 1985)

- $r_{0}=0.005 \mathrm{~m}$ (radius of a single fuel pin) 


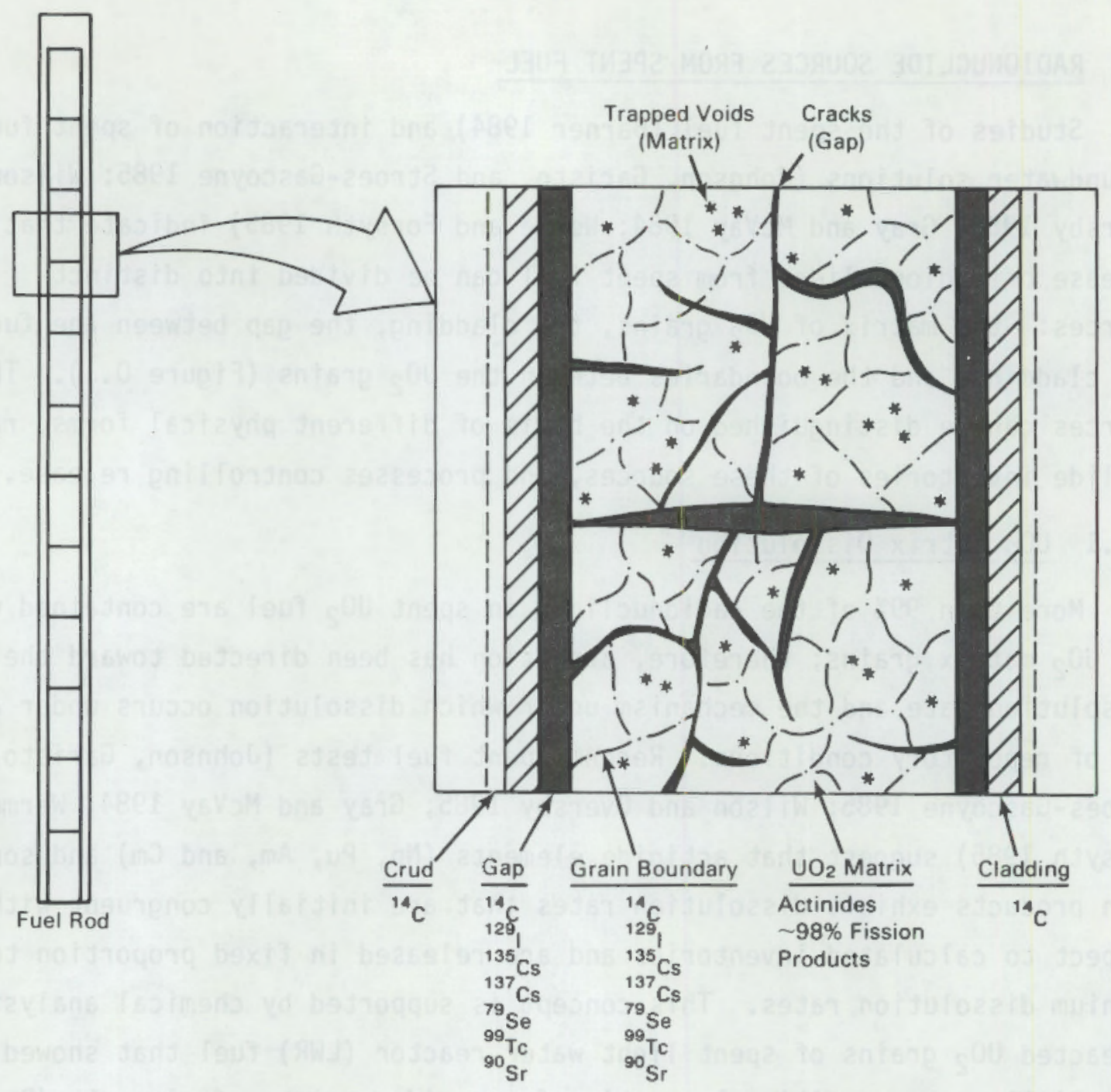

FIGURE 0.1. Schematic Cross-Section of Spent Nuclear Fuel

- $\varepsilon=0.01$

- $\mathrm{UO}_{2}$ solubility $=2.51 \times 10^{-8} \mathrm{gm} / \mathrm{m}^{3}$ at $\mathrm{pH} 6$ (Garisto and Garisto $1985)$.

The calculated $R$ is $1.9 \times 10^{9}$, well within the conditions appropriate for transport control. This $R$ value represents a conservative minimum value for several reasons, as seen from Equation (D.4). First, the $r_{0}$ value is clearly a minimum value, and $R$ will scale directly with $r_{0}$. Second, the " $j_{0}$ " value is based upon observed net reaction rates from $\mathrm{UO}_{2}$ test data taken after several 
days. Because the observed reaction rates will decrease from an initial value of $j_{0}$ with time as saturation is approached, the " $j_{0}$ " value used and the $R$ calculated are minimum values.

\section{D.2.2 Gap and Grain Boundaries}

The volatile and more mobile fission products, such as ${ }^{137} \mathrm{Cs},{ }^{135} \mathrm{Cs},{ }^{129} \mathrm{I}$, ${ }^{99} \mathrm{Tc},{ }^{93} \mathrm{Mo},{ }^{79} \mathrm{Se}$, and possibly ${ }^{90} \mathrm{Sr}$, tend to migrate out of the $\mathrm{U0}_{2}$ matrix and down thermal gradients in fuel pins. These radionuclides tend to accumulate at grain boundaries as secondary phases precipitated in the fuel matrix and voids, and in the fuel-cladding gap (including the gas plenum at the top of the fuel rod). Based on the limited amount (typically< $1.5 \%$ ) of the total fission gases released from LWR fuel (Bain, McInteer, and Papazoglou 1985; Barner 1984), the entire gap and grain boundary sources should contain less than $1 \%$ to $2 \%$ of the inventory of volatile fission products. Activation product ${ }^{14} \mathrm{C}$ may also be preferentially segregated from the fuel matrix phase. However, the ${ }^{14} \mathrm{C}$ distribution in the fuel, gap, or cladding is well characterized.

After the initial rapid release of gap fission products, the preferential release rates of many of these same elements are expected to gradually decrease and eventually approach the fuel matrix dissolution rate as the limited inventory of these nuclides, which have segregated from the fuel matrix, is exhausted. The inventory that is preferentially released during this period will include the fission products located along grain boundaries. The individual release contribution of the gap and grain boundaries cannot be easily separated because the same mechanisms, such as grain growth, bubble formation, and diffusion, lead to the accumulation of both gap and grain boundary inventories. Furthermore, essentially no data are available on the chemical nature and proportion of grain boundary phases. Consequently, the the WPR model of the AREST code combines these inventories to yield a single source for modeling purposes. A key factor, therefore, in the calculated release from the gap/ grain-boundary sources is the inventory of contained nuclides. The combined gap-plus-grain boundary inventory can represent about $1 \%$ to $2 \%$ of fission product activity, depending on burnup and history. Particularly important is the irradiation temperature, which determines the degree of fuel restructuring, gas release, and phase segregation more than any other factor. Improved 
realism in gap and grain boundary release requires more detailed characterization of the amount and variability of readily soluble fission products located in these phases than is currently available.

\section{D.2.3 Cladding}

The cladding of LWR fuel is typically a zircaloy alloy, and may include "crud" deposits formed on the cladding during reactor operation. The cladding contains a limited amount of nuclides produced by neutron activation. None of these nuclides, except ${ }^{3} \mathrm{H}$, fall below the $0.1 \%$ cutoff of the calculated total release rate limit for consideration in performance evaluations (10 CFR 60 1983). Thus, cladding must be considered as a "waste form".

In particular, the cladding contains an appreciable fraction of the total ${ }^{14} \mathrm{C}$ inventory of spent fuel (Van Konynenburg et al. 1985). This ${ }^{14} \mathrm{C}$ is formed as an activation product of $(n, p)$ reaction of $14_{N}$ impurities and from $(n, a)$ reaction of ${ }^{17} 0$. The ORIGEN (Croff 1983) calculations of ${ }^{14} \mathrm{C}$ inventories in both cladding and the $\mathrm{UO}_{2}$ fuel depend sensitively on the initial concentrations of ${ }^{14} \mathrm{~N}$ impurities; these are not well known nor is the variation in impurity concentration among spent fuel samples. The distribution of ${ }^{14} \mathrm{C}$ within the cladding is also not well characterized. A further complicating factor is that ${ }^{14} \mathrm{C}$ produced from irradiation of 170 in the coolant may become incorporated in the "crud" deposits (Wilson 1985). This would represent a ${ }^{14} \mathrm{C}$ inventory and source not accounted by conventional ORIGEN calculations.

To date, a limited amount of research has also been conducted on the release of radionuclides, particularly ${ }^{14} \mathrm{C}$, from cladding. Because of the volatility of ${ }^{14} \mathrm{C}$ as $\mathrm{CO}_{2}$ gas, cladding interactions under both steam and saturated hydrologic conditions are of relevance to predictive modeling of cladding performance as a waste form.

There is evidence (Van Konynenburg et al. 1985) of rapid release of ${ }^{14} \mathrm{C}$, probably as $\mathrm{CO}_{2}$ gas, from the outside surface of intact cladding at $275^{\circ} \mathrm{C}$ in air. Approximately $0.3 \%$ of the calculated ${ }^{14} \mathrm{C}$ inventory for the total spent fuel assembly was released. Results of ${ }^{14} \mathrm{C}$ released from a ruptured fuel rod 
at the same high-temperature air conditions, however, indicate that approximately $9 \%$ of the ${ }^{14} \mathrm{C}$ inventory would be released as a gas if all the rods were to rupture.

This rapid release of ${ }^{14} \mathrm{C}$-bearing $\mathrm{CO}_{2}$ gas from the cladding under steam conditions can be modeled with a "inventory-limited" mass transfer model identical to that applied to gap release under aqueous conditions. In this case, the released gas is assumed to be released instantaneously to the void space within the container. Diffusional release from this region across the boundary of the waste package (WP) subsystem is driven by the localized concentration gradient of $\mathrm{CO}_{2}$ away from the cladding. Because gaseous diffusion coefficients for species are at least four orders of magnitude higher than in water, the mass transfer limited release from the waste package will be relatively rapid but not instantaneous. Note that the effect of ambient $\mathrm{CO}_{2}$ in the steam atmosphere is conservatively neglected.

Modeling the interaction of cladding with groundwater is limited by the lack of detailed characterization and test data. As two extremes, the release of ${ }^{14} \mathrm{C}$ could be controlled by slow uniform corrosion of the cladding or, alternatively, the ${ }^{14} \mathrm{C}$ could be concentrated in the surface "crud" layer from which it is rapidly released upon contact with water.

The few tests that have been performed on cladding/groundwater interaction (Wilson 1985; Wilson 1986) show rapid release of an appreciable portion (approximately $0.05 \%$ ) of the estimated cladding ${ }^{14} \mathrm{C}$ inventory. After this rapid release, the ${ }^{14} \mathrm{C}$ concentration in solution is observed to plateau, showing only slight increase or decrease. Thus, ${ }^{14} \mathrm{C}$ release from cladding probably includes contributions from both rapid dissolution of a surface "crud" layer and slower release by corrosion of the bulk cladding. This tentative statement, however, is based on a limited set of preliminary tests. The inadequacy of this data base and the lack of detailed characterization currently preclude establishing a definitive model for cladding release. The WPR model of AREST currently models these two separate sources of nuclides from the cladding. An "inventory-limited" model is used to predict release rates from the outer crud or surface layer. A "solubility-limited" model is used to calculate release rates from the bulk cladding. 


\section{D.3 REFERENCES}

Bain, G. A., W. A. McInteer, and T. P. Papazoglou. 1985. "Release and Migration of Fission Products in High Burnup Fuel." In Proceedings of the ANS Topical Meeting on Light Water Reactor Fuel Performance, pp. 4-1 to 4-18, American Nuclear Society.

Barner, J. 0. 1984. LWR Spent Fuel Approved Testing Materials for Radionuclide Release Studies. PNL-4686, Pacific Northwest Laboratory, Richland, Washington.

Berner, R. A. 1978. "Rate Control of Mineral Dissolution under Earth Surface Conditions." Am. J. Sci. 278:1235-1252.

Boudart, M. 1976. "Consistency between Kinetics and Thermodynamics." J. Phys. Chem. 80(26):2869-2870.

Croff, A. G. 1983. "ORIGEN2--A Versatile Computer Code for Calculating the Nuclide Compositions and Characteristics of Nuclear Materials." Nuclear Technology 62:335-351.

Dibble, W., and W. Tiller. 1981. "Kinetic Model of Zeolite Paragenesis in Tuffaceous Sediments." Clay and Clay Min. 29(5):323.

Disposal of Nuclear Radioactive Waste in Geologic Repositories, 10 CFR Part 60, Vol. 46, No. 130 (1983) (Cited in text as 10 CFR 60, 1983).

Garisto, F., and N. Garisto. 1985. "A U0, Solubility Function for the Assessment of Used Nuclear Fuel Disposal." Nucl. Sci. Eng. 90:103-110.

Gray, W. and G. McVay. 1984. "Comparison of Spent Fuel and $\mathrm{UO}_{2}$ Release in Salt Brines." In Proceedings of the third spent fuel workshop, ed. L. Werme. SKBF/KBS Technical Report 83-76, SKBS/KBS, Stockholm, Sweden.

Johnson, L., N. Garisto, and S. Stroes-Gascoyne. 1985. "Used-Fuel Dissolution Studies in Canada." In Waste Management '85: Proceedings of the 1985 Symposium on Waste Management, ed. R. G. Post, pp. 479-482. University of Arizona, Tucson, Arizona.

Katayama, B., D. Bradley, and C. Harvey. 1980. Status Report on LWR Spent Fuel IAEA Leach Tests. PNL-3173, Pacific Northwest Laboratory, Richland, Washington.

Kim, C., P. Chambré, and T. Pigford. 1986. Mass-Transfer-Limited Release of a Soluble Waste Species. LBL-20899, Lawrence Berkeley Laboratory, Berkeley, California.

Lasaga, A. C. 1981. "Rate Laws of Chemical Reactions and Transition State Theory." in Reviews in Minerology Volume 8, Kinetics of Geochemical Processes, eds. A. C. Lasaga and R. J. Kirkpatrick, pp. 1-68, 135-169. Minerologic Society of America, Washington, D.C. 
Paces, T. 1978. "Reversible Control of Aqueous Aluminum and Silica During the Irreversible Evolution of Natural Waters." Geochim. Cosmochim. Acta, 42: 1487-1493.

Pigford, T., and P. Chambré. 1986. "Reliable Predictions of Waste Performance in a Geologic Repository." In High-Level Waste Disposal, ed. H. C. Burkholder, pp. 163-186. Battelle Press, Columbus, Ohio.

Rimstidt, J. D., and H. L. Barnes. 1980. "The Kinetics of Silica-Water Reactions," Geochim. Cosmochim. Acta, 44:1683-1699.

Van Konynenburg, R., C. Smith, H. Culham, and C. Otto, Jr. 1985. "Behavior of Carbon-14 in Waste Packages for Spent Fuel in a Repository in Tuff," In Scientific Basis for Nuclear Waste Management VIII, C. Jantzen, J. Stone and R. Ewing, pp. 405-412. Elsevier, Amsterdam, Netherlands.

Werme, L., and R. S. Forsyth. 1985. "Spent Fuel as a Wasteform--The Swedish Program for Studies and Evaluation of Spent Fuel for Direct Disposal." In Waste Management 85: Proceedings of the 1985 Symposium on Waste Management, ed. R. G. Post, pp. 483-488. University of Arizona, Tucson, Arizona.

Wilson, C. N. 1985. Results from NNWSI Series 1 Spent Fuel Leach Tests, HEDL-TME 84-30, Westinghouse Hanford Company, Richland, Washington.

Wilson, C. N. 1986. Results from NNWSI Series 2 Spent Fuel Dissolution Tests, Cycles 1 and 2, HEDL-TME 85-22, Westinghouse Hanford Company, Richland, Washington.

Wilson, C., and V. Oversby. 1985. "Radionuclide Release from PWR Fuels in a Reference Tuff Repository Groundwater." In Waste Management 85: Proceedings of the 1985 Symposium on Waste Management, ed. R. G. Post, p. 497. University of Arizona, Tucson, Arizona.

Wolery, T. J. 1980. Chemical Modeling of Geologic Disposal of Nuclear Waste: Progress Report and a Perspective, UCRL-52748, Lawrence Livermore Laboratory, Livermore, California.

Zavoshy, S., P. Chambré, and T. Pigford. 1985. "Mass Transfer in a Geologic Environment." In Scientific Basis for Nuclear Waste Management VIII, eds. C. Jantzen, J. Stone and R. Ewing, P. 311. Elsevier, Amsterdam, Netherlands. 



\section{APPENDIX E}

MASS TRANSFER RELEASE EQUATIONS 
APPENDIX E

\section{MASS TRANSFER RELEASE EQUATIONS}

Two principal mass transfer models that are used in the Waste Package Release (WPR) model of the AREST code. Section E.1 describes the analytical solutions used for calculating time-dependent, solubility-limited fractional release rates in the WPR model from both the waste form and waste package. Particular emphasis is given to this solubility-limited model as applied to the release of radionuclides from the $\mathrm{UO}_{2}$ matrix and, potentially, from the uniform corrosion of cladding. The justifications for applying a solubility-controlled mass transfer model to $\mathrm{UO}_{2}$ and cladding have been made in Appendix 0 . Included in this section is a discussion of solubility control imposed by separate radionuclide-bearing solids (i.e., incongruent or apparently incongruent dissolution) and solubility control imposed by the congruent dissolution of the primary waste form (e.g., $\mathrm{UO}_{2}$ ).

Section E.2 presents a mass transfer equation for calculating the timedependent, fractional release rates for highly soluble radionuclides from the waste package. This model assumes rapid release of a fixed inventory of such nuclides into a void volume within a failed container and subsequent diffusional transport through the waste package and into the surrounding host rock. This inventory-limited model is applied in the WPR model to gap/grain boundary and cladding sources of radionuclides within spent fuel. The justification for this application is provided in Appendix D (also see Kim, Chambré, and Pigford 1986). Both of these mass transfer models were developed by Pigford, Chambré and coworkers at the University of California at Berkeley under separate contract to the U.S. Department of Energy's (DOE) Office of Civilian Radioactive Waste Management (OCRWM).

\section{E.1 SOLUBILITY-LIMITED MODEL FOR MATRIX RELEASE}

The following equations have been derived by Chambré, Pigford, and coworkers (Chambré et al. 1985) to describe the time-dependent, diffusive mass 
transport of a radionuclide from a waste package. Similar mass-transfer models have been developed by Neretnieks and coworkers in Sweden (Neretnicks 1984;

Neretnicks and Rasmuson 1984; KBS 1983) and by Johnson and coworkers in Canada (Johnson, Garisto, and Stroes-Gascoyne 1985; Garisto et al. 1986).

The waste package geometry used in the AREST model is based on a spherical waste form, of equal area to the actual cylindrical waste form container, that is surrounded by a spherical porous shell, typically a packing material. Both the waste form and packing (or analogous material) are imbedded in a rock extending infinitely in all directions, as shown in Figure E.1. It is assumed that there are no radioactive-decay precursors. The parameters and dimensions in Figure E.1 are described more fully below.

Two governing equations that are used to describe the mass transfer of a radionuclide. The first equation is for the mass transfer rate, $\dot{M}(r, t)$

$$
\dot{M}(r, t)=4 \pi\left(\varepsilon_{1} D_{f} R_{0} r C_{s}\right)-\frac{1}{r\left[1+\gamma\left(\frac{R_{0}}{R_{1}}\right)\right]} \int_{0}^{\infty}\left[I_{1} I_{2} d n\right], R_{0}<r<R_{1}, t>0
$$

and the second governing equation is for the time-dependent concentration of a radionuclide within the waste package, $c(r, t)$

$$
C(r, t)=C_{s}\left\{f(r)+\int_{0}^{\infty}\left[I_{1} I(r, n) d n\right]\right\}, R_{0}<r<R_{1}, t>0
$$

where $r$ is the radial distance from the center of the waste form and $t$ is the time after permanent repository closure. Other terms in Equations (E.1) and (E.2) are defined as:

$$
\begin{gathered}
f(r)=\frac{R_{0} 1+\gamma\left(r / R_{1}\right)}{r} \frac{1+\gamma\left(R_{0} / R_{1}\right)}{1} \\
I_{1}=\frac{1}{1+\frac{D_{1} n^{2}}{\lambda}}+\frac{\exp \left(-D_{1} t n^{2}-\lambda t\right)}{1+\frac{\lambda}{D_{1} n^{2}}}
\end{gathered}
$$



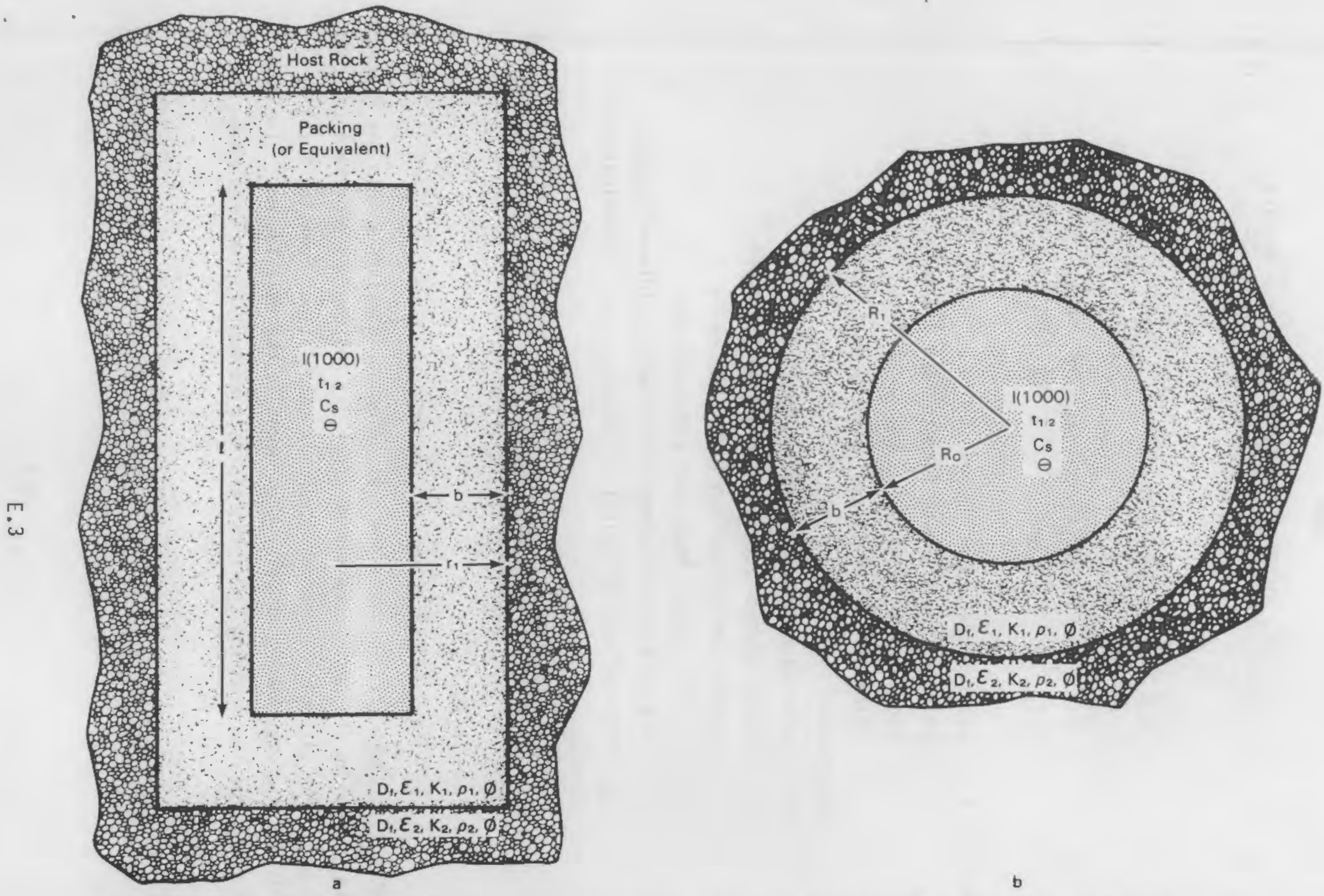

FIGURE E.1. Waste Package Geometry for Solubility-Limited Release Model (a) Actual Waste Package Configuration, (b) Equivalent Spherical Configuration 


$$
\begin{gathered}
I_{2}=\frac{{ }^{2} \varepsilon_{1} \varepsilon_{2}{ }^{\beta} n}{\pi} \frac{n\left(\cos \left(n\left[r-R_{0}\right]\right)-\sin \left(n\left[r-R_{0}\right]\right) / r\right\}}{H(n)} \\
\left.H(n)=\left[\varepsilon_{1} n \cos (n b)+a \sin (n b)\right]^{2}+\beta \varepsilon_{2} n \sin (n b)\right]^{2} \\
I(r, n)=\frac{-2 R_{0} \varepsilon_{1} \varepsilon_{2} 2^{\beta}}{\pi r} \frac{n \sin \left(n\left[r-R_{0}\right]\right)}{H(n)}
\end{gathered}
$$

$$
\text { where } \begin{aligned}
\dot{M}(r, t) & =\text { mass transfer rate }(\mathrm{gm} / \mathrm{sec}) \\
C_{s} & =\text { concentration at waste form surface }\left(\mathrm{gm} / \mathrm{cm}^{3}\right) \\
t & =\text { time }(\mathrm{sec}) \\
\lambda & =\text { radioactive decay }(1 / \mathrm{sec})=\ln 2 / \text { half-life } \\
R_{0} & =\text { waste form radius }(\mathrm{cm}) \\
R_{1} & =\text { outer edge of packing radius }(\mathrm{cm}) \\
D_{f} & =\text { diffusion coefficient in the water }\left(\mathrm{cm}^{2} / \mathrm{sec}\right) \\
\varepsilon_{1} & =\text { porosity of the packing (dimensionless) } \\
\varepsilon_{2} & =\text { porosity of the host rock (dimensionless) } \\
K_{1} & =\text { retardation coefficient in the packing (dimensionless) } \\
K_{2} & =\text { retardation coefficient in the host rock (dimensionless) } \\
D_{1} & =D_{f} / K_{1} \\
a & =\left(\varepsilon_{1}-\varepsilon_{2}\right) / R_{1} \\
b & =R_{1}-R_{0}=\text { packing thickness (cm) } \\
\beta & =\left(K_{1} / K_{2}\right)^{1 / 2} \\
\gamma & =\left(\varepsilon_{1}-\varepsilon_{2}\right) / \varepsilon_{2} .
\end{aligned}
$$

Equations $(E .1)$ to $(E .2)$ can be solved at selected locations within the waste package, such as the waste form surface $\left(r=R_{0}\right)$ and the waste package boundary $\left(r=R_{1}\right)$. The integral in the mass transfer calculation, Equation (E.1) is highly oscillatory, making singularities occur in the calculations. The present technique for handling the integral is to accumulate the area under the 
curve, using a small step size, as $n$ goes from zero to infinity. If the nuclide of concern is stable $(\lambda=0)$, then $I_{1}$ of the integrals in Equations $(E .1)$ and $(E .2)$ reduce to

$$
I_{1}=\exp \left(-D_{1} t^{2}\right)
$$

For the purposes of discussion in this appendix, Equation (E.1) can be written in a more streamlined notation

$$
\dot{M}(r, t)=4 \varepsilon_{1} D_{f} R_{0} r C_{s} \psi(r, t)
$$

where $\psi(r, t)$ will be called the nuclide-specific mass transfer function

$$
\Psi(r, t)=\frac{1}{r\left[1+\gamma\left(\frac{R_{0}}{R_{1}}\right)\right]}-\int_{0}^{\infty}\left[I_{1}, I_{2} d n\right], R_{0}<r<R_{1}, t>0
$$

The mass transfer rate, $\dot{M}(r, t)$, is related to the fractional release rate, $\dot{f}(r, t)$, as defined by 10 CFR $60(1983)$ by the following relationship:

$$
\dot{f}(r, t)=\frac{\dot{M}(r, t)}{I(1000)}
$$

where $\mathrm{I}(1000)$ is arbitrarily defined as the inventory of a given radionuclide 1000 years after permanent closure of the repository. A related parameter, the instantaneous fraction release rate, $\dot{F}(r, t)$, can also be defined

$$
\begin{gathered}
\dot{F}(r, t)=\frac{\dot{M}(r, t)}{I(t)} \\
t=t_{r}+t_{f}
\end{gathered}
$$


where $t_{f}$ is the time between repository closure and containment failure, $t_{r}$ is the time after containment failure up to time $t$, and $I(t)$ is the time-dependent inventory of a given radionuclide at time $t$. The time-dependent inventory can be related to the 1000 -year inventory by:

$$
I(t) I(1000) \exp \lambda(1000-t)
$$

where $\lambda$ is the decay constant of the radionuclide. Figure E.2 plots the ratio of $I(t) / I(1000)$ versus time for several half lives up to 10,000 years after permanent closure.

\section{E.1.1 Incongruent Dissolution/ Individual Solubility Limits}

The most general approach to calculating fractional release rates is to assume that the surface concentration term, $C_{S}$, of Equation $E .1$ is equal to the solubility limit, $C^{*}$, imposed by a discrete radionuclide-bearing solid (Pigford and Chambré 1986; Zavoshy, Chambré, and Pigford 1985):

$$
\left(c_{s}\right)_{i}=\left(c^{\star}\right)_{i}
$$

One complication is that the solubility, $c^{\star}$, is expressed for an element that may have several isotopes with different decay constants. Because of this "shared solubility," an effective isotopic solubility, $c_{e}^{\star}$, must be defined:

$$
\left(c_{s}\right)_{i}=\left(c_{e}^{\star}\right)_{i}=x_{i}\left(c^{\star}\right)=\frac{I_{i}(t)}{I_{T}(t)}\left(c^{\star}\right)
$$

where $x_{i}$ is the time-dependent isotopic mass fraction of nuclide $i$ with respect to the total inventory of all nuclides of the same element. This timedependent $x_{j}$ term is particularly important if two (or more) isotopes have extremely different half-lives, such as ${ }^{135} \mathrm{Cs}$ and ${ }^{137} \mathrm{Cs}$.

In general, the $C_{s}$ values for different nuclides will not be equal or correlated to each other. Because of this and many other reasons, the mass 


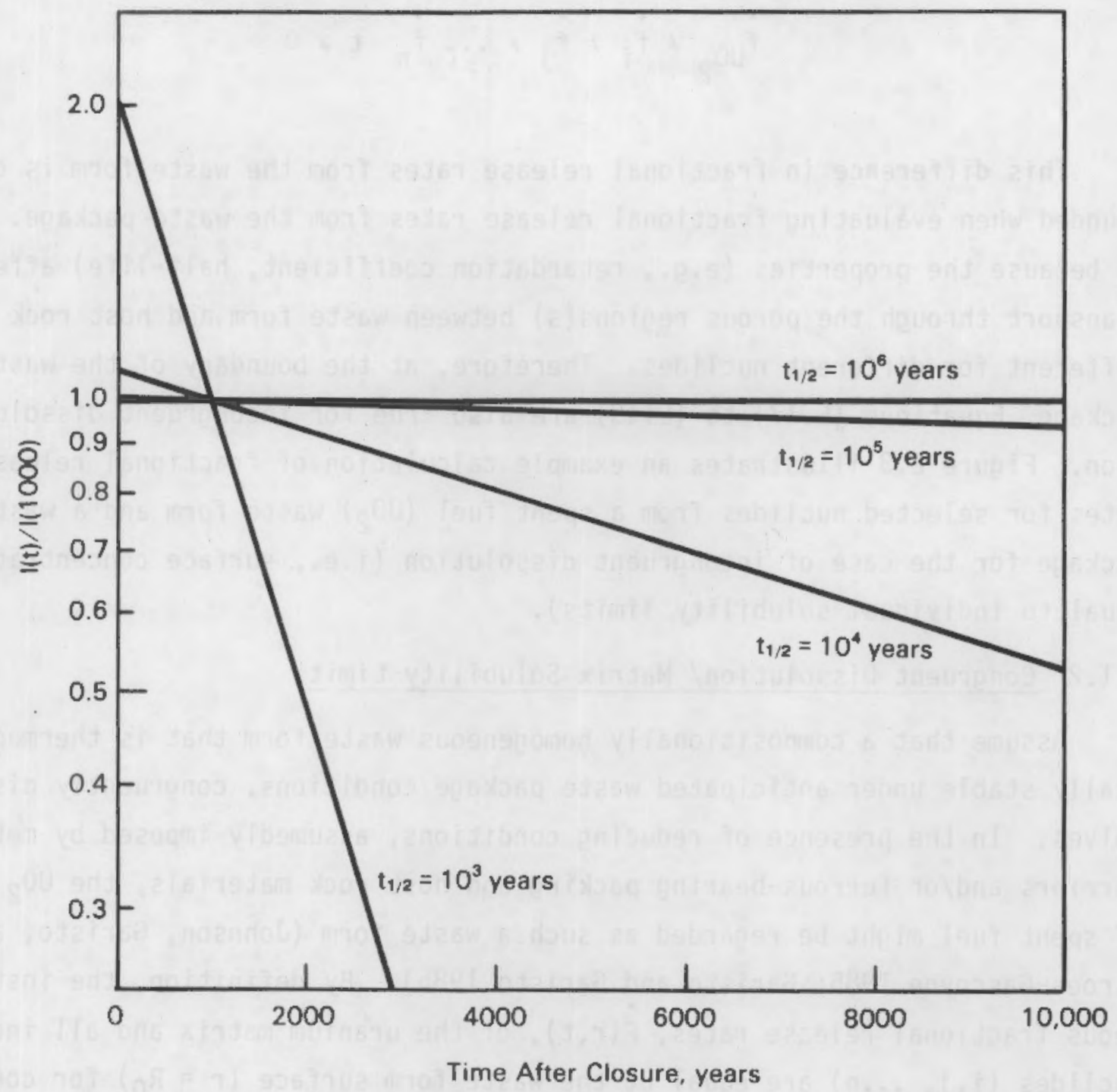

FIGURE E.2. Variation of Inventory from Radioactive Decay

transfer rates $\left(\dot{M}_{j}\right)$ and fractional release rates $\left(\dot{f}_{j}\right)$ of nuclides from the waste form surface will not be equal or correlated to each other

$$
\begin{aligned}
& \left(c_{s}\right)_{U 0_{2}} \neq\left(c_{s}\right)_{i} \neq\left(c_{s}\right)_{n} t>0 \\
& \dot{M}_{U_{2}} \neq \dot{M}_{i} \neq \dot{M}_{j} \neq \ldots \dot{M}_{n} t>0
\end{aligned}
$$




$$
\dot{f}_{U 0_{2}} \neq \dot{f}_{i} \neq \dot{f}_{j} \neq \ldots \dot{f}_{n} t>0
$$

This difference in fractional release rates from the waste form is compounded when evaluating fractional release rates from the waste package. This is because the properties (e.g., retardation coefficient, half-life) affecting transport through the porous regions(s) between waste form and host rock are different for different nuclides. Therefore, at the boundary of the waste package, Equations (E.17) to (E.19) are also true for incongruent dissolution. Figure E.3 illustrates an example calculation of fractional releases rates for selected nuclides from a spent fuel $\left(\mathrm{UO}_{2}\right)$ waste form and a waste package for the case of incongruent dissolution (i.e., surface concentrations equal to individual solubility limits).

\section{E.1.2 Congruent Dissolution/ Matrix Solubility Limit}

Assume that a compositionally homogeneous waste form that is thermodynamically stable under anticipated waste package conditions, congruently dissolves. In the presence of reducing conditions, assumedly imposed by metals barriers and/or ferrous-bearing packing and host rock materials, the $\mathrm{UO}_{2}$ matrix of spent fuel might be regarded as such a waste form (Johnson, Garisto, and Stroes-Gascoyne 1985; Garisto and Garisto 1985). By definition, the instantaneous fractional release rates, $\dot{F}(r, t)$, of the uranium matrix and all included nuclides $(i, j, \ldots n)$ are equal at the waste form surface $\left(r=R_{0}\right)$ for congruent dissolution

$$
\dot{F}\left(R_{0}, t\right)_{U 0_{2}}=\dot{F}\left(R_{0}, t\right)_{i}=\dot{F}\left(R_{0}, t\right)_{j}=\ldots \dot{F}\left(R_{0}, t\right)_{n}, t>0
$$

The NRC-defined (10 CFR 60,1983 ) fractional release rates, $\dot{f}(r, t)$, do not obey Equation $(E .20)$ because the mass transfer rates, $\dot{M}(r, t)$, are normalized to a fixed inventory evaluated at 1000 years after permanent closure rather than being normalized to a inventory corrected for radioactive decay. The two fractional release rates are related for congruent (and incongruent) dissolution as follows: 


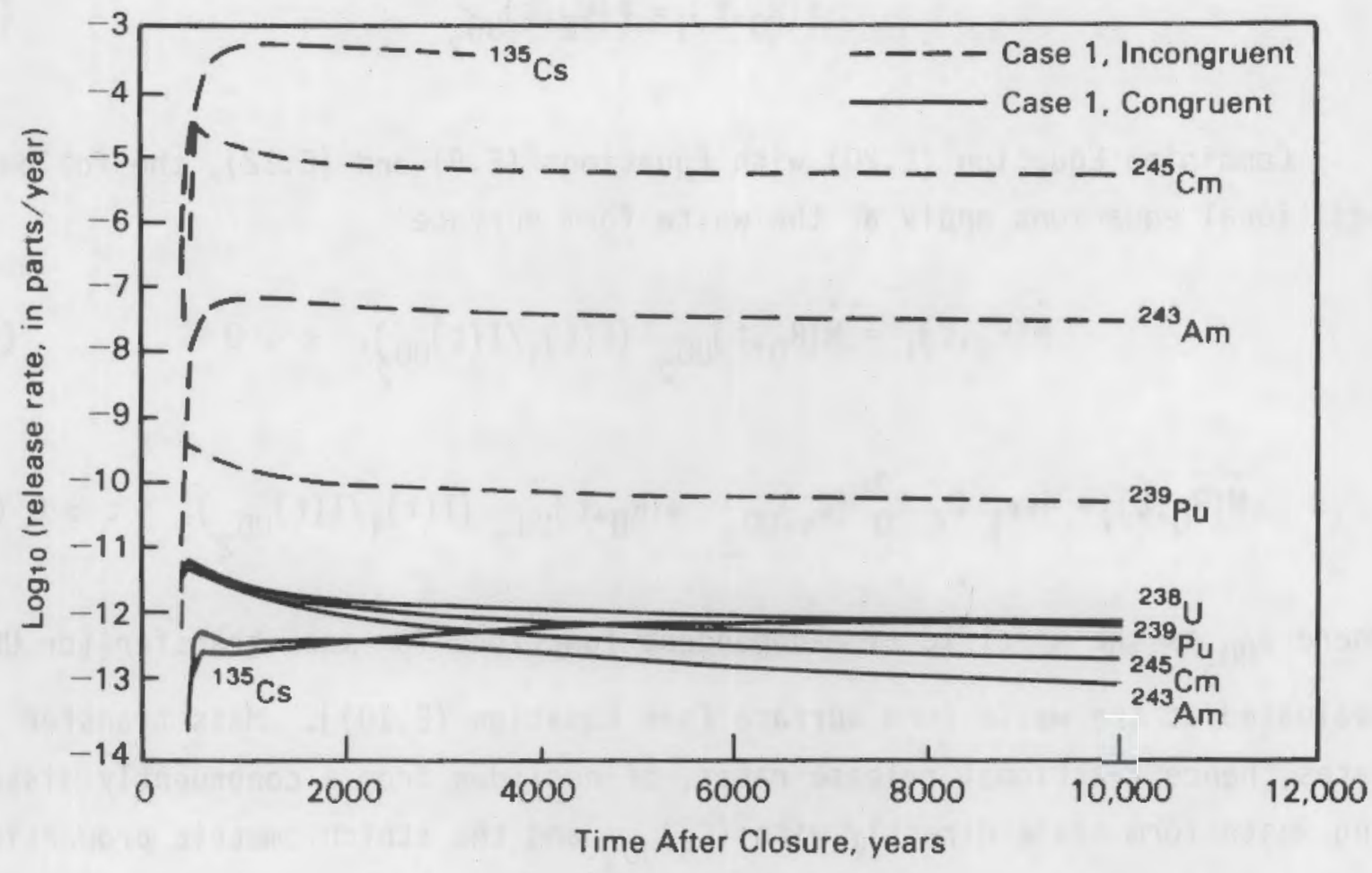

FIGURE E.3. Fractional Release Rate

$$
\dot{f}\left(R_{0}, t\right)_{i}=\dot{F}\left(R_{0}, t\right)_{i}\left[I(t)_{j} / I(1000)_{i}\right]
$$

Combining Equations (E.20) and (E.21):

$$
\dot{f}\left(R_{0}, t\right)_{i}=\dot{f}\left(R_{0}, t\right)_{U 0_{2}}\left[I(t)_{i} / I(1000)_{i}\right]\left[I(1000)_{U 0_{2}} / I(t)_{U 0_{2}}\right]
$$

For 238 (half-1ife, $t_{1 / 2}$, of $4.47 \times 10^{9}$ years) the dominant uranium isotope of the matrix, the change in inventory between 1000 and 10,000 years after permanent closure is $0.002 \%$ (Figure E.2). Accordingly, the 1000-year and timedependent uranium inventories are essentially equal over the time frame of interest. If $i$ is also a long-lived nuclide, the time-dependent inventories and inventories at 1000 years will also be approximately equal, so that Equation (E.22) reduces to 


$$
\dot{f}\left(R_{0}, t\right)_{i} \simeq \dot{f}\left(R_{0}, t\right)_{U_{2}}
$$

Combining Equation (E.20) with Equations (E.9) and (E.12), the following additional equations apply at the waste form surface

$$
\begin{gathered}
\dot{M}\left(R_{0}, t\right)_{i}=\dot{M}\left(R_{0}, t\right)_{U_{2}}\left(I(t)_{i} / I(t)_{U 0}\right), t>0 \\
\dot{M}\left(R_{0}, t\right)_{i}=4 \pi \varepsilon_{1} D_{f} R_{0}^{2}\left(C_{s}\right)_{U 0_{2}} \psi\left(R_{0}, t\right)_{U_{0}}\left(I(t)_{i} / I(t)_{U_{0}}\right), \quad t>0(E .25) .
\end{gathered}
$$

where $\psi_{\mathrm{UO}_{2}}$ is the specific time-dependent functions for mass transfer for $\mathrm{UO}_{2}$ evaluated at the waste form surface [see Equation (E.10)]. Mass transfer rates, hence fractional release rates, of nuclides from a congruently dissolving waste form scale directly with $\left(\mathrm{C}_{\mathrm{S}}\right)_{\mathrm{UO}_{2}}$ and the stoichiometric proportion of that nuclide in the $\mathrm{UO}_{2}$ matrix. This relationship applies even to that proportion of highly soluble nuclides such as ${ }^{14} \mathrm{C},{ }^{129} \mathrm{I}$, and ${ }^{135} \mathrm{Cs}$, which may be uniformly distributed (though not necessarily chemically bound) within a congruently dissolving $\mathrm{UO}_{2}$ matrix. This model assumes that the congruently dissolving waste form matrix, $\mathrm{UO}_{2}$ for example, is a stable solid phase with a fixed specific solubility (see Johnson, Garisto, and Stroes-Gascoyne 1985).

Equations (E.20) to (E.25) assume that no nuclide-bearing solid forms subsequent to the congruent dissolution of the $\mathrm{UO}_{2}$ matrix. That is, Equations (E.20) to (E.25) are valid only if

$$
\left(c_{s}\right)_{i}<\left(c^{\star}\right)_{i}
$$

where $\left(C_{s}\right)_{j}$ is the surface concentration of nuclide $i$ controlled by congruent dissolution of the $\mathrm{UO}_{2}$ matrix, and $\left(C^{*}\right)_{j}$ is the solubility concentration of $i$ imposed by the potential formation of a new solid phase at the $\mathrm{UO}_{2}$ surface [Equations (E.15) or (E.16)]. If the condition in Equation (E.26) is not met, then that specific nuclide will be incongruently released (at a lower 
instantaneous fractional release rate) with respect to uranium and the other included nuclides. Calculation of incongruent release has been discussed previously, so that the remainder of this section will assume that the condition of Equation (E.26) is met.

The surface concentration of $i,\left(C_{s}\right)_{i}$, is no longer equal to a solubility limit imposed by its own nuclide-bearing solid as in the incongruent case. Combining Equations E.9 and E.25 gives the following expression for the timedependent concentration of $i$ at the $\mathrm{UO}_{2}$ surface:

$$
\left(C_{s}\right)_{j}(t)=\left(C_{s}\right)_{U_{2}}\left[I(t)_{j} / I(t)_{U_{2}}\right]\left[\Psi\left(R_{0}, t\right)_{U_{2}} / \Psi\left(R_{0}, t\right)_{j}\right], \quad t>0
$$

Note that $\left(c_{s}\right)_{j}(t)$ is directly proportional to the solubility of $\mathrm{UO}_{2}$, the timedependent stoichiometric proportion of $i$ in the $\mathrm{UO}_{2}$ matrix, and the timedependent ratio of mass transfer functions. As steady-state release is approached, the ratio of the mass transfer functions approaches a constant ratio, $Y$, leaving

$$
\left(C_{s}\right)_{i}=r\left(C_{s}\right)_{U 0_{2}}\left[I(t)_{i} / I(t)_{U_{2}}\right], t+t_{s s}
$$

where $t_{\text {ss }}$ is defined as the time at which quasi-steady state is approached (Zavoshy, Chambré, and Pigford 1985). Note that Equations E.20 to E.25 are strictly valid only for time-independent $\left(C_{s}\right)_{j}$.

The fractional release rate at the waste package boundary is the more relevant concern of the WPR model in the AREST code. For congruent dissolution, the same boundary condition [Equation (E.27)], evaluated at the waste form surface, remains true. The simple relationships regarding mass transfer rates [Equation (E.24)] and instantaneous fractional release rates [Equation $(E .20)]$, however, do not apply at the waste package boundary $\left(r=R_{1}\right)$. Instead, the following relationships from Equations (E.9) and (E.11) can be written:

$$
\dot{M}\left(R_{1}, t\right)_{i}=4 \pi \varepsilon_{1} 0_{f} R_{0} R_{1}\left(C_{s}\right)_{i} \Psi\left(R_{1}, t\right)_{i}, t>0
$$




$$
\dot{M}\left(R_{1}, t\right)_{U 0_{2}}=4 \pi \varepsilon_{1} D_{f} R_{0} R_{1}\left(C_{s}\right)_{U O_{2}} \Psi\left(R_{1}, t\right)_{U_{2}}, t>0
$$

and

$$
\dot{f}\left(R_{1}, t\right)_{i}=\frac{\dot{M}\left(R_{1}, t\right)_{i}}{I(1000)_{i}}
$$

Combining Equations (E.29) and (E.9) and rearranging terms gives:

$$
\dot{M}\left(R_{1}, t\right)_{i}=\left(R_{1} / R_{0}\right) \dot{M}\left(R_{0}, t\right)_{j}\left[\Psi\left(R_{1}, t\right)_{i} / \Psi\left(R_{0}, t\right)_{j}\right], \quad t>0
$$

Substituting from Equation (E.24) gives:

$$
\begin{gathered}
\dot{M}\left(R_{1}, t\right)_{i}=\left(R_{1} / R_{0}\right) \dot{M}\left(R_{0}, t\right)_{U 0_{2}}\left[I(t)_{j} / I(t)_{U 0_{2}}\right] \\
{\left[\Psi\left(R_{1}, t\right)_{j} / \Psi\left(R_{0}, t\right)_{j}\right], \quad t>0}
\end{gathered}
$$

At steady state, the ratio of the mass transfer functions equals a constant value, $Y$, so that Equation (E.33) becomes

$$
\dot{M}\left(R_{1}, t\right)_{i}=Y\left(R_{1} / R_{0}\right) \dot{M}\left(R_{0}, t\right)_{U 0_{2}}\left[I(t)_{j} / I(t)_{U 0_{2}}\right], t \rightarrow t_{S S}
$$

Equations (E.31), (E.33), and (E.34) demonstrate that under congruent dissolution the release rate of a nuclide from the waste package will be directly related to the release rate of uranium at the waste form surface and the stoichiometric proportion of the nuclide in the $\mathrm{UO}_{2}$ matrix.

The importance of these equations, especially Equations (E.25) and (E.33) describing radionuclide release under congruent dissolution conditions is illustrated in Figure E.3. This figure contrasts the congruent release for the same nuclides and conditions as shown for incongruent release case. Note that 
the release rates for all nuclides are many orders of magnitude lower in the congruent case. Confirmation of congruent dissolution of the matrix of spent fuel $\mathrm{UO}_{2}$ under conditions where $\mathrm{UO}_{2}$ is stable (Johnson, Garisto, and StroesGascoyne 1985; Garisto and Garisto 1985) has the potential, therefore, for simplifying and enhancing the defensibility of release rate calculations in several ways:

- by reducing the amount of experimental solubility data that must be obtained to support release rate calculations

- by significantly lowering release rates for all nuclides incorporated in the $\mathrm{UO}_{2}$ matrix, including highly soluble nuclides $\left(\mathrm{e.g.},{ }^{14} \mathrm{C}\right.$, ${ }^{129} \mathrm{I},{ }^{135} \mathrm{Cs}$ )

- by providing a common, technically defensible basis for performance assessment of controlled release from spent fuel for all repository projects

- by permitting a much larger degree of uncertainty/variation in other repository and design parameters that affect engineered barrier system performance while still meeting NRC performance objectives.

While a large number of experiments have produced results confirming the congruent dissolution of the $\mathrm{UO}_{2}$ matrix of spent-fuel (Johnson, Garisto, and Stroes-Gascoyne 1985; Forsyth and Werme 1985; Oversby and Wilson 1985; Wuertz and Ellinger 1986). Questions remain regarding $\mathrm{UO}_{2}$ matrix metastability because of locally oxidizing conditions and radiation damage to the crystal structure. More experimental studies directed at confirming congruent $\mathrm{UO}_{2}$ dissolution, particularly close to $\mathrm{UO}_{2}$ saturation, and evaluation of $\mathrm{UO}_{2}$ stability under expected waste package conditions are needed.

\section{E.2 INVENTORY-LIMITED MODEL FOR GAP AND CLADDING RELEASE}

The following mass transfer equations have been derived by Chambré, Pigford and coworkers (Kim, Chambré, and Pigford 1986) to describe the release of highly soluble inventory-limited radionuclides from a waste package. These 
present equations are based on a planar geometry, assuming a waste form, a void volume over the waste form, a porous layer (or equivalent), and the host rock (Figure E.4).

It is assumed that, over the time scale of interest, groundwater immediately fills the void volume. A certain mass of nuclide is assumed to dissolve instantaneously from the waste form into this void, providing an initial concentration of the nuclide. The parameters and dimensions of the barriers in this model are transformed from the actual cylindrical geometry of a given waste package as described below.

The equation for the mass transfer rate, $\dot{M}\left(R_{1}, t\right)$, into the host rock is

$$
\begin{gathered}
\dot{M}\left(R_{1}, t\right)=2 k_{1} \varepsilon_{1} N_{0} S_{v} \frac{\exp (-\lambda t)}{(\delta+1)}-\sum^{N}\left(\frac{1}{\pi t}\right) \quad \exp \frac{-(2 N+1)^{2} b^{2}}{4 D_{1} t} \\
-\gamma_{0} D_{1} \exp \left[(2 N+1) b_{\gamma_{0}}+D_{1 \gamma_{0}}{ }^{2} t\right] \\
\operatorname{erfc} \frac{(2 N+1) b}{\left.2\left(D_{1} t\right)^{1 / 2}+\gamma_{0}\left(D_{1} t\right)^{1 / 2}\right) \frac{\delta}{\delta+1}+1}, N=0,1, \ldots \\
\dot{f}\left(R_{1}, t\right)=\frac{M\left(R_{1}, t\right)}{I(1000)} \\
\dot{F}\left(R_{1}, t\right)=\frac{\dot{M}\left(R_{1}, t\right)}{T(t)}
\end{gathered}
$$

where $\dot{M}\left(R_{1}, t\right)=$ mass transfer rate into the host rock (gm/sec)

$b=$ packing thickness $(\mathrm{cm})$

$\lambda=$ radioactive decay constant $(1 / \mathrm{sec})=\ln 2 /$ half -1 ife

$\mathrm{t}=\mathrm{time}(\mathrm{sec})$

$V_{v}=$ volume of the void $\left(\mathrm{cm}^{3}\right)$

$\mathrm{S}_{\mathrm{v}}=$ surface area of the void $\left(\mathrm{cm}^{2}\right)$

$D_{f}=$ diffusion coefficient in the water $\left(\mathrm{cm}^{2} / \mathrm{sec}\right)$ 

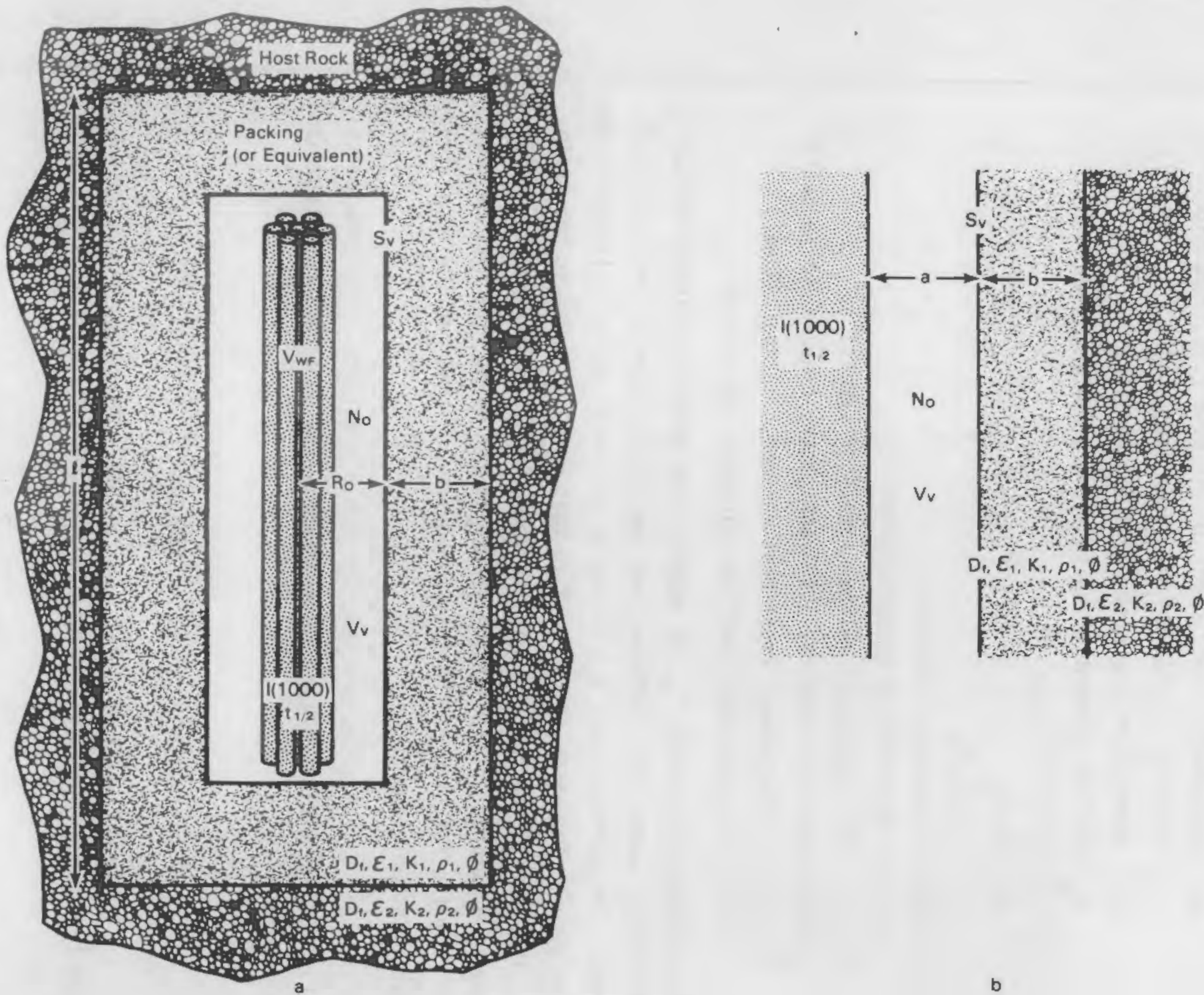

FIGURE E.4. Waste Package Geometry for Inventory-Limited Release Model (a) Actual Waste Package Configuration, (b) Equivalent Planar Configuration 


$$
\begin{aligned}
K_{1} & =\text { retardation coefficient in the packing (dimensionless) } \\
K_{2} & =\text { retardation coefficient in the host rock (dimensionless) } \\
\varepsilon_{1} & =\text { porosity of the packing (dimensionless) } \\
\varepsilon_{2} & =\text { porosity of the packing (dimensionless) } \\
N_{0} & =\text { initial concentration in void }\left(\mathrm{gm} / \mathrm{cm}^{3}\right) \\
\delta & =\left(K_{1} / K_{2}\right)^{1 / 2} \varepsilon_{1} / \varepsilon_{2} \\
D_{1} & =D_{f} / K_{1} \\
Y_{0} & =K_{1} \varepsilon_{1} S_{v} / V_{v} \\
\text { exp } & =\text { exponential function } \\
\text { erfc } & =\text { complementary error function } \\
\dot{f}\left(R_{1}, t\right) & =\text { NRC fractional release rate (parts/year) } \\
I(1000) & =\text { nuclide inventory } 1000 \text { years after closure (gm/package) } \\
\dot{F}\left(R_{1}, t\right) & =\text { instantaneous fractional release rate (parts/year) } \\
I(t) & =\text { time-dependent nuclide inventory (gm/package). }
\end{aligned}
$$

The volume of the void, $V_{v}$, is equal to the difference in the volumes of the cylindrical waste form container and the total volume of enclosed spent fuel rods. The surface area, $S_{y}$, is the surface area of the cylindrical waste form container. The width of the void in this model is equal to the ratio $v_{v} / S_{v}$. The initial concentration in the void, $N_{0}$, is calculated by dividing the mass of a soluble nuclide by the volume of the void. The nuclide mass is derived from the fraction of the total inventory of that nuclide occurring in the readily soluble source.

All of the calculations are done in double precision. The complementary error function is estimated use the continued fraction algorithm (Stegun and Zucker 1970):

$$
\operatorname{erfc}(y)=\frac{\exp (-y)^{2}}{\operatorname{sqrt}(\pi)} F
$$

Thus the term $[\exp (x) \operatorname{erfc}(y)]$ in Equation (E.35) is simplified to

$$
\frac{\exp \left(x-y^{2}\right)}{\operatorname{sqrt}(\pi)} F
$$


Figure E.5 illustrates an example solution of Equation (E.35) for the release of ${ }^{135} \mathrm{Cs},{ }^{137} \mathrm{Cs}$, and ${ }^{129}$ I from a gap source occurring 1000 years after repository closure. There are several key features to note. First, the mass of the instantaneously dissolved gap nuclide, $m_{j}$, can be expressed as a fraction of the total inventory of that nuclide, $x_{i}$, so that

$$
N_{0}=\frac{m_{i}}{V_{v}}=\frac{x_{i} I(t)_{i}}{v_{v}}
$$

Examination of Equations (E.35) and (E.39) shows that the instantaneous fractional release rate will not be a function of time-varying inventory. That is, $\dot{f}\left(R_{1}, t\right)_{j}$ will be independent of when the release starts. From Equation (E.21) it can he shown that

$$
\dot{f}\left(R_{1}, t\right)_{i}=\dot{F}\left(R_{1}, t\right)_{i}\left[I(t)_{j} / I(1000)_{j}\right]
$$

For long-lived nuclides $\left(t_{1 / 2} \gg t\right)$, the term $I(t)_{j} / I(1000)_{j}$ is nearly unity. Therefore for long-lived nuclides such as ${ }^{129} \mathrm{I}$ and ${ }^{135} \mathrm{Cs}$ (but not ${ }^{137} \mathrm{Cs}$ ), the NRC fractional release rate curves at 1000 years after repository closure shown in Figure E.5 for an individual waste package are nearly correct whether loss of containment occurs $10,000,100$ or even 10 years after repository closure. This approximation would not be true for the shart-lived ${ }^{137} \mathrm{Cs}$ isotope in Figure E.5.

A second key feature of the calculated release rate behavior is that "instantaneous" release (Johnson, Garisto, and Stroes-Gascoyne 1985) from the waste package does not occur. This is because release from the waste form is delayed by transport through the packing (or equivalent) barrier before nuclides are released from the waste package. This mass transport is explicitly taken into account in the AREST code. Such an approach is more realistic than equating "instantaneous" release from the waste form with release from the waste package. Because of diffusion through packing, release rates from the waste packages remain finite, even though instantaneous dissolution into groundwater is assumed. 
NRC

Release Rate Limit

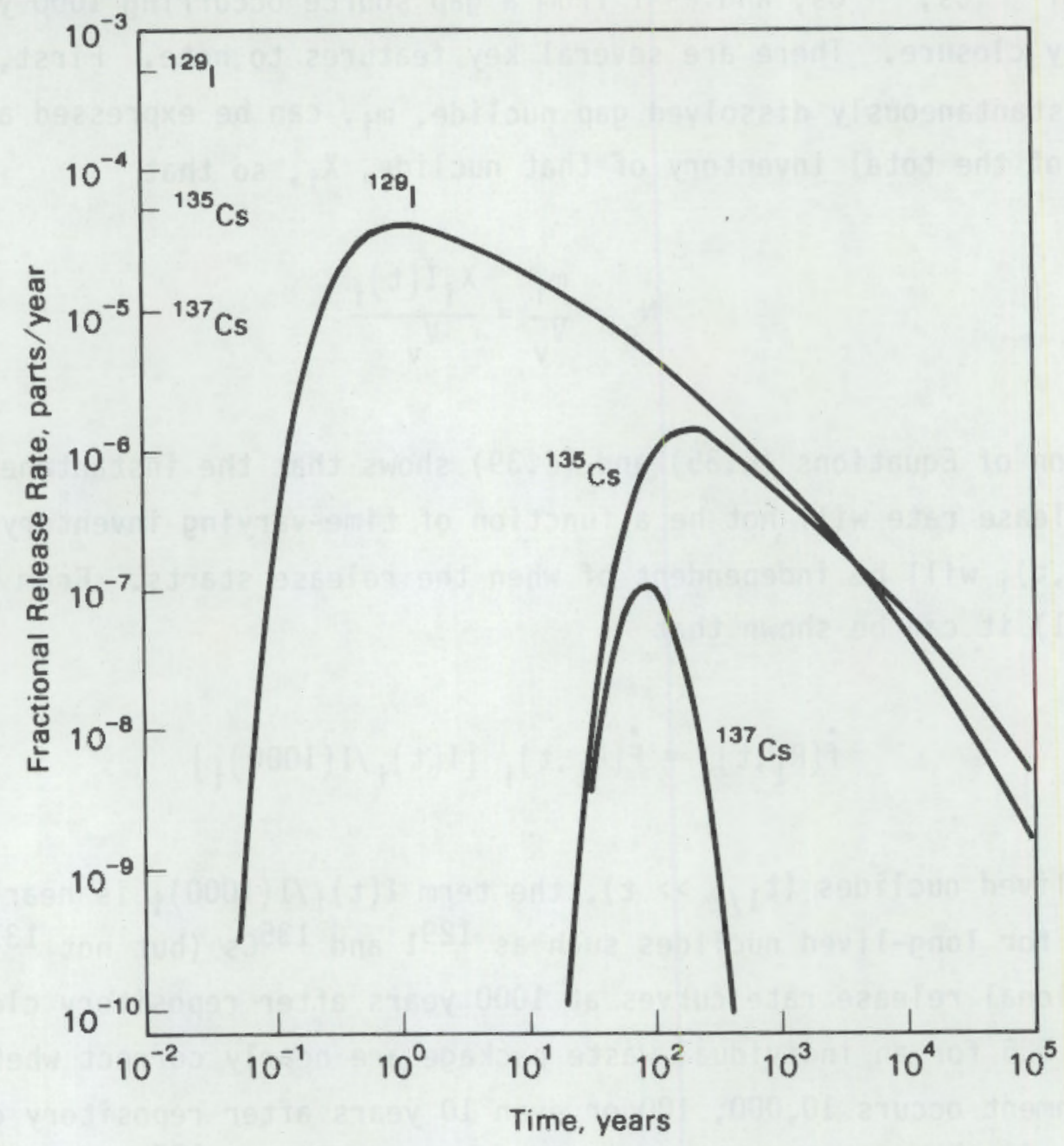

FIGURE E.5. Fractional Release Rate Versus Time for Gap Model (from Kim, Chambre, and Pigford 1986). Allowable fractional release rates (10 CFR 60,1983 ) for nuclides noted along vertical axis

A third feature of this inventory-limited release model includes the effect on release rates of radioactive decay and mass transport form the source volume. Both of the processes lead to a decrease in concentration of nuclide $i$ at the source, and hence to a decrease in the concentration gradient that drives release. Specifically, note in Figure $E .5$ that the release rate of ${ }^{137} \mathrm{Cs}$ falls off faster than that for ${ }^{135} \mathrm{Cs}$ because of the shorter half-life of ${ }^{137} \mathrm{Cs}$. In addition, Figure $E .5$ also shows that the time to peak release rate 
is earlier for nonretarded nuclides (e.g., ${ }^{129} 1$ ) than for nuclides with higher retardation coefficients (e.g., the Cs isotopes).

\section{E.3 REFERENCES}

Chambré, T. H. Pigford, W. W.-L. Lee, J. Ahn, S. Kajiwara, C. L. Kim, H. Kimura., H. Lung, W. J. Williams, and S. J. Zavoshy. 1985. Mass Transfer and Transport in a Geologic Environment. LBL-19430, Lawrence Berkeley Laboratory, Berkeley, California.

Disposal of Nuclear Radioactive Waste in Geologic Repositories, 10 CFR Part 60, Vol. 46 No. 130 (1983). (Cited in text as 10 CFR 60, 1983).

Forsyth, R. S., and L. 0 Werme. 1985. "The Corrosion of Spent $\mathrm{UO}_{2}$ Fuel in Synthetic Groundwater," In Scientific Basis of Nuclear Waste Management IX, ed. L. 0. Werme, pp. 327-336. Materials Research Society, Pittsburgh, Pennsylvania.

Garisto, F., and N. C. Garisto. 1985. "A U0, Solubility Function for the Assessment of Used Nuclear Fuel Disposal." Nucl. Sci. Eng., 90:103-110.

Garisto, N. C., K. B. Harvey, F. Garisto, and L. H. Johnson. 1986. "Source Term Models for the Assessment of Nuclear Fuel Waste Oisposal in Canada," In Waste Management '86: Proceedings of the 1986 Symposium on Waste Management, ed. R. G. Post, pp. 397-401. University of Arizona, Tucson, Arizona.

Johnson, L., N. Garisto, and S. Stroes-Gascoyne. 1985, "Used-Fuel Dissolution Studies in Canada." In Waste Management '85: Proceedings of the 1985 Symposium on Waste Management, ed. R. G. Post, pp. 479-482. University of Arizona, Tucson, Arizona.

Karnbranslesakerhet (KBS). 1983. Final Storage of Spent Nuclear Fuel-KBS-3. Karnbranslesakerhet Report SKBF/KBS, Stockholm, Sweden.

Kim, C., P. Chambré, and T. Pigford. 1986. Mass-Transfer-Limited Release of a Soluble Waste Species. LBL-20899, Lawrence Berkeley Laboratory, Berkeley, California.

Neretnieks, 1. 1984. "The Impact of Alpha-Radiolysis on the Release of Radionuclides from Spent Fuel in a Geologic Repository." In Scientific Basis for Nuclear Waste Management VII, ed. G. L. McVay, pp. 1009-1022. Elsevier, Amsterdam, Netherlands. 
Neretnieks, I., and A. Rasmuson. 1984. "An Integrated Approach to the Description of Radionuclide Release and Transport in the Geosphere." In Scientific Basis for Nuclear Waste Management VII, ed. G. L. McVay, pp. 269278. Elsevier, Amsterdam, Netherlands.

Oversby, V., and C. N. Wilson. 1985. "Derivation of a Waste Package Source Term for NNWSI," In Scientific Basis of Nuclear Waste Management IX, ed. L. 0. Werme, pp. 337-346. Materials Research Society, Pittsburgh, Pennsylvania.

Pigford, T., and P. Chambré. 1986. "Reliable Predictions of Waste Performance in a Geologic Repository." In High-Level Waste Disposal, ed. H. C. Burkholder, pp. 163-186. Battelle Press, Columbus, Ohio.

Stegun, I. A., and R. Zucker. 1970. "Automatic Computing Methods for Special Functions." Journal of Research of the National Bureau of Standards-B. Mathematics Sciences, Vol. 74B, No. 3, July-Sept. 1970.

Wuertz, R., and M. Ellinger. 1986. "Source Term for the Activity Release from a Repository for Spent Fue1." In Scientific Basis for Nuclear Waste Management IX, ed. L. 0. Werme, pp. 392-400. Materials Research Society, Pittsburgh, Pennsylvania.

Zavoshy, S., P. Chambré, and T. Pigford. 1985. "Mass Transfer in a Geologic Environment." In Scientific Basis for Nuclear Waste Management VIII, eds. C. Jantzen, J. Stone and R. Ewing, p. 311-322. Elsevier, Amsterdam, Netherlands. 
No. of

Copies

OFFSITE

30 DOE Technical Information Center

H. Ahagen

U.S. Department of Energy Chicago Operations Office 6800 South Cass Avenue

Argonne, IL 60439

C. K. Aidun

Battelle Memorial Institute

Office of Nuclear Waste Isolation

505 King Avenue

Columbus, $\mathrm{OH} 43201$

D. H. Alexander

Office of Civilian Radioactive

Waste Management RW-24

U.S. Department of Energy

Washington, D.C. 20545

G. Appel

U.S. Department of Energy

Salt Repository Project

505 King Avenue

Columbus, $\mathrm{OH} 43201$

H. Avci

Office of Waste Technology

Development

7000 S. Adams Street

Willowbrook, IL 60521

R. Baker

U.S. Department of Energy

Chicago Operations office

6800 South Cass Avenue

Argonne, IL 60439
No. of

Copies

J. K. Bates

Argonne National Laboratory

9700 South Cass Avenue

Argonne, IL 60439-4837

G. Bidoglio

Joint Research Centre

Radionchemistry Division

21020 Ispra (VA)

ITALY

F. Bingham

Sandia National Laboratory

P.0. Box 5800

Albuquerque, NM 87185

A. 8ranstetter

Office of Waste Technology

Development

7000 S. Adams Street

Willowbrook, IL 60521

C. L. Carnahan

MS $50 E$

Lawrence Berkeley Laboratory

1 Cyclotron Road

Berkeley, CA 94720

K. Chang

Division of Waste Management

MS-623-SS

U.S. Nuclear Regulatory

Commission

Silver Springs, MD 20910

M. Cloninger

Weston

955 L.'Enfant Plaza

Washington, D.C. 20024

C. R. Cooley

Office of Civilian Radioactive

Waste Management RW-43

U.S. Department of Energy

Washington, D.C. 20545 
No. of

Copies

W. E. Coons

IT Corporation

2340 Alamo SE

Albuquerque, NM 87106

G. A. Dinwiddie

U.S. Geological Survey

U.S. Department of the Interior

National Center, MS-410

12202 Sunrise Valley Drive

Reston, Virginia 22092

Document Control Center

Division of Waste Management

U.S. Nuclear Regulatory

Commission

Washington, D.C. 20555

N. A. Eisenberg

Office of Civilian Radioactive Waste Management RW-24

U.S. Department of Energy

Washington, D.C. 20545

M. W. Frei

Office of Civilian Radioactive Waste Management RW-23

U.S. Department of Energy

Washington, 0.C. 20545

N. C. Garisto

AECL - Whiteshell Nuclear

Research Establishment

Pinawa, Manitoba

CANADA ROE $1 L 0$

B. Grambow

Hahn-Meitner-Institut

GMBH, Postfach 390128

Glienicker Str. 100

0-1000 Berlin 39

FEDERAL REPUBLIC OF GERMANY

D. E. Grandstaff

Department of Geology

Temple University

Philadelphia, PA 19122
No. of

Copies

J. Hadermann

Institut Federal de Recherches en Matiere de Reacteurs

$\mathrm{CH}-5303$ Wurenlingen

SWITZERLAND

W. Harrison

Argonne National Laboratory

6700 South Cass Avenue

Argonne, Illinois 60439

D. Hodgkinson

Theoretical Physics Division

Atomic Energy Research

Establishment

Harwell

0xOn OXI1 ORA

UNITED KINGOOM

T. 0 . Hunter

Sandia National Laboratory

P. 0. Box 5800

Albuquerque, NM 87185

G. Jacobs

Oak Ridge National Laboratory

P. 0. Box X

Bethel Valley Road

MS 038, B1dg. 1505

Oak Ridge, TN 37831

H. Jaffee

International Research and Development Policy

Office of Assistant Secretary for International Affairs IE-12

U.S. Department of Energy

Washington, D.C. 20545

C. M. Jantzen

E. I. du Pont de Nemours \& Co., Inc.

Savannah River Laboratory

Aiken, SC 29808 
No. of

Copies

L. H. Johnson

AECL - Whiteshell Nuclear

Research Establishment

Pinawa, Manitoba

CANADA ROE $1 L 0$

J. F. Kerrisk

Los Alamos National Lahoratory

Los Alamos, NM 87545

J. F. Kircher

Battelle Memorial Institute

Office of Nuclear Waste

Isolation

$505 \mathrm{King}$ Avenue

Columbus, $\mathrm{OH} 43201$

N. Kjellbert

SKB $A B$

Box 5864

S-102 48 Stockholm

SWEDEN

C. Large

U.S. Department of Energy

Oak Ridge Operations Office

P. 0. Box E

Oak Ridge, TN 37831

W. W. $-L$. Lee

Department of Nuclear

Engineering

University of California

Berkeley, CA 94720

D. M. LeNeveu

AECL - Whiteshell Nuclear

Research Establishment

Pinawa, Manitoba

CANADA ROE $1 L 0$

W. Lutze

Hahn-Meitner Institut

Department of Ceramic Materials

Postfach 390128

Glienicker Str. 100

D-1000 8erlin 39

FEDERAL REPUBLIC OF GERMANY
No. of

Copies

\author{
H. J. Machiels \\ Electric Power Research \\ Institute \\ Box 10412 \\ Palo Alto, CA 94303 \\ C. McCombie \\ NAGRA \\ Parkstrasse 23 \\ CH-5401 Baden \\ SWITZERLAND \\ I. McKinley \\ NAGRA \\ Parkstrasse 23 \\ CH-5401 Baden \\ SWITZERLAND \\ D. Michlewicz \\ Weston \\ 955 L'Enfant Piaza \\ Washington, D.C. 20024
}

T. Mishima

Deputy General Manager

Waste Isolation Office

Waste Management and Row

Materials Division

Power Reactor and Nuclear Fuel

Development Corporation

1-9-13 Akasaka, Minato-ku

Tokyo 107

JAPAN

J. Myers

IT Corporation

2340 Alamo SE

Albuquerque, NM 87106

J. 0. Neff

U.S. Department of Energy

Salt Repository Project Office

$505 \mathrm{King}$ Avenue

Columbus, $\mathrm{OH} 43201$ 
No. of

Copies

I. Neretnieks

Department of Chemical

Engineering

Royal Institute of Technology

S-100 44 Stockholm

SWEDEN

R. O'Brien

Director of Safeguards and Security DP-34

U.S. Department of Energy

Washington, D.C. 20545

W. J. O'Connell

Lawrence Livermore National Laboratory

P. 0. Box 808

Livermore, CA 94550

0. L. 0liver

Mechanical Engineering

Department

University of Toledo

Toledo, $\mathrm{OH} 43606$

N. Patera

U.S. Department of Energy

Chicago Operations Office

6800 South Cass Avenue

Argonne, IL 60439

E. Peltonen

TVO Industrial Power Co. Ltd.

Fredrikinkatu 51-53

Helsinki

FINLAND

C. Pescatore

Brookhaven National Laboratory

Upton, NY 11973

T. H. Pigford

Department of Nuclear

Engineering

University of California

Berkeley, CA 94720
No. of

Copies

G. E. Raines

Battelle Memorial Institute

Office of Nuclear Waste Isolation

505 King Avenue

Columbus, $\mathrm{OH} 43201$

M. Revelli

Lawrence Livermore National Laboratory

P. 0. Box 808

Livermore, CA 94550

B. Ross

Disposal Safety Inc. 1629 K Street NW, Suite 600

Washington, D.C. 20006

J. Rotert

U.S. Department of Energy

Nevada Operations Office

P. 0. Box 14100

Las Vegas, NV 89114-4100

J. E. Rounsaville

U.S. Department of Energy

Oak Ridge Operations Office P. 0. Box E

Dak Ridge, TN 37831

B. C. Rusche, Director

Office of Civilian Radioactive Waste Management RW-1

U.S. Department of Energy

Washington, D.C. 20545

S. Sharland

Theoretical Physics Division

Atomic Energy Research

Establishment

Harwell

Oxon 0X11 ORA

UNITEO KINGDOM 
No. of

Copies

H. Shaw

Lawrence Livermore National Laboratory

P. 0. Box 808

Livermore, CA 94550

B. Silva

Lawrence Livermore National Laboratory

P. 0. Box 808

Livermore, CA 94550

R. Stein

Office of Civilian Radioactive Waste Management RW-24

U.S. Department of Energy

Washington, D.C. 20545

K. W. Stephens

Stephens \& Associates

10424 Windfall Court

Damascus, MD 20872

C. Thegerstrom

Division of Radiation Protection and Waste Management

OECD/Nuclear Energy Agency

38 Boulevard Suchet

F-75016 Paris

FRANCE

2 J. L. Torres

Director of International Security Affairs DP-33

U.S. Department of Energy Washington, D. C. 20545

D. L. Vieth

U.S. Department of Energy

Nevada Operations Office

P. 0. Box 14100

Las Vegas, NV 89114-4100
No. of

Copies

J. Waddell

Battelle Memorial Institute

Office of Nuclear Waste Isolation

$505 \mathrm{King}$ Avenue

Columbus, $\mathrm{OH} 43201$

H. Wanner

Nuclear Energy Agency

Data Bank

Batiment 445

91191 Gif-sur-Yyette Cedex

FRANCE

L. 0 . Werme

Swedish Nuclear Fuel and Waste Management Co.

Box 4864, S-102 48 Stockholm SWEDEN

ONSITE

10 DOE RICHLAND OPERATIONS OFFICE

D. E. Crouter

M. S. Karol

A. J. Knepp

L. T. Lakey

S. L. Marcum (4)

0 . L. 01 son

J. J. Sutey

5 WESTINGHOUSE HANFORO COMPANY

M. S. Bensky

B. Sagar

P. F. Salter

W. K. Terry

M. S. Bensky 
No. of

Copies

63 PACIFIC NORTHWEST LABORATORY

M. K. Altenhofen (3)

M. J. Apted (5)

W. W. Ballard

D. J. Bradley

C. P. Brim

P. G. Doctor

D. W. Engel

R. L. Erikson

T. E. Gates

K. I. Johnson

M. R. Kreiter

A. M. Liebetrau (30)

J. L. McElroy

L. G. Morgan

P. D. Peters

C. R. Reid

P. W. Reimus

D. M. Strachan

A. E. Van Luik

C. N. Wilson

C. F. Windisch

Publishing Coordination MH (2)

Technical Report Files (5) 